REVISTA DE PSICOLOGÍA

VOLUMEN 11, NÚMERO 1, ENERO - JUNIO 2021 



\section{REVISTA DE PSICOLOGÍA VOLUMEN 11, NÚMERO 1}

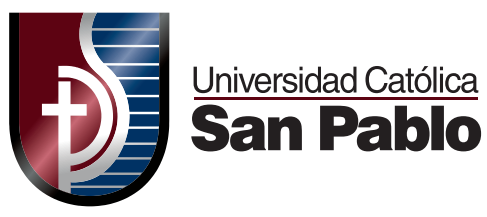

AREQUIPA, 2021 
Revista de Psicología

Rev. Psicol. (Arequipa. Univ. Catól. San Pablo)

Journal of Psychological Research \& Humanities

ISSN 2306-0565 VERSIÓN IMPRESA / ISSN 2311-7397 VERSIÓN ON LINE

AÑO 2020 ENERO - ABRIL, VOLUMEN 10, NÚMERO 1

DIRECTOR EDITOR

Walter L. Arias Gallegos. Universidad Católica San Pablo (Perú)

Esta revista se encuentra indizada en

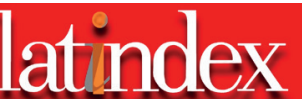

COMITÉ EDITORIAL

Lorena Diez Canseco Briceño. Universidad Católica San Pablo (Perú)

Marcio Soto Añari. Universidad Católica San Pablo (Perú)

Jorge Olaechea Catter. Pontificia Universidad Gregoriana (Italia)

Jean-Paul Swinnen. Pontificia Universidad Católica Argentina (Argentina)

Ermanno Pavesi. Gustav-Siewerth-Akademie di Weilheim-Bierbronnen (Suiza)

Mitchell Clark. Mount Royal University (Canadá)

COMITÉ DE REVISORES NACIONALES:

Ramón León Donayre. Universidad de Lima (Lima)

Santiago Cueto Caballero. Pontificia Universidad Católica del Perú (Lima)

Federico León. Universidad del Pacífico (Lima)

Charles Portilla Revollar. Universidad Católica de Santa María (Arequipa)

Aymé Barreda Parra. Universidad Nacional de San Agustín (Arequipa)

Edwin Salas Blas. Universidad San Martín de Porres (Lima)

Ricardo Canales. Universidad Nacional Mayor de San Marcos (Lima)

Flor Vilches Velásquez. Universidad Católica de Santa María (Arequipa)

Carlos Ponce Díaz. Universidad Inca Garcilaso de la Vega (Lima)

Aníbal Meza. Universidad San Ignacio de Loyola (Lima)

Jenny Quezada. Universidad Femenina del Sagrado Corazón (Lima)

Gina Chávez Ventura. Universidad Privada del Norte (Trujillo)

Paula Delgado Cuzzi. Universidad Católica San Pablo (Arequipa)

César Merino Soto. Universidad San Martín de Porres (Lima)

Gabriela Cáceres Luna. Universidad Católica San Pablo (Perú)

Juan Carlos Rios Toce. Aurea Consulting (Perú)

Tomás Caycho Rodríguez. Universidad Privada del Norte (Perú)

COMITÉ DE REVISORES INTERNACIONALES:

Sara Fernández Guinea. Universidad Complutense de Madrid (España)

Ana María Jacó-Vilela. Universidade do Estado do Rio de Janeiro (Brasil)

Marcos Ríos Lago. Universidad nacional de Educación a Distancia (España)

Hugo Klappenbach. Universidad Nacional de San Luis (Argentina)

María Regina Maluf. Universidade de São Paulo (Brasil)

Norman López Velásquez. Universidad de Los Lagos (Chile)

David de Noreña Martínez. Universidad Nacional de Educación a Distancia (España)

Manolete Moscoso. University of South Florida (Estados Unidos)

María Cristina Richaud. CIIPME (Argentina)

Oscar Veliz García. Universidad Católica del Norte (Chile)

Jorge Valencia Ríos. Universidad de Antioquia (Colombia)

María Andrea Piñeda. Universidad Nacional de San Luis (Argentina)

Gilberto Oviedo. Universidad de los Andes (Colombia)

María Gracia Murillo Deglane. Glendale Community College (Estados Unidos)

José Emilio García. Universidad Católica de Asunción (Paraguay)

Juan Carlos Tuppia. Pontificia Universidad Gregoriana (Italia)

Fernanda Inés García Vásquez. Instituto Tecnológico de Sonora (México)
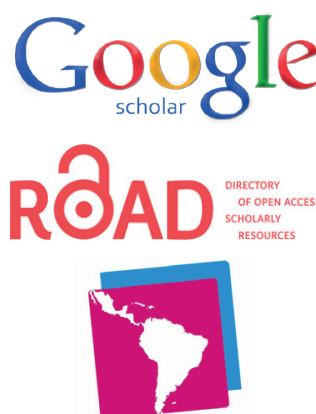

LatinREV

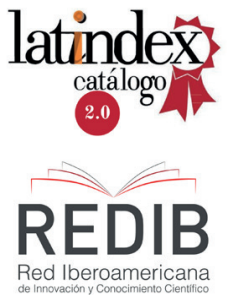

ALICIA:

\section{Universidad Católica}

San Pablo

TRADUCCIÓN

Mitchell Clark

DISEÑO Y DIAGRAMACIÓN

José Luis Vizcarra Ojeda

(c) Departamento de Psicología

Facultad de Ciencias Económico Empresariales y Humanas

Universidad Católica San Pablo

Campus Campiña Paisajista s/n. Quinta Vivanco. Arequipa (Perú).

Teléfono (+51 54) 605630, anexo 362 / warias@ucsp.edu.pe

Hecho el depósito legal en la Biblioteca Nacional del Perú $\mathrm{N}^{\circ}$ 2011-11207

Impreso en Joshua V\&E S.A.C. Calle Angamos № 118 Urb. María Isabel Cercado - Arequipa.

No está permitida la reproducción parcial o total de esta obra a excepción de lo contemplado en el decreto legislativo 822. 


\section{ÍNDICE}

Editorial

Walter L. Arias Gallegos

Resiliencia y estilos parentales en adolescentes que practican arte en un liceo municipal de Talca

Resilience and Parental Styles in Adolescents Practicing Art in a Municipal High School in Talca

Constanza Fuentes Valdés y Eugenio Saavedra Guajardo

En defensa de la realidad espiritual de la inteligencia

In defense of the Spiritual Dimension of Intelligence

Franco Fabricio Carpio Chanamé

Análisis psicométrico de dos escalas de actitudes hacia la estadística

Psychometric Analysis of Two Scales of Attitudes Towards Statistics

Luis Fernando Ramos Vargas

Asociación entre creencias implícitas acerca de la inteligencia y el rendimiento académico en escolares de 10 a 14 años de Arequipa metropolitana

The Association Between Implicit Theories of Intelligence and Academic Achievement in Children Between 10 to 14 Years of Age from Metropolitan Arequipa

Joselyn Mayeli Melo Peña y Rosario Carolina Salcedo Soto

Presencia de berrinches en niños y niñas de 2 a 3 años

Presence of Tantrums in Boys and Girls from 2 to 3 Years of Age

Fabiola Stefany Tito Abado, Paola Arlette Cáceres Gallegos

y Charles Portilla Revollar 
Autoeficacia y felicidad en estudiantes que aspiran a ingresar a la universidad

Self-efficacy and Happiness in Students Wishing to Apply to University

Melany Rosario Medina Chugnas, Andrea Virginia Saxsa Alegre y Miguel Barboza-Palomino

Una aproximación a la clasificación de heridas afectivas

An Approach to the Clasification of Affective Wounds

Paola Rodríguez Pacas, Humberto Del Castillo Drago y Mónica Caballero Andrade

Afrontamiento de la Incertidumbre en jóvenes imposibilitados de regresar del extranjero por pandemia de COVID-19

Coping with Uncertainty in Young People Unable to Return from Abroad Due to the COVID-19 Pandemic

Gina Chávez-Ventura, Henry Santa-Cruz-Espinoza, César Vásquez-Olcese y Janeth Molina-Alvarado

Salud mental, bienestar psicológico y estrés en personal de salud en el contexto de la COVID-19

Mental Health, Psychological Wellbeing and Stress in the

Healthcare Personnel in the Context of COVID-19

Giovanna Elizabeth Reyes Neyra, Rossmery Shirley Arce Delgado, Alexander Cruz Sotomayor y Nohely Andrea Portilla Pauccara

Uso excesivo del celular, calidad de sueño y soledad en jóvenes

de la ciudad de Arequipa

Excessive Use of Cell Phone, Quality of Sleep and Loneliness in Young People in The City of Arequipa

Atena Sota Velásquez, Melani Maldonado López, Manuel Ytuza Cusirramos, María del Carmen Cornejo Torres y Yessenia Cusirramos Carpio 


\section{Editorial}

\section{Fortaleciendo la investigación psicológica en Arequipa}

En este primer número de la Revista de Psicología de la Universidad Católica San Pablo, correspondiente al año 2021, tenemos algunas novedades que comentar con respecto al formato de publicación; pues además de trabajar con la 7 ma edición de la APA, se ha modificado un poco el formato de la portada de los artículos, con los datos estandarizados para las publicaciones seriales. Asimismo, cabe comentar que tratando de alinearnos con los criterios actuales de Concytec, hemos eliminado las secciones finales de nuestra revista; por lo que, de aquí en adelante solo se recibirán artículos de investigación empírica o de revisión. Esto también permitirá que la revista logre más indexaciones en nuevas bases de datos. Al respecto, desde este número ya estamos indexados en tres nuevas bases de datos como Redib, el catálogo de Latindex y Alicia.

Por otro lado, dado el contexto actual, en el que la investigación psicológica está posicionándose cada vez con más fuerza en la región Arequipa, en la que ya se publican de forma regular cinco revistas de psicología, editadas por diversas instituciones de la ciudad; es que la Revista de Psicología de la Universidad Católica San Pablo, ha ampliado la cantidad de artículos publicados por número, dado el incremento de trabajos que son recibidos por nuestra redacción. En ese sentido, el presente número contempla una diversidad de temas que abordan aspectos psicométricos, espirituales, evolutivos y de la salud; dentro del marco de la psicología educativa, la ciberpsicología, la psicología del desarrollo, la psicología positiva y la psicología clínica; campos que son objeto de diversos estudios sistemáticos en Arequipa y el país (Arias et al., 2015).

Dentro de estos temas, se tienen dos artículos relacionados con el COVID19 que ha generado una pandemia a escala global con serias repercusiones económicas, sociales y psicológicas en nuestra población; pero que a su vez, ha movilizado esfuerzos para comprender, investigar y prevenir sus consecuencias negativas en la salud física y mental de las personas más vulnerables. Ello no ha implicado desatender otros temas de gran relevancia en la sociedad como el desarrollo del niño, el papel de la familia en la formación de niños y 
adolescentes, o variables de índole tecnológica y educativa; con gran impacto en las manifestaciones psicológicas de diferentes grupos etarios.

Se cuenta asimismo, con colaboraciones del extranjero y de diversas regiones del país; que permiten dinamizar la comunicación académica entre los investigadores nacionales e internacionales. En ese sentido, en un reporte previo, se encontró que los índices de internacionalización de nuestra revista eran bajos (Palomino \& Arias, 2018), por ello, esperamos que manteniendo la regularidad de la revista y elevando la exigencia en el proceso de edición; la Revista de Psicología irá revirtiendo tales resultados. Por lo pronto, somos la revista psicológica con una regularidad constante y con mayor número de indexaciones en todo el sur del país; lo cual es fruto del trabajo coordinado y el apoyo institucional del Departamento de Psicología y el Centro de Investigación Psicológica de la Universidad Católica San Pablo, en la que se cuenta con 10 profesores investigadores acreditados por Concytec, quienes desarrollan su actividad académica en varias líneas de investigación psicológica.

Cabe señalar que toda la actividad investigativa que tiene lugar en nuestro seno institucional se hace en clave de integración del saber, animada por un diálogo fecundo entre la fe y la razón (Newman, 1993); ya que la ciencia y la religión, no tienen por qué verse como campos conflictivos entre sí, pues ambos hacen despliegue de sus métodos y fundamentos epistemológicos orientados por un horizonte de búsqueda de la verdad. Estos principios rectores han hecho posible que la investigación psicológica germine prósperamente en nuestra casa de estudios, y que la Revista de Psicología haya cumplido de forma satisfactoria, con un crecimiento paulatino, 10 años de existencia; contribuyendo con el desarrollo de la psicología en nuestra región.

Parte de nuestras fortalezas, radican en la gestión del conocimiento científico, ubicando a la persona humana en el centro de nuestro quehacer profesional y académico con una visión integral y una perspectiva ética. Todo ello en sintonía con la identidad cultural propia de nuestra región (Love, 2020), que está posicionada históricamente como una de las más representativas a nivel nacional, tanto en el plano socioeconómico como académico. Podemos decir entonces, que los esfuerzos desplegados en la Universidad Católica San Pablo, están contribuyendo sólidamente con el desarrollo de la ciencia, la cultura y la enseñanza de las jóvenes generaciones; que se forman con elevados estándares de exigencia y, particularmente en el Departamento de Psicología, desde donde se apuesta por una preparación profesional de los futuros psicólogos de cara a la trascendencia humana y espiritual. 
Esperamos que el presente número de la Revista de Psicología de la Universidad Católica San Pablo, sea el reflejo de todo lo comentado, y ofrezca a sus lectores y colaboradores información pertinente y actualizada que es producto de la actividad psicológica e investigativa en nuestra región.

Dr. Walter L. Arias Gallegos

Director de la Revista de Psicología

Universidad Católica San Pablo 


\section{Referencias}

Arias, W. L., Arista, M., Choque, M., Angles, U., Chávez, P., \& Herrera, B. (2015). Una encuesta acerca de los psicólogos más representativos y el futuro de la psicología en Arequipa. Liberabit, 21(1), 123-139.

Love, T. (2020). La república independiente de Arequipa. Pontificia Universidad Católica del Perú - Universidad Católica de Santa María.

Newman, J. H. (1993). La fe y la razón. Sermones universitarios. Ediciones Encuentro.

Palomino, A. A., \& Arias, W. L. (2018). La Revista de Psicología de la Universidad Católica San Pablo (2011-2018): Un análisis histórico y bibliométrico. Revista Peruana de Historia de la Psicología, 4, 41-64. 


\title{
Resiliencia y estilos parentales en adolescentes que practican arte en un liceo municipal de Talca
}

\author{
Resilience and Parental Styles in Adolescents Practicing Art \\ in a Municipal High School in Talca \\ Constanza Fuentes Valdés \\ Departamento de Educación Municipal de Talca, Chile \\ iD https://orcid.org/oooo-0002-7167-303X \\ Correspondencia: Constanzafuentes.v@gmail.com
}

\author{
Eugenio Saavedra Guajardo \\ Universidad Católica del Maule, Chile \\ (iD) https://orcid.org/oooo-ooo3-2843-9739
}

\begin{abstract}
Resumen
Los estilos parentales que establecen los padres y/o cuidadores con los hijos tienen implicancias en el desarrollo de la personalidad y el desarrollo de la resiliencia, sin embargo, tanto en Chile como en el resto del mundo no se ha estudiado el comportamiento de estas variables en adolescentes que practican arte. La presente investigación tuvo por objetivo describir y analizar cómo los estilos parentales se relacionan con la variable resiliencia en adolescentes que practican arte; a saber, artes escénicas, artes musicales y artes visuales. Todo ello en una muestra de 184 sujetos en edades comprendidas entre los 15 y 19 años de ambos sexos pertenecientes a un liceo de formación artística de Talca. Se aplicó la escala de resiliencia SV-RES (Saavedra y Villalta, 2008) y la Escala Parental Breve (EPB) que evaluó tres dimensiones del estilo parental. Esta investigación cuantitativa de tipo descriptiva correlacional arrojó como resultados la existencia de relación positiva alta entre los estilos parentales y la resiliencia, asimismo se logró identificar que existe diferencia significativa entre la resiliencia de los adolescentes que practican música y artes visuales. Los resultados apuntan a generar futuras estrategias en contextos educacionales enfocados en fortalecer los estilos parentales, asimismo se da pie para generar futuras investigaciones que permitan comparar adolescentes que practican arte y los que no para describir los niveles y perfiles de resiliencia.
\end{abstract}


Palabras clave: Resiliencia, estilos parentales, adolescencia, currículo artístico, contexto escolar.

\begin{abstract}
The parenting styles employed by parents and/or caregivers have implications for the development of personality and the development of resilience in children. However, both in Chile and in the rest of the world the behavior of these variables has not been studied among teenagers who practice art. The objective of this research was to describe and analyze how parenting styles are related to resilience in adolescents who participate performing arts, musical arts and visual arts. For this purpose a sample of 184 subjects between the ages of 15 and 19 of both sexes were recruited from a lyceum for artistic development in Talca. The Scale of Resilience SV-RES (Saavedra and Villalta, 2008) and the Short Parenting Scale (EPB) that evaluated three dimensions of the parenting style was administered. This quantitative research, of correlational descriptive type, resulted in a strong positive relationship between parenting styles and resilience. It was also possible to identify a significant difference between the resilience of adolescents who practice music and those who practice visual arts. The results aim to generate future strategies in educational contexts, focused on strengthening positive parenting styles. In addition, this study gives rise to the need for future research that compares adolescents who practice art and those who do not in order to determine the relative levels and profiles of resilience.

Keywords: Resilience, parental styles, adolescence, artistic curriculum, school context.
\end{abstract}

\section{Introducción}

En las últimas décadas ha aumentado el interés en estudiar la resiliencia, sin embargo hasta la actualidad no se han realizado muchos estudios que relacionen las variables de estilos parentales y resiliencia en población adolescente, considerando que la salud mental de los niños y adolescentes debiera ser el objetivo de las políticas públicas actuales.

Estudios recientes dan a conocer que en todo el mundo, entre el 10 y el 20 $\%$ de los adolescentes experimentan problemas de salud mental (Dray et al., 2017). Bajo esa óptica las estrategias destinadas a fortalecer los factores de protección de los adolescentes proporcionan un enfoque potencial para aumentar la salud mental en los jóvenes y disminuir los factores de riesgo. En este sentido la resiliencia es considerada un factor protector que es necesario estudiar. Así, Castiblanco y De la Salas, (2008) afirman que "las escuelas, las familias y las comunidades son ambientes clave para que los individuos desarrollen la capacidad de sobreponerse a la adversidad, se adapten a las presiones y problemas 
que enfrentan y desarrollen las competencias sociales, académicas y vocacionales necesarias para salir adelante en la vida" (p. 40). Lo anterior permite considerar a los padres como forjadores de resiliencia en sus hijos a través de los estilos que puedan establecer en la relación parental con ellos. Por otro lado, la resiliencia en este estudio se entenderá a partir de la definición propuesta por Saavedra (2011), quien señala que ésta es fruto de la interacción entre factores de riesgo y factores protectores presentes en el contexto y en el sujeto mismo. Cuando el equilibrio es suficientemente estable para resistir los cambios adversos de las circunstancias que vive el sujeto, se le define como resiliente (Romero \& Saavedra, 2016). En esa línea da a entender que la resiliencia no es absoluta ni estática, por lo tanto las personas más que ser resilientes "tienen conductas resilientes o se comportan resilientemente". De manera similar, Cyrulnik (1999) destaca que una persona no puede actuar resilientemente estando en soledad, ya que la resiliencia se construye en la interacción con los otros, con el entorno y con su medio social (citado en Romero y Saavedra, 2016).

En Chile existen escasos estudios que aborden la variable resilienciay los estilos parentales en población adolescentes, sobre todo en contextos educativos donde se practique el arte. En este sentido, el sistema escolar es una fuente que permite promover las capacidades resilientes en los adolescentes. En esa línea, estudios como el de Acevedo y Restrepo (2012) señalan que docentes resilientes son un elemento esencial para potenciar la resiliencia de estudiantes.

Considerando lo anterior esta investigación tiene por objetivo describir la relación entre los estilos parentales y la resiliencia en adolescentes que practican arte en un liceo municipal de Talca a través de la Escala de Resiliencia SV-RES y Escala Parental Breve (EPB).

\section{Resiliencia}

Resiliencia es un concepto en el que hasta la actualidad no se ha establecido un consenso sobre su definición, pues son muchos autores quienes la conceptualizan. La resiliencia se ha comenzado a estudiar desde hace cincuenta años aproximadamente. Autores como Sanders, Munford, Thimasarn-Anwary Liebenberg (2017) señalan que la resiliencia ha sido conceptualmente diversificada, pues pasó de considerarse como un rasgo o patrón de desarrollo unidimensional a ser una construcción multidimensional que varía dependiendo del contexto temporal, la edad, el sexo, los antecedentes culturales y los factores biológicos que influyen en la resiliencia y se combinan para entrar en juego en diferentes momentos y dar respuesta en situaciones que se experimentan como riesgos. La resiliencia entonces, puede ser entendida como la capacidad que tienen algunos seres humanos de responder adaptativamente a las situaciones de adversidad a las que se ven expuestos (Saavedra \& Villalta, 2008). Algunas investigaciones han reportado 
que una interacción entre los factores individuales y ambientales determinan el grado de resiliencia que una persona posee (Windle, Bennett, \& Noyes, 2011).

Investigaciones como las de Sidheek, Satyanarayana, Sowmya y Chandra (2017), señalan que la resiliencia actúa como un amortiguador frente a las dificultades ambientales y previene el desajuste psicológico. La resiliencia se convierte así en un paso importante para empoderar a los adolescentes de entornos desfavorecidos, pero como indican Oldfield et al. (2018), la resiliencia se desarrolla cuando hay una interacción entre el riesgo (es decir, negligencia parental) y factores de protección (es decir, la escuela y pares), lo que lleva a la adaptación positiva.

En cuanto a la evaluación de la resiliencia, Saavedra y Villalta (2008), diseñaron y validaron una escala compuesta por 12 factores ilustrados en la Tabla 1, que se agruparon en cuatro ámbitos, desde la conducta evidente (Respuesta resiliente) hasta el sistema de creencias que la interpreta y la hace recurrente (Condiciones de base). Asimismo, los 12 factores describen distintas modalidades deinteracción del sujeto: consigo mismo, con los otros, con sus posibilidades.

Tabla 1. Los 12 factores de Resiliencia

\begin{tabular}{|c|l|l|l|l|}
\hline & $\begin{array}{c}\text { Condiciones } \\
\text { de base }\end{array}$ & $\begin{array}{l}\text { Visión de sí } \\
\text { mismo }\end{array}$ & \multicolumn{1}{|c|}{$\begin{array}{c}\text { Visión de } \\
\text { problema }\end{array}$} & $\begin{array}{c}\text { Conducta } \\
\text { resiliente }\end{array}$ \\
\hline Yo soy, yo estoy & $\begin{array}{l}\text { F1: } \\
\text { Identidad }\end{array}$ & $\begin{array}{l}\text { F2: } \\
\text { Autonomía }\end{array}$ & $\begin{array}{l}\text { F3: } \\
\text { Satisfacción }\end{array}$ & $\begin{array}{l}\text { F4: } \\
\text { Pragmatismo }\end{array}$ \\
\hline Yo tengo... & $\begin{array}{l}\text { F5: } \\
\text { Vínculos }\end{array}$ & $\begin{array}{l}\text { F6: } \\
\text { Redes }\end{array}$ & $\begin{array}{l}\text { F7: } \\
\text { Modelos }\end{array}$ & $\begin{array}{l}\text { F8: } \\
\text { Metas }\end{array}$ \\
\hline Yo puedo... & $\begin{array}{l}\text { F9: } \\
\text { Afectividad }\end{array}$ & $\begin{array}{l}\text { F10: } \\
\text { Autoeficacia }\end{array}$ & $\begin{array}{l}\text { F11: } \\
\text { Aprendizaje }\end{array}$ & $\begin{array}{l}\text { F12: } \\
\text { Generatividad }\end{array}$ \\
\hline
\end{tabular}

Para efectos de este estudio se entenderá resiliencia desde una mirada contextualizada, considerando que el individuo está expuesto a adversidades y logra adaptarse a éstas de manera positiva gracias a la activación de factores protectores ambientales, individuales, familiares, comunitarios y políticos.

\section{Adolescencia}

La adolescencia es el periodo de transición entre la infancia y la adultez, en el que se produce un proceso de maduración que implica cambios físicos, psicológicos y sociales (Alsinet et al., 2003). Respecto a su rango de duración, aunque varía según las diferentes fuentes médicas, antropológicas y psicológicas; se suele admitir el inicio entre los 14 y 15 años y finaliza a los 19 (OMS, 2017). La adolescencia también se caracteriza por muchos cambios que requieren de la adaptación de parte del adolescente. Esta puede ser una oportunidad para mejorar el desarrollo, pero también 
puede resaltar las vulnerabilidades del adolescente. Aunque la mayoría de los jóvenes afrontan adecuadamente estos cambios, este período de desarrollo se caracteriza por una mayor presencia de problemas de externalización e internalización (Jaureguizar, et al., 2018). Es un período donde las amistades y el apoyo de los compañeros son esenciales, y en el que los jóvenes buscan la autonomía de sus cuidadores y se acercan a sus amigos y compañeros por el apoyo social (Charalampous et al., 2018).

Una de las tareas centrales de la adolescencia es la búsqueda de la identidad personal y la construcción de una imagen coherente de sí mismo, que siente las bases para afrontar los desafíos de la etapa adulta, pues la identidad es una reflexión para la adaptación individual al contexto (Motos-Teruel, 2017). Por lo tanto, los aspectos mencionados desembocan en la idea de que durante la adolescencia se produce un proceso de búsqueda interior, se cuestionan los valores personales y aparecen nuevos compromisos y prioridades (Berk, 2004).

Respecto a la escuela, es importante destacar que las relaciones interpersonales cobran real importancia. En este sentido, los compañeros juegan un papel importante en la socialización durante esta etapa, sin desconocer que la familia sigue siendo una fuente esencial de apoyo, referencia y educación. Rodríguez-Fernández, Droguet y Revuelta (2012) afirman que la crianza ha sido identificada durante mucho tiempo como uno de los factores influyentes más importantes en el ajuste psicosocial de los niños y adolescentes (como se citó en Jaureguizar et al., 2018).

La familia sin duda es factor que favorece el ajuste psicológico en los adolescentes. En esa línea, Van Petegem, ZimmerGembeck, Soenens, Vansteenkiste, Brenning, Mabbe y Zimmermann (2017) plantean que una parte importante del proceso de socialización incluye a los padres quienes también van a influir en el proceso de regulación del comportamiento. Barber y Xia (2013) afirman que durante la adolescencia, la regulación incluye la participación activa de los padres en el establecimiento de normas, la comunicación de las expectativas y la formulación de solicitudes de comportamiento más apropiado cuando se producen transgresiones (Van Petegem et al., 2017). La regulación baja o inconsistente de los padres puede poner a los adolescentes en riesgo de exteriorizar ciertos problemas de conducta.

\section{Estilos parentales}

Existen modelos teóricos que permiten dar cuanta de los proceso de socialización en la familia desde una perspectiva ecológica, al considerar los contextos en que se dan dichas interacciones (Capano \& Massonnier, 2016; Oliva \& Arranz, 2011). Lo anterior presenta especial atención debido a que los planteamientos de Saavedra y Villalta (2008) dan cuenta de que cuando un niño es sometido de manera prolongada a situaciones críticas, dependerá en gran medida de las competencias y sostén de sus 
padres o cuidadores, para enfrentar esa adversidad.

El ajuste psicológico de los niños podría explicarse por sus percepciones de aceptación o rechazo por parte de los cuidadores primarios (Jaureguizar, et al, 2018). Cuando los padres entregan menor apoyo se relaciona con una mayor depresión y ansiedad entre los adolescentes (Yap et al., 2014), además de bajo rendimiento en el ámbito escolar $o$ académico.

Los estilos parentales se consideran como un conjunto de acciones de los padres hacia los hijos que les son comunicadas a éstos; crean un clima emocional en el que se manifiestan las conductas de los cuidadores (Darling
\& Steinberg, 1993); describen cómo los hijos perciben las prácticas de socialización de sus padres, cómo es la forma en que responden a sus necesidades (de respuesta) y la forma en que utilizan el control (exigencia) (Baumrid, 1991; Maccoby \& Martin, 1983). Baumrind (1966), respecto del grado de control que ejercen los padres, propone tres tipos de estilo parental: autoritario, democrático y permisivo. Considerando estos planteamientos, se puede decir que el estilo de los padres juega un papel crucial en la determinación y comportamiento de los adolescentes (Charalampous et al., 2018). La Tabla 2 ejemplifica la interacción de los estilos y tipologías parentales considerando los aportes de Baumind (1966), Macoby y Martin (1993), Darling y Steinberg (1993).

\section{Tabla 2. Estilos y tipologías parentales}

\begin{tabular}{|c|c|c|}
\hline Responsividad & Exigencia & Estilo \\
\hline Alta & Alta & Democrático \\
Alta & Baja & Autoritario \\
Baja & Alta & Permisivo \\
Baja & Baja & Negligente \\
\hline
\end{tabular}

Durante la adolescencia, los padres tienden a vigilar y controlar a sus hijos, y se espera que el establecimiento de las normas de comportamiento de los adolescentes se mantengan en la adultez. En este proceso de relación con los padres, los adolescentes, según el estilo parental predominante van adquiriendo control, mayor autonomía y más posibilidades para determinar sus propias formas de acción. Los adolescentes necesitan percibir de los padres, confianza, respeto mutuo y buena comunicación en las relaciones; siendo cruciales para el ajuste psicológico de los adolescentes (Vansteenkiste et al., 2010), y de esa forma, fortalecer las conductas resilientes ante situaciones de estrés y/o amenaza. Estudios actuales de Kaniusonyte y Zukauskiene (2018) señalan que un estilo basado en autonomía y apoyo a los jóvenes por parte de sus los padres en el sentido de esforzarse para lograr tomar la perspectiva de sus hijos y animarles a buscar sus objetivos y resolver 
problemas por sí mismos, se asocia positivamente con el tener hijos resilientes. Estos padres responsivos que respetan el mundo psicológico interno de sus hijos promueven la formación de su identidad. En éste sentido los estilos de los padres pueden jugar un papel importante en cómo los adolescentes se regulan positivamente frente a una situación específica.

Es también necesario precisar algunas características de los adolescentes resilientes, que para efectos de este estudio se tomaran en cuenta, sobre la base de las consideraciones de Kotliarenco, Cáceres y Fontecilla, (1996); González y Medina (2007), quienes destacan lo siguiente: niños y niñas, y adolescentes resilientes, se caracterizan por presentar mayor tendencia hacia el acercamiento, mayor autoestima, autonomía e independencia, habilidades de afrontamiento, menor tendencia a la evitación de los problemas, menores sentimientos de desesperanza y fatalismo, locus de control interno, habilidades de resolución de problemas, empatía, conocimiento y manejo adecuado de relaciones interpersonales y sentido del humor.

\section{Currículo artístico en contexto educacional}

Las escuelas han sido durante mucho tiempo el sitio para la programación orientada a aumentar las habilidades en los niños y adolescentes, debido a la facilidad de acceso que proporcionan a los jóvenes y el vínculo entre el éxito académico, participación escolar y otros objetivos de desarrollo del niño, como la autoestima y la autoeficacia (Ungar et al., 2017). En Chile se ha proporcionado dentro de la normativa educacional, un currículo artístico para algunas escuelas a lo largo del país; es decir los estudiantes que optan por este tipo de sistema, pueden estudiar música, artes visuales o artes escénicas. En esta línea, Arnheim (1993) concibe a las artes como los medios privilegiados para proporcionar estímulos sensitivos, las considera materias centrales para el desarrollo de las sensibilidades y para la imaginación. Asimismo, la habilidad artística humana se considera una actividad de la mente, "una actividad que involucra el uso y la transformación de diversas clases de símbolos y de sistemas simbólicos" (Gardner, 1987, p. 30).

La educación en artes visuales se centra fundamentalmente en el desarrollo del pensamiento creativo y el fortalecimiento de la individualidad artística de los estudiantes. El carácter diferente de la educación en el campo de las artes musicales y visuales nos permite suponer, según Nogai (2017), que los estudiantes de este tipo de escuelas revelan mayores niveles de afrontamiento del estrés y autocontrol. Así, los estudiantes de música serían más resilientes que los estudiantes de artes visuales.

En Chile, específicamente en el campo educacional se presta cada vez mayor atención a promover el arte a través de la formación curricular escolar, debido al reconocimiento de la importancia que adquiere el fomento de ésta en los adolescentes, sobre todo si se contemplan las presiones y el estrés creciente al que 
están sometidos en contextos escolares y familiares.

La Comisión Nacional de la Cultura y las Artes (CNCA, 2011) define la educación artística como "un proceso de formación de sujetos mediante el arte, el cual conforma un campo de conocimiento distinto al lógico matemático o al narrativo lingüístico, ambos fuertemente arraigados a nuestro actual sistema escolar" (p, 10).

\section{Resiliencia y contexto escolar}

En el contexto de las escuelas, se observa la capacidad de resiliencia cuando un estudiante sigue trabajando y logra tener éxito académico, incluso después de que él o ella, experimentan un factor de riesgo como la intimidación o un episodio de enfermedad (Lal et al., 2014, citado en Ungar et al., 2017, p.13).

Desde el punto de vista ecológico, Ungar et al. (2007) han demostrado que la resiliencia es el resultado de un conjunto de interacciones que ayudan a que los niños y adolescentes puedan acceder a los recursos categorizados en siete grandes categorías de recursos: 1) recursos materiales, 2) relaciones de apoyo, 3) identidad personal deseable, 4) experiencias de potencia y control, 5) adherencia a las tradiciones culturales, 6) experiencias de la justicia social, y 7) experiencias de cohesión social con los demás. En la investigación de Ungar et al. (2017) se concluye que cuanto más de estos siete recursos están disponibles y accesibles en los jóvenes, es más probable que tengan éxito en la escuela y en sus comunidades. La escuela no solo está disponible para proporcionar oportunidades educativas, sino también debe verse como una fuente de apoyo para la resiliencia general de los estudiantes, a través de la estimulación del sentido de pertenencia, autoestima, compromiso social y rendimiento académico.

\section{Método}

En el presente estudio de tipo correlacional (Hernández et al., 2010), se pretende 1) identificar los niveles de resiliencia en adolescentes que practican arte en un Liceo Municipal de Talca evaluados a través de la Escala de Resiliencia SV-RES, 2) identificar los estilos parentales en adolescentes que practican arte en un Liceo Municipal de Talca evaluados a través de la Escala Parental Breve (EPB), 3) relacionar los estilos parentales y la resiliencia en éstos adolescentes, e 4) identificar el perfil de resiliencia en éstos adolescentes.

\section{Población y Muestra}

La muestra del estudio estuvo conformada por 184 adolescentes hombres y mujeres entre 15 y 19 años de edad que pertenecen a un liceo de formación artística de la ciudad de Talca. El 58.2 \% corresponden a mujeres, el $40.8 \%$ varones y el $1.2 \%$ trangéneros. La muestra fue seleccionada por medio de métodos no probabilísticos, mediante la técnica de grupos intactos. 


\section{Instrumento}

Para evaluar la resiliencia se empleó la Escala de Resiliencia SV-RES para jóvenes y adultos (Saavedra \& Villalta, 2008) por ser un instrumento creado y validado en población chilena. El tiempo de aplicación es breve (aproximadamente 20 minutos), posee una base teórica sólida, articulando los modelos de Grotberg (1996) y de Saavedra (2003). Esta escala permite obtener un puntaje global de resiliencia y puntajes por áreas (Saavedra \& Villalta, 2008). Se aplica desde los 15 a 65 años, y contiene 60 ítems distribuidos en 12 factores específicos de resiliencia con cinco alternativas de respuesta, que van desde Muy de acuerdo a Muy en desacuerdo. Presenta una homogeneidad alta con correlaciones superiores a .76 y un índice de confiabilidad de .96 , obtenida mediante la prueba alfa de Cronbach.

Para evaluar los estilos parentales se empleó la Escala Parental Breve (EPB) de Cumsille, Martínez, Rodríguez y Darling (2014), que fue desarrollada a partir del PSI II (Darling \& Toyokawa, 1997). Se optó por este instrumento por estar validado en población de adolescentes chilenos. Es una escala breve, que consta de 12 ítems son cinco alternativas que van desde Muy de acuerdo a Muy en desacuerdo, y que se compone de tres subescalas: 2 que evalúan dimensiones del estilo parental (responsividad/ calidez y demanda parental) y una que evalúa la práctica parental de monitoreo. Las dos variables de los estilos parentales mostraron niveles moderados de adecuación y la consistencia interna fue apropiada para las tres subescalas, con valores superiores a .81 , mediante la prueba alfa de Cronbach.

\section{Procedimiento de recogida y análisis de datos}

Para este trabajo se obtuvieron todos los permisos requeridos para la investigación en seres humanos y la aprobación por parte de un comité académico de la universidad. Se siguieron los estándares de ética de la declaración de Helsinki de 1964 , a saber: valor, validez científica, selección equitativa del sujeto, proporción favorable de riesgo-beneficio, evaluación independiente y consentimiento y asentimiento informado.

En primer lugar se contó con autorización del sostenedor del establecimiento educacional, posteriormente se reclutó la muestra de manera intencional. Se aplicó una hoja de consentimiento informado para los padres y adolescentes mayores de 18 años y de asentimiento informado a todos los adolescentes menores de 18 años. Además, se analizaron los datos mediante el programa estadístico SPSS, mediante la prueba t de Student para comparar medias y coeficiente de Pearson para correlacionar variables.

\section{Resultados}

Se calculó la media y desviación estándar del grupo total y por especialidad de la escala SV-RES. Los resultados expuestos en la Tabla 3 muestran que 
la resiliencia promedio del grupo total es 249,67 (D.E. $=37,26$ ) que corresponde con la categoría de resiliencia de nivel medio. El promedio del grupo total en la escala parental breve es de 52,48 (D.E. $=6,72)$.

Tabla 3. Resultados por especialidad de resiliencia SV-RES y Escala Parental Breve EPB

\begin{tabular}{|l|c|c|c|}
\hline \multicolumn{4}{|c|}{ Escala de Resiliencia SV-RES } \\
\hline \multirow{2}{*}{ Grupo Total } & Muestra & Media & Desviación estándar \\
Artes visuales & 184 & 249,67 & 37,26 \\
Danza & 66 & 241,71 & 40,31 \\
Música & 27 & 252,19 & 41,65 \\
Teatro & 35 & 259,37 & 30,37 \\
\hline & 56 & 251,77 & 34,13 \\
\hline \multirow{3}{*}{ Escala Parental Breve (EPB) } \\
Grupo Total & Muestra & Media & Desviación estándar \\
Artes visuales & 184 & 52,48 & 6,72 \\
Danza & 66 & 51,2 & 7,22 \\
Música & 27 & 54,26 & 7,39 \\
Teatro & 35 & 53,89 & 4,47 \\
\hline
\end{tabular}

Para determinar la relación entre la resiliencia y los estilos parentales en adolescentes que practican arte fueron calculados los coeficientes de correlación de Pearson como se aprecia en la Tabla 4 , obteniéndose un coeficiente $r=.62$ para la dimensión de Reponsividad/calidez, que corresponde a una correlación positiva alta; un coeficiente $\mathrm{r}=.39$ para la dimensión de Demanda/expectativa, que corresponde a una correlación positiva moderada; $y$ un coeficiente $\mathrm{r}=.59$ para la dimensión de Monitoreo, que corresponde a una correlación positiva moderada alta.

Tabla 4. Correlaciones entre dimensiones Escala Parental Breve y Resiliencia

\begin{tabular}{|l|c|}
\hline \multicolumn{1}{|c|}{ Dimensiones EPB } & r \\
\hline Responsividad/calidez & .62 \\
\hline Demanda/expectativa & .39 \\
\hline Monitoreo & .59 \\
\hline
\end{tabular}

Se calculó también la resiliencia por dimensiones como se expone la Figura 1 , donde las tres dimensiones con mayores puntajes son Modelos $(21,8)$, Generatividad $(21,8)$ y Aprendizaje $(21,6)$, lo que permite interpretar que los 
adolescentes más resilientes se perciben como personas prácticas, que pueden ser capaces de plantearse metas y terminar lo que comienzan, que se perciben como creativos y persistentes. Las tres dimensiones con menores puntajes corresponden a las dimensiones de Identidad $(19,6)$, Afectividad $(19,8)$ y Vínculos
$(20,3)$. Estos puntajes indican que los adolescentes que practican arte pueden presentar dificultades para establecer relaciones personales de confianza y también presentan dificultad en juicios referidos al valor de la socialización primaria y las redes sociales con implicancias en su historia personal.

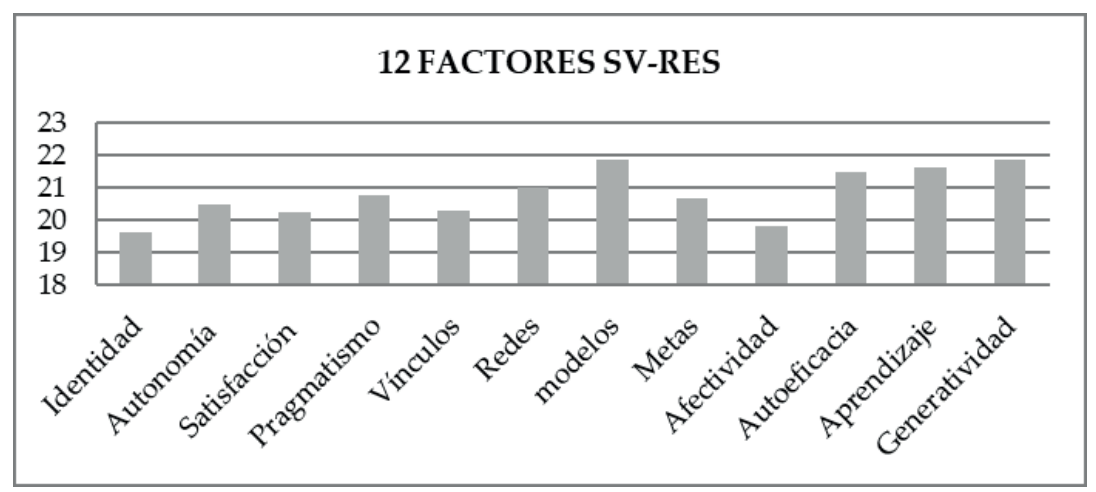

Figura 1. Resultados por dimensiones de Escala de Resiliencia SV-RES

De los resultados obtenidos en la Escala Parental Breve (EPB) que ilustra la Figura 2, la dimensión con mayor puntaje corresponde a Demanda/expectativa $(18,55)$, mientras que la dimensión monitoreo fue valorada con menor puntaje $(16,90)$. Estos puntajes permiten determinar que los adolescentes interpretan que los padres esperan que sean responsables, respetuosos y de que informen acerca de dónde se encuentran. Al presentar puntajes bajos en la dimensión Monitoreo, esto indica que los adolescentes están interpretando que a sus padres no les preocupa averiguar qué es lo que hacen o con quién se involucran.

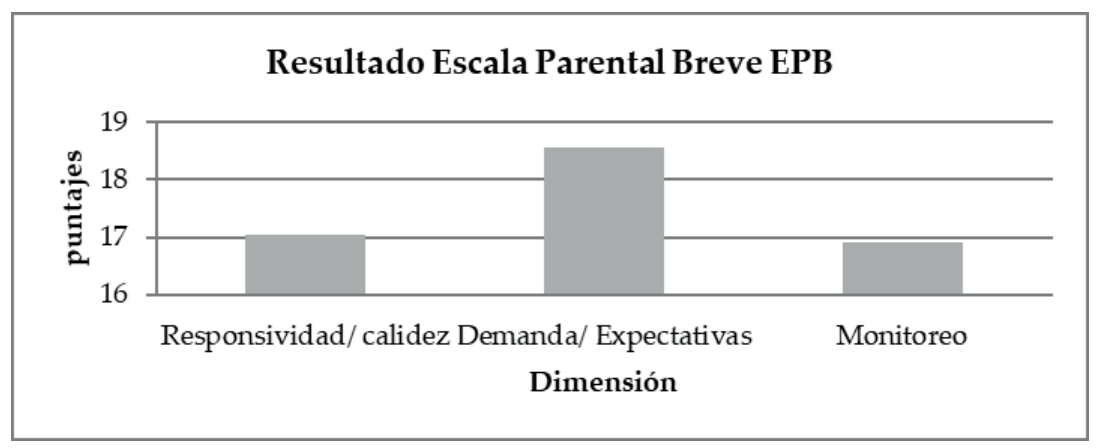

Figura 2. Resultados generales escala parental breve 


\section{Discusión}

Esta investigación tuvo como propósito describir la relación entre la resiliencia y los estilos parentales en adolescentes que practican arte; a saber artes visuales, danza, música y teatro. Sobre todo, se pretendió identificar los niveles y los perfiles de resiliencia, así como la percepción de los estilos parentales en sus respectivas dimensiones. Los resultados de esta investigación comprueban las hipótesis propuestas, es decir, que los estilos parentales se relacionan con los niveles de resiliencia en adolescentes que practican arte en un liceo municipal de Talca.

Los adolescentes que practican arte obtienen altos niveles de resiliencia en la dimensión Generatividad. Por otra parte el estilo parental Responsividad/ calidez se asocia con mayores niveles resiliencia en adolescentes, lo que refuerza lo planteado por Saavedra y Villalta (2008), cuando indican que si en la familia existe calidez y apoyo, habrá la confianza necesaria para un sano desarrollo de los hijos.

Por otro lado, de acuerdo a los perfiles de resiliencia, los estudiantes de artes visuales presentan mayor desarrollo en las dimensiones Modelos, Generatividad y Aprendizaje; y menores puntajes en las dimensiones Identidad, Afectividad y Vínculos; lo que se asocia con lo señalado por Motos-Teruel (2017), quien refiere que una de las tareas centrales de la adolescencia es la búsqueda de la identidad y la construcción de una imagen coherente de sí mismo con base en las relaciones con otras personas cercanas.

El nivel de resiliencia obtenido se ubica en un nivel promedio en los adolescentes evaluados. La dimensión Demanda/ expectativa fue la que obtuvo mayor puntuación, destacando por tanto, que en este grupo etario se presenta una tendencia a percibir que se establecen normas y límites con bajo nivel de monitoreo y responsividad.

Este estudio permite proponer nuevas proyecciones en materia de investigación a propósito de los resultados. En este sentido queda abierta una arista para realizar investigaciones comparativas entre adolescentes que practican arte y adolescentes que no practican arte. Asimismo considerando que se trató de una muestra intencional, se debe profundizar más en el comportamiento de las variables estudiadas en una población más representativa de adolescentes chilenos.

A pesar de esta limitación, en la práctica también se pueden generar intervenciones en el área de la promoción de la resiliencia, a través de la incorporación de asignaturas artísticas como parte del plan común de estudios para favorecer su desarrollo desde la etapa preescolar; como también generar estrategias dentro de las políticas educacionales que abarquen a las familias dentro del proceso de educación emocional de los adolescentes, específicamente en la temática 
de los estilos parentales; pues está demostrado que se puede fomentar la resiliencia de los adolescentes a través del apoyo y el afecto recibido, así como del establecimiento de límites de sus padres y/o cuidadores.

\section{Financiamiento}

La presente investigación fue autofinanciada.

\section{Conflictos de interés}

Los autores declaran que no tienen conflictos de interés. 


\section{Referencias}

Acevedo, V., \& Restrepo, L. (2012). De profesores, familias y estudiantes: fortalecimiento de la resiliencia en la escuela. Revista Latinoamericana de Ciencias Sociales, Niñez y Juventud, 10(1), 301-319.

Alsinet, C. Pérez, R., \& Agullo, M. (2003). Adolescentes y percepciones del riesgo. Revista de Estudios sobre Juventud, 18, 90-101.

Arnheim, R. (1993). Consideraciones sobre la educación artística. Paidós.

Baumrind, D. (1966). Effects of Authoritative Parental Control on Child Behavior. Child Development, 37(4), 887-907. http://dx.doi.org/10.2307/1126611

Baumrind, D. (1991). Los estilos de crianza y desarrollo de los adolescentes. En J. Brooks-Gunn, R. Lerner, y A. Petersen (Eds.). La enciclopedia de la adolescencia (pp. 746 - 758). Garland.

Barber, B., \& Xia, M. (2013). The centrality of control to parenting and its effects. En R. E. Larzelere, A. Sheffield \& A. W. Harrist (Eds.), Authoritative parenting: Synthesizing nurturance and discipline for optimal child development (pp. 61-87). American Psychological Association. https://doi.org/10.1037/13948-004

Berk, L. (2004). Development through the Lifespan. 3th. ed. Pearson Education.

Capano, A., Del Luján, M., \& Massonnier, N. (2016). Estilos relacionales parentales: estudio con adolescentes y sus padres. Revista de Psicología, 34(2), 413-444.

Castiblanco, J., \& De la Salas, M. (2008). Potenciación de pautas parentales resilientes de familias con hijos adolescentes. Tendencias y Retos, 13, 39-54.

Charalampous, K., Demetriou, C., Tricha, L., Ioannou, M., Georgiou, S., Nikiforou, M., \& Stavrinides, P. (2018). The effect of parental style on bullying and cyber bullying behaviors and the mediating role of peer attachment relationships: A longitudinal study. Journal of Adolescence, 64, 109-123. http://dx.doi.org/10.1016/j. adolescence.2018.02.003

Consejo Nacional de la Cultura y las Artes (2011). Estudio de caracterización de las Escuelas Artísticas. Centro de Innovación en Educación. 
Cumsille, P., Martínez, M. L., Rodríguez, V., \& Darling, N (2014). Análisis psicométrico de la escala parental breve (EPB): Invarianza demográfica y longitudinal en adolescentes chilenos. Psykhe, 23(2), 1-14. http://dx.doi.org/10.7764/psykhe.23.2.665

Darling, N., \& Steinberg, L. (1993). Parenting style as context: An integrative model. Psychological Bulletin, 113, 487-496. http://dx.doi.org/10.1037/o033- 2909.113.3.487

Dray, J., Bowman, J., Campbell, E., Freund, M., Hodder, R., Wolfenden, L., \& Wiggers, J. (2017). Effectiveness of a pragmatic school-based universal intervention targeting student resilience protective factors in reducing mental health problems in adolescents. Journal of Adolescence, 57, 74-89. http://dx.doi.org/10.1016/j. adolescence.2017.03.009

Gardner, H. (1987). Arte, mente y cerebro. Paidós.

Kaniusonyte, G., \& Zukauskiene, R. (2018). Adolescents' self-perception of morality, competence, and sociability and their Interplay with quality of family, friend, and school relationships: a three-wave longitudinal study. Journal of Youth and Adolescence, 47(8), 1743-1754. https://doi.org/10.1007/s10964-018-0864-z

Kotliarenco, M., Cáceres, I., \& Fontecilla, M. (1997). Estado de arte en resiliencia. Organización Panamericana de la Salud - Oficina Sanitaria Panamericana.

Motos-Teruel, T. (2017). Hacer Teatro: beneficios para el desarrollo positivo en adolescentes. Revista Latinoamericana de Estudios Educativos, 34, 219-248.

Nogaj, A. A. (2017). Locus of control and styles of coping with stress in students educated at polish music and visual art schools - A cross-sectional study. Polish Psychological Bulletin, 48(2), 279-287. http://dx.doi.org/10.1515/ppb-2017-0031

Oldfield, J., Stevenson, A., Ortiz, E., \& Haley, B. (2018). Promoting or suppressing resilience to mental health outcomes in at risk young people: The role of parental and peer attachment and school connectedness. Journal of Adolescence, 64, 13-22. http://dx.doi.org/10.1016/j.adolescence.2018.01.002

Rodríguez-Fernández, L. Droguett, L., \& Revuelta, D. (2012). Ajuste escolar y personal en la adolescencia: El papel del autoconcepto académico y del apoyo social percibido. Revista de Psicodidáctica, 17(2). http://dx.doi.org/10.1387/Rev. Psicodidact.3002 
Romero, C., \& Saavedra, E. (2016). Impacto de un programa recreativo en la resiliencia de estudiantes de $7^{\circ}$ grado de un colegio primario. Liberabit, 22(1), 43-56.

Saavedra, E. (2011). La resiliencia desde una mirada post racionalista. Dos historias de vida. Editorial Académica Española.

Saavedra, E. (2014). La construcción de la respuesta resiliente, un modelo y su evaluación. En J. M. Madariaga (Coord.), Nuevas miradas sobre la resiliencia. Ampliando ámbitos y prácticas (pp. 111-127). Gedisa.

Saavedra, E., \& Villalta, M. (2008). Escala de Resiliencia SV-RES, para jóvenes y adultos. CEANIM.

Sanders, J., Munford, R., Thimasarn-Anwar, T., \& Liebenberg, L. (2017). Validation of the child and youth resilience measure (CYRM-28) on a sample of at-risk New Zealand youth. Research on Social Work Practice, 27(7), 827-840.

Sidheek, K. P. F., Satyanarayana, V. A., Sowmya, H. R., \& Chandra, P. S. (2017). Using the Kannada version of the Connor Davidson Resilience Scale to assess resilience and its relationship with psychological distress among adolescent girls in Bangalore, India. Asian Journal of Psychiatry, 30, 169-172. http://dx.doi. org/10.1016/j.ajp.2017.10.015

Ungar, M., Ghazinour, M., \& Richter, J. (2013). Annual research review: What is resilience within the social ecology of human development? Journal of Child Psychology and Psychiatry, 54, 348-366. http://dx.doi.org/10.1111/jcpp.12025

Ungar, M., Connelly, G., Liebenberg, L., \& Theron, L. (2017). How schools enhance the development of young People's resilience. Social Indicators Research, 1-13. http://dx.doi.org/10.1007/s11205-017-1728-8

Van Petegem, S., Zimmer-Gembeck, M., Soenens, B., Vansteenkiste, M., Brenning, K., Mabbe, E., \& Zimmermann, G. (2017). Does general parenting context modify adolescents' appraisals and coping with a situation of parental regulation? the case of autonomy-supportive parenting. Journal of Child and Family Studies, 26(9), 2623-2639. http://dx.doi.org/10.1007/s10826-017-0758-9

Vansteenkiste, M., Luyckx, K., \& Goossens, L. (2010). ¿Por qué los adolescentes se reúnen información o se adhieren a las normas de los padres? El examen de los motivos autónomos y controlados detrás de estilo de la identidad de los 
adolescentes. Diario de la Juventud y la Adolescencia, 39, 1343-1356. http://dx.doi. org/10.1007 / s10964-009-9469-X

Windle, G., Bennett, K., \& Noyes, J. (2011). A methodological review of resilience measurement scales. Health and Quality of Life Outcomes, 9. http://www.hqlo. com/content/ 9/1/8

Yap, M. B., Pilkington, P. D., Ryan, S. M., \& Jorm, A. F. (2014). Parental factors associated with depression and anxiety in young people: A systematic review and meta-analysis. Journal of Affective Disorders, 156, 8-23.

Recibido: 7 de noviembre de 2019

Revisado: 1 de octubre de 2020

Aceptado: 8 de diciembre de 2020 



\title{
En defensa de la realidad espiritual de la inteligencia
}

\author{
In defense of the Spiritual Dimension of Intelligence \\ Franco Fabricio Carpio Chanamé \\ Universidad Peruana Cayetano Heredia, Lima, Perú \\ (iD) https://orcid.org/oooo-0ooz-9058-4876 \\ Correspondencia: franco.carpio.c@upch.pe
}

\begin{abstract}
Resumen
El desarrollo de la neurociencia nos ha permitido comprender mejor el misterio del cerebro y la inteligencia, con sus sorprendentes hallazgos no obstante ha traído consigo el riesgo tentador de materializar de manera absoluta la realidad del ser humano. El presente artículo se presenta como una exposición apologética de la irreductibilidad de la inteligencia a la materia siguiendo el método filosófico. Esta defensa, sin embargo, no se circunscribe a la sola inmaterialidad de esta capacidad humana, sino que pretende hacer explícita la subsistencia o trascendencia de la misma a la luz de la filosofía tomista.
\end{abstract}

Palabras clave: Inteligencia, espiritualidad, alma, realismo psicológico.

\begin{abstract}
The development of neuroscience has allowed us to better understand the mystery of the brain and intelligence which has produced surprising discoveries. However, this understanding has brought with it the tempting risk of the absolute materialization of the human being. This article is presented as an apologetic exposition of the irreducibility of intelligence to matter following the philosophical method. This defense, nevertheless, is not focused only on the no-materiality of this human capacity, instead, it aims to demonstrate its transcendence or subsistence under the light of the tomist philosophy.
\end{abstract}

Key words: Intelligence, spirituality, soul, psychological realism. 


\section{Introducción}

El progreso de la ciencia moderna y su consecuente repercusión en la neurociencia sorprenden al esclarecer, en cierta medida, la complejidad de los procesos psíquico-químicos que actúan en nosotros. Sin embargo, el entusiasmo natural que producen estos hallazgos puede traer consigo el riesgo de olvidar que en el hombre existen caracteres que no se reducen a la materialidad del ser humano.

Este texto se empeña en exponer una reflexión acerca de naturaleza humanay en argumentar, como el título muestra, a favor deuna realidad trascendente en el hombre. Esta exposición, sin embargo, no promete ser exhaustiva ni agotar la explicación de la cuestión del intelecto ni la totalidad del fenómeno psíquico-químico del ser humano. El método es, pues, filosófico y se tratará el objeto de esa manera.

Antes de comenzar la exposición de estas ideas, es preciso establecer algunas nociones presupuestas. El punto de partida es una filosofía denominada realismo moderado, atribuida a Aristóteles y Tomás de Aquino por lo cual suele llamarse filosofía aristotélico-tomista. Si el término aristotélico-tomismo es correcto escapa a los motivos de este discurso, bastará con decir que, desde nuestro punto de vista, esta concepción del mundo explica con sistematicidad y lógica la realidad conocida.

\section{La composición hilemórfica}

El supuesto fundamental es que la realidad existe fuera de nuestra mente y se puede analizar según la composición hilemórfica: hyle-materia, morphé-forma, según la cual se entiende que toda realidad corpórea tiene dos principios constitutivos irreductibles, en el que uno (materia) es la posibilidad de determinación y el otro (forma) es el principio de determinación de la posibilidad real. Por ejemplo, si se considera un roble común (quercus robur), el principio que determina al roble ser roble es la forma substancial, que no se debe confundir con la mera forma geométrica, siendo evidente la variedad de disposiciones espaciales y características externas de los robles. Esta forma substancial informa o determina a la materia, a la cual se le ha llamado prima o primera, para constituir a una substancia corpórea. La materia prima es indeterminada, pura potencialidad, que es capaz de existir sucesivamente en unión con una multiplicidad indefinida de formas, cuando el árbol muere o se desintegra, la materia es informada inmediatamente por otras formas, y es la materia prima la que permite la continuidad en el cambio. Por otro lado, la materia sensible ya se encuentra en sí misma informada, por lo que se le ha llamado materia segunda (Copleston, 1960).

Si se considera a la materia en sí misma se cae en la cuenta que la pura materialidad indeterminada es inconsistente en el ser, la materia en sí misma no explica su configuración o modo de ser o determinación — como se mostrará más adelante-, lo que nos lleva a concluir que materia y forma son principios reales y necesarios de toda realidad corpórea. La relación entre esos dos principios se entiende a la luz de 
la relación de potencia y acto, que son dos modos de ser, en donde encontramos que ser en acto es un ser real cuya posibilidad de ser está de facto existiendo, mientras que la potencia es la posibilidad real de ser ese acto. Esta potencialidad no es una mera abstracción, pues si lo fuera, es decir, sin en efecto solo fuera una construcción lógica y no sustrato ontológico real, la substancia no podría realmente ser en acto; se daría un paso de la nada al ser -o lo que es lo mismo, un salto desde lo simple y llanamente lógico a lo real, error del argumento ontológico-, lo cual es imposible (Artigas, \& Sanguineti, 1993).

Se puede considerar que uno de los puntos más discutibles de ese análisis es la necesidad de acudir al principio "forma", pues la materia podría explicar en sí misma su modo de ser a través de la estructura que recibe en el espacio. Esto puede ser objetado de dos maneras: la primera parte del hecho de que los conceptos de estructura y configuración no son numéricamente idénticos, no son sinónimos reductibles el uno al otro. La estructura se entiende como disposición y orden simpliciter mientras que configuración vendría a ser la disposición de las partes que dan las propiedades a un objeto (Real Academia Española, s/f). Si se considera la mínima realidad material conocida, independientemente de su análisis físico como corpúsculo u onda, no se sigue que por estar dispuestas en un momento y lugar determinados (o distribución de probabilidad según la física cuántica), y necesariamente en virtud de su disposición, se comporten de cierta manera, la materialidad de la cosa y su orden en sí mismos no explican su dinamismo (tampoco la materialidad en sí misma explica su orden), bien podría comportarse de un modo u otro y estas posibilidades son consideradas en virtud de su contingencia. La materia no explica en sí misma este dinamismo, por lo cual es lícito pensar en la necesidad de otro principio "de configuración" que dé razón del dinamismo evidente en la realidad, al cual llamamos forma, de otra manera tendría que aceptarse una realidad estática en este plano.

Sin embargo, ni siquiera una realidad corpórea estática sería posible si negamos este principio inmaterial. Podemos llegar a una razón, ya no en orden a la "operación" o dinamismo de la materia, sino en virtud de su propio existir. Como se había mencionado anteriormente, una materia indeterminada en sí misma es inconsistente en el ser, un dinamismo sin determinación alguna no es posible. El estudio del caos está relacionado con la predictibilidad, con el conocimiento de la determinación, no con la existencia de la misma (Artigas, 2009). En el cambio algo se modifica y algo permanece, de otra forma habría que admitirse una aniquilación y creación continuas. El propio existir de la realidad corpórea (la materia y sus cualidades, energía, temperatura, etc.) exige una determinación en virtud de la que posea la capacidad de cierta operación. ¿Por qué la materia no podría ser principio de su propia determinación? La propia pregunta expone la contradicción de esa propuesta: en el orden ontológico, la causa es anterior al efecto, aunque en el temporal sean realidades instantáneas y simultáneasy/o con origen en la eternidad 
(si se aceptara, como los griegos, la eternidad del mundo), una determinación en el ente corpóreo causa de su propia determinación 1) eliminaría la realidad a determinar (en los entes corpóreos una determinación real no puede existir sin una realidad con posibilidad de ser determinada, como el agua no puede llenar $250 \mathrm{ml}$. de volumen en una taza sin que esa taza como recipiente no existiera y, aunque esa taza esté llena, la posibilidad de estar llena no desaparece aunque esté ya "satisfecha"), 2) en el mismo sentido es ilógico el aceptar que lo causado pueda ser causa de sí mismo y, por último, 3) siendo la materia principio de la potencia, la potencia solo tiene su realidad en relación al acto y nada puede ser en acto y en potencia al mismo tiempo y en el mismo sentido.

Como consecuencia, si pensamos en una realidad material sin un principio de naturaleza (principio estructural y organizativo), que es la forma, nos vemos obligados a negar la pluralidad de los entes. Puesto que una cosa difiere de otra solamente en virtud de lo que tiene de diferentes (valga la redundancia), distinguimos dos entes pertenecientes al mismo género por su diferencia específica (v. gr. la razón en el hombre), cuya expresión se nota en nuestro lenguaje: había notado ya Aristóteles (1994) que definir también es explicar las cosas por las diferencias. Si soloy llanamente existe la materia, sin ningún otro principio que dé razón de ella, no habría distinción real alguna; ya que, aunque, como notaron los escolásticos, el principio de individuación es la materia quantitate signata, la forma al organizarla en una naturaleza cuantificada, dándole una identidad numéricamente distinta, es, en este sentido, principio de individuación sin el cual no existiría multitud de entes (Chevalier, 1968).

\section{La realidad espiritual del alma}

Consideremos ahora al ser humano compuesto de materia y forma. A su forma substancial (que conforma la substancia "hombre") la llamaremos alma. Tomando en cuenta las operaciones más propias del hombre, encontramos las acciones libres (entiéndase no una libertad absolutamente indeterminada, sino la capacidad de autodeterminarse en virtud de un fin y a esa capacidad llamamos libertad), dentro de las cuales podemos enumerar el entender, razonar, elaborar juicios, etc. A este conjunto de acciones se le ha atribuido tradicionalmente como principio inmediato la inteligencia, como potencia operativa del alma (García, 2011).

Esta relación tradicional entre el entender, razonar, etc. y la inteligencia se ha visto desafiada por el gran avance positivo en las neuroimágenes funcionales, que permiten identificar las zonas del cerebro que se activan al emprender estas actividades, por lo cual se ha pretendido reducir la inteligencia a la materia (sistema nervioso).

Lo primero que podemos decir ante este hecho, es que la actividad y el mismo ser de la materia no dan razón de sí fundándose en la propia materialidad exclusivamente, como ya se ha expuesto. Segundo, considerar a las acciones del intelecto como mera representación fenoménica de los 
movimientos de la materia trae consigo dos obstáculos: 1) resolver cómo es que de lo material fluye lo inmaterial y 2) sigue sin explicar el principio de dinamismo de la materia, por lo que no satisface la cuestión. Es pues, razonable, pensar que, a partir del principio inmediato formal, que es la inteligencia, se siguen movimientos materiales, lo cual se encuentra en perfecta armonía con la unión substancial de materia y forma.

Sin embargo, el considerar que las acciones intelectivas se explican por un aliquid —un "algo" - que llamamos inteligencia, en la forma del hombre, a la cual llamamos alma, es decir, en la propia formalidad de la substancia ser humano, no exige en primera instancia su espiritualidad, ya que todo ser corpóreo estaría compuesto de materia y de forma.

\section{Hecho, realidad, verdad}

Pártase de la definición de espiritual, como aquella realidad inmaterial que trasciende al supuesto en el que es o, dicho de otra forma, aquella realidad inmaterial que subsiste (Verneaux, 1970). Para averiguar si la inteligencia es de carácter espiritual, consideremos el objeto de su operación, que es conocer. Para esto debemos, de cierta manera, distinguir entre tres términos a fin de identificar el objeto propio del intelecto: el hecho, la realidad y la verdad.

Definamos un hecho como el evento dado junto y en relación al objeto; es un hecho que, por ejemplo, el lector de este artículo es una persona, que está leyendo este texto y que advierte que conoce esto a través de su entendimiento. Sin embargo, el hecho está determinado en el aquí y ahora, este instante ínfimo que ha transcurrido ya al pasar la mirada por las palabras es objeto propio de los sentidos externos, que presentan esta realidad instantánea a los sentidos internos, y estos generan la percepción del hecho, la memoria, por ejemplo, permite recordar lo que se ha leído párrafos más arriba, dando cierta noción de continuidad a la multiplicidad de hechos, precisamente, continuos, así cuando los sentidos externos tienen su objeto en el aquí y ahora, los sentidos internos (v.gr. memoria) tienen cierta movilidad en el tiempo o tienen su objeto fuera de él en cuanto es irreal (el phantasma o species sensibilis que existe solo en la imaginación). Sin memoria, por ejemplo, sería imposible la noción de cambio y por lo tanto de tiempo (Verneaux, 1970).

En nuestro entendimiento se aprehende una estabilidad mayor que solo lo instantáneo, pero no se aprehende un continuo (por más que tenga estabilidad), lo que nos lleva a considerar una idea más amplia que el simple hecho, a lo cual podríamos llamar realidad, más profunda que el hecho, puesto que el hecho es en cuanto que es en la realidad. Sin embargo, el entendimiento puede aprehender conceptos que no son en sí mismos reales, lo que se evidencia en las ciencias físico-matemáticas: la abstracción de conceptos como un polígono de infinitos lados, la sucesión infinita de números irracionales o de sucesiones continuas, etc., pero ha de tenerse en cuenta que 1) estos objetos son del entendimientoy no de la imaginación, cuyo objeto es la imagen o fantasma de 
lo sensible, es evidente, pues, que no es posible imaginar un polígono de infinitos lados pero sí entenderlo. Además, 2) estos objetos no son tan solo una no-realidad, el valor real no es intrínseco, pero viene dado por la abstracción de - y por tanto en relación a- los hechos presentes en la realidad y a esto podemos llamar verdad. Estos conceptos físicos-matemáticos son verdaderos en cuanto son proporcionados a la realidad, por eso las teorías científicas que prueban estar más adheridas a lo que se observa se imponen ante las anteriores, que se consideran superadas, lo cual ha sido más que evidente en medicina: la verdad que se encuentra en la realidad y se descubre a partir del hecho tiene cierta independencia del momento y el espacio determinados. Que el glaucoma, por ejemplo, sea una enfermedad oftalmológica provocada por aumento de la presión intraocular es tan verdadero ahora como lo fue hace mil años a pesar de que esa verdad no sea evidente de suyo y no haya sido conocida. Que el glaucoma sea esto no depende del momento y las circunstancias en que se descubrió (de hecho, esto se comprende mejor al caer en la cuenta de que se dice des-cubrir y no generar o crear), el hecho en el que se descubrió es la expresión de la verdad y no al revés.

Lo real es necesariamente verdadero, decir que una realidad es falsa es un absurdo, lo que lo real tiene de realidad es en la medida en es que es verdad, no hay pues una existencia falsa, o un ser falso, pero sí decimos que hay un ser que es verdadero. Sin embargo, es de experiencia que la realidad es cambiante y hay cosas reales ahora que antes no eran o que no serán después, por ejemplo, el planeta Tierra no ha existido siempre.

En esto hay que distinguir el plano sensible, por un lado, y el plano metasensible, por el otro. El objeto que tengo frente a mí es ciertamente este en particular, cuando conozco algo me pregunto primero ¿qué es? La respuesta corresponde al plano metasensible de la forma, en virtud de la cual esta cosa es lo que es. Es un árbol, es madera, un hombre, una piedra. De esto hay que aclarar que las realidades sensibles necesariamente tienen materia y forma, por lo que su esencia no solo implica su formalidad, sino también su materialidad. En una segunda inflexión del conocer nos preguntamos ¿qué es esto (esta madera, etc.)? Esta es la madera de la cruz de Cristo, este hombre es Juan, mi padre, etc. Se responde añadiendo los accidentes particulares de lo sensible: por ejemplo: Juan, mi padre, nació en tal día, tal año, vivió durante tanto tiempo fue enterrado en tal lugar, son hechos comprendidos en la realidad que es mi padre.

Ahora bien, ha de notarse que comprender toda esta realidad sensible presupone comprender realidades en abstracto o, si se quiere, formales: qué es hombre, qué es tiempo, qué es un día, etc. A través del hecho de este hombre, Juan, descubro una realidad, y, digamos, una doble expresión de la verdad, en lo sensible y lo formal. Todo se aprehende en razón de algo verdadero y no en razón de algo falso, ya que saber lo falso supone lo verdadero sin lo cual no se conoce la razón de falsedad. Así, una vez que Juan muere, su existencia, 
que se ha aprehendido como verdadera, no es falseable, seguirá siendo verdadera a pesar de todos los eventos indeterminados posteriores. Hay que notar que el tiempo permite la generación de verdades, ya que, por ejemplo, un nuevo hombre es una realidad inédita (Yepes, 1997), permite su puesta en acto, pero no las elimina. Una verdad no puede volverse falsa y suponiendo que así fuera, sería ininteligible en razón de lo cual no se puede aprehender lo falso primariamente. Por eso, el cambio o el movimiento no elimina que la verdad sea, independientemente de su expresión circunstancial para nosotros, a pesar de que lo sensible cambie. Nada impide, además, que una verdad sea accesible a la inteligencia en el tiempo como efecto de una causa o como causa de un efecto.

\section{El objeto metasensible y universal de la inteligencia}

Puede decirse, entonces, que hay realidades más universales y otras más concretas. Esta universalidad se daría, según pensamos, en razón de la mayor identificación con lo verdadero, lo concreto, por su parte, en razón de la mayor identificación con el hecho (cuya verdad se descubreal discurrir por la realidad, aunque no se haga conscientemente, se acepta generalmente y se ha planteado como marco teórico que los hechos son reales). Así, este libro, este gato, esta casa son realidades que tienen en sí una verdad, aunque esa realidad sea contingente, mas esto no es una cuestión principal en el tema a tratar aquí en cuanto que se puede exponer que podemos conocerverdades universales en su independencia de un espacio-tiempo determinado.
Esto se observa al considerar la misma realidad cambiante: los seres corpóreos son contingentes. Son, pero pueden no haber sido, la realidad es que, al pensar en ellos, descubrimos la verdad de que son y la verdad de que su existencia no es necesaria en sí misma, pues vemos que el mundo constantemente cambia ya que no es de necesidad absoluta. El pensar que el mundo no fue alguna vez no hace más que confirmar esta proposición, si no fue y es ahora, entonces es contingente, pero ¿en dónde estaría la verdad del mundo antes de existir? No hay un antes si no hay tiempo. Por otro lado, se puede cuestionar esta conclusión con base en la presunción de la eternidad del mundo, sin embargo, «si todas las cosas tienen la posibilidad de no ser, esta posibilidad debería realizarse inevitablemente en el tiempo infinito» (Copleston, 196o, p. 135). Por lo que existen conclusiones que se presentan como inevitables, y de estas conclusiones la inteligencia aprehende su verdad. En el caso que a nosotros respecta, que el mundo no es subsistente por sí. De esta forma se pone en evidencia que es posible la concepción de una verdad independiente del tiempo, ya que la materia al ser principio de indeterminación no se puede alienar de la contingencia. Podemos aprehender la verdad, que no es más que la actualidad de la cosa (del acto metafísico), que en tanto que dada la actualidad infalseable esta verdad aprendida es inalienable e independiente. Cuanto más nos acercamos a las estructuras ontológicas de la realidad, esto resulta mucho más radical y evidente. Dado que el ser, y en consecuencia toda actualidad, pues no podemos ser nada si antes no somos 
(no puedo ser médico sin antes simplemente ser), nos viene dado a través de la forma (que nos "organiza"), para que la realidad sea, en cualquier sentido necesita un principio formal, necesita estar en acto. Acaso nos damos cuenta de la trascendencia del hecho expresado en la simplísima frase "algo es". Lo mismo se puede decir de los primeros principios o de que el todo es mayor que la parte. Son verdades universales. En estas verdades que gozan de independencia físico-temporal y que son objetos de la inteligencia, la inteligencia conoce lo universal. Lo cierto es que la aprehensión de la verdad sucede siempre en un plano real fuera de lo sensible, es decir de lo espacio-temporal, aunque tenga relación con ello. Esto merece una breve explicación: naturalmente el hombre conoce de manera más propia los entes sensibles, dado que la naturaleza humana es corpórea, al respecto escribiría Tomás de Aquino: «Potentia cognoscitiva proportionatur cognoscibili. Intellectus humani, qui est coniuctus corpori, propium obiectum est quidditas sive natura in materia corporalis existens et per huiusmodus naturas visibilium rerum etiam in invisibilium rerum aliqualem cognitionem ascendit» (Summa Theologiae I, 84, 7). Así pues, el objeto material del conocimiento humano es la suma de todos los objetos conocibles, de forma primaria los entes sensibles, pero todo esto no podría ser conocido si no por un principio de adecuación de la cosa y el intelecto, aquello que la hace inteligible. En instancia última, este principio es que la cosa sea, su esse, ya que nada cae bajo el entendimiento si no es sub ratione entis (Verneaux, 1970). No aprehendemos algo que no sea, algo que no tiene esse es la nada y la nada no es, pues, algo.

Ahora bien, el concepto se encuentra abstraído de caracteres individuales. Cuando conozco lo que es un hombre, no solo conozco a este hombre sino, además, el universal hombre, aplicable a todos los hombres particulares. No sería aplicable a una multiplicidad de entes si es que, en efecto, no estuviera abstraído de los caracteres sensibles. Este hombre que conozco es real y el concepto "hombre" que he aprehendido también lo es, pues es algo del hombre lo que conozco. Si dijera que el concepto es de la imaginación y por tanto algo no real, aceptaría la imposibilidad de conocer las cosas, sino tan solo la idea que tengo de ellas, una idea de algo que no sé qué es y de lo cual no podría saber tampoco que es. En fin, el conocimiento sería imposible.

Que el objeto de la inteligencia sea universal no significa, sin embargo, que el hombre tenga un conocimiento universal (es decir de todo lo que es posible conocer) ni que tenga un conocimiento absoluto de las realidades, el conocimiento del objeto no implica la posesión intelectual total del mismo, por ejemplo, sé qué es el mar, pero no sé cuál es el volumen de agua que contiene, cuál es la proporción de sus minerales, etc. El hombre siempre puede conocer más y mejor. Esto tampoco implica que el hombre no tenga conocimiento de las realidades individuales, pues lo cognoscible es su objeto y lo particular es ciertamente cognoscible: conozco este libro, esta casa, etc. Lo que lo hace posible es que quien conoce es el ser humano y 
este tiene sentidos, que tienen por objeto lo concreto, además de alguna forma la inteligencia también puede conocer lo particular, cosa que no será tratada aquí. Baste citar una frase que expresa lo dicho: species non est id quod cognoscitur sed id quo obiectum cognoscitur.

\section{La subsistencia de la inteligencia}

Después de considerar el objeto de la inteligencia se puede conocer, por lo menos, algo de su naturaleza. Proseguimos en consonancia con la sentencia escolástica operatio sequitur esse: la operación (efecto) debe ser proporcional al principio operativo (causa). Dado que el objeto y la operación (la inteligencia como potencia del alma es inmaterial, por tanto, su movimiento, el inteligir o conocer, también lo es) son en sí mismos inmateriales, con toda abstracción de lo sensible, en última instancia, sin materia y sin quando, se sigue que la inteligencia no dependa en sí misma del cuerpo. La dificultad en dar un rápido asentimiento a esta conclusión radica en el hecho evidente de que cuando existe afectación del cuerpo, propiamente del sistema nervioso central, existe también defecto o imposibilidad de raciocinio. Debe haber pues un tipo de relación entre el entendimiento y la materia, pero esa relación no podría ser de dependencia intrínseca, según lo que se ha expuesto, entonces esta dependencia tendría que ser extrínseca. La respuesta de Tomás de Aquino es resolver esta cuestión en la imaginación: «Es esencial a la naturaleza visible el existir en un individuo que no es tal sin materia corpórea (...). Por lo tanto, no se puede conocer verdadera y completamente la naturaleza de cualquier objeto material si no se la conoce como existente en concreto. Pero lo particular lo percibimos por los sentidos y la imaginación. Para que el entendimiento entienda en acto su objeto es necesario que recurra a las imágenes de la fantasía a fin de descubrir la naturaleza universal existiendo en un objeto singular» (S. Th. I, 84, 7). Lo que es consecuencia de que nihil est in intellectu quod non prius fuerit in sensu. Conocemos pues, lo universal desde lo particular, lo cual es proporcional a nuestra naturaleza humana, y por tanto corpórea, según se ha dicho.

Otro hecho interesante se encuentra en la capacidad reflexiva de la inteligencia. En efecto la inteligencia conoce que conoce, cosa que no sucede con las facultades sensibles, ni si quiera con la imaginación pues ella no puede imaginar su imaginar, a pesar de desarrollar la más alta abstracción posible en el hombre en el plano sensible. Imaginar es recrear una imagen de un fenómeno sensible (de ahí que no se puedan imaginar conceptos únicamente inteligibles como la forma, la esencia, Dios, etc.), el imaginar no es sensible, por lo tanto, no se puede imaginar el propio imaginar. Esto es característico de este tipo de facultades, sensibles, las cuales dependen intrínsecamente de la materia, puesto que la operación sigue al ser, si la forma de ser es material, la operación intrínsecamente será dependiente de la materia, pero la materia no es reflexiva, no puede volverse sobre sí misma, de la forma en que los ojos no ven que ven, la mano no siente su tacto, etc. Por lo tanto, si la inteligencia es reflexiva, no depende intrínsecamente de la materia. 


\section{Conclusiones}

Lo expuesto no es más que consecuencia de que todo conocimiento y noción de realidad se resuelve en el ente (Alvira et al., 1989). La noción más primaria de la realidad es ser, y si se considera el ser en sí mismo no es, en efecto, determinado por una realidad espacio temporal, el ser simpliciter, a diferencia de las creaturas quienes somos composición de sery esencia. Gracias a esta noción analógica del ente podemos conocer todo lo que es, ya que ens et verum convertuntur (Alvira et al., 1989), siendo que lo que es, es en tanto es verdadero, no es de extrañarse que, ya que es el objeto de la inteligencia, esta verdad sea universal.

Una cuestión que suscita este análisis es, sin duda, la inmortalidad. Podríamos decir que, si es que la inteligencia subsiste sin la materia, nada obliga a que esta desaparezca luego de que perezca el cuerpo, y dado que la facultad es del alma, el alma no tiene por qué perecer. Sin embargo, la inmortalidad en sí misma es un problema también. Ser y no morir, ¿para qué?

Mas la consecuencia inevitable de esta breve reflexión es preguntarse qué hay de ese ser simpliciter, si la inteligencia tiendea loverdadero, inexorablemente tiendeal ser sin más, en tanto tiende la facultad, tiende también el supuesto. El hombre tiende a una plenitud deverdad, llámese si se quiere, de felicidad, teniendo en cuenta lo dicho por Marías (1980) citando al Estaragita: «Aunque se es hombrey mortal, no hay que tener - dice Aristóteles - sentimientos humanos y mortales, sino que es menester inmortalizarse en lo posible y vivir de acuerdo con lo más excelente que hay en nosotros, aunque sea una exigua porción de nuestra realidad. Lo más excelente es lo más propio de cada cosa, y sería absurdo no escoger la propia vida si no la de algún otro» (Aristóteles, 1985, p. 78).

Así pues, esta tendencia a la felicidad, lejos de ser — como quizás diría Sartre (1993) - “una pasión inútil", se descubre como todo lo contrario al saber que nuestra naturaleza se inclina hacia esa verdad fundamento de las verdades gracias a nuestra inteligencia espiritual.

\section{Financiamiento}

La realización del artículo no recibió financiamiento externo.

\section{Conflictos de interés}

El autor declara que no tiene conflictos de interés. 


\section{Referencias}

Alvira, T., Clavell, L., \& Melendo, T. (1989). Metafísica. EUNSA.

Aristóteles. (1985). Ética a Nicómaco. Gredos. (J. Pallí Bonet, Trad.)

Aristóteles. (1994). Metafísica. Gredos. (T. Calvo Martinez, Trad.)

Artigas, M. (2009). Filosofía de la ciencia. EUNSA.

Artigas, M., \& Sanguineti, J. J. (1993). Filosofía de la naturaleza. EUNSA.

Aquino, T. de (2011). Suma Teológica, Vol. III. BAC.

Chevalier, J. (1968). Historia del pensamiento, Vol. I. Aguilar.

Copleston, F. (1960). El pensamiento de Santo Tomás. Fondo de Cultura Económica.

García, J. A. (2011). Antropología filosófica. EUNSA.

Marías, J. (1980). Historia de la filosofía. Revista de Occidente.

Real Academia Española. (s.f.). Diccionario de la Lengua Española, 23ava. ed. https:// dle.rae.es

Sartre, J. (1993). El ser y la Nada. Editorial Losada.

Verneaux, R. (1970). Filosofía del hombre. Herder.

Yepes, R. (1997). La persona y su intimidad. EUNSA.

Recibido: 1 de octubre de 2020

Revisado: 11 de marzo de 2021

Aceptado: 16 de mayo de 2021 

Rev. Psicol. (Arequipa. Univ. Catól. San Pablo) / Año 2021 / Vol 11 / N 1 / pp. 41-6o ISSN 2306-0565 versión impresa / ISSN 2311-7397 versión on line

\title{
Análisis psicométrico de dos escalas de actitudes hacia la estadística
}

\author{
Psychometric Analysis of Two Scales of Attitudes Towards Statistics \\ Luis Fernando Ramos Vargas \\ Universidad Católica de Santa María, Arequipa, Perú \\ (iD https://orcid.org/oooo-0002-7167-303X \\ Correspondencia: 1ramosv@ucsm.edu.pe
}

\section{Resumen}

La estadística se ha consolidado en uno de los pilares de la ciencia y del método científico, sin embargo, es una de las asignaturas, que genera mayor rechazo en los estudiantes. Esta investigación tuvo por objetivo analizar las propiedades psicométricas de dos escalas de actitudes hacia la estadística en estudiantes de psicología de una universidad particular de Tacna. Se trata de una investigación instrumental de dos escalas: Escala de Actitudes hacia la Estadística de Estrada [EAEE] et al. (2003) y Escala de Actitudes hacia la Estadística de Cazorla [EAC] et al. (1999). Participaron 243 estudiantes ( $M=20.34$ años; $D E=3.38$ años) de la carrera de psicología de una Universidad Particular de Tacna, de los cuales 71.13\% fueron de sexo femenino. Se empleó el Análisis de Componentes Principales con rotación varimax hallando 4 componentes para EAEE : Valoración positiva, Valoración negativa, Dificultad y Evitación y Utilidad de la Estadística y 2 componentes para EAC: Actitudes positivas y Actitudes negativas; se obtuvieron valores de Alfa de Cronbach adecuados. Se encontró evidencia de validez mediante la relación entre componentes. No hubo diferencias estadísticamente significativas por sexo y por año de estudios. Se analiza teóricamente la estructura obtenida para ambas escalas y se comparan con la estructura hallada en los antecedentes.

Palabras clave: Actitudes, estadística, análisis psicométrico, estudio instrumental.

\section{Abstract}

Statistics has become one of the pillars of science and the scientific method, however, it is one of the subjects that generates the greatest rejection by students. This research aimed to analyze the psychometric properties of two scales of attitudes towards statistics in psychology students from a private university of Tacna. It is an instrumental investigation of two scales: Estrada's Scale of Attitudes Towards Statistics [EAEE] et al. (2003) and Scale of Attitudes towards Statistics of Cazorla 
[EAC] et al. (1999). The sample was comprised of 243 students $(M=20.34$ years; $S D=3.38$ years, $71.13 \%$ were female) from the Psychology career at the private university of Tacna. The Principal Component Analysis with varimax rotation was used, finding 4 components for EAEE: Positive assessment, Negative assessment, Difficulty and Avoidance and Utility of the Statistics and 2 components for EAC: Positive attitudes and Negative attitudes; Adequate Cronbach's Alpha values were obtained. Evidence of validity was demonstrated through the relationship between components. There were no statistically significant differences by sex or by year of studies. The structure obtained for both scales is theoretically analyzed and compared with the structure found in the antecedents.

Keywords: Attitudes, statistics, psychometric analysis, instrumental study.

\section{Introducción}

En la actualidad, las tablas y figuras estadísticas expuestas en medios decomunicación, comolosperiódicos, las redes sociales, la televisión, etc. se han convertido en parte cotidiana en lavida de los individuos, esto debido al incremento considerable de información disponible. Este escenario caracterizado por la abundante información estadística al alcance del ciudadano, lo obliga a desarrollar la capacidad de comprender y analizar dichainformación (Estrada, 2002). El mundo contemporáneo está comprendiendo que la cultura estadística es un componente importante para los futuros ciudadanos (Aparicio \& Bazán, 2005).

Desdeel sigloXX, la estadística se ha consolidado en uno de los pilares de la ciencia y del método científico, e incluso se piensa que el siglo XXI se considerará como el siglo de la educación estadística (Batanero, 2001). Por lo que el proceso de enseñanza aprendizaje de esta asignatura, se ha vuelto en un tema recurrente de análisis, caracterizándose por la existencia de numerosas publicaciones periódicas que abordan esta problemática como el Teaching Statistics,
Journal of Statistics Education y Statistics Education Research Journal, entre otras (Molina et al., 2011). Por lo que es esperable que la asignatura deestadística estéganando espacios importantes en la currícula de gran número de carreras profesionales. La educación estadística se ha incrementado alrededor del mundo, y en todos los niveles educativos, en donde se observa su incorporación en el currículo escolar de diversos países y la masificación en la mayoría de las carreras universitarias (Raeazaona et al., 2013) lo que implica una mayor necesidad de desarrollar la cultura estadística (Behar et al., 2013).

El rápido crecimiento de estudios sobre la formación en métodos estadísticos en escolares y estudiantes universitarios, ha sido producto de diversos factores, pero quizás el más importante radica en que la estadística posee un importanterol en la formación científica y técnica de profesionales en diversas áreas del conocimiento (Comas etal., 2017). Un estudiante universitario que sepa desarrollar análisis estadísticos, será un futuro profesional que tomará decisiones en base a la evidencia, mejorando de forma notoria su práctica profesional, y solucionando 
problemas de su contexto mediante la aplicación del método científico.

Es conocido que un gran número de estudiantes de psicología, y de ciencias sociales en general, optan por estas carreras, debido a la creencia incorrecta de asumir que en su formación ya no estudiarán temas relacionados con números, por lo que al cursar asignaturas como Estadística descriptiva, Inferencial oAplicada, desarrollan un rechazo inmediato hacia ellas. Ninay Martínez (2018) encontraron que más de la mitad (53\%) de susparticipantes presentaronactitudesnegativas hacia la estadística. Rodríguez (2011) explica que para los profesores de carreras como Psicología, Sociología, Ciencias de la Comunicación, es una experiencia casi universal encontrarse con un número importantedealumnosquepresentan una actitud desfavorable hacia la estadística.

Pérez et al. (2015) señalan que las investigaciones de las actitudes hacia la estadística en población universitaria han ganado fuerza en los últimos años. Blanco (2008) explica que las actitudes hacia la estadística tienen una importante influencia sobre los procesos de enseñanza-aprendizaje y sobre el rendimiento académico inmediato. GarcíaMartínez etal. (2015) indican que las actitudes hacia la estadística tienen un importante valor, ya queestas pueden convertirseen una gran barrera para su aprendizaje, incluso Pérez et al. (2015) afirman que las actitudes hacia la estadística pueden ser importantes para explicarel mal desempeñoen la materia. Comasetal. (2017) explican que "lasactitudes son parte integrantede todas las materias de aprendizaje y ocupan un lugar central en el actoeducativo, guiando el proceso perceptivo y cognitivo que comparta el aprendizaje de cualquier contenido educativo" (p. 480).

Ramos (2019) explica que es importante evaluar lasactitudes de los estudiantes sobre esta asignatura, para lo cual se requiere realizar estudios psicométricosal respecto, obteniendo medidas más precisas sobre cómo las acciones de los docentes, logran modificar las actitudes registradas al inicio, con la contrastación al final de la asignatura. En la revisión deantecedentes, se encontró que la mayoría deestudios seaplicóa estudiantes de carreras de Ciencias de la Salud, aunque en los últimos años, se ha incrementado la producción deinvestigación con estudiantes de otras áreas del conocimiento.

Los instrumentos de medición sobre las actitudes hacia la Estadística cuentan con características y una estructura interna diversa. Uno de los instrumentos más utilizados es el cuestionario SATS-28 que evalúa las actitudes hacia la Estadística en 4 dimensiones: afecto (actitudes positivas y negativas), competencia cognitiva, valor y dificultad (García et al., 2015; Peña et al., 2015; Santabárbara et al., 2019; Santabárbara et al., 2019; Santabárbara \& López-Antón, 2020). Otro instrumento conocido es la Escala de Actitudes hacia la Estadística de Auzmendi, que tiene 5 factores: Utilidad, Ansiedad, Confianza, Agrado y la Motivación (Nina \& Martínez, 2018; Valencia, 2017). La Escala de Actitudes hacia la Estadística de Estrada, reporta una estructura de 5 dimensiones: Valoración positiva, Valoración negativa, Habilidad hacia la estadística, Afectividad hacia la 
estadística y Utilidad de la estadística (Torres et al., 2015). También se encontró que en un estudio con profesores, la Escala de Estrada presentó multidimensionalidad, con 4 factores: el primero denominado Competencia y valoración académica de la estadística, el segundo se denominó Valoración del rol de la estadística, el tercero se llamó Utilidad y gusto personal por la estadística y el cuarto se denominó Disposición y comprensión de la estadística (Estrada et al., 2013). Otro instrumento sería la Escala de actitudes hacia la estadística de Cazorla, sobre la cual, Torres et al. (2015) reportan una estructura de 2 factores: Valoración positiva y valoración negativa.

El presente estudio tiene por objetivo analizar las propiedades psicométricas de dos escalas de actitudes hacia la estadística en estudiantes de psicología de una universidad particular de Tacna.

\section{Método}

\section{Diseño de la investigación}

Esunestudiodetipoinstrumental (Montero\& León, 2002) porque la investigación tienepor objetivo el estudio de las propiedades psicométricas de dos Escalas hacia la Estadística: Escala de Actitudes hacia la Estadística de Estrada, Bataneroy Fortuny (2003) y la Escala de Actitudes hacia la Estadística de Cazorla, Silva y Vendramini (1999).

\section{Participantes}

Participaron 243 estudiantes de la Carrera Profesional de Psicología de una universidad particular de Tacna. De los cuales 71.13\% fueron de sexo femenino y el $28.87 \%$ fueron desexo masculino (hubo cuatro datos perdidos). La edad tuvo un rango de 30 años (16 a 46 años), con una media de 20.34 años y una $\mathrm{DE}$ igual a 3.38 años. Los participantes cursaban entre el 1ero al 1omo ciclo, distribuyéndose de la siguiente forma: $11.52 \%$ en el primero, $24.69 \%$ en el segundo, $3.70 \%$ en el tercero, $16.87 \%$ en el cuarto, $16.87 \%$ en el quinto, $6.58 \%$ en el sexto, $7.41 \%$ en el sétimo, $4.53 \%$ en el octavo, $4.53 \%$ en el noveno y $3.29 \%$ en el décimo. Se evaluaron al total de estudiantes matriculados en el ciclo 2016-II.

\section{Instrumentos}

Seutilizaron de manera conjunta dos escalas tipo Likert, aplicados de manera colectiva. La aplicación conjunta deambos instrumentos se ha reportado previamente en estudios instrumentales en Colombia, Chileyen Perú (Pérezetal., 2015; Tarazona etal., 2013; Torres et al., 2015). Las escalas fueron:

Escala de Actitudes hacia la Estadística de Estrada et al. (2003). La escala se construyó combinando tres escalas: Statistics Attitudes Survey (SAS), la escala Attitudes Towards Statistics (ATS) y la Escala de Actitudes hacia la Estadística (EAEA). Es una escala de 25 ítems que tiene 5 opciones de respuesta, donde se le otorga un punto a la respuesta de Muy en desacuerdo y 5 puntos a la respuesta Muy de acuerdo (Tarazona, Bazán \& Aparicio, 2013). De los 25 ítems, 14 ítems poseen una dirección 
positiva (preguntas $2,4,5,7,8,10,12,13,16$, $17,18,20,22,24)$ y 11 poseen una dirección negativa (preguntas 1, 3, 6, 9, 11, 14, 15, 19, 21, 23, 25). Para la calificación, las preguntas negativas se han revertido. Los puntajes altos reflejan una actitud positiva hacia la estadística (Pérez et al., 2015).

Escala de Actitudes hacia la Estadística de Cazorla et al. (1999). La escala se construyó a partir de una adaptación de la escala de actitudes en relación a las matemáticas creada por Aiken (1974) y adaptada por Brito (1998) al portugués. Se trata de una escala unidimensional tipo Likert, con 20 ítems, 10 afirmativos (preguntas 3, 4, $5,9,11,14,15,18,19,20)$ y 10 negativos $(1$, 2, 6, 7, 8, 10, 12, 13, 16, 17) (Pérez et al., 2015; Torres et al., 2015). En su versión original, esta escala tiene puntuación que va desde el 1 (Totalmente en desacuerdo) hasta el 4 (Totalmente de acuerdo). Para el presente estudio, se utiliza una versión con 5 opciones de respuesta que incluye una alternativa neutral, además se modifica las alternativas de respuesta desde Muy en desacuerdo y Muy de acuerdo. Dicha estrategia se ha utilizado en estudios previos (Pérez et al., 2015; Tarazona et al., 2013; Torres et al., 2015).

\section{Procedimiento}

Inicialmente se coordinó con la Dirección de la Carrera Profesional de Psicología, yunavez obtenidos los permisos, se coordinó con los docentes para laaplicación de los instrumentos. En segundo lugar, las escalas resueltas se digitalizaron al software Microsoft Excel y posteriormente se utilizó el software estadístico R (versión 3.5.2) con su plataforma $\mathrm{R}$
Studiopara losanálisisestadísticos. Seempleó el Análisis de Componentes Principales con rotación varimax, siguiendo las indicaciones de Field, Milles y Field (2012), y para hallar la confiabilidad se utilizó la prueba Alfa de Cronbach. Además, se estudia la evidencia basada en la relación entre las variables mediante las correlaciones entre los componentes obtenidos del ACP. Finalmente, se aplicaron pruebas de comparación según el sexoy el año de estudios de los participantes. Cabe señalar que el presente estudio es la continuación del trabajo presentado en el número anterior (Ramos, 2019).

\section{Resultados}

Los resultados se presentan en el siguiente orden: primero se presentan los análisis descriptivos por escala, luego se presentan los análisis de componentes principales efectuados, posteriormente los análisis de consistencia interna, las correlaciones entre los componentes (evidencia basada en las relaciones con otras variables) y al final se presentan los resultados de las pruebas de comparación entreel sexoyelañodeestudios.

\section{Escala de Actitudes hacia la Estadística de Estrada}

Se presentan los estadísticos descriptivos: media, desviación estándar, curtosis y asimetría, para cada ítem de la escala original. En la Tabla 1 se pueden ver los estadísticos mencionados. Cabe señalar que se han invertido los ítems inversos acorde la indicación de los autores de la escala. La columna NA muestra los datos perdidos. 
Tabla 1. Estadísticos descriptivos de la Escala de Actitudes de Estrada

\begin{tabular}{|c|c|c|c|c|c|}
\hline Ítem & Media & DE & Asimetría & Curtosis & NA \\
\hline $\begin{array}{l}\text { 1. Me molesta la información estadística que aparece en algunos } \\
\text { programas de TV. }\end{array}$ & 3.63 & 1.02 & -0.73 & -0.33 & 4 \\
\hline 2. La Estadística ayuda a entender el mundo de hoy. & 4.17 & 0.85 & -1.52 & 3.12 & 1 \\
\hline 3. A través de la Estadística se puede manipular la realidad. & 2.39 & 1.08 & 0.64 & -0.46 & 1 \\
\hline $\begin{array}{l}\text { 4. La estadística es fundamental en la formación básica del } \\
\text { ciudadano. }\end{array}$ & 3.62 & 0.92 & -0.8 & 0.2 & 2 \\
\hline $\begin{array}{l}\text { 5. Uso la Estadística para resolver problemas de la vida } \\
\text { cotidiana. }\end{array}$ & 3.06 & 1.15 & -0.1 & -1.2 & 1 \\
\hline 6. En la escuela no se debería de enseñar Estadística. & 4.29 & 0.87 & -1.67 & 3.32 & 1 \\
\hline 7. Me divierto en las clases que se explica Estadística. & 3.2 & 1.06 & -0.14 & -0.92 & o \\
\hline 8. Los problemas de la Estadística me resultan fáciles. & 3.1 & 1.06 & -0.29 & -1.01 & 1 \\
\hline $\begin{array}{l}\text { 9. No entiendo las informaciones Estadísticas que aparecen en } \\
\text { los periódicos. }\end{array}$ & 3.51 & 1.02 & -0.64 & -0.46 & o \\
\hline $\begin{array}{l}\text { 10. Me gusta la Estadística porque me ayuda a comprender más } \\
\text { profundamente la complejidad de ciertos temas. }\end{array}$ & 3.44 & 1.05 & -0.61 & -0.53 & 2 \\
\hline 11. Me siento intimidado frente a los datos estadísticos. & 3.44 & 1.05 & -0.63 & -0.48 & o \\
\hline 12. Encuentro interesante el mundo de la Estadística. & 3.43 & 1.1 & -0.51 & -0.74 & o \\
\hline $\begin{array}{l}\text { 13. Me gustan los trabajos serios donde aparecen estudios } \\
\text { estadísticos. }\end{array}$ & 3.35 & 1.16 & -0.34 & -0.94 & o \\
\hline 14. Utilizo poco la Estadística fuera de mi Centro de Estudio. & 2.49 & 1.15 & 0.46 & -0.95 & 2 \\
\hline $\begin{array}{l}\text { 15. En la clase de Estadística nunca entiendo de qué están } \\
\text { hablando. }\end{array}$ & 3.92 & 0.86 & -0.87 & 0.76 & 1 \\
\hline $\begin{array}{l}\text { 16. Me apasiona la estadística porque ayuda a ver los problemas } \\
\text { objetivamente. }\end{array}$ & 3.02 & 1.09 & -0.1 & -0.99 & 2 \\
\hline 17. La Estadística es fácil. & 3.02 & 1.03 & -0.07 & -0.97 & o \\
\hline $\begin{array}{l}\text { 18. Me entero más del resultado de las elecciones cuando } \\
\text { aparecen representaciones gráficas. }\end{array}$ & 4.03 & 0.95 & -1.35 & 1.79 & 1 \\
\hline 19. La estadística solo sirve para la gente del área de ciencias. & 4.11 & 0.89 & -1.21 & 1.37 & o \\
\hline 2o. Me gusta hacer problemas cuando uso la Estadística. & 2.71 & 0.98 & 0.23 & -0.96 & o \\
\hline 21. La Estadística no sirve para nada. & 4.52 & 0.61 & -1.11 & 1.21 & 3 \\
\hline $\begin{array}{l}\text { 22. A menudo explico a mis compañeros problemas de } \\
\text { Estadística que no han entendido. }\end{array}$ & 2.77 & 1.07 & 0.06 & -1.27 & 1 \\
\hline $\begin{array}{l}\text { 23. Si pudiera eliminar alguna materia o curso sería la } \\
\text { Estadística. }\end{array}$ & 4.04 & 0.93 & -0.99 & 0.77 & o \\
\hline 24. La estadística ayuda a tomar decisiones más documentadas. & 3.97 & 0.83 & -1.29 & 2.32 & 1 \\
\hline 25. Evito las informaciones estadísticas cuando las leo. & 3.65 & 0.99 & -0.81 & -0.02 & 2 \\
\hline
\end{tabular}

En el análisis descriptivo se observa que los ítems 21, 6, 2, 19, 23 y 18 presentan las medias más altas (mayores a 4, considerando queel puntaje máximo es de 5 puntos). Los ítems 21 (La estadística no sirve para nada), 6 (En la escuela no debería enseñarse estadística), 
19 (La estadística solo sirve para la gente del área de ciencias) y 23 (Si pudiera eliminar alguna materia o curso sería la Estadística) son ítems inversos, lo que significa que los evaluados han respondido de forma positiva hacia la estadística.

Los ítems 3 (A través de la Estadística se puede manipular la realidad.), 14 (Utilizo poco la Estadística fuera de mi Centro de Estudio), 20 (Me gusta hacer problemas cuando uso la estadística) y 22 (A menudo explico a mis compañeros problemas de Estadística que no han entendido). Los ítems 3 y 14 son inversos, y los ítems 20 y 22 comprenden acciones específicas a la utilización deestadística, que podría tratarse que muestran una actitud negativa hacia su aplicación.

Análisis de componentes principales de la EAEE

Se elaboró una matriz de correlaciones con los ítems de la escala, donde se encontraron 5 correlaciones que están por encima de .80, lo quepodría significarque no existe la multicolineadad entrelosítems. También seencontró que el ítem 3 y 14 presentaba correlaciones menoresa.20, siendoel ítem 3 con las correlaciones más bajas. Al analizar losvalores KMO por variable, se obtuvieron valores entre .50 y .92. Comoel ítem 3 obtuvounvalor KMOde.5 y correlaciones bajas con el resto de los ítems, se decidió retirarlo del análisis.

Se aplicó un análisis de componentes principales (ACP) a los 24 ítems con rotación ortogonal (varimax). La prueba deesfericidad de Bartlettfuesignificativa $\left(\chi_{2}(276)=1780.19\right.$, $\mathrm{p}<.01$ ), y el índice de adecuación muestral
Kaiser-Meyer-Olkin (KMO) presentó un valor de .86, y todos los valores individuales fueron mayores a .7, con excepción del ítem 14 (.61), lo cual supera los valores aceptables de.5. Estos resultados indican una adecuada intercorrelación entre los datos y la factibilidad de aplicar el ACP. Además, se calculó la determinante de la matriz de correlación hallando un valor de 0.0004 , lo que supera el valor mínimo 0.00001 , esto quiere decir que no se han detectado problemas de multicolinealidad.

Se aplicó un análisis inicial para obtener los eigenvalues para cada componente de los datos y se encontraron 6 componentes que superaban el criterio de Kaiser (>1), pero en el gráfico de sedimentación se observaron 4 componentes hasta el punto de inflexión. Por tanto se decidió trabajar con el modelo de 4 componentes para mayor parsimonia.

El análisis de componentes principales de 4 factores logra explicar el $48 \%$ de la varianza. Se consideró como criterio de inclusión a aquellos ítems que cumplieron dos requisitos: el primero, tuvieron un peso factorial mayor a .40 y el segundo, que no presentaran un peso similar o superior en otro componente. En la Tabla 2 se presentan los resultados del ACP. Al primer componente se le ha denominado "Valoración positiva", compuesto por losítems 7, 8, 22, 12, 20, 17, 16, 13y10; el segundo componentesedenomina "Valoración negativa", compuesto por los ítems 19, 21, 23, 24, 18, 15y 6; el tercer componente se denomina "Dificultad y evitación", compuesto por los ítems 9, 11, 25 y 1; y el cuarto componente se denomina "Utilidad de la estadística", compuesto por los ítems: $2,14,4$ Y 5 . 
Tabla 2. Cargas factoriales del ACP con rotación varimax

\begin{tabular}{|c|c|c|c|c|}
\hline & $\begin{array}{c}\text { Valoración } \\
\text { positiva }\end{array}$ & $\begin{array}{c}\text { Valoración } \\
\text { negativa }\end{array}$ & $\begin{array}{c}\text { Dificultad y } \\
\text { evitación }\end{array}$ & $\begin{array}{l}\text { Utilidad de la } \\
\text { estadística }\end{array}$ \\
\hline Est7 & .75 & & & \\
\hline Est8 & .72 & & & \\
\hline Est22 & .69 & & & \\
\hline Est12 & .67 & & & \\
\hline Est2o & .65 & & & \\
\hline Est17 & .65 & & & \\
\hline Est16 & .61 & & & .45 \\
\hline Est13 & .6 & & & \\
\hline Estıo & .53 & & & .4 \\
\hline Est19 & & .72 & & \\
\hline Est21 & & .72 & & \\
\hline Est23 & & .66 & & \\
\hline Est24 & & .55 & & \\
\hline Est18 & & .48 & & \\
\hline Est15 & & .46 & & \\
\hline Est6 & & .46 & & \\
\hline Est9 & & & .73 & \\
\hline Est11 & & & .61 & \\
\hline Est25 & & & .6 & \\
\hline Estı & & & .43 & \\
\hline Est2 & & & & .61 \\
\hline Est14 & & & & .51 \\
\hline Est4 & & & & .5 \\
\hline Est5 & & & & .43 \\
\hline
\end{tabular}

Análisis de confiabilidad

Se analiza la confiabilidad según el método de consistencia interna con la prueba Alfa de Cronbach. Se procesó la información según los cuatro componentes hallados en el ACP presentado. La Tabla 3 muestra los valores del Alfa de Cronbach. 
Tabla 3. Consistencia interna por componentes de la EAEE

\begin{tabular}{|lccc|}
\hline \multicolumn{1}{|c}{ Componente } & Nro. ítems & Alfa de Cronbach & IC 95\% \\
\hline Valoración positiva & 9 & .87 & $.84^{-} .89$ \\
Valoración negativa & 7 & .73 & $.68-.78$ \\
Dificultad y evitación & 4 & .60 & $.51^{-} .68$ \\
Utilidad de la estadística & 4 & .43 & $.32-.55$ \\
\hline
\end{tabular}

En la Tabla 3, se observa que los primeros componentes presentan un Alfa de Cronbach (>.6o), esto significa que estos componentes presentan buena consistencia interna. Sin embargo, el componente "Utilidad de la estadística" obtuvo un valor relativamente bajo, aunque al observar su IC, se aprecia que su valor está próximo a .6o.

\section{Escala de Actitudes hacia la Estadística} de Cazorla

Se presentan los estadísticos descriptivos: media, desviación estándar, curtosis y asimetría para cada ítem. En la Tabla 4 se pueden ver los estadísticos mencionados. Cabe señalar que se han invertido los ítems inversos acorde la indicación de los autores de la escala. La columna NA muestra los datos perdidos. 
Tabla 4. Estadísticos descriptivos de la Escala de Actitudes de Cazorla

\begin{tabular}{|c|c|c|c|c|c|}
\hline Ítem & Media & DE & Asimetría & Curtosis & NA \\
\hline 1. Yo quedo terriblemente tenso (a) en la clase de estadística. & 3.84 & 0.97 & -0.94 & 0.43 & 1 \\
\hline $\begin{array}{l}\text { 2. Yo no gusto de la Estadística y me asusta tener que hacer el } \\
\text { curso de estadística. }\end{array}$ & 3.8 & 1.06 & -0.83 & -0.04 & 1 \\
\hline $\begin{array}{l}\text { 3. Yo creo que la Estadística es muy interesante y gusto de las } \\
\text { clases de Estadística. }\end{array}$ & 3.35 & 1.04 & -0.3 & -0.85 & o \\
\hline 4. La Estadística es fascinante y divertida. & 3.04 & 1.03 & -0.16 & -0.93 & o \\
\hline $\begin{array}{l}\text { 5. La Estadística me hace sentir seguro(a) y es al mismo } \\
\text { tiempo estimulante. }\end{array}$ & 3.05 & 1.04 & -0.13 & -0.99 & o \\
\hline $\begin{array}{l}\text { 6. Cuando estudio Estadística mi cabeza "queda en blanco" y } \\
\text { no consigo pensar claramente. }\end{array}$ & 3.8 & 0.93 & -0.9 & 0.63 & o \\
\hline $\begin{array}{l}\text { 7. Yo tengo una sensación de inseguridad cuando me esfuerzo } \\
\text { en Estadística. }\end{array}$ & 3.55 & 1.08 & -0.6 & -0.6 & o \\
\hline $\begin{array}{l}\text { 8. La Estadística me deja inquieto(a), descontento, } \\
\text { irritado(a), impaciente. }\end{array}$ & 3.78 & 1.04 & -0.86 & -0.03 & o \\
\hline $\begin{array}{l}\text { 9. El sentimiento que yo tengo con relación a la Estadística } \\
\text { es bueno. }\end{array}$ & 3.53 & 0.98 & -0.78 & -0.05 & 1 \\
\hline $\begin{array}{l}\text { 10. La Estadística me hace sentir como si estuviese perdido(a) } \\
\text { en una selva de números y sin encontrar la salida. }\end{array}$ & 3.77 & 1.03 & -0.85 & 0.01 & 1 \\
\hline 11. La Estadística es algo que yo aprecio grandemente. & 2.97 & 1.1 & -0.13 & -1.05 & o \\
\hline $\begin{array}{l}\text { 12. Cuando yo escucho la palabra Estadística, yo tengo un } \\
\text { sentimiento de aversión (rechazo). }\end{array}$ & 3.71 & 1.04 & -0.7 & -0.35 & 1 \\
\hline $\begin{array}{l}\text { 13. Yo encaro la Estadística con un sentimiento de indecisión, } \\
\text { que es resultado del miedo de no ser capaz en Estadística. }\end{array}$ & 3.47 & 1.1 & -0.6 & -0.69 & o \\
\hline 14. Yo gusto realmente de la Estadística. & 3.02 & 1.1 & -0.14 & -1.03 & 1 \\
\hline $\begin{array}{l}\text { 15. La Estadística es una de las materias que yo realmente } \\
\text { gusto de estudiar en la Universidad. }\end{array}$ & 2.93 & 1.1 & 0.13 & -0.96 & o \\
\hline $\begin{array}{l}\text { 16. Pensar sobre la obligación de resolver un problema de } \\
\text { Estadística me deja nervioso(a). }\end{array}$ & 3.36 & 1.09 & -0.49 & -0.81 & o \\
\hline $\begin{array}{l}\text { 17. Yo nunca guste de la Estadística y es la materia que más } \\
\text { me da miedo. }\end{array}$ & 3.72 & 1.06 & -0.8 & -0.13 & o \\
\hline 18. Yo quedo feliz en la clase de Estadística. & 3.07 & 1.03 & -0.07 & -1.04 & 2 \\
\hline $\begin{array}{l}\text { 19. Yo me siento tranquilo(a) en Estadística y gusto mucho } \\
\text { de esa materia. }\end{array}$ & 3.21 & 1.03 & -0.28 & -1.06 & o \\
\hline $\begin{array}{l}\text { 20. Yo tengo una reacción definicitamente positiva con } \\
\text { relación a la Estadística: yo gusto y aprecio esa materia. }\end{array}$ & 3.25 & 1.03 & -0.32 & -0.89 & o \\
\hline
\end{tabular}

En la Tabla 4 se observa que las medias de los 20 ítems se encuentran cercanas al puntaje medio de la escala (3). Los ítems que tuvieron valores mayores en la media fueron: ítem 1 (Yo quedo terriblemente tenso(a) en la clase de estadística), ítem 2 (Yo no gusto de la Estadística y measusta tener que hacer el curso de estadística) e ítem 6 (Cuando estudio Estadística mi cabeza "queda en blanco" y no consigo pensar claramente). En comparación con los promedios de la Tabla 1, las medias de los ítems de la Escala de Actitudes de
Cazorla presentan valores más orientados al valor medio (Indeciso).

Análisis de componentes principales de la Escala de Actitudes de Cazorla

Se elaboró una matriz de correlaciones con los ítems de la Escala donde se observó que todas las correlaciones eran mayores a .20 y menores a .8o, lo que podría significar que no existe la multicolineadad entre los ítems. Al analizar los valores KMO por variable, todos los ítems obtuvieron 
valores mayores a .90. Acorde a estos resultados, se decide incluir a la totalidad de los ítems en el análisis.

Se aplicó un análisis de componentes principales (ACP) a los 20 ítems con rotación ortogonal (varimax). La prueba de esfericidad de Bartlett fue significativa $(\chi 2(190)=3133.72, \mathrm{p}<.01)$, y el índice de adecuación muestral Kaiser-Meyer-Olkin (KMO) presentó un valor de .94, lo cual superan los valores aceptables de .5. Estos resultados indican una adecuada íntercorrelación entre los datos y la factibilidad de aplicar el ACP. Además, se calculó la determinante de la matriz de correlación hallando un valor de 0.000002 , lo que podría implicar la presencia de multicolinealidad.

Se aplicó un análisis inicial para obtener los eigenvalues para cada componente de los datos. Se decidió trabajar con 2 componentes, debido a que superaban el criterio de Kaiser (>1), y se podían detectar con claridad en el gráfico de sedimentación.

El análisis de componentes principales de 2 factores logra explicar el 6o\% de la varianza. Se consideró como criterio de inclusión a aquellos ítems que cumplieran dos requisitos: el primero, tuvieron un peso factorial mayor a .40 y el segundo, que no presentaran un peso similar o superior en otro componente. En la Tabla 5 se presentan los resultados del ACP. El primer componente se le ha denominado "Actitudes positivas", compuesto por los ítems 4, 20, 18, 14, 19, 11, 3, 15, 5 y 9 ; el segundo componente se denomina
"Actitudes negativas", compuesto por los ítems 10, 1, 6, 8, 16, 7, 17, 13, 2 y 12.

Tabla 5. Cargas factoriales del ACP con rotación varimax

\begin{tabular}{|lcc|}
\hline Caz4 & $\begin{array}{c}\text { Actitudes } \\
\text { positivas }\end{array}$ & $\begin{array}{c}\text { Actitudes } \\
\text { negativas }\end{array}$ \\
Cazzo & .81 & \\
Caz18 & .8 & \\
Caz14 & .86 & \\
Caz19 & .75 & \\
Caz11 & .75 & \\
Caz3 & .74 & \\
Caz15 & .73 & \\
Caz5 & .72 & \\
Caz9 & .54 & .48 \\
Caz10 & & .75 \\
Caz1 & & .75 \\
Caz6 & & .73 \\
Caz8 & & .72 \\
Caz16 & & .71 \\
Caz7 & & .68 \\
Caz17 & & .68 \\
Caz13 & & .67 \\
Caz2 & .41 & .67 \\
Caz12 & .45 & .53 \\
\hline
\end{tabular}

La Escala de Actitudes hacia la Estadística de Cazorla presente una estructura similar a la reportada en trabajos previos con ítems que implican actitudes negativas y positivas. Para 
facilitar la interpretación, se invierte los valores de los ítems del componente Actitud negativa y se mantienen los valores de los ítems del componente Actitud positiva. Esto quiere decir, que, a mayores puntajes en el componente de Actitudes positivas, el participante presenta una evaluación más favorable hacia la estadística, mientras que a mayores puntajes en el componente de Actitudes negativas, el participante presenta una evaluación más desfavorable hacia la estadística.

Análisis de confiabilidad

Se analiza la confiabilidad según la prueba de Alfa de Cronbach para evaluar su consistencia interna. Se procesó la información según los dos componentes hallados en el ACP presentado. La Tabla 6 muestra los valores del Alfa de Cronbach.

Tabla 6. Consistencia interna por componentes

\begin{tabular}{|cccc|}
\hline Componente & Nro ítems & Alfa de Cronbach & IC 95\% \\
\hline Actitud positiva & 10 & .93 & $.92^{-} .95$ \\
Actitud negativa & 10 & .91 & $.899^{-.92}$ \\
\hline
\end{tabular}

En la Tabla 6, se observa que los primeros componentes presentan un Alfa de Cronbach (>.90), esto significa que estos componentes presentan buena consistencia interna.

\section{Correlaciones entre los componentes de las escalas}

Se elabora una matriz decorrelaciones entre los puntajes totales de los componentes hallados de las escalas empleadas en la presente investigación. La Tabla 7 muestra dicha matriz.

Tabla 7. Matriz de correlaciones entre los componentes de las Escalas

\begin{tabular}{|lcccccc|}
\hline \multicolumn{1}{|c}{ Componentes } & $\mathbf{1}$ & $\mathbf{2}$ & $\mathbf{3}$ & $\mathbf{4}$ & $\mathbf{5}$ & $\mathbf{6}$ \\
\hline 1. Valoración positiva & -- & & & & & \\
2. Valoración negativa & $.40^{* * *}$ & -- & & & & \\
3. Dificultad y evitación & $.40^{* * *}$ & $.37^{* * *}$ & -- & & & \\
4. Utilidad de la estadística & $.39^{* * *}$ & $.22^{* * *}$ & $.31^{* * *}$ & -- & & \\
5. Actitudes positivas & $.83^{* * *}$ & $.39^{* * *}$ & $.38^{* * *}$ & $.33^{* * *}$ & -- & \\
6. Actitudes negativas & $-.56^{* * *}$ & $-.52^{* * *}$ & $-.50^{* * *}$ & $-.21^{* * *}$ & $-.64^{* * *}$ & -- \\
\hline
\end{tabular}

${ }^{* * *} p<.001$

En la Tabla 7 se aprecia que se halla- significativas) mayores a .20 y menores ron correlaciones (estadísticamente .83 . El componente Actitudes negativas de 
la Escala de Actitudes hacia la Estadística de Cazorla obtuvo correlaciones negativas y de tamaño medio con el resto de componentes. Mientras que el resto de correlaciones tienen una dirección positiva y con valores bajos a medios.

\section{Análisis comparativo}

Se realizó también un análisis descriptivo de los componentes hallados.
Posteriormente se realizaron comparaciones por sexo y luego por ciclo académico. En la Tabla 8 se muestran los resultados para toda la muestra y separados por sexo. Además, se han añadido pruebas de comparación (t de student para muestras independientes). No se encontraron diferencias estadísticamente significativas según el sexo de los evaluados.

Tabla 8. Estadísticos descriptivos para los componentes según el sexo

\begin{tabular}{|lccccccc|}
\hline \multirow{2}{*}{ Componente } & \multicolumn{2}{c}{ Total } & \multicolumn{2}{c}{ Masculino } & \multicolumn{2}{c|}{ Femenino } & Prueba de \\
& Media & DE & Media & DE & Media & DE & comparación \\
\hline Valoración positiva & 27.96 & 6.72 & 28.88 & 7.42 & 27.74 & 6.27 & $\mathrm{t}(109.46)=1.13$ \\
\hline Valoración negativa & 28.75 & 3.85 & 28.81 & 3.99 & 28.82 & 3.72 & $\mathrm{t}(118.6)=-0.02$ \\
\hline Dificultad y evitación & 14.14 & 2.81 & 14.44 & 3.05 & 14.12 & 2.74 & $\mathrm{t}(114.8)=0.05$ \\
\hline Utilidad & 13.25 & 2.61 & 13.49 & 2.48 & 13.19 & 2.63 & $\mathrm{t}(133.03)=0.82$ \\
\hline Actitudes positivas & 31.36 & 8.28 & 31.12 & 9.25 & 31.66 & 7.68 & $\mathrm{t}(108.01)=-0.43$ \\
\hline Actitudes negativas & 23.16 & 7.68 & 23.07 & 8.21 & 22.98 & 7.3 & $\mathrm{t}(113.94)=0.08$ \\
\hline
\end{tabular}

Se compararon los resultados por componentes con el ciclo académico, sin embargo, comolos tamaños delosgrupos porcicloson pequeñossedecideagruparlosporaño(seles agrupa en 5 grupos, desde el rero hasta 5 to año). En la Tabla 9semuestran los resultados para toda la muestray separados por año de estudios. Para las comparaciones degrupos seutilizan la prueba no paramétrica Kruskal Wallisdebidoaquelostamañosdelosgrupos son pequeños (<30 personas) yel no cumplimiento de la homocedasticidad.

Tabla 9. Estadísticos descriptivos para los componentes según el año de estudios

\begin{tabular}{|lccc|}
\hline \multicolumn{1}{|c}{ Componente } & H & gl & P \\
\hline Valoración positiva & 13.46 & 4 & $<.01$ \\
Valoración negativa & 7.65 & 4 & .11 \\
Dificultad y evitación & 4.42 & 4 & .35 \\
Utilidad & 5.02 & 4 & .29 \\
Actitudes positivas & 12.81 & 4 & $<.05$ \\
Actitudes negativas & 8.37 & 4 & .08 \\
\hline
\end{tabular}

Se encontraron diferencias significa- positiva de la Escala de Actitudes hacia la tivas en el componente de Valoración Estadística de Estraday en el componente 
Actitudes positivas. Se aplicaron pruebas post hoc de Nemenyi utilizando el método Chi-cuadrado para determinar cuáles son los grupos que se diferencian. Sin embargo, no se detectaron diferencias entre los grupos.

\section{Discusión}

La presente investigación tuvo por objetivo analizar las propiedades psicométricas de dos escalas de actitudes hacia la estadística en estudiantes de Psicología de una universidad particular. Como principales resultados se puede reportar que la Escala de Actitudes hacia la Estadística elaborada por Estrada et al. (2006) presenta una estructura conformada por 4 componentes: Valoración positiva, Valoración negativa, Dificultad y evitación, y Utilidad de la estadística; además presentó una adecuada consistencia interna, con excepción de los puntajes del componente Utilidad. En el análisis de la Escala de Actitudes hacia la Estadística de Cazorla et al. (1999), se encontraron dos componentes, que van acorde a lo hallado en estudios previos (Torres et al., 2015). Los componentes hallados son denominados Actitudes positivas hacia la estadística y Actitudes negativas hacia la estadística, además ambos componentes presentaron coeficientes altos de consistencia interna, que significa que las puntuaciones del instrumento son confiables.

En el análisis psicométrico de la Escala de Actitudes hacia la Estadística de Estrada, se encontró una estructura de 4 componentes. Esta estructura interna difiere de la reportada en el estudio de Torres et al.
(2015), quienes hallaron 5 factores. Una diferencia radica en que para el estudio de Torres el al. se utilizó el Análisis Factorial Exploratorio y se eliminaron 4 ítems (ítems 1, 3, 17 y 18) del análisis, mientras que para el presente se utilizó el Análisis de Componentes Principales y solo se ha eliminado un ítem (ítem 3) debido a que no se relacionaba con el resto de los ítems.

Al comparar los ítems que constituyen las dimensiones halladas con el estudio de Torres et al. (2015), se puede identificar que los ítems de la dimensión Valoración positiva difieren de lo hallado en el presente estudio. En el análisis de componentes principales se halló que de los 9 ítems que corresponden a la primera dimensión, 4 ítems han coincidido con la estructura del antecedente (ítems 12, 16, 13y 10). Estos ítems se caracterizan por señalar gustos y preferencias hacia la estadística, por ejemplo: "Encuentro interesante el mundo de la estadística”, "Me apasiona la estadística porque ayuda a ver los problemas objetivamente", "Me gustan los trabajos donde aparecen estudios estadísticos" y "Me gusta la Estadística porque me ayuda a comprender más profundamente la complejidad de ciertos temas". Al analizar el contenido, todos los ítems mencionados muestran una dirección directa con el constructo que se está midiendo. Es interesante que todos los ítems (7, 8, 20 y 22) de la dimensión Habilidad hacia la estadística del estudio de Torres et al. (2015) se ubiquen en la dimensión Valoración positiva del presente trabajo. Este hallazgo podría significar que las 
habilidades que posea el evaluado para la estadística, le permiten desarrollar una valoración positiva hacia ésta. Una situación parecida ocurrió con la dimensión Utilidad del presente estudio, donde los ítems 2 (La estadística ayuda a entender el mundo de hoy) y 4 (La estadística es fundamental en la formación básica del ciudadano) se consideran dentro de la dimensión Valoración positiva del estudio mencionado. Y finalmente, dos ítems de la dimensión Valoración positiva del antecedente se ubican en la dimensión de Valoración negativa, ítems 6 (En la escuela no se debería enseñar estadística) y 24 (La estadística ayuda a tomar decisiones más documentadas).

Siguiendo con la comparación, en la segunda dimensión Valoración negativa reportada por Torres et al. (2015), han coincidido con tres ítems ubicados en dicha dimensión para el presente estudio: ítem 19 (La estadística solo sirve para la gente del área de Ciencias), 15 (En la clase de estadística nunca entiendo de qué están hablando) y 21 (La estadística no sirve para nada). Es evidente que el contenido de los ítems mencionados muestran un rechazo hacia la estadística. Respecto a los ítems 25 (Evito las informaciones estadísticas cuando las leo) y 9 (No entiendo las informaciones estadísticas que aparecen en los periódicos), estos dos se ubican en el componente Dificultad y evitación, lo que podría significar que a medida que sea más difícil entender la estadística, esto contribuye a desarrollar una valoración negativa al respecto. Para la dimensión de afectividad reportada por Torres et al. (2015), sus ítems se ubican en la dimensión Valoración negativa, ítem 23 (Si pudiera eliminar alguna materia o curso seria la Estadística) e ítem 11 (Me siento intimidado frente a los datos estadísticos), que se ubican en la dimensión Dificultad y evitación. Finalmente, la dimensión Utilidad ha coincidido con los ítems reportados en el presente estudio. Este análisis comparativo de los contenidos de los ítems muestra que lo hallado coincide parcialmente con lo reportado en el estudio de Torres et al. (2015), pero es necesario realizar más estudios instrumentales sobre la estructura interna del instrumento, ya que con lo hallado se estaría aportando a establecer la multidimensional de la prueba de Estrada.

$\mathrm{Al}$ analizar la estructura interna de la Escala de Actitudes hacia la Estadística de Cazorla, se encuentra que los componentes están delimitados de manera más acorde a como fue planteado originalmente el instrumento. La estructura hallada coincidió de manera perfecta con la información reportada sobre la escala en mención. Se decidió llamar a los componentes Actitudes positivas y Actitudes negativas para evitar las confusiones con Valoración positiva y Valoración negativa que se utilizó para la escala de Estrada. Para facilitar la interpretación, se trabajó con 2 componentes independientes. Los puntajes altos en el componente de Actitudes positivas reflejan una actitud más favorable hacia la estadística, mientras que los puntajes altos en el 
componente de Actitudes negativas reflejan actitudes más desfavorables hacia la estadística.

Con respecto a la confiabilidad de las escalas, se encontró que la Escala de Estrada presenta valores adecuados, con excepción del componente Utilidad, aunque al calcular sus intervalos de confianza, estos se encuentran próximos a .6o, por lo que podría considerarse que los 4 componentes presentan adecuada consistencia interna. En el caso de la escala de actitudes de Cazorla, se muestran coeficientes mayores a .9o, lo que indicaría que el instrumento presenta niveles adecuados de consistencia interna.

Se aplicaron correlaciones entre las sumas totales de los componentes hallados, encontrando que todos se correlacionaron de manera estadísticamente significativa. Los resultados más llamativos se centran en las correlaciones entre las Actitudes positivas y Valoración positiva (.83), que era una relación teórica esperable, ya que en ambas variables los mayores puntajes implican mejores actitudes hacia la estadística. Un resultado que merece resaltarse, son las correlaciones entre las actitudes negativas y los componentes Valoración negativa, Dificultad y evitación, y Utilidad de la estadística, en los cuales se obtuvieron correlaciones con dirección negativa. Desde un punto de vista teórico se esperaba una correlación positiva entre este componente y la Valoración negativa, pero se obtuvo un coeficiente de - -52 . Al revisar el contenido de los ítems, en el componente Actitudes negativas de la escala de Cazorla, se formulan los ítems desde una perspectiva centrada en lo afectivo, por ejemplo, se utilizan adjetivos como: nervioso, tenso, asustado, inquieto, descontento, etc. Mientras que en los ítems incluidos en el componente Valoración negativa se utilizan términos más orientados hacia los gustos y preferencias, por ejemplo: la estadística es para gente de ciencias, la estadística no sirve para nada, si pudiera eliminar un curso sería la estadística. En estas diferencias en el contenido de los ítems podría explicarse el resultado de la correlación. Además, este resultado permite resaltar la naturaleza de las actitudes, que se constituyen como evaluaciones sobre fenómenos que comprenden pensamientos, afectos y conductas. Al evaluar las actitudes, debemos hacerlo desde sus componentes cognitivos, afectivos y conductuales (Ramos, 2019), ya que si nos centramos específicamente en uno, la medición estaría incompleta.

Se han comparado los puntajes totales de los componentes en función al sexo y el año de estudio de los estudiantes evaluados. En ambos casos no se hallaron diferencias estadísticamente significativas entre los grupos. Este resultado es acorde con otros estudios que no han encontrado diferencias de las actitudes estadísticas según el sexo (Pérez et al., 2015).

Las limitaciones del estudio han sido las siguientes: en los estudios instrumentales que han empleado la escala de actitudes de Estrada, no se ha reportado evidencias de validez en base a su estructura interna, sino que los autores han elegido otras 
metodologías para estudiar sus propiedades psicométricas (Pérez et al., 2015; Tarazona et al., 2013) y también con otras poblaciones (Estrada et al., 2013; TejeroGonzález \& Castro-Morera, 2011), por lo que la comparación entre la estructura encontrada y otros estudios fue limitada. Otra limitación, fue el reducido número de los estudios realizados con estudiantes de psicología, pues la gran mayoría se ha realizado con carreras de Ciencias de la Salud (Peña et al., 2015; Santabárbara et al., 2019; Santabárbara \& López-Antón, 2020). Aunque la valoración de las actitudes hacia la estadística es un tema que está creciendo de forma acelerada (Aparicio \& Bazán, 2005; Tarazona et al., 2013), aún falta realizar investigaciones en estudiantes de ciencias sociales. Otra limitación fue no haber considerado otras variables que permitan entender de manera más completa el fenómeno de las actitudes hacia la estadística. Se recomienda que futuros estudios puedan profundizar en el tema, agregando preguntas sobre el historial del estudiante en asignaturas relacionadas con matemática, estadísticay ciencias, sus calificaciones, la autoeficacia que posea para la estadística, el desempeño en asignaturas de investigación a lo largo de sus estudios universitarios, entre otras.

Para concluir, se puede afirmar que las escalas utilizadas en el presente estudio, la Escala de Actitudes hacia la Estadística de Estrada y la de Cazorla cuentan con validez evidenciada por su estructura interna de 4 y 2 componentes, respectivamente; y además, tienen confiabilidad adecuada. También se analizó la evidencia de validez en relación a otras variables, encontrando que los componentes de ambos instrumentos están relacionados; sin embargo, es necesario abordar el tema desde los componentes de las actitudes, cognitivo (¿cómo piensan?), afectivo (¿cómo sienten?) y conductual (¿cómo actúan?) frente a la estadística y la investigación científica (Ramos, 2019). El desarrollar esta línea de investigación permitirá establecer estrategias para el cambio de actitudes, tanto en lo que es la estadística aplicada como la investigación científica, promoviendo el pensamiento crítico en los estudiantes e incrementando la producción científica en nuestro medio, y formando capital humano competente para solucionar problemas de la sociedad mediante la aplicación del método científico.

\section{Financiamiento}

El estudio fue autofinanciado.

\section{Conflictos de interés}

El autor declara que no tienen conflictos de interés. 


\section{Referencias}

Aiken, L. R. (1974). Two scales of attitudes toward mathematics. Journal for Research in Mathematics Education, 5(2), 67-71.

Aparicio, A. S., \& Bazán, J. L. (2005). Actitud y rendimiento en estadística en profesores peruanos. Acta Latinoamericana de Matemática Educativa, 19, 644-650.

Batanero, C. (2001). Didáctica de la estadística. Departamento de Didáctica de la Matemática.

Behar, R., Grima, P., Ojeda, M. M., \& Cruz, C. (2013). Educación estadística en cursos introductorios a nivel universitario: Algunas reflexiones. En Educación Estadística en América Latina: Tendencias y Perspectivas (pp. 343-360). https://www.researchgate.net/publication/329058929_Educacion_estadistica_en_cursos_introductorios_a_nivel_universitario_Algunas_reflexiones

Blanco, A. (2008). Una revisión crítica de la investigación sobre las actitudes de los estudiantes universitarios hacia la estadística. Revista Complutense de Educación, 19(2), 311-330.

Brito, M. R. (1998). Adaptação e validação de uma Escala de Atitudes em relação à Matemática. Zetetiké, 6(9), 109-162.

Cazorla, I. M., Silva, S. B., \& Vendramini, C. (1999). Adaptação e Validação de uma escala de atitudes em relação à estatística. Atas da Conferência Internacional "Experiências e expectativas do ensino de estatística-desafios para o século XXI". Florianópolis, Santa Catarina.

Comas, C., Martins, J. A., Nascimento, M. M., \& Estrada, A. (2017). Estudio de las Actitudes hacia la Estadística en Estudiantes de Psicología. Bolema: Boletim de Educação Matemática, 31(57), 479-496. https://doi.org/10.159o/198o-4415v31n57a23

Estrada, A, Bazán, J., \& Aparicio, A. (2013). Análisis de las actitudes y conocimientos estadísticos elementales en la formación del profesorado. AIEM Avances de Investigación en Educación Matemática, 3, 5-23.

Estrada, A., Batanero, C., \& Fortuny, J. M. (2003). Actitudes y estadística en profesores en formación y en ejercicio. Presentado en el 27 Congreso Nacional de Estadística e Investigación Operativa. https://bit.ly/2ORıc8 
Estrada, Asunción. (2002). Análisis de las actitudes y conocimientos estadísticos elementales en la formación del profesorado [Universitat Autonoma de Barcelona]. https://www.tesisenred.net/handle/10803/4697

Field, A., Milles, J., \& Field, Z. (2012). Discovering statistics using R. SAGE Publications.

García-Martínez, J. A., Fallas-Vargas, M. A., \& Romero-Hernández, A. (2015). Las actitudes hacia la estadística del estudiantado de orientación. Revista Electrónica Educare, 19(1), 25-41. https://doi.org/10.15359/ree.19-1.2

Molina, J. G., Rodrigo, M. F., \& Bonavia, T. (2011). La docencia de estadística en el grado de psicología: Una experiencia de colaboración interdisciplinar con la asignatura de psicología social del trabajo. @tic Revista d’innovació educativa, 6, 21-29.

Montero, I., \& León, O. G. (2002). Clasificación y descripción de las metodologías de investigación en Psicología. Revista Internacional de Psicología Clínica y de la Salud, 2(3), 503-508.

Nina, A. R., \& Martínez, S. R. (2018). Actitudes hacia la Estadística y factores asociados en estudiantes universitarios. Revista Digital Investigación \& Negocios, 11(18), 64-71.

Peña, A., Suárez, R., Sanjuan, G., Rabell, O., Gómez, M., \& Morales, S. C. (2015). Actitudes hacia la asignatura de Estadística en estudiantes de la Facultad de Ciencias Médicas «General Calixto García», 14(6), 872-883.

Pérez, L. E., Aparicio, A. S., Bazán, J. L., \& Abdounur, O. J. (2015). Actitudes hacia la estadística de estudiantes universitarios de Colombia. Educación Matemática, 27(3). http://www.scielo.org.mx/scielo. php?script=sci_arttext\&pid=S1665-58262015000300111\&lang=es

Ramos, L. (2019). Análisis psicométrico de una Escala de Actitudes hacia la Investigación Científica. Revista de Psicología (Universidad Católica San Pablo), 9(2), 35-52.

Ramos, L. F. (2019). La educación estadística en el nivel universitario: Retos y oportunidades. Revista Digital de Investigación en Docencia Universitaria, 13(2), 67-82. https://doi.org/10.19083/ridu.2019.1081

Rodríguez, N. (2011). Actitudes de los estudiantes universitarios hacia la estadística. Interdisciplinaria, 28(2), 199-205. 
Santabárbara, J., \& López-Antón, R. (2020). Actitudes hacia la estadística y rendimiento académico en estudiantes de Grado en Medicina. Revista de la Fundación Educación Médica, 23(1), 9. https://doi.org/10.33588/fem.231.1033

Santabárbara, J., Montenegro, S., \& López-Antón, R. (2019). Conocimientos básicos en bioestadística y epidemiología y actitudes hacia la estadística en estudiantes de posgrado de medicina. Revista de la Fundación Educación Médica, 22(3), 145. https://doi.org/10.33588/fem.223.993

Tarazona, E., Bazán, J. L., \& Aparicio, A. S. (2013). Actitudes hacia la estadística en universitarios peruanos de mediana edad. Revista Digital de Investigación en Docencia Universitaria, 7(1), 57-76. https://revistas.upc.edu.pe/index.php/ docencia/article/view/187

Tejero-González, C. M., \& Castro-Morera, M. (2011). Validación de la escala de actitudes hacia la estadística en estudiantes españoles de ciencias de la actividad física y del deporte. Revista Colombiana de Estadística, 34(1), 1-14. http://www. scielo.org.co/pdf/rce/v34n1/v34n1ao1.pdf

Torres, F., Aparicio, A. S., Bazán, J. L., \& Abdounur, O. J. (2015). Actitudes hacia la estadística en universitarios del área de las ciencias de una universidad pública de Chile. Educação Matemática Pesquisa, 17(1), 45-73.

Valencia, D. (2017). Actitudes hacia la estadística en estudiantes de psicología de una Universidad Privada de Lima. Acta Psicológica Peruana, 2(1), 104-117.

Recibido: 14 de octubre de 2020

Revisado: 15 de marzo de 2021

Aceptado: 6 de mayo de 2021 


\section{Asociación entre creencias implícitas acerca de la inteligencia y el rendimiento académico en escolares de 10 a 14 años de Arequipa metropolitana}

The Association Between Implicit Theories of Intelligence and Academic

Achievement in Children Between 10 to 14 Years of Age

from Metropolitan Arequipa

Joselyn Mayeli Melo Peña

Universidad Católica San Pablo, Arequipa, Perú.

(iD) https://orcid.org/oooo-ooo1-6911-4514

Rosario Carolina Salcedo Soto

Universidad Católica San Pablo, Arequipa, Perú

(iD https://orcid.org/oooo-0oo2-6468-5016

Correspondencia: rosario.salcedo@ucsp.edu.pe

\section{Resumen}

La presente investigación tiene por objetivo determinar la asociación entre las creencias implícitas acerca de la inteligencia de los escolares con el desempeño escolar de estudiantes de colegios nacionales y particulares del área metropolitana de Arequipa del 5 to y 6 to grado de primaria y 1er año de secundaria. Corresponde a un diseño no experimental, transversal y correlacional. Se encuestaron a 434 estudiantes de colegios públicos y privados de Arequipa Metropolitana. Se administró la Escala de Teorías Implícitas, traducida y adaptada a la población colombiana y al contexto peruano. Los principales resultados evidencian que los colegios privados presentaron puntajes más altos de mentalidad fija, así como un mejor rendimiento. Se concluye que el rendimiento académico bajo puede verse influenciado por la creencia de la inteligencia incremental, además de no contar con el apoyo en los estudios y entrega de recursos académicos.

Palabras clave: Rendimiento académico, inteligencia, creencia fija, creencia incremental.

\section{Abstract}

The present study was conducted to determine if there was an association between implicit theories and academic achievement in schoolchildren in the 
5th and 6th grade of primary school and the ist grade of secondary school. A no experimental, transversal, correlational design was used for this study. 434 students in public and private educational institutions in Metropolitan Arequipa were surveyed. The Implicit Theory Scale was used. This scale was translated and adapted for a Colombian population and was adapted to the Peruvian context. Results indicated that private schools had higher fixed-mind scores, as well as better performance. There was a significant association between family support and academic performance. It was concluded that low academic performance could be influenced by a growth mentality, not having support in their studies, and delivery of academic resources.

Keywords: Academic performance, intelligence, fixed belief, incremental belief.

\section{Introducción}

De acuerdo con los resultados del PISA 2015 (Programme for International Student Assessment) llevado a cabo por Organización para la Cooperación y Desarrollo Económico; nuestro país se encuentra dentro de los diez países con rendimiento académico más bajos en las áreas de matemática, lectura y ciencia a nivel mundial. Aproximadamente tres de cada cuatro alumnos no aprobaron matemáticas, un promedio del $70 \%$ de las evaluaciones en ciencias fue anulada y el $60 \%$ demostró que no entendía lo que leía (BBC, 2016). Si bien los resultados de PISA 2018 dieron a conocer que el Perú ocupa el puesto 64 de 77 países, donde se observan ciertas mejorías, se tienen resultados similares a la prueba del 2015, debido a que los alumnos evaluados continuamos dentro de los últimos puestos a nivel de los países latinoamericanos (Gestión, 2019). A partir del Informe Nacional de Evaluación Censal de Estudiantes 2018 (ECE) que realizó el Ministerio de Educación del Perú, se conoce que la mayoría de los escolares del año 2019 se encontraron en un nivel de logro elemental o parcial.
Hace algunos años Carol Dweck (2007) planteó una nueva perspectiva que intenta abordar la problemática ligada al desempeño escolar haciendo referencia a las creencias implícitas que tienen los alumnos respecto a su propia inteligencia, a lo que se denomina teoría implícita de la inteligencia. Este constructo está dispuesto en un continuo que va desde la inteligencia como fija hasta la inteligencia como incremental. El primero considera a la capacidad cognitiva como estable e inmutable a lo largo del tiempo. Por tanto, personas con este tipo de creencias sobre la inteligencia tienden a atribuir un mal desempeño académico a una pobre inteligencia, por lo cual invierten un menor esfuerzo por cambiar su situación académica. De este modo se observa una especie de auto profecía cumplida. Por el contrario, la creencia incremental refiere que la inteligencia es maleabley es posible mejorarla con esfuerzo; por tanto, esto favorece al desempeño académico.

De acuerdo a Dweck (2007) es posible cambiar estas creencias ya que serían 
disposiciones mentales, y de ese modo se puede ayudar en el desempeño académico de los escolares. Las teorías implícitas de Dweck (2007) han sido estudiadas en países como China (Wang \& Fei-YinNg, 2012), Australia (Tarbetsky \& Martín, 2016), Francia (Lammel \& Guillén, 2011), España (Carpintero et al., 2003), México (Lammel \& Guillén (2011) y Colombia (Galvis et al., 2010), mas no en Perú.

Por ello, en la presente investigación se tiene por objetivos:1) identificar el tipo de creencias implícitas acerca de la inteligencia que tienen los estudiantes del 5to y 6to

\section{Inteligencia}

\section{Definiciones de Inteligencia}

Alfred Binet definió la inteligencia señalando que es una capacidad fundamental que tiene efectos importantes para la vida práctica. Sin embargo, sostuvo que los alumnos requieren aprender de otros aspectos que no se tomaron en cuenta en la prueba de inteligencia que crea con Simon, como es el caso de la atención, la voluntad y el carácter; los cuales se reflejan en la docilidad, la disciplina, los hábitos regulares y especialmente en la continuidad de esfuerzo para aprender (Binet \& Simon, 1916). Por otro lado, Charles Spearman (1904) se refirió a la inteligencia como un conjunto de habilidades cognitivas que se relacionan entre sí, sin que ninguna de ellas sea un factor principal de la misma. Por ende, se enfocó en la generalización de la inteligencia llamada factor G (Fineburg, 2009). grado de primaria y 1 er año de secundaria del área metropolitana de Arequipa, 2) describir el nivel del desempeño escolar de los estudiantes del 5 to y 6 to grado de primaria y $1 e r$ año de secundaria del área metropolitana de Arequipa y 3 ) determinar las diferencias de nivel académico, nivel socioeconómico, entorno familiar, sexo y tipo de colegio (particular o nacional) en los tipos de creencias implícitas acerca de la inteligencia y el desempeño académico de estudiantes 5 to y 6 to grado de primaria y er año de secundaria del área metropolitana de Arequipa.

Mientras que Catell y Horn (1967) expresaron que la inteligencia está compuesta por habilidades fluidas que guían la habilidad individual de un sujeto, a razonar y actuar con rapidez, resolver nuevos problemas y codificar memorias de corto plazo. Asimismo, sostuvieron una diferencia entre inteligencia fluida y cristalizada. La inteligencia fluida está enraizada en la eficiencia fisiológica (Horn, 1965). El otro factor, llamado inteligencia cristalizada, provienen del aprendizaje y la influencia de la cultura, y se plasma en tests de conocimiento, información general, el uso del lenguaje y una diversidad de habilidades que se adquieren (Horn \& Catell, 1967), ero ambas dependen una de la otra (Horn \& Catell, 1966).

También, Piaget (1969) planteó una visión de la inteligencia centrada en cómo se obtiene el conocimiento en la medida que uno va desarrollándose, y que 
evolucionaría a través de etapas Su contribución permitió modificar el rumbo de la investigación dedicada al desarrollo del niño, combatiendo la visión de ser un organismo pasivo, condicionado y moldeado por el entorno.

A su vez, Vigotsky (1979, citado por Arias, 2013) refirió que la inteligencia si bien precisa del factor hereditario también lo depende de las influencias culturales, siendo estas últimas las más relevantes, ya que permite la modificación de la inteligencia, la cual toma la dirección que cada cultura le impone. Por ende la inteligencia puede acrecentarsey también decrecer, de manera que la persona al recibir estímulos beneficiosos de su entorno, enriquece su pensamiento y acorta la distancia entre la zona de desarrollo real (ZDr) y la zona de desarrollo potencial (ZDp), permitiendo así, el desarrollo de la inteligencia. Por otro lado, Gardner (1987, citado por Macías) señala que la inteligencia implica la habilidad para resolver un problema o para elaborar productos que son importantes en un contexto cultural. Por tanto, este enfoque se vio dirigido a rescatar también el aspecto cultural (Berríos, 2018), buscando conocer cómo una persona manifiesta su inteligencia, de modo que se postula la existencia de siete inteligencias, teoría que ha generado diversas críticas (Arias, 2014).

En lo que respecta a la presente investigación tomaremos en cuenta la definición de inteligencia según Dweck, quien refiere, que es una suma de capacidades mentales que orientan las emociones, los pensamientos y las acciones para conocer, comprender y hallar soluciones a los problemas habituales de forma táctica y eficaz (Fandiño, 2008).

\section{Teorías implícitas acerca de la inteligencia}

\section{Definición de las Teorías Implícitas}

Carol Dweck, docente de psicología en la Universidad de Stanford, sostiene que existen tres creencias que paralizan el desarrollo del intelecto: la primera es considerar la inteligencia como invariable, la segunda es respecto a medir el potencial a raíz del resultado conseguido en un momento dado, y la tercera creencia es sobre las personas que no requieren del esfuerzo para conseguir logros como el éxito académico puesto que poseen talentos innatos (Dweck, 1999). En efecto, las creencias de la inteligencia suponen que las acciones del individuo dependen de construcciones mentales no conscientes y tienen una vinculación afectiva, por lo cual denomino a esta propuesta como teoría implícita de la inteligencia. No obstante al estar inducidas por las experiencias y construcciones personales pueden cambiar como también adaptarse ante situaciones nuevas, perteneciendo a un dominio en particular y dependen de que sean reconocidas o no (Bollousa, 2014). En el ámbito académico, Dweck (2007) encontró una relación positiva entre el tipo de creencias acerca de la inteligencia con los resultados académicos de los estudiantes. En síntesis, según la autora la inteligencia es maleable y las creencias que tiene la persona sobre la inteligencia atañen en su rendimiento académico. 


\section{Tipos de creencias según la teoría implícita acerca de la inteligencia}

Carol Dweck desde sus inicios como investigadora tuvo un gran interés por conocer cómo las personas lidian con el fracaso, por lo cual se dedicó a hacer diversas investigaciones en el área educativa (Dweck, 2017). En efecto, Dweck (2007) detecto que las creencias en función a la inteligencia se clasificarían en: la creencia fija y la creencia de crecimiento. En cuanto a la creencia fija, se hace referencia a aquellas personas que tienen la idea de que su inteligencia no es modificable, tienden a evitar las dificultades que se les presentan, ya que son consideradas como aspectos externos a la persona, por ende siendo el esfuerzo y la práctica ineficientes se dan por vencidos con facilidad, y por tanto, en el plano académico, no se toman acciones para revertir la situación (Dweck, 2007). Es conveniente señalar que la evitación del esfuerzo sucede por dos motivos: creer que el logro sin esfuerzo es propia de genios, y porque muchas veces se encuentran justificaciones para no tomar riesgos que suponen enfrentar dificultades (Dweck, 2017). Por tanto, muchas veces los estudiantes tienden a enfocarse en lo negativo, creando identidad personal negativa en el plano académico. Así, cuando las personas con creencia fija dejan de sentirse inteligentes o talentosos en algún aspecto, simplemente pierden el interés en ello. Asimismo, en el plano de las interacciones personales, buscan relacionarse con personas que no les den a conocer sus características negativas, procurando mostrarse superiores en vez de buscar su propio desarrollo (Carpintero, et al.,
2003). Esto les genera también emociones negativas por sentir temor de perder las valoraciones positivas que se le atribuyen.

En cuanto a la creencia de crecimiento, la persona considera la posibilidad de mejora en sus habilidades para adquirir nuevos conocimientos, por lo que orienta sus metas al aprendizaje, lo cual significa asumiry superar las dificultades a lo largo del tiempo a través del esfuerzo (Gayón, 2010). De manera que se procura tomar el control de la situación, implementando buenas estrategias y recibiendo ayuda de los demás durante el proceso (Dweck, 2017). Por ende, tienen una interpretación resiliente de los desafíos, tanto académicos como de otro tipo, teniendo en cuenta que la resiliencia implica la respuesta emocional frente a las dificultades académicas o sociales, de forma positiva y beneficiosa para el desarrollo de la persona (Yeager \& Dweck, 2012). Por tanto, al estar interesados en mejorar y enfocarse en la lucha por superar las dificultades, desarrollan un mejor conocimiento de sus habilidades y capacidades (Dweck, 2017), yvan en búsqueda de interacciones que le permitan incrementar sus conocimientos, tomando las críticas como oportunidades de mejora (Carpintero et al., 2003).

Es importante señalar que la autora de la propuesta de la teoría implícita de la inteligencia, reconoce que hay factores que promueven que una persona pueda desarrollarse intelectualmente de forma positiva, como son los estímulos parentales y una buena educación (Dweck, 2017). Se tiene que señalar que en ambas creencias se pueden experimentan 
emociones negativas, pero la diferencia radica en cómo las interpretan según la confianza en sí mismo. Las personas con creencia fija se valoran en medida de las emociones negativas y muestran confianza sólo cuando nada malo les acontece (Dweck, 2017).

\section{¿Se puede tener ambas mentalidades?}

Con motivo de distinguir ambas mentalidades, se han presentado como alternativas opuestas, sin embargo, en la mente humana estas dos mentalidades o creencias, pueden coexistir en una misma persona, a pesar de que esto pueda parecer contradictorio o inconsistente (Dweck et al, 1996). Es posible que una de estas mentalidades se manifieste con mayor intensidad, o que una u otra mentalidad, se presenten en situaciones o áreas particulares (Dweck, 2017). Asimismo, es crucial comprender que el contexto y las experiencias del día a día de la persona, da lugar muchas veces una fusión de creencias fijas y de crecimiento (Bollousa, 2014).

\section{Desarrollo de las creencias acerca de la inteligencia del niño}

El proceso de transición de primaria a secundaria es un punto crítico para el desarrollo de los escolares, en el cual oscilan entre las edades de 10 a 14 años de edad. Si bien la escuela primaria es un entorno que brinda apoyo y contrarresta las consecuencias de las creencias fijas de la inteligencia, posteriormente, en la escuela secundaria, tienen lugar cambios académicos que pueden ser generar desafíos muy demandantes para los estudiantes. Además, se marca el inicio de la adolescencia, que es una etapa de cambios psicológicos, físicos y sociales, donde se enfatiza en la competencia. Es por este motivo, el alumno con creencias fijas se ve menos equipado para superar tales retos (Blackwell et al., 2007).

En ese sentido, en una investigación realizada con alumnos que se encontraban en la transición de la primaria a la secundaria, se reportó que los alumnos con creencia fija presentaban una disminución en sus notas, a comparación de los que tenían una creencia crecencial, quienes obtuvieron una mejoría en sus calificaciones. Los alumnos con creencias fijas tendían a despreciar sus capacidades por las dificultades propias de la educación secundaria, culpándose a sí mismos o a los demás de sus fracasos; en cambio los de mentalidad crecencial, si bien se sentían abrumados por los retos que implicaba la secundaria, su respuesta fue profundizar y hacer lo necesario para incrementar sus aprendizajes, esforzándose más y cambiando de estrategias si la situación lo requería (Dweck, 2017).

En consecuencia, los alumnos con creencias fijas ven la transición de primaria a secundaria como un proceso difícil, como una amenaza, y como una situación en la que pueden ser catalogados de forma negativa. Por ende, el alumno con creencia fija hace uso de sus recursos, no para aprender, sino para proteger su ego, esforzándose menos y evitando el fracaso (Dweck, 2017). 
Por otro lado, Dweck y Elliott (1983) explicaron que la razón por la cual existían alumnos capaces que creían que no lo eran, radicaba en los objetivos de la persona, ya que algunas se orientan hacia sus metas de aprendizaje y otras hacia al resultado. Dweck (2002) demostró también, que elogiar a los niños por su inteligencia, más que por su esfuerzo, socava su motivación y ocasionaba que los niños mientan para obtener elogios. Por consiguiente, Dweck (2007) se preguntó sobre aquello que haría que las personas se centren en determinado objetivo, lo cual le llevó a la conclusión de que las personas que desean demostrar resultados, creerían que su inteligencia es estática, mientras que quienes desean mejorar sus aprendizajes tenían una creencia de la inteligencia como una habilidad dinámica y maleable.

Además, de los estudios de Dweck, se han llevado a cabo varias investigaciones sobre la teoría implícita de la inteligencia en diversos países del mundo. Por ejemplo, Tarbetsky et al. (2016) realizaron una investigación con 87 estudiantes australianos indígenas y 87 estudiantes australianos no indígenas, concluyendo que las creencias implícitas y las habilidades son un factor motivacional que predice el logro académico, siendo los estudiantes indígenas quienes presentaron bajos niveles en rendimiento académico, acompañado del predominio de creencias fijas. Por otro lado, quienes manifestaron mayores creencias incrementales obtuvieron un buen resultado académico, siendo las estudiantes mujeres quienes mostraron un mayor rendimiento general. Estos resultados se contraponen a los que obtuvo Gayón (2010), quien no encontró diferencias significativas entre niños y niñas, como lo indicaron los estudios de Dweck y Leggett (1988), y Leggett (1986), quienes encontraron además, que los escolares de sexo femenino mostraban mayor tendencia por la creencia de tipo fija.

En otro estudio, Galvis et al. (2010) evaluaron a 107 escolares que cursaban los grados quinto, sexto y séptimo de un colegio en Colombia, reportando que hubo predominio de la creencia de tipo de crecimiento mediada por el esfuerzo y el aprendizaje. Mientras que, en una investigación de Lammel y Guillén (2011) se encontró que los niños mexicanos evidenciaron una creencia predominante sobre la inteligencia fija, mientras que los niños franceses tenían puntajes más altos en creencias de la inteligencia incremental. Estos resultados se explicaron, debido a que los niños franceses perciben la inteligencia como algo individual y cognitivo, mientras que los niños mexicanos tienen una conceptualización dual que se conforma por el aspecto social y cognitivo.

A su vez, Wang y Fei-YinNg (2012) realizaron dos estudios cada uno con una duración de seis meses en población china. El primer estudio con 581 estudiantes (231 varones y 350 mujeres) con un promedio de edad de 16 años y en el segundo estudio participaron 361 de los estudiantes de décimo grado (124 niños, 237 niñas), que fueron evaluados con el cuestionario de Dweck (2000). Los estudiantes chinos, tendieron a ver a la 
inteligencia como más inmutable que el rendimiento escolar, y resaltaron la importancia de un enfoque positivo en el trabajo escolar.

\section{Rendimiento académico}

Según Figueroa (2004), el rendimiento académico es el producto de la comprensión del contenido de los programas de estudio, siendo reflejado en calificaciones dentro de una escala convencional (Noack, 2018). Por otro lado, la UNESCO (2015) refiere que el logro del aprendizaje es un componente indispensable que evidencia la calidad educativa. Mientras que para Woolfolk (2010) el rendimiento académico aporta información sobre el aprendizajey de las formas en que integran sus conocimientos, desde niveles de menor a mayor complejidad.

Asimismo, en cuanto al sistema de evaluación escolar peruano, en el nivel de Educación Primaria se hace uso de una escala literal y descriptiva, son los siguientes niveles: AD o "Logro destacado" refiere que el alumno manifiesta los aprendizajes previstos y a su vez, ha superado el nivel esperado en función a la competencia. A o "Logro esperado" se otorga en la medida en que los alumnos consiguen demostrar el nivel esperado de forma provechosa en un tiempo determinado. Asimismo, se obtendrá B o "En proceso" cuando el estudiante está en trayecto a adquirir el aprendizaje, y por ello, requerirá de apoyo en un tiempo programado que le permita conseguirlo. Co "En inicio" se da a aquellos estudiantes que denotan un progreso mínimo en cuanto al aprendizaje de los contenidos, evidenciando inconvenientes para lograrlo, de tal manera que necesitarán de un apoyo por un tiempo más prolongado (Ministerio de Educación del Perú, 2017).

En cuanto a la Educación Secundaria, el Ministerio de Educación de Perú aplica de forma escalonada una calificación académica cualitativa. En efecto, AD significa un logro muy satisfactorio (LMS), A logro satisfactorio (LS), B logro básico (LB) y C logro inicial (I) (Correo, 2019).

En nuestro país, como en otros de Latinoamérica, el rendimiento académico, está fuertemente asociado con la condición socioeconómica de los estudiantes. Así, los factores sociales y económicos contribuyen a explicar el pensamiento de la sociedad y su evolución. Por tanto, es de suma importancia tomarlos en cuenta en las investigaciones educacionales (Dongo, 2009), ya que la carencia de dinero en algunos grupos sociales, tienen por consecuencia crecientes problemas de educación (Rodríguez, 2015).

Una explicación a estas deficiencias educativas mediadas por la condición socioeconómica, tiene que ver con el involucramiento de la familia en el rendimiento de los hijos. Lastre, López y Alcázar (2018) realizaron una investigación que reveló la asociación entre variables de acompañamiento de la familia y rendimiento académico en estudiantes de $3^{\circ}$ de primaria en Colombia; reportando que los alumnos de mayor nivel socioeconómico obtuvieron un rendimiento académico más alto 
debido a que tenían acompañamiento por parte de sus padres.

Asimismo, se llevó a cabo una investigación para indagar la influencia de la estructura familiar en el rendimiento académico en matemática y lectura de los escolares de $6^{\circ}$ de primaria de diferentes países de América Latina, con una muestra de 90 mil niños y sus respectivas familias de 2450 instituciones educativas; concluyéndose que los estudiantes de familias nucleares alcanzan un rendimiento superior en matemática y en lectura en comparación con los alumnos de familias monoparentales. Por otro lado, se halló una correlación positiva entre el nivel educativo de los padres y el rendimiento académico de sus hijos. A su vez, se encontró que a medida que se incrementa el nivel socioeconómico familiar, las diferencias de rendimiento académico entre familias monoparentales y familias nucleares son más notorias, a comparación de sectores pobres que mantienen un rendimiento bajo, independientemente dela estructura familiar (Cervini et al., 2014). Por el contrario, Cruz et al. (2014) reportaron una relación débil entre el desempeño escolary el nivel socio económico.

Tomando en cuenta las variables familiares, se realizó una investigación en España, con 486 escolares de secundaria, entre 12 y 18 años; en el que se reportó que el desempeño académico puede verse influido por las expectativas o percepciones que los padres presentan sobre las posibilidades académicas de sus hijos, siendo la madre la de mayor influencia.
Igualmente se encontró asociación entre el nivel educativo y empleo de los padres con el desempeño académico de sus hijos, obteniendo un efecto positivo en el rendimiento de los hijos, a medida que se incrementan estas variables. Esto se explica, por el hecho, de que las clases sociales medias o acomodadas, cuentan con ingresos familiares suficientes para adquirir los materiales de estudio requeridos (Fajardo et al., 2017). En general, como dice Olmeda (2016), el rendimiento no es una variable independiente del contexto en el que vive el alumno.

En cuanto a la edad, Peña (2015) refiere que los alumnos menores en edad dentro de un mismo grado escolar poseen un desempeño escolar bajo en pruebas estandarizadas. Así mismo, Backhoff, Sánchez, Peón y Andrade (2010) sostienen que los escolares con una edad acorde a su nivel de estudios tienen un mejor rendimiento.

Por otro lado, se debe agregar que, con respecto al sexo, Soto y colaboradores (2015) encontraron que no existe una diferencia significativa entre el rendimiento escolar a pesar que las mujeres tienden a tener calificaciones ligeramente más altas. De manera análoga la Organización para la Cooperación y Desarrollo Económico (OECD, 2013), señala que existe una leve propensión a que las mujeres posean mejores calificaciones y menos disertaciones en el colegio. 


\section{Método}

\section{Diseño}

El diseño de este estudio fue no experimental, transversal y correlacional puesto que no se manipularon variables independientes para generar efectos en variables dependientes, y sólo se observó la asociación entre las variables de estudio en un momento dado (León \& Montero, 2007).

\section{Participantes}

La muestra estuvo conformada por 434 alumnos de quinto y sexto grado de educación primaria y primero de secundaria. La selección de la muestra se hizo por conveniencia. Se eligió a colegios particulares y nacionales, diurnos y mixtos La población a la que se dirigió la presente investigación abarcó niños con un desarrollo típico es decir no tienen algún tipo de dificultad en su desarrollo.

\section{Instrumentos}

Para evaluar las creencias implícitas de la inteligencia se utilizó The Implicit Theory of Intelligence Scale (ITIS) cuyos autores son Abd-El-Fattah y Yates (2006), y está basado en el modelo de Dweck (1999, 2002). La versión inglesa fue validada a la población de Colombia, y fue adaptada y traducida por expertos (Muñiz \& Hambleton, 1996; Flores et al., 2006). La versión que se utilizó en este trabajo constó de 14 ítems, siete de los cuales evalúan creencias fijas y los siete restantes creencias de crecimiento. Esta versión fue validada para estudiantes escolares por Gayón (2010), con un índice de confiabilidad de .90 con el método test-retest.

Para evaluarel rendimientoacadémicodelos escolares se dispuso con un formato en el cual se registraron las calificaciones del primer trimestre, en donde figuran el promedio de las calificaciones correspondientes para los cursos de lenguajey matemática; obteniéndose como medida del desempeño escolar (Stromso \& Braten, 2004).

Para el registro del nivel socioeconómico se aplicó una ficha sociodemográfica que elaborada a partir de los datos obtenidos por la APEIM, que constó de cinco niveles, A, B, C, D y E; cada una con una descripción sobre qué se requiere para cada nivel, que permitió obtener información en el aspecto económico sobre el hogar del estudiante. Existen investigaciones en nuestro país que hicieron uso de las variables propuestas por APEIM vara evaluar el nivel socioeconómico que han dado cuenta de su validez y confiabilidad (Hoyos, 2016; Vera \& Vera, 2013; Zegarra, 2013).

\section{Procedimiento}

En primer lugar se coordinó con las autoridades de las instituciones educativas los permisos correspondientes para la ejecución de la investigación. Seguidamente, se procedió a la aplicación de la prueba dentro del horario escolar de los estudiantes. Vale precisar que se pasó a entregar los consentimientos a los padres de familia, esperando una semana para el regreso de éste y poder pasar al asentimiento por parte 
de los alumnos quienes también tenían la libertad de negarse a participar de la investigación. Asimismo junto con el consentimiento de los padres de familia se les entregó dos preguntas referentes a datos socioeconómicos, y las preguntas restantes se recabaron de los datos registrados en la institución educativa. La aplicación de la prueba y la ficha sociodemográfica se dio grupalmente. Finalmente se revisaron los registros de notas de los estudiantes para identificar su desempeño escolar, lo cual permitió diferenciar a los estudiantes de bajo rendimiento escolar.

\section{Criterios para el análisis de datos}

La información recolectada en las encuestas fue ingresada a una matriz de datos en el software Excel. Posteriormente, se procedió a realizar el análisis exploratorio, descriptivo e inferencial de los datos en el software $\mathrm{R}$ v3.5.1. Para comenzar, se estimaron las medidas de tendencia central en las variables cuantitativas y frecuencias porcentuales en las variables cualitativas. De este modo se pudo determinar que ambas dimensiones de las teorías implícitas tienen distribuciones aproximadas a la normalidad (Teorías fijas: $\mathrm{W}=0.95, \mathrm{p}=.45$; Teorías incrementales: $\mathrm{W}=0.93, \mathrm{p}=.20$ ). Al analizar las frecuencias del desempeño académico en los cursos de comunicación y matemática se observaron frecuencias menores a 5 en las notas $\mathrm{AD}$ y $\mathrm{C}$, lo cual genera dificultades en la estimación de modelos estadísticos. Es por este motivo que se recodificó dicha variable con dos categorías: Alto rendimiento (que comprende las notas AD y A) y Bajo rendimiento (que comprende las notas B y C). Del mismo modo, al analizar el nivel socioeconómico de los estudiantes se observaron frecuencias bajas en los estratos A y E, por lo cual se recodificó esta variable, para lo cual se juntaron los estratos A con B, y D con $\mathrm{E}$, para poder tener estimaciones más adecuadas. Además, las comparaciones de promedios se analizaron utilizando $t$ de Student cuando se compararon dos grupos, y ANOVA cuando se compararon más de dos grupos. Para realizar los contrastes específicos de las pruebas de ANOVA se utilizó la prueba post-hoc con ajuste de Bonferroni. Del mismo modo cuando se analizaron las diferencias entre dos variables categóricas se utilizó la prueba de Chi-Cuadrado.

\section{Resultados}

En la Tabla 1 se encuentran los estadísticos descriptivos de los tipos de creencias acerca de la inteligencia reportadas por los estudiantes de la muestra de la presente investigación. Se pudo observar que los participantes reportaron un puntaje estadísticamente significativo mayor en las creencias fijas $(M=2.78)$ que en las creencias incrementales $(M=1.81$, $t=33.88, \mathrm{gl}=433, \mathrm{p}<.001$ ) 
Tabla 1. Valores descriptivos de los tipos de creencias acerca de la inteligencia de los estudiantes

\begin{tabular}{|lcccc|}
\hline \multicolumn{1}{|c}{ Variable } & M & DE & Min & Max \\
\hline Creencias Fijas & 2.78 & 0.41 & 1.29 & 4.00 \\
Creencias Incrementales & 1.81 & 0.40 & 1.00 & 3.14 \\
\hline
\end{tabular}

En la Tabla 2 se pueden observar las diferencias entre los promedios de los tipos de las creencias acerca de la inteligencia entrecada uno de los niveles académicos que fueron encuestados. En ambos tipos, creencias fijas eincrementales, noseobservaron diferencias estadísticamente significativas $\left(F_{(2,431)}=0.97\right.$, $\mathrm{p}=.38 ; F_{(2,431)}=1.50, \mathrm{p}=.22$, respectivamente), por lo que se considera que los promedios son iguales para los tres niveles.

Tabla 2. Comparación de tipos de las creencias acerca de la inteligencia por nivel académico

\begin{tabular}{|c|c|c|c|c|c|c|c|c|}
\hline & \multicolumn{2}{|c|}{$\begin{array}{c}5^{\text {to }} \\
\text { Primaria }\end{array}$} & \multicolumn{2}{|c|}{$\begin{array}{c}\text { 6to } \\
\text { Primaria }\end{array}$} & \multicolumn{2}{|c|}{$\begin{array}{c}\text { 1ro } \\
\text { Secundaria }\end{array}$} & \multirow[t]{2}{*}{$F(2,431)$} & \multirow[t]{2}{*}{$\mathbf{p}$} \\
\hline & $\mathbf{M}$ & DE & $\mathbf{M}$ & DE & $\mathbf{M}$ & DE & & \\
\hline C. Fijas & 1.77 & 0.38 & 1.83 & 0.45 & 1.83 & 0.38 & 0.97 & .38 \\
\hline C. Incrementales & 2.73 & 0.43 & 2.82 & 0.36 & 2.79 & 0.42 & 1.50 & .22 \\
\hline
\end{tabular}

En la Tabla z es posible observar la comparación del rendimientoacadémico en comunicacióny matemática por nivel académico. Se observaron diferencias significativas entrelos participantes, donde los estudiantes de 5 to y 6toen su mayoría tienen un rendimientoalto; mientras que, los estudiantes de primero de secundaria tienen un rendimiento bajo $\left(X_{(2)}^{2}=\right.$ 40.47, p<.001). En estesentidolosestudiantes de secundaria parecen tener mayores dificultades con el rendimiento en este curso. Al igual que en el curso de comunicación, seobservaron diferencias significativas entre los distintos niveles académicos en el curso de matemática. Los estudiantes de 5to y 6to tienen mejor rendimiento académico que los estudiantes 1ro de secundaria $\left(X_{(2)}^{2}=\right.$ $9 \cdot 54, \mathrm{p}=.008)$. 
Tabla 3. Comparación del rendimiento académico en comunicación y matemática por nivel académico

\begin{tabular}{|c|c|c|c|c|c|c|}
\hline & \multicolumn{2}{|c|}{ Alto } & \multicolumn{2}{|c|}{ Bajo } & \multirow{2}{*}{$\mathbf{x} 2(2)$} & \multirow{2}{*}{$\mathbf{p}$} \\
\hline & $\mathbf{N}$ & $\%$ & $\mathbf{N}$ & $\%$ & & \\
\hline \multicolumn{7}{|c|}{ Comunicación } \\
\hline 5to & 71 & 61.2 & 45 & 38.8 & 40.47 & .001 \\
\hline 6 to & 92 & $79 \cdot 3$ & 24 & 20.7 & & \\
\hline 1ero & 87 & 43.0 & 115 & $59 \cdot 9$ & & \\
\hline \multicolumn{7}{|c|}{ Matemática } \\
\hline $5^{\text {to }}$ & 59 & 50.9 & 57 & 49.1 & $9 \cdot 54$ & .008 \\
\hline 6to & 65 & 56.0 & 51 & 44.0 & & \\
\hline 1ero & 79 & 39.0 & 123 & 61.0 & & \\
\hline
\end{tabular}

En la Figura 1 se puede observar la relación entre los tipos de creencias acerca de la inteligencia y el rendimiento académico en comunicación y matemática. Con respecto a las creencias fijas y el curso de comunicación se observaron diferencias significativas de acuerdo con la prueba t de Student $\left(t_{(431)}=\mathbf{2 . 9 1}, \mathrm{p}=.003\right)$. Específicamente los estudiantes con alto desempeño en comunicación tienen un promedio significativamente más alto que el de los estudiantes con un bajo desempeño. Por el contrario, en cuanto a las creencias incrementales se observaron diferencias significativas $\left(t_{(431)}=\mathbf{- 2 . 3 9}, \mathrm{p}=\right.$ .02). En este caso los estudiantes con un bajo desempeño en comunicación, son los que tienen un promedio más alto en este tipo de creencia por sobre los estudiantes con un alto desempeño. Estos dos resultados si bien apuntan a la existencia de una relación entre las creencias acerca de la inteligencia y el rendimiento académico, van en contra de lo propuesto en la hipótesis de la presente investigación. 

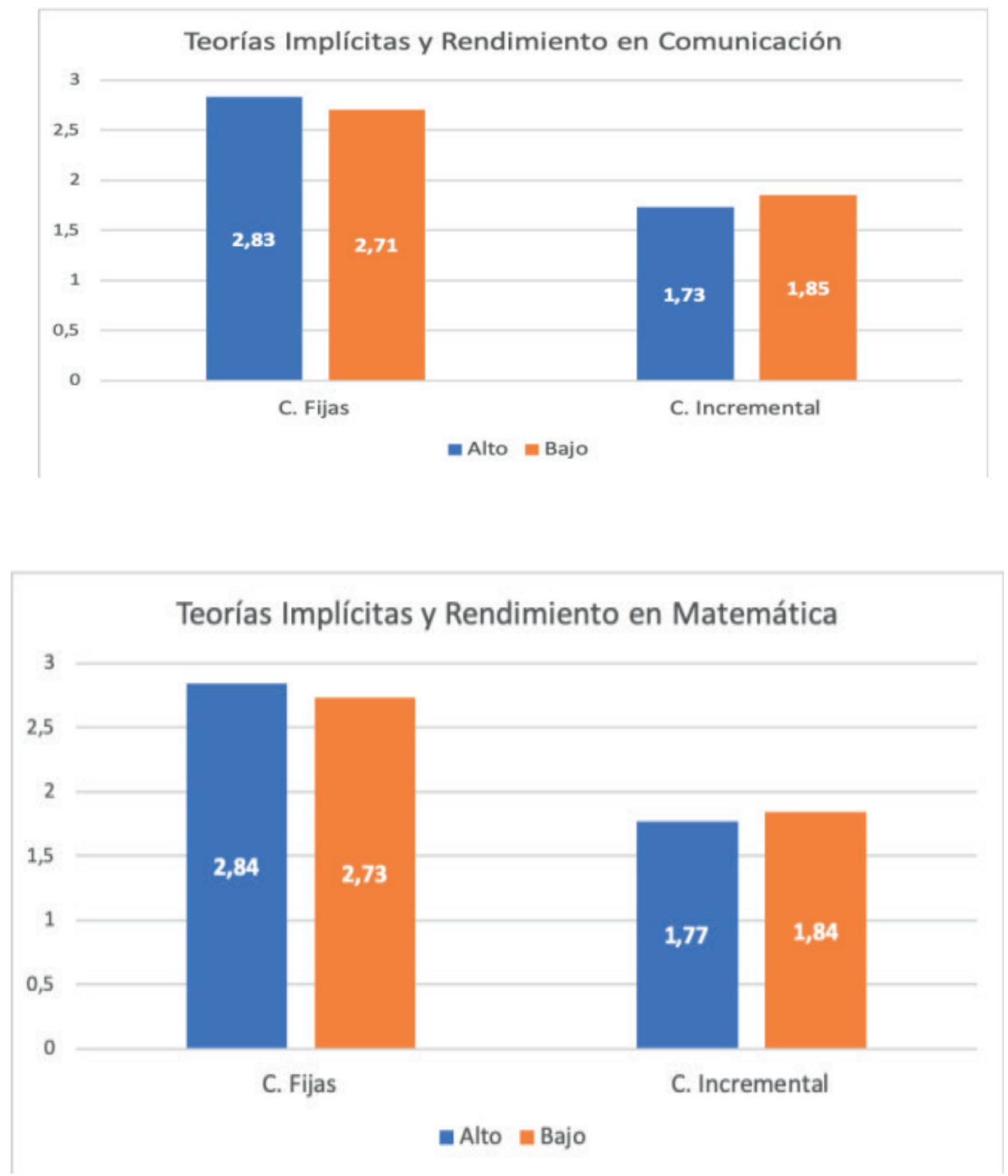

Figura 1. Asociación entre los tipos de creencias acerca de la inteligencia y rendimiento académico en comunicación y matemática

Enel casodel cursodematemáticaseencuentraun patrón similaral observadoen el rendimiento en comunicación. Los estudiantes con alto rendimiento presentan una media significativamente más alta en creencias fijas que los estudiantes con un desempeño bajo $\left(\mathrm{t}_{(431)}=2.84, \mathrm{p}=.005\right)$. Además, los estudiantes con un bajo desempeño en matemática presentan una media significativamente más alta en creencias incrementales que los 


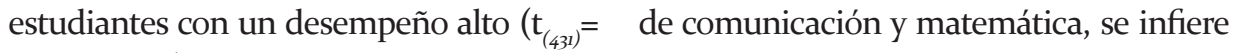
$-2.00, \mathrm{p}=.05)$. Estos resultados nuevamente queal menos en una muestra arequipeña las van en contra de lo que era esperado de creenciasfijasseasocianaunaltodesempeño acuerdocon la revisión de literatura realizada. y las creencias incrementales seasocian a un Yalobservarseel mismo patrón en loscursos desempeño bajo.

Tabla 4.

Comparación de los tipos de creencias acerca de la inteligencia por sexo de los estudiantes

\begin{tabular}{|lcccccc|}
\hline & \multicolumn{2}{c}{ Femenino } & \multicolumn{2}{c}{ Masculino } & \multirow{2}{*}{ (412) } & p \\
& M & DE & M & DE & & .95 \\
C. Fijas & 2.78 & 0.43 & 2.78 & 0.38 & -0.06 & .21 \\
C. Incrementales & 1.84 & 0.42 & 1.79 & 0.38 & 1.26 & .26 \\
\hline
\end{tabular}

En la Tabla 4 se encuentra la compara- significativas por género (Creencias fijas: ción de promedios de los tipos de creen- $t_{(412)}=-0.06, p=.95$; Creencias incremencias acerca de la inteligencia por sexo de tales: $\left.\mathrm{t}_{(412)}=1.26, \mathrm{p}=.21\right)$. Por lo que el los estudiantes. En ninguno de los tipos sexo no es determinante al momento de creencias acerca de la inteligencia se de formar las creencias acerca de la observaron diferencias estadísticamente inteligencia. 
Tabla 5.

Nivel familiar y creencias fijas acerca de la inteligencia

\begin{tabular}{|c|c|c|c|c|}
\hline & $\mathbf{M}$ & DS & $\mathbf{F}$ & $\mathbf{p}$ \\
\hline \multicolumn{5}{|l|}{ Tipo de familia } \\
\hline Nuclear & 1.77 & 0.38 & 0.97 & .38 \\
\hline Extensa & 1.83 & 0.45 & & \\
\hline Monoparental & 1.83 & 0.38 & & \\
\hline \multicolumn{5}{|c|}{ Personas que ayudan al estudiante con las tareas } \\
\hline Padre & 2.81 & 0.43 & 2.92 & .03 \\
\hline Madre & 2.82 & 0.41 & & \\
\hline Otro & 2.81 & 0.35 & & \\
\hline Nadie & 2.68 & 0.43 & & \\
\hline \multicolumn{5}{|c|}{ Frecuencia de ayuda en las tareas } \\
\hline Frecuentemente & 2.77 & 0.44 & 3.75 & .01 \\
\hline$A$ veces & 2.81 & 0.39 & & \\
\hline Rara vez & 2.87 & 0.36 & & \\
\hline Nadie & 2.68 & 0.42 & & \\
\hline \multicolumn{5}{|c|}{ Nivel de instrucción de la persona que ayuda con las tareas } \\
\hline Primaria Incompleta & 2.89 & 0.57 & 2.63 & .02 \\
\hline Primaria Completa & 2.64 & 0.42 & & \\
\hline Secundaria Incompleta & 2.73 & 0.39 & & \\
\hline Secundaria Completa & 2.82 & 0.41 & & \\
\hline Superior Incompleta & 2.90 & 0.41 & & \\
\hline Superior Completa & 2.78 & 0.37 & & \\
\hline Nadie & 2.68 & 0.43 & & \\
\hline \multicolumn{5}{|c|}{ Tipo de ocupación de quien ayuda con las tareas al estudiante } \\
\hline Empresa & 2.80 & 0.31 & 2.64 & .03 \\
\hline Propio & 2.87 & 0.46 & & \\
\hline Eventual & 2.83 & 0.38 & & \\
\hline No trabaja & 2.79 & 0.41 & & \\
\hline Nadie & 2.68 & 0.43 & & \\
\hline \multicolumn{5}{|c|}{ Tiempo de reacción ante los requerimientos de material académico de los estudiantes } \\
\hline Inmediatamente & 2.80 & 0.43 & 0.52 & 67 \\
\hline Tardan & 2.77 & 0.37 & & \\
\hline Falta dinero & 2.81 & 0.59 & & \\
\hline No prestan atención & 2.62 & 0.47 & & \\
\hline \multicolumn{5}{|c|}{ Tiempo de recreación con la familia } \\
\hline Poco & 2.72 & 0.44 & 0.66 & .52 \\
\hline Algo & 2.79 & 0.40 & & \\
\hline Mucho & 2.79 & 0.41 & & \\
\hline
\end{tabular}

En la Tabla 5 es posible observar la de la inteligencia. Con respecto a la tipo comparación las características de nivel de familia no se observaron diferencias y entorno familiar y las creencias acerca significativas $\left(F_{(2,431)}=0.97, \mathrm{p}=.38\right)$, por 
lo que de acuerdo con estos resultados el tipo de familia no tiene implicancias sobre el desarrollo de creencias fijas de la inteligencia. Para la comparación de la persona reportada como quien ayuda al estudiante y las creencias fijas se observan diferencias significativas $\left(F_{(3,430)}=2.92, \mathrm{p}=\right.$ 0.03 ) donde de acuerdo a los contrastes de Bonferroni las diferencias específicas se encuentran entre quienes reciben ayuda de la madre y quienes no reciben ayuda de nadie $(p=.038)$, donde quienes reciben ayuda de la madre tienen un promedio mayor de creencias fijas que quienes no reciben ayuda de nadie.

Para la comparación entre frecuencia de ayuda con las tareas se observaron diferencias significativas en las creencias fijas $\left(F_{(2,431)}=3.75, \mathrm{p}=.01\right)$, y de acuerdo con los contrastes post hoc las diferencias específicas se encuentran entre aquellos participantes que reciben ayuda rara vez contra los que no reciben ayuda de ningún tutor con creencias fijas más altas para los primeros $(p=.01)$. Del mismo modo para el nivel de instrucción de quien ayuda con las tareas y las creencias fijas se observan diferencias significativas $\left(F_{(5,428)}=2.63, \mathrm{p}=\right.$
.02), donde de acuerdo a los contrastes post-hoc las diferencias específicas se encuentran entre aquellos tutores que tienen un nivel de instrucción superior incompleta frente a los que no reciben ayuda de nadie ( $\mathrm{p}=.007$ ) siendo los primeros quienes muestran un promedio superior al segundo.

Con respecto a las creencias fijas de la inteligencia y el tipo de ocupación de quien ayuda en las tareas, se observan diferencias estadísticamente significativas $\left(F_{(4,429)}=2.64, \mathrm{p}=.03\right)$, donde de acuerdo a los contrastes post hoc, las diferencias específicas se encuentran entre aquellos que tienen un negocio propio y aquellos que no reciben ayuda de ningún familiar o tutor $(p=.04)$, siendo los primeros quienes tienen un promedio de creencias fijas más alto que los segundos. Para la relación entre el tiempo de reacción de frente a las necesidades académicas del estudiante y las creencias fijas de la inteligencia no se observaron diferencias $\left(F_{(3,430)}=.52, \mathrm{p}=\right.$ $.67)$. Del mismo modo para la relación entre creencias fijas y tiempo de recreación con la familia, no se observaron diferencias significativas $\left(F_{(2,431)}=0.66, \mathrm{p}=.52\right)$. 
Tabla 6.

Nivel familiar y creencias incrementales acerca de la inteligencia

\begin{tabular}{|c|c|c|c|c|}
\hline & M & DS & $\mathbf{F}$ & p \\
\hline \multicolumn{5}{|l|}{ Tipo de familia } \\
\hline Nuclear & 2.73 & 0.43 & 1.50 & .22 \\
\hline Extensa & 2.82 & 0.36 & & \\
\hline Monoparental & 2.79 & 0.42 & & \\
\hline \multicolumn{5}{|c|}{ Personas que ayudan al estudiante con las tareas } \\
\hline Padre & 1.80 & 0.41 & 0.32 & .81 \\
\hline Madre & 1.82 & 0.40 & & \\
\hline Otro & 1.78 & 0.42 & & \\
\hline Nadie & 1.83 & 0.35 & & \\
\hline \multicolumn{5}{|c|}{ Frecuencia de ayuda en las tareas } \\
\hline Frecuentemente & 1.82 & 0.40 & 0.13 & .93 \\
\hline A veces & 1.80 & 0.41 & & \\
\hline Rara vez & 1.80 & 0.42 & & \\
\hline Nadie & 1.83 & 0.36 & & \\
\hline \multicolumn{5}{|c|}{ Nivel de instrucción de la persona que ayuda con las tareas } \\
\hline Primaria Incompleta & 1.89 & 0.52 & 0.40 & .88 \\
\hline Primaria Completa & 1.67 & 0.32 & & \\
\hline Secundaria Incompleta & 1.78 & 0.43 & & \\
\hline Secundaria Completa & 1.79 & 0.34 & & \\
\hline Superior Incompleta & 1.84 & 0.43 & & \\
\hline Superior Completa & 1.81 & 0.43 & & \\
\hline Nadie & 1.83 & 0.36 & & \\
\hline \multicolumn{5}{|c|}{ Tipo de ocupación de quien ayuda con las tareas al estudiante } \\
\hline Empresa & 1.75 & 0.38 & 1.29 & .27 \\
\hline Propio & 1.85 & 0.42 & & \\
\hline Eventual & 1.85 & 0.39 & & \\
\hline No trabaja & 1.84 & 0.45 & & \\
\hline Nadie & 1.83 & 0.35 & & \\
\hline \multicolumn{5}{|c|}{ Tiempo de reacción ante los requerimientos de material académico de los estudiantes } \\
\hline Inmediatamente & 1.79 & 0.40 & 2.02 & .11 \\
\hline Tardan & 1.83 & 0.38 & & \\
\hline Falta dinero & 2.07 & 0.62 & & \\
\hline No prestan atención & 1.64 & 0.35 & & \\
\hline \multicolumn{5}{|c|}{ Tiempo de recreación con la familia } \\
\hline Poco & 1.93 & 0.49 & 3.75 & .02 \\
\hline Algo & 1.83 & 0.38 & & \\
\hline Mucho & 1.77 & 0.39 & & \\
\hline
\end{tabular}

En la Tabla 6 es posible observar la de la inteligencia. Con respecto a la tipo comparación las características de nivel de familia no se observaron diferencias familiar y las creencias incrementales significativas $\left(F_{(2,431)}=1.50, \mathrm{p}=.22\right)$, por lo 
que de acuerdo con estos resultados el tipo de familia no tiene implicancias sobre el desarrollo de creencias incrementales de la inteligencia. Para la comparación de la persona reportada como quien ayuda al estudiante y las creencias incrementales tampoco se observaron diferencias significativas $\left(F_{(2,431)}=0.32, \mathrm{p}=.81\right)$. Del mismo modo para la comparación entre frecuencia de ayuda con las tareas no se observaron diferencias significativas en las creencias incrementales $\left(F_{(2,431)}=.13, \mathrm{p}=.93\right.$. Para el nivel de instrucción de quien ayuda con las tareasy las creencias incrementales tampoco se observan diferencias significativas $\left(F_{(5,428)}=0.40, \mathrm{p}=.88\right)$. Con respecto a las creencias incrementales y el tipo de ocupación de quien ayuda en las tareas, no se observan diferencias estadísticamente significativas $\left(F_{(4,429)}=1.29, \mathrm{p}=.27\right)$. Para la relación entre el tiempo de reacción frente a las necesidades académicas del estudiante y las creencias incrementales de la inteligencia no se observaron diferencias $\left(F_{(3,430)}=2.02, \mathrm{p}=.11\right)$. Sin embargo, se observan diferencias estadísticamente significativas en la dimensión de creencias incrementales $\left(F_{(2,431)}=3.75, \mathrm{p}=.02\right)$, de acuerdo con los contrastes post-hoc las diferencias específicas se encuentran entre los grupos de mucho tiempo con la familia frente a poco tiempo con la familia $(\mathrm{p}=0.03)$; siendo los últimos quienes presentan un promedio superior en este tipo de creencias. Por lo cual de acuerdo con estos resultados el tiempo que pasen los hijos con la familia impacta sobre el desarrollo de creencias incrementales de la inteligencia.

Tabla 7.

Comparación del NSE de los estudiantes y los tipos de creencias acerca de la inteligencia

\begin{tabular}{|lccccc|}
\hline & \multicolumn{2}{c}{ C. Fijas } & \multicolumn{2}{c|}{ C. Incrementales } \\
& $\boldsymbol{M}$ & $\boldsymbol{D} \boldsymbol{E}$ & $\boldsymbol{M}$ & $\boldsymbol{D} \boldsymbol{E}$ \\
\hline A / B & 2.76 & 0.44 & 1.76 & 0.38 \\
C & 2.81 & 0.43 & 1.82 & 0.40 \\
D / E & 2.68 & 0.41 & 1.80 & & 0.41 \\
$F_{(4,429)}$ & & 0.49 & & 0.41 & \\
$P$ & & & & \multicolumn{2}{c}{.80} \\
\hline
\end{tabular}

En la Tabla 7 es posible ver la comparación de promedios de los dos tipos de creencias acerca de la inteligencia con el nivel socioeconómico de los estudiantes. En ninguno de los dos tipos de creencias se pudieron observar diferencias significativas (Creencias fijas: $F_{(4,429)}=1.49$, $\mathrm{p}=.21$; Creencias incrementales: $F_{(4,429)}=$ $0.41, \mathrm{p}=.80$ ), esto indica que independientemente del estrato económico del que provenga la persona, no afecta al tipo de creencias de la inteligencia. 
Tabla 8.

Comparación de los tipos de creencias acerca de la inteligencia y tipo de colegio

\begin{tabular}{|lcccccc|}
\hline & \multicolumn{2}{c}{ Estatal } & \multicolumn{2}{c}{ Particular } & \multirow{2}{*}{ T(431) } & P \\
\hline T. Fijas & M & DE & M & DE & & .03 \\
T. Incrementales & 2.73 & 0.40 & 2.82 & 0.41 & -2.21 & .05 \\
\hline
\end{tabular}

En la Tabla 8 se observa la comparación entre los tipos de creencias acerca de la inteligencia y tipo de colegio con el tipo de colegio. Para las creencias fijas se pudo observar que los estudiantes de colegios particulares tienen un promedio significativamente mayor que los estudiantes de colegios estatales $\left(t_{(431)}=-2.21, \mathrm{p}=.03\right)$. Por el contrario, para las creencias incrementales se observó un promedio significativamente mayor para los estudiantes de los colegios estatales por sobre los estudiantes del colegio particular $\left(t_{(431)}=\right.$ 1.99, $\mathrm{p}=.05)$.

Tabla 9.

Comparación del rendimiento académico en comunicación y matemática por sexo de los estudiantes

\begin{tabular}{|c|c|c|c|c|c|c|}
\hline & \multicolumn{2}{|c|}{ Alto } & \multicolumn{2}{|c|}{ Bajo } & \multirow{2}{*}{$\mathbf{X}^{2}(\mathbf{1})$} & \multirow[b]{2}{*}{$\mathbf{p}$} \\
\hline & $\mathbf{N}$ & $\%$ & $\mathbf{N}$ & $\%$ & & \\
\hline \multicolumn{7}{|c|}{ Comunicación } \\
\hline Femenino & 132 & 64.4 & 73 & 35.6 & 6.81 & .009 \\
\hline Masculino & 118 & 51.5 & 111 & 48.5 & & \\
\hline \multicolumn{7}{|l|}{ Matemática } \\
\hline Femenino & 103 & 50.2 & 102 & 49.8 & 1.62 & .20 \\
\hline Masculino & 100 & $43 \cdot 7$ & 129 & 56.3 & & \\
\hline
\end{tabular}

En la Tabla 9 se puede observar las diferencias de sexo en el rendimiento académico del curso de comunicación y matemática. Se observaron diferencias significativas $\left(X_{(1)}^{2}=6.81, \mathrm{p}=.009\right)$ donde las mujeres obtuvieron un mejor rendimiento académico que el de los hombres en el curso de comunicación. En lo que respecta al curso de matemática no se pudieron observar diferencias significativas $\left(X_{(1)}^{2}=1.62, \mathrm{p}=.20\right)$, por lo que se considera que las notas de hombres y mujeres en matemática son estadísticamente similares. 
Tabla 10.

Rendimiento académico en comunicación y el nivel familiar

\begin{tabular}{|c|c|c|c|c|c|c|}
\hline & \multicolumn{2}{|c|}{ Alto } & \multicolumn{2}{|c|}{ Bajo } & \multirow[b]{2}{*}{$\mathbf{X}^{2}$} & \multirow[b]{2}{*}{$\mathbf{p}$} \\
\hline & $\mathbf{N}$ & $\%$ & $\mathbf{N}$ & $\%$ & & \\
\hline \multicolumn{7}{|l|}{ Tipo de familia } \\
\hline Nuclear & 110 & $54 \cdot 7$ & 91 & $45 \cdot 3$ & 7.09 & .03 \\
\hline Extensa & 100 & 65.8 & 52 & 34.2 & & \\
\hline Monoparental & 40 & $49 \cdot 4$ & 41 & 50.6 & & \\
\hline \multicolumn{7}{|c|}{ Personas que ayudan al estudiante con las tareas } \\
\hline Padre & 38 & $59 \cdot 4$ & 26 & 40.6 & 8.31 & .04 \\
\hline Madre & 105 & 61.4 & 66 & 38.6 & & \\
\hline Otro & 58 & 63.0 & 34 & $37 \cdot 0$ & & \\
\hline Nadie & 49 & 45.8 & 58 & 54.2 & & \\
\hline \multicolumn{7}{|c|}{ Frecuencia de ayuda en las tareas } \\
\hline Frecuentemente & 50 & 55.6 & 40 & $44 \cdot 4$ & $9 \cdot 99$ & .02 \\
\hline A veces & 105 & $64 \cdot 4$ & 58 & $35 \cdot 6$ & & \\
\hline Rara vez & 46 & $64 \cdot 4$ & 28 & $35 \cdot 6$ & & \\
\hline Nadie & 49 & 45.8 & 58 & 54.2 & & \\
\hline \multicolumn{7}{|c|}{ Nivel de instrucción de la persona que ayuda con las tareas } \\
\hline Primaria Incompleta & 3 & 60.0 & 2 & 40.0 & 10.01 & .12 \\
\hline Primaria Completa & 7 & 70.0 & 3 & 30.0 & & \\
\hline Secundaria Incompleta & 18 & 60.0 & 12 & 40.0 & & \\
\hline Secundaria Completa & 42 & 55.2 & 34 & $44 \cdot 7$ & & \\
\hline Superior Incompleta & 49 & $63 \cdot 3$ & 28 & 36.4 & & \\
\hline Superior Completa & 82 & 63.6 & 47 & 36.4 & & \\
\hline Nadie & 49 & 45.8 & 58 & 54.2 & & \\
\hline \multicolumn{7}{|c|}{ Tipo de ocupación de quien ayuda con las tareas al estudiante } \\
\hline Empresa & 82 & 61.2 & 52 & 38.8 & 9.62 & .05 \\
\hline Propio & 35 & $59 \cdot 3$ & 24 & 40.7 & & \\
\hline Eventual & 30 & $57 \cdot 7$ & 22 & 42.3 & & \\
\hline No trabaja & 54 & 66.7 & 27 & $33 \cdot 3$ & & \\
\hline Nadie & 49 & 45.8 & 58 & 54.2 & & \\
\hline \multicolumn{7}{|c|}{ Tiempo de reacción ante los requerimientos de material académico de los estudiantes } \\
\hline Inmediatamente & 149 & 61.3 & 94 & 38.7 & 6.52 & .09 \\
\hline Tardan & 95 & $54 \cdot 3$ & 80 & $45 \cdot 7$ & & \\
\hline Falta dinero & 5 & 50.0 & 5 & 50.0 & & \\
\hline No prestan atención & 1 & 16.7 & 5 & $83 \cdot 3$ & & \\
\hline \multicolumn{7}{|c|}{ Tiempo de recreación con la familia } \\
\hline Poco & 22 & 46.8 & 25 & 53.2 & 2.57 & .27 \\
\hline Algo & 106 & 59.6 & 72 & 40.4 & & \\
\hline Mucho & 122 & 58.4 & 87 & 41.6 & & \\
\hline
\end{tabular}

En la Tabla 1o se observan las frecuencias con el rendimiento académico en el curso y porcentajes del nivel familiar comparado de comunicación. De acuerdo con estos 
resultados se observa una relación significativa entre tipo de familia y rendimiento $\left(X_{(2)}^{2}=7.09, p=.03\right)$, donde las familias extensas son las que tienen un porcentaje mayor de hijos con desempeño académico alto en este curso, mientras que las familias nucleares y monoparentales tienen cantidades cercanas al $50 \%$ en ambos tipos de desempeño. De este modo se establece una relación entre el tipo de familia y el desempeño en este curso. La prueba de Chi-Cuadrado también arrojó resultados estadísticamente significativos para la relación entre desempeñoy personas que ayudan al estudiante con las tareas $\left(X_{(3)}^{2}=\right.$ 8.31, $\mathrm{p}=.04)$. Específicamente se observa que aquellos estudiantes que reciben algún apoyo sean de padre, madre u otro tutor tienen un desempeño académico mejor que aquellos que no reciben ayuda de nadie. Esto indica que la atención que brindan los padres a las tareas que tienen los hijos es importante para el desempeño al menos en el curso de comunicación. Se observa una relación significativa entre el rendimiento y frecuencia de ayuda en las tareas $\left(X_{(3)}^{2}=9.99, \mathrm{p}=.02\right)$, donde las familias que ayudan a veces y rara vez a los estudiantes muestran un desempeño académico más alto que aquellos que reciben ayuda frecuentemente o que no reciben ayuda en lo absoluto. Esto indicaría que la cantidad de veces que el estudiante afecta también sobre el desempeño en este curso, siendo necesario moderar la cantidad de veces que el estudiante debe ser ayudado. Para la relación entre el nivel de instrucción y rendimiento no se observaron diferencias significativas $\left(X_{(6)}^{2}=10.01, \mathrm{p}=.12\right)$, indicando que, si bien la ayuda es importante para el desempeño en este curso, el nivel de instrucción de los padres no es un factor determinante. La prueba de Chi-Cuadrado arrojó resultados significativos para la relación entre rendimiento y el tipo de ocupación del quien ayuda con las tareas $\left(X_{(2)}^{2}=9.62, p=.05\right)$. Específicamente se puede observar que aquellos padres que no trabajan logran que la mayoría de sus hijos tengan un desempeño alto, seguido por aquellos padres que son empleados en una empresa. Indicando que probablemente el tiempo que tienen disponible los padres para poder ayudar a sus hijos tiene implicancias sobre el desempeño al menos en el curso de comunicación. La relación entre la respuesta ante necesidad de material académico y el desempeño no resultó significativa $\left(X_{(3)}^{2}=6.52, \mathrm{p}=\right.$ .09 ). No se pudieron observar diferencias significativas en la relación entre tiempo de recreación con la familia y rendimiento $\left(X_{(2)}^{2}=2.57, \mathrm{p}=.27\right)$, por lo que estas dos variables no estarían vinculadas o no tendrían implicancia una sobre la otra. 


\section{Tabla 11.}

\section{Rendimiento académico matemática y nivel familiar}

\begin{tabular}{|c|c|c|c|c|c|c|}
\hline & \multicolumn{2}{|c|}{ Alto } & \multicolumn{2}{|c|}{ Bajo } & \multirow[b]{2}{*}{$\mathbf{X}^{2}$} & \multirow[b]{2}{*}{$\mathbf{p}$} \\
\hline & $\mathbf{N}$ & $\%$ & $\mathbf{N}$ & $\%$ & & \\
\hline \multicolumn{7}{|l|}{ Tipo de familia } \\
\hline Nuclear & 100 & 49.8 & 101 & 50.2 & 17.99 & .001 \\
\hline Extensa & 82 & 53.9 & 70 & 46.1 & & \\
\hline Monoparental & 21 & $25 \cdot 9$ & 60 & 74.1 & & \\
\hline \multicolumn{7}{|c|}{ Personas que ayudan al estudiante con las tareas } \\
\hline Padre & 31 & 48.4 & 33 & 51.6 & 4.12 & .24 \\
\hline Madre & 85 & $49 \cdot 7$ & 86 & 50.3 & & \\
\hline Otro & 46 & 50.0 & 46 & 50.0 & & \\
\hline Nadie & 41 & 38.3 & 66 & 61.7 & & \\
\hline \multicolumn{7}{|c|}{ Frecuencia de ayuda en las tareas } \\
\hline Frecuentemente & 44 & 48.9 & 46 & 51.1 & 4.10 & .25 \\
\hline$A$ veces & 81 & $49 \cdot 7$ & 82 & 50.3 & & \\
\hline Rara vez & 37 & 50.0 & 37 & 50.0 & & \\
\hline Nadie & 41 & 38.3 & 66 & 61.7 & & \\
\hline \multicolumn{7}{|c|}{ Nivel de instrucción de la persona que ayuda con las tareas } \\
\hline Primaria Incompleta & 3 & 60.0 & 2 & 40.0 & 12.17 & .06 \\
\hline Primaria Completa & 4 & 40.0 & 6 & 60.0 & & \\
\hline Secundaria Incompleta & 17 & 56.7 & 13 & $43 \cdot 3$ & & \\
\hline Secundaria Completa & 31 & 40.8 & 45 & 50.2 & & \\
\hline Superior Incompleta & 47 & 61.0 & 30 & 39.0 & & \\
\hline Superior Completa & 60 & 46.5 & 69 & $53 \cdot 5$ & & \\
\hline Nadie & 41 & 38.3 & 66 & 61.7 & & \\
\hline \multicolumn{7}{|c|}{ Tipo de ocupación de quien ayuda con las tareas al estudiante } \\
\hline Empresa & 58 & $43 \cdot 3$ & 76 & 56.7 & 9.41 & .06 \\
\hline Propio & 30 & 50.8 & 29 & 49.2 & & \\
\hline Eventual & 26 & 50.0 & 26 & 50.0 & & \\
\hline No trabaja & 48 & 59.2 & 33 & 40.7 & & \\
\hline Nadie & 41 & 38.3 & 66 & 61.7 & & \\
\hline \multicolumn{7}{|c|}{ Tiempo de reacción ante los requerimientos de material académico de los estudiantes } \\
\hline Inmediatamente & 121 & 49.8 & 122 & 50.2 & 11.61 & .008 \\
\hline Tardan & 81 & 46.3 & 94 & $53 \cdot 7$ & & \\
\hline Falta dinero & 1 & 10.0 & 9 & 90.0 & & \\
\hline No prestan atención & o & o.o & 6 & 100 & & \\
\hline \multicolumn{7}{|c|}{ Tiempo de recreación con la familia } \\
\hline Poco & 16 & 34.0 & 31 & 66.0 & 3.47 & .17 \\
\hline Algo & 87 & 48.9 & 91 & 51.1 & & \\
\hline Mucho & 100 & 47.8 & 109 & 52.2 & & \\
\hline
\end{tabular}

En la Tabla 11 se puede ver la comparación familia y el rendimiento $\left(X_{(2)}^{2}=17.99\right.$, $\mathrm{p}<$ de nivel familiary rendimiento académico .oo1), donde las familias monoparentales en el curso de matemática. Se observa tienen mayores dificultades con el desemuna relación significativa entre el tipo de peño en este curso, siendo el $71 \%$ de sus 
hijos quienes tienen un desempeño bajo. Mientras que en las familias nucleares y extensas no es posible determinar un patrón ya que en ambos casos son cercanos al 50\% para ambos desempeños. De acuerdo con los resultados no se observa una relación significativa entre estas, el desempeño y persona que ayuda al estudiante con las tareas $\left(X_{(3)}^{2}=4.12, \mathrm{p}=.24\right)$. Lo cual indica que la atención y ayuda que los padres puedan brindar a sus hijos en el curso de matemática no es necesariamente determinante sobre el desempeño académico sobre el curso de matemática. Del mismo modo, la prueba de Chi-Cuadrado entregó resultados no significativos para la relación entre frecuencia de ayuda con las tareas y rendimiento en matemática $\left(X_{(3)}^{2}=4.10, \mathrm{p}=.25\right)$, lo cual indica que particularmente para el curso de matemática la cantidad de veces que el estudiante reciba ayuda de sus padres o tutores no afecta significativamente a su desempeño académico. Para el nivel de instrucción y rendimiento no se observó una relación significativa $\left(X^{2}{ }_{(6)}=12.17, \mathrm{p}=.06\right)$, por lo que tampoco habría implicancia del nivel de instrucción del padre o tutor sobre el rendimiento académico en matemática. Para la relación entre tipo de ocupación de quien ayuda con las tareas y rendimiento no se observaron diferencias significativas $\left(X_{(4)}^{2}=9.41, \mathrm{p}=.06\right)$, por lo que para el curso de matemática el tipo de trabajo o tiempo que tengan, los padres o tutores, disponible para poder ayudar a los estudiantes no está relacionado al desempeño académico. La prueba de Chi-Cuadrado arrojó un resultado significativo para la relación entre tiempo de reacción ante los requerimientos de material académico y rendimiento $\left(X_{(2)}^{2}=11.61, \mathrm{p}=.008\right)$. Específicamente se observa que los padres que atienden inmediatamente o tardan un poco tienen un desempeño en matemática significativamente más alto que aquellos que no tienen dinero o no prestan atención. Finalmente, para la relación entre tiempo de recreación con la familia y rendimiento no se observó un resultado estadísticamente significativo $\left(X_{(2)}^{2}=3.47\right.$, $\mathrm{p}=.17$ ). 
Tabla 12.

Comparación del NSE de los estudiantes y el rendimiento académico en comunicación y matemática

\begin{tabular}{|c|c|c|c|c|c|c|}
\hline & \multicolumn{2}{|c|}{ Alto } & \multicolumn{2}{|c|}{ Bajo } & \multirow{2}{*}{$X^{2}(4)$} & \multirow{2}{*}{$\mathbf{p}$} \\
\hline & $\mathbf{N}$ & $\%$ & $\mathbf{N}$ & $\%$ & & \\
\hline \multicolumn{7}{|c|}{ Comunicación } \\
\hline $\boldsymbol{A} / \boldsymbol{B}$ & 89 & 64.5 & 49 & $35 \cdot 5$ & 4.65 & .32 \\
\hline C & 96 & 56.1 & 75 & 43.9 & & \\
\hline$D / E$ & 65 & 52.0 & $6 o$ & 48.0 & & \\
\hline \multicolumn{7}{|c|}{ Matemática } \\
\hline $\boldsymbol{A} / \boldsymbol{B}$ & 65 & 47.1 & 73 & 52.9 & 1.16 & .88 \\
\hline C & 76 & 44.4 & 95 & 55.6 & & \\
\hline$D / E$ & 62 & 49.6 & 63 & 50.4 & & \\
\hline
\end{tabular}

En la Tabla 12 se observan las frecuencias y porcentajes del nivel socioeconómico comparado con el rendimiento académico de los estudiantes en comunicación y matemática. En el caso de comunicación no se pudo observar una relación significativa $\left(X_{(2)}^{2}=4.65, \mathrm{p}=.32\right)$, indicando que el rendimiento académico en este curso no está relacionado al estrato socioeconómico del que provenga el estudiante. $\mathrm{Al}$ igual que con el curso de comunicación, no se observó una relación significativa entre el rendimiento en matemática y nivel socioeconómico $\left(X_{(4)}^{2}=1.16, \mathrm{p}=.88\right)$.

Tabla 13.

Comparación del rendimiento académico en comunicación y matemáticas y tipo de colegio

\begin{tabular}{|c|c|c|c|c|c|c|}
\hline & \multicolumn{2}{|c|}{ Alto } & \multicolumn{2}{|c|}{ Bajo } & \multirow{2}{*}{$\mathbf{X}^{2}(\mathbf{1})$} & \multirow{2}{*}{$\mathbf{p}$} \\
\hline & $\mathbf{N}$ & $\%$ & $\mathbf{N}$ & $\%$ & & \\
\hline \multicolumn{7}{|c|}{ Comunicación } \\
\hline Estatal & 103 & 49.8 & 104 & 50.2 & $9 \cdot 36$ & .002 \\
\hline Particular & 147 & 64.8 & 80 & 35.2 & & \\
\hline \multicolumn{7}{|l|}{ Matemática } \\
\hline Estatal & 86 & 41.5 & 121 & 58.5 & 3.95 & .05 \\
\hline Particular & 117 & 51.5 & 110 & 48.5 & & \\
\hline
\end{tabular}

En la Tabla 13 se encuentra la comparación del rendimiento académico en comunicación y matemática y el tipo de establecimiento educativo. La prueba de Chi-Cuadrado indicó que existe una relación estadísticamente significativa $\left(X_{(1)}^{2}=\right.$ $9 \cdot 36, \mathrm{p}=.002)$, donde específicamente se observa que los estudiantes de colegios particulares en su mayoría tienen un desempeño alto en el curso de matemática mientras que los estudiantes de colegios estatales se encuentran divididos entre los dos tipos de desempeño. Esto parecería indicar que hay 
diferencias en el tipo de enseñanza o tipo de evaluación que se realiza en estos colegios. Al igual que con el curso de comunicación se observan diferencias significativas en matemática $\left(X_{{ }_{(4}}{ }^{2}=\right.$ 3.95, $\mathrm{p}=.05)$, donde los estudiantes de colegios estatales tienen un desempeño significativamente más bajo que los estudiantes de los colegios particulares. Esto nuevamente indica que las diferencias educativas y de evaluación entre los colegios no solamente se limitan al curso de comunicación, sino también al curso de matemática.

\section{Discusión}

El objetivo general de la presente investigación fue determinar la asociación entre las creencias implícitas de inteligencia y el rendimiento académico de los estudiantes, dado que varios estudios han demostrado la existencia de efectos positivos en función de las teorías implícitas de inteligencia de los estudiantes sobre sus resultados académicos (Dweck, 2007). Sin embargo, los resultados de la presente investigación fueron opuestos, dado que seencontró que los alumnos con una creencia de crecimiento sobre la inteligencia presentan un bajo rendimiento en ambos cursos, mientras que los escolares con creencia fija alcanzaron un mejor desempeño en ambas asignaturas. Cabe la posibilidad de que, al corresponder las notas de los cursos a la primera parte del año escolar, el nivel de exigencia no fue altamente desafiante como para ver si las creencias incrementales y fijas presentan diferencias en su predicción del rendimiento académico (Blackwell et al., 2007).
Así también a través de investigaciones longitudinales llevadas a cabo por Dweck (2017), se determinó que luego del periodo de transición de primaria a secundaria se evidenciaba que los que poseían una creencia de crecimiento manifestaban luego de dos años de seguimiento un mejor rendimiento. Asimismo, Hong et al. (1999) comentaron que la teoría implícita posee diferentes características para los rasgos de los seres humanos por lo que una persona puede poseer un tipo de creencia para la inteligencia y otra para la asignatura de matemática. Por otro lado, es importante señalar que Hong et al. (1999), Athantic (2017) y Dweck (2017), han sugerido de alguna forma, que la razón por la cual se obtiene resultados opuesto a lo predicho por Dweck radicaría en que las creencias están aliadas a constructos o estructuras de conocimiento (atribuciones y metas). Por lo que si bien de acuerdo a lo estipulado, una creencia fija estaría conectada con una atribución negativa y a una orientación de metas al resultado, tendría un impacto negativo en el rendimiento académico: y no se daría el mismo escenario si el individuo también posee una creencia fija acerca de su inteligencia pero la vinculación hacia estas estructuras es débil o que contrariamente le dé mayor importancia al aprendizaje y al esfuerzo como haría una persona con creencia incremental acerca de su inteligencia (Dweck et al.,1995).

Por otro lado, la investigación llevada a cabo por Castella y Byrne (2015) concluyó que el creer que es posible mejorar la inteligencia no es lo mismo que el estudiante crea personalmente que puede 
mejorar su propia inteligencia. Por ende es importante mencionar que las creencias de crecimiento de la inteligencia según Dweck no se refieren solo al esfuerzo sino que precisa de otros aspectos como es el uso de estrategias nuevas y otros recursos disponibles (Dweck, 2017), de manera que el esfuerzo junto con los otros medios creen el progreso del aprendizaje, refutando la idea de que todos tenemos exactamente el mismo potencial en todos los ámbitos o que podemos aprender todo con la misma facilidad (Blackwell et al., 2007). Es así que la posesión de una creencia de crecimiento significa una real comprensión del nivel de desarrollo de las habilidades de forma realista a pesar de los obstáculos o fracasos. Es importante indicar que Dweck (2017) destaca que la creencia fija es ventajosa debido a que la convicción de querer lograr resultados implica mayor autoexigencia aunque su desventaja será no contribuir a arriesgarse a crecer de una forma más integral en diferentes ámbitos nuevos que permitan aumentar la capacidad de resiliencia y estabilice la confianza en las personas a pesar de no obtener los resultados esperados.

Asimismo, Gayón (2010) evidenció que existe una tendencia por la creencia de tipo fija en general, como se ha encontrado en este estudio. Sin embargo esta no se expresa de forma diferenciada según el sexo, tipo de creencia fija y crecencial en los tres niveles 5to, 6to de primaria y ro de secundaria, pues los resultados no fueron significativos. Lo que podría ser explicado a través del estudio de King (2019) quien refiere que el contagio social de las creencias implícitas de la inteligencia entre compañeros de clases cumple un rol determinante, pudiendo hacer a los estudiantes más susceptibles a las influencias de sus pares. Habría que decir también que el factor cultural tiene que ver en gran medida con los resultados, como lo sustentan Lammel y Guillén (2011), quienes hallaron que la percepción sobre la inteligencia, depende de diferentes realidades y las predisposiciones cognitivas del niño, estando en consonancia con lo expuesto por Dweck (200o), para quien la sociedad en general se dirige a insertar la idea de una creencia fija de la inteligencia como inmutable, pudiendo ser internalizada por los niños y por ende tendiendo a dicha creencia. Teniendo en cuenta que en nuestro país, las prácticas pedagógicas y el desenvolvimiento de los escolares muchas veces no se enfocan en los procesos sino en los resultados, pues muchos de ellos solo buscan aprobar los cursos en lugar de aprender los contenidos enseñados (Arias, 2014).

Además, se reafirmó a través de nuestro estudio lo que Dweck (2017) señala en cuanto a las diferencias en las calificaciones entre primaria y secundaria, lo que se refleja en el mejor rendimiento académico en términos generales en los escolares de 5 to y 6 to de primaria. Por ende, los estudiantes mayores obtuvieron un desempeño más bajo que los estudiantes más jóvenes, debido a que se reduce la intervención de los padres en la educación de los mayores (Sánchez et al., 2010) como ha sido probado en la presente investigación. En tal sentido, algunos desafíos en el nivel secundario se relacionan con la variedad 
de maestros y las nuevas metodologías de enseñanza que se emplean en este nivel escolar (Blackwell et al., 2007). Del mismo modo se halló que hay un mayor desempeño académico en el curso de comunicación en la mayoría de estudiantes en general, y un rendimiento más bajo en el curso de matemática. Esto último puede deberse a diversos factores tanto a nivel de logro del estudiante, pudiendo manifestar bajas expectativas académicas que poseen de ellos mismos, así como un estilo de afrontamiento poco productivo y una falta de creatividad para ser más eficaz y flexible frente a las tareas propias del curso (Lamana \& De la Peña, 2018), o la intervención del docente cuando los alumnos presentan dificultades en el aprendizaje de las matemáticas (Caciá et al., 2012).

Por otro lado, se halló que quienes reciben ayuda de la madre tienen un promedio mayor de teorías fijas que quienes no reciben ayuda de nadie. En este sentido, parece admitirse la idea de que la expectación que tenga la madre en relación al futuro educativo de su hijo es un factor decisivo en su éxito escolar, situándose incluso por encima de los ingresos económicos (Gil, 2011). Con respecto a la relación entre la dimensión de tipo de creencia sobre la inteligencia y el nivel de instrucción, se encontró que los alumnos que prevalecen en su creencia fija reciben ayuda de padres con nivel de instrucción superior incompleta, en comparación de aquellos que no reciben ayuda. Así, Fajardo, Maestre, Felipe, León del Barco y Polo del Río (2017), manifiestan que el rendimiento académico puede verse influido por las expectativas o percepciones que los padres presentan sobre las posibilidades académicas de sus hijos, de manera que es posible que las experiencias educativas de los padres se asocian con el rendimiento académico de sus hijos. Sumado al grado de instrucción de los padres, los escolares que comparten mayor tiempo con el entorno familiar y que la ocupación de la persona encargada de ayudar sea impartir un negocio propio presentan tendencia a una creencia de tipo fija. En consecuencia tal y como argumenta Dweck (1999), estas creencias son consistentes con las que se expresan en su entorno, tanto de los sistemas educativos en los que están inmersos como de sus padres y otros adultos.

Sin embargo, independientemente del estrato económico del que el escolar proviene, las creencias con respecto a la inteligencia y el rendimiento académico no se ven afectados. $\mathrm{Al}$ respecto, Cruz et al. (2014) hallaron una relación débil entre el desempeño escolar y el nivel socio económico, y destaca que el acceso a recursos materiales no define las creencias sobre la inteligencia ni su desempeño académico; sino más bien, el acompañamiento que le brindan en casa al estudiante. Además, es posible que en la medida que la sociedad validada el hecho de que una persona con bajos recursos económicos no pueda desarrollarse académicamente, se da lugar a que en esta investigación no existan diferencias en las creencias sobre la inteligencia en relación al estrato económico (Santín, 2001). 
En lo que respecta a la relación de los factores sociales con el rendimiento académico se observaron diferencias significativas, de modo que las mujeres obtuvieron un rendimiento académico superior al de los hombres en la asignatura de comunicación, coincidiendo con Barahona (2014) quien refiere que las mujeres tenderían a un mejor desempeño académico porque adquieren un comportamiento apropiado, manifestando una mayor responsabilidad y constancia. Además, se observa que aquellos estudiantes que reciben algún apoyo, sea de padre, la madre u otro adulto, tienen un mejor desempeño académico que aquellos que no reciben ayuda de nadie, al menos en el curso de comunicación. Estos resultados son similares a los hallazgos de Lastre, López y Alcázar (2018), quienes señalan que el desempeñoacadémico alto lo obtienen los alumnos que tienen acompañamiento por parte de sus padres. En relación a ello, se encontramos que las familias en las que se ayuda a veces y rara vez a los estudiantes, su desempeño académico más alto que aquellos casos en los que reciben ayuda parental frecuentemente o que no reciben ayuda en lo absoluto en el curso de comunicación. Esto indicaría que la cantidad de veces en que se ayuda al estudiante afecta su desempeño en este curso, siendo necesario moderar la cantidad de veces que el estudiante debe ser ayudado en tal asignatura. A su vez se puede observar que en las familias extensas se tienen mejores notas en comunicación mientras que las familias monoparentales tienen mayores dificultades con el desempeño en matemática. En ese sentido, Cervini, Dari y Quiroz (2014) llegaron a la conclusión de que los educandos de familias con ambos progenitores alcanzan un mejor rendimiento académico al contrario de familias monoparentales, ello se debe según López y Pibaque (2018), a que su situación familiar genera en el estudiante una escasa interacción social, viéndose perjudicado su desempeño académico mediado por el efecto de sus relaciones interpersonales. Barca, Peralbo, Porto, Marcos y Brenlla (2011) respaldan esta particularidad y la asocian a la motivación intrínseca y el aprendizaje autorregulado, como ha sido remarcado en oros estudios (Zimmerman \& Schunk, 2001).

En relación a las creencias acerca de la inteligencia en función al tipo instituciones educativas (privadas o estatales) en que estudian los alumnos, se encontró que aunque en los colegios estatales predomina una creencia de tipo crecencial, su rendimiento es aún bajo. Cabe señalar que en nuestro país los colegios estatales hacen un acompañamiento deficiente del escolar, mientras que las instituciones privadas, motivadas por la competencia institucional, suelen proporcionar mejores oportunidades de preparación académica a los estudiantes. En resumen, tenemos que en relación al análisis de los resultados y nuestro objetivo general, los alumnos con creencia fija tienen un mayor rendimiento en ambos cursos, a comparación de los escolares con creencia de crecimiento, de forma contrapuesta a lo que la Dweck (2017) propone; pero que puede explicarse por la ausencia de situaciones académicas desafiantes que destaquen la influencia del tipo de creencia en el desempeño académico así como por 
un contexto sociofamiliar que no brinda los soportes adecuados, mediados por el grado académico de los padres, su nivel socioeconómico y su acompañamiento académico, así como por la calidad de la enseñanza recibida en las instituciones educativas. Por ello, se puede concluir que existe una predominancia por la creencia de tipo fija como consecuencia de las percepciones del niño sobre la inteligencia, su contexto cultural y la influencia de los padres.

Por todo lo señalado, se recomienda continuar con investigaciones en el campo de la psicología educativa ya que ello favorecen a la educación peruana y por ende a nuestro país que tanto requiere de mejoras basadas en evidencias científicas. En efecto, es fundamental que principalmente en esta rama de la psicología, se promueva la aplicación de estos hallazgos mediante diversos recursos psicológicos, educacionales y psicopedagógicos.

\section{Financiamiento}

El estudio fue autofinanciado.

\section{Conflictos de interés}

Las autoras declaran que no tienen conflictos de interés. 


\section{Referencias}

Abd- El- Fattah, S., \& Yates, G. (2006). Implicit Theory of Intelligence Scale. Testing for factorial invariance and mean structure. Paper presentedo en la Australian Association for Research in Education Annual Conference. https://pdfs.semanticscholar.org/o4cd/374aa46ef5d5of6949fe31c463fi83bf2759.pdf

Álvarez, F. (2012). Diferencias en la calidad de educación e ineficiencia: Un análisis basado en el método de frontera estocástica. Documentos de Trabajo (pp. 1-25). CAF https://scioteca.caf.com/bitstream/handle/123456789/242/diferencias_calidad_educacion_ineficiencia_metodo_frontera_estocastica.pdf

Aparicio, M., Cala, M., \& Adarve, S. (2010). Teorías implícitas de la inteligencia en estudiantes de quinto a séptimo grado de un colegio del municipio de Girón, Santander. II Congreso Internacional de Investigación y Práctica Profesional en Psicología (pp. 312-314). https://www.aacademica.org/ooo-031/417.pdf

Arias, W. L. (2013). Teoría de la Inteligencia: una aproximación neuropsicológica desde el punto de vista de Lev Vigotsky. Cuadernos de Neuropsicología, 7(1), 22-37. http//:doi.org/10.7714/cnps/7.1.201

Arias, W. L. (2014). Estilos de aprendizaje e inteligencia en estudiantes universitarios de Arequipa (Perú). Journal of Learning Styles, 7(14), 88-107. http://learningstyles. uvu.edu/index.php/jls/article/view/201/175

Asociación Peruana de Empresas de Investigación de Mercado (2013). Aspectos metodológicos. http://apeim.com.pe/

Aronson, J., Fried, C. B., \& Good, C. (2002). Reducing the Effects of Stereotype Threat on African American College Students by Shaping Theories of Intelligence. Journal of Experimental Social Psychology, 38(2), 113-125. http://dx.doi.org/10.1006/ jesp.2001.1491

Backhoff, E., Sánchez M., Peón M. \& Andrade, E. (2010). Comprensión lectora y habilidades matemáticas de estudiantes de educación básica en México: 2000-2005. Revista Electrónica de Investigación Educativa, 2(1) 1-15. https://redie.uabc.mx/ redie/article/view/242/738

Barahona, P. (2014). Factores determinantes del rendimiento académico de los estudiantes de la Universidad de Atacama. Estudios Pedagógicos, 40(1), 25-39. http://dx.doi.org/10.4067/So718-07052014000100002 
Barca, L. A., Peralbo, U. M., Porto, R. A., Marcos, M. J. L., y Brenlla, B. J. C. (2011). Metas académicas del alumnado de Educación Secundaria Obligatoria (ESO) y Bachillerato con alto y bajo rendimiento escolar. Revista de Educación, 354, 341-368.

BBC. (2016). Los países de América Latina “con peor rendimiento académico". http:// www.bbc.com/mundo/noticias/2016/o2/160210_paises_bajo_rendimiento_educacioniinforme_ocde_bm

Berríos, C. (2018). Docentes y sus creencias sobre la inteligencia: ¿Están en sintonía con las discusiones actuales? Castalia, 4(30), 68-78. https://doi. org/10.25074/o7198051.30.911

Binet. A., \& Simon, T. (1916). The development of intelligence in children. Williams \& Wilkins.

Blackwell, L., Trzesniewski, K. \& Dweck, C. (2007). Implicit theories of intelligence predict achievement across and adolescent transition: A longitudinal study and intervention. Child Development, 78(1), 246-263. https://doi. org/10.1111/j.1467-8624.2007.00995.X

Boullosa, G. (2014). Teorías Implícitas sobre la evaluación de los aprendizajes que poseen los docentes de arquitectura de una universidad privada en Lima. (Tesis para optar por el grado de Magíster en Educación). Pontificia Universidad Católica del Perú, Lima, Perú. http://tesis.pucp.edu.pe/repositorio/bitstream/ handle/20.500.12404/5499/BOULLOSA_RIVAS_GLORIA_TEORIAS_DOCENTES. pdf? sequence $=1 \&$ isAllowed $=\mathrm{y}$

Byrnes, J. (1996). Cognitive development and learning in instructional context. Allyn \& Bacon.

Caciá, D., Reyes, M., Rosales, C., \& Marroquín, E. (2012). Factores que inciden en el rendimiento en matemática de niñas y niños del primer ciclo del nivel de educación primaria en escuelas públicas de Guatemala. https://intercoonecta.aecid. es/Gestin\%2odel\%2oconocimiento/Informe\%2oFinal\%2oInvestigacion\%20 en\%2oMatematicas.pdf

Capital (31 de marzo del 2015). ¿Son realmente los colegios privados mejores que los públicos en Perú? https://capital.pe/actualidad/son-realmente-los-colegios-privados-mejores-que-los-publicos-en-peru-noticia-783304 
Camacho, K. (2011). Teorías implícitas de la inteligencia en Docentes de la Universidad Pontificia Bolivariana. (Tesis para optar por el título de psicología). Universidad Pontificia Bolivariana, Medellín, Colombia. https://repository.upb.edu.co/ bitstream/handle/20.500.11912/1153/digital_20765.pdf?sequence=1\&isAllowed=y

Carpintero, E., Cabezas, D., González, C., \& Fernández, P. (2003). Análisis de las teorías implícitas de la inteligencia en alumnos de educación primaria. EduPsykhé, 2(1), 81-105. https://dialnet.unirioja.es/descarga/articulo/1075778.pdf

Cervini, R., Dari N., \& Quiroz, S. (2014). Estructura familiar y rendimiento académico en países de América Latina: Los datos del Segundo Estudio Regional Comparativo y Explicativo. Revista Mexicana de Investigación Educativa, 19(61), 569-597. http:// www.scielo.org.mx/scielo.php?script=sci_arttext\&pid=S1405-66662014000200010

Correo (21 de octubre 2013). Colegios privados versus nacionales. https://diariocorreo. pe/peru/colegios-privados-versus-nacionales-71949/?ref=dcr

Correo (29 de enero de 2019). Años escolar 2019: se terminó calificación del o al 20. https://diariocorreo.pe/edicion/lima/ano-escolar-notas-en-libretas-de-secundaria-seran-letras-y-ya-no-numeros-867559/

Cruz, Z., Medina, J., Vázquez, J., Espinosa, E., \& Antonio, A. (2014). Influencia del nivel socioeconómico en el rendimiento académico de los alumnos del programa educativo de ingeniería industrial en la Universidad Politécnica de Altamira. En G.Nélida, G. Santamaria, L. Almaza (Coords.). Manual de Ciencias Administrativas y Sociales (pp. 24-38). https://dialnet.unirioja.es/servlet/articulo? codigo $=4887110$

Cuenca, R., Carillo, S., De los Rios, C., Reátegui, L., \& Ortiz, G. (2017). La calidad y equidad de la educación secundaria en el Perú. Institutos de Estudios Peruanos. http://repositorio.iep.org.pe/bitstream/IEP/923/1/Cuenca-Ricardo_CalidadEquidad-Educacion-Secundaria.pdf

De Castella, K., \& Byrne, D. (2015). My intelligence may be more malleable than yours: the revised implicit theory of intelligence (self-theory) scale is a better predictor of achievement, motivation, and student disengagement. European Journal of Psychology of Education, 30(3), 245-267. https://doi.org/10.1007/s10212-015-0244-y

Dongo, M. (2009). Significado de los factores sociales y culturales en el desarrollo cognitivo. Revista de Investigación en Psicología, 2(2), 227-237. https://doi. org/10.15381/rinvp.v12i2.3767 
Dweck, C. S. (1975). The role of expectations and attributions in the alleviation of learned helplessness. Journal of Personality and Social Psychology, 31, 674-685.

Dweck, C. (1986). Motivational processes affecting learning. American Psychologist, 41, 1040-1048. http://dx.doi.org/10.1037/0003-066X.41.10.1040

Dweck, C. S. (1999). Self-theories: Their role in motivation, personality, and development. Essays in social psychology. Psychology Press.

Dweck, C.S. (2002). Messages that motivate: How praise molds students' beliefs, motivation, and performance (In Surprising Ways). En J. Aronson (Ed.), Improving academic achievement. Academic Press.

Dweck, C. S. (2007). La actitud al éxito. Ediciones Vergara.

Dweck, C. S. (2017). Mindset: How you can fulfill your potential. Kindle.

Dweck, C. S., Chiu, C., \& Hong, Y. (1995). Implicit Theories: Elaboration and Extension of the Model. Psychological Inquiry, 6(4), 322-333. https://doi.org/10.1207/ s15327965plio6o4_12

Dweck, C. S., \& Elliott, E. S. (1983). Achievement Motivation. En P. H. Mussen (Gen. Ed.), \& E. M. Hetherington (Ed.), Handbook of Child Psychology Vol. 4, (pp. 643-691). Wiley.

Dweck, C. S., \& Legget, E. (1998). A social cognitive approach to motivation and personality. Psychological Review, 95, 256-273. https://doi.org/10.1037/0033-295X.95.2.256

Dweck, C. S., \& Reppucci, N.D. (1973). Learned helplessness and reinforcement responsibility in children. Journal of Personality and Social Psychology, 25, 109-116.

Elliot, A., Harackiewicz, J., Barron, K. Pintrich, P., \& Thrash, T. (2002). Revision of achievement goal theory: Necessary and Illuminating. Journal of Education Psychology, 94(3), 638-645. https://doi.org/10.1037/oo22-0663.94.3.638

El Comercio (3 de diciembre 2016). Prueba PISA: casi 80\% de estudiantes latinoamericanos tienen bajo nivel en lectura y matemáticas. https://elcomercio.pe/ mundo/prueba-pisa-casi-8o-de-estudiantes-latinoamericanos-tienen-bajo-nivel-en-lectura-y-matematicas-nndc-noticia/?ref=ecr 
Escudero, E., Moguel, A., Zapata, M., \& Muñoz, E. (2010). Comprensión lectora y habilidades matemáticas de estudiantes de educación básica en México: 20002005. Revista Electrónica de Investigación Educativa, 12(1). https://redie.uabc. $\mathrm{mx} /$ redie/article/view/242/738

Ellis, J. (2005). Aprendizaje Humano. 4ta Edición. Pearson Educación.

Fandiño, Y. J. (2008). Una enseñanza e investigación inteligentes de la inteligencia para el éxito escolar y el éxito en la vida cotidiana. Revista Iberoamericana de Educación, 46(9), 1-12. https://rieoei.org/RIE/article/view/1881

Figueroa C. (2004). Sistemas de evaluación académica. El Salvador.

Flores, G., Contreras L., \& Backhoff, E. (2006). Traducción y adaptación de pruebas: lecciones aprendidas y recomendaciones para países participantes en TIMSS. PISSA y otras comparaciones internacionales. Revista Electrónica de Investigación Educativa, 8, (2). https://redie.uabc.mx/redie/article/view/143/245

Galvis, M., Cala, M., \& Adarve S. (2010). Teorías implícitas de la inteligencia en estudiantes de quinto a séptimo grado de un colegio del Municipio de Girón, Santander. II Congreso Internacional de Investigación y Práctica Profesional en Psicología XVIIJornadas de Investigación Sexto Encuentro de Investigadores en Psicología del MERCOSUR. Recuperado de: https://www.aacademica.org/ooo031/417.pdf. El 23 de octubre del 2019.

García L. (2016). Nivel socioeconómico y rendimiento académico: estudiantes resilientes. (Tesis doctoral en Psicología). Universidad Complutense de Madrid, España. https://eprints.ucm.es/38862/1/T37677.pdf. El 23 de octubre del 2019

Gayón, L. (2010). Relación entre las teorías implícitas de la inteligencia de padres e hijos y rendimiento académico. (Tesis para optar el grado de psicóloga). Universidad Pontificia Bolivariana, Medellín, Colombia. https://repository.upb.edu.co/ bitstream/handle/20.500.11912/826/digital_19151.pdf?sequence=1\&isAllowed=y

Gestión (3 de diciembre del 2016). Perú mejora en prueba PISA 2018, pero sigue último entre los países de la región. https://gestion.pe/peru/peru-mejora-en-prueba-pisa-2018-pero-sigue-ultimo-entre-los-paises-de-la-region-nndc-noticia/?ref=gesr.

Gross-Loh, C. (2019). Don't Let Praise Become a Consolation Prize. [online] The Atlantic. https://www.theatlantic.com/education/archive/2016/12/ how-praise-became-a-consolation-prize/510845/ 
Hernández, R., Fernández, C., \& Baptista, P. (2010). Metodología de la investigación.

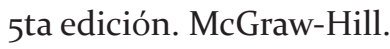

Horn, J. L. (1965). Fluid and crystallized intelligence: A factor analytic study of the structure among primary mental abilities. [Tesis para obtener el grado de Doctor en Psicología] University of Illinois, USA.

Horn, J. L., \& Cattell, R. B. (1966). Refinement and test of the theory of fluid and crystallized general intelligences. Journal of Educational Psychology, 57, 253-270.

Horn, J. L., \& Cattell, R. B. (1967). Age differences in fluid and crystallized intelligence. Acta Psychologica, 26, 107-129.

Hoyos R. (2016). Niveles socioeconómicos y motivación en la elección de la carrera profesional en estudiantes preuniversitarios. (Tesis para optar el grado de Maestra en Psicología). Universidad San Martín de Porres, Lima, Perú. http://www.repositorioacademico.usmp.edu.pe/bitstream/usmp/2320/1/hoyos_drg.pdf

King, R. B. (2019). Mindsets are contagious: The social contagion of implicit theories of intelligence among classmates. British Journal of Educational Psychology. 9o(2), 349-363. https://doi.org/10.1111/bjep.12285

Krakovsky, M. (2019). The Effort Effect: According to a Stanford psychologist, you'll reach new heights if you learn to embrace the occasional tumble. https://stanfordmag.org/contents/the-effort-effect

Kurtz-Costes, B., McCall, R.J., Kinlaw, C.R., Wiesen, C.A., \& Joyner, M.H. (2005). What does it mean to be smart? The development of children's beliefs about intelligence in Germany and the United States. Applied Developmental Psychology, 26, 217-233. http://dx.doi.org/10.1016/j.appdev.2004.12.005

Lamana, M., \& De la Peña, C. (2018). Rendimiento académico en matemáticas. Relación con creatividad y estilos de afrontamiento. Revista Mexicana de Investigación Educativa, 23(79), 1075-1092. http://www.scielo.org.mx/pdf/rmie/v23n79/14056666-rmie-23-79-1075.pdf

Lammel A., \& Guillén E. (2011). Las concepciones implícitas de la inteligencia contextos culturales. Diferentes (México y Francia). Revista Electrónica de Psicología Iztacala, 14(2) 15-19. http://www.medigraphic.com/pdfs/epsicologia/epi-2011/ epi112b.pdf 
Lastre, K., López, L., \& Alcázar, C. (2018). Relación entre apoyo familiary el rendimiento académico en estudiantes colombianos de educación primaria. Psicogente, 21(39), 102-115. http://www.scielo.org.co/pdf/psico/v21n39/o124-0137-psico-21-39-00102. pdf

Linares A. (2008). Desarrollo Cognitivo: Master en paidopsiquiatría. Módulo 1: Las teorías de Piaget y Vygotsky. Universidad Autónoma de Barcelona. http://www. paidopsiquiatria.cat/files/teorias_desarrollo_cognitivo_o.pdf

López, P., \& Pibaque, M. (2018). Familias monoparentales y el desarrollo social en los adolescentes. Revista Científica Dominio de las Ciencias, 4(3), 152-162. 10.23857/ dc.v4i3.799

Macías, M. A. (2002). Las múltiples inteligencias. Psicología desde El Caribe, 10, 27-38. https://www.redalyc.org/pdf/213/21301003.pdf

Makuc, M. (2011). Teorías implícitas sobre comprensión textual y la competencia lectora de estudiantes de primer año de la Universidad de Magallanes. Revista Signos, 48(87), 29-53. https://www.redalyc.org/pdf/1570/157036980oo2.pdf

Marchago, J. (1989). El profesor y el autoconcepto de los alumnos. Escuela Española.

Ministerio de Educación del Perú (2017). Currículo Nacional de la Educación Básica. http://www.minedu.gob.pe/curriculo/pdf/consulta-virtual-del-curriculo-nacional.pdf

Montero, I., \& León, O. (2007). A guide for naming research studies in Psychology. International Journal of Clinical and Health Psychology, 7, 847-862.

Muñiz, J., \& Hambleton. (1996). Directrices para la traducción y adaptación de test. Papeles de Psicólogo, 66. http://www.papelesdelpsicologo.es/resumen?pii=737

Nicholls, J. (1983) Conceptions of ability and achievement motivation: a theory and its implications for education. En S. Paris, G. Olsen, H., Stevenson (Eds.), Learning and motivation in the classroom. Erlbaum.

Noack, E. M. (2018). Uso de Técnicas de mentalidad de crecimiento y su impacto en el rendimiento académico de los estudiantes de grado uno de un colegio privado de la ciudad de Guatemala. (Tesis de grado) http://recursosbiblio.url.edu.gt/ tesiseortiz/2018/o5/83/Montenegro-Erika.pdf 
OCDE (2013). Education at a Glance 2013 OECD indicators. http://www.oecd.org/ education/Panorama\%2ode\%2ola\%2oeducacion\%202013.pdf

Olmeda, L. (2016). Nivel socioeconómico y rendimiento académico: Estudiantes resilientes. [Tesis para optar por el grado de Doctora en Psicología]. Universidad Complutense de Madrid, España. https://eprints.ucm.es/38862/1/T37677.pdf

Peña, A. (2015). Ganadores y perdedores: fecha de nacimiento, edad relativa en la escuela, y los resultados en la infancia y la edad adulta. http://ntrzacatecas.com/2015/11/15/ influye-la-edad-de-alumnos-en-su-rendimiento-escolar-revela-estudio/

Romagnoli, C., \& Cortese, I. (2015). ¿Cómo la familia influye en el aprendizaje y rendimiento escolar? Valoras. www.valoras.uc.cl

Rodríguez, J. (2015). El rendimiento escolar y la intervención del trabajo social. Universidad de Cuenca.

Sánchez, P., Valdés, A., Reyes, N., \& Martínez, E. (2010). Participación de padres de estudiantes de educación primaria en la educación de sus hijos en México. Liberabit, 16(1), 71-80.

Santín D. (2001). Influencia de los factores socioeconómicas en el rendimiento escolar internacional: hacia la igualdad de oportunidades educativas. http://eprints. ucm.es/6725/1/o101.pdf

Spearman, C. (1904). "General intelligence”, Objectively determined and measured. American Journal of Psychology, 15, 201-293. https://doi.org/10.2307/1412107

Soto, M., Da Cuña, I., Lantarón, M., \& Labajos, T. (2015) Influencia de las variables sociodemográficas y socioeducativas en el rendimiento académico de alumnos del Grado en Fisioterapia. FEM: Revista de la Fundación Educación Médica, 18(6), 397-404. https://doi.org/10.4321/s2014-98322015000700007

Stromso, H., \& Braten, I. (2004). Epistemological beliefs and implicit theories of intelligence as predictors of achievement goals. Contemporary Educational Psychology, 29, 371-388. https://doi.org/10.1016/j.cedpsych.2003.10.001

Sulmont, L. (2018). Implementación sistemática en las escuelas de las expectativas de aprendizaje y enseñanza para alumnos y docentes. AD MESTRO, 1(3), 14-17. 
Tarbetsky, A., Collie. R., \& Martin, A. (2016). The role of implicit theories of intelligence and ability in predicting achievement from indigenous Australian students. Contemporary Educational Psychology, 47, 61-71. https://doi.org/10.1016/j. cedpsych.2016.01.002

Tomás, J., \& Almenara, J. (2008). Desarrollo cognitivo: Las teorías de Piaget y de Vygotsky. Master en Paidopsiquiatria. Universidad Autónoma de Barcelona. http://www.paidopsiquiatria.cat/files/teorias_desarrollo_cognitivo_o.pdf

UNESCO (2015). Informe de resultados TERCE: Tercer estudio regional comparativo y explicativo. Logros de aprendizaje. https://unesdoc.unesco.org/ark:/48223/ pfoooo243532

Universidad de Internacional de Valencia. (2015). Influencia de los factores sociales y familiares en el bajo rendimiento. https://www.universidadviu.es/influencia-de-los-factores-sociales-y-familiares-en-el-bajo-rendimiento-en-el-aprendizaje/

Vélez, E., Schiefelbein, E., \& Valenzuela, J. (1994). Factores que afectan el rendimiento académico en la educación primaria. Revisión de la literatura de América Latina y el Caribe. Revista Latinoamericana de Innovación de América Latina, 17, 29-53. http://disde.minedu.gob.pe/bitstream/handle/123456789/4317/ Factores\%2oque\%2oafectan\%2oel\%2orendimiento\%2oacad\%C3\%A9mico\%20 en\%2ola\%2oeducaci $\% \mathrm{C}_{3} \%$ B3n\%2oprimaria\%2orevisi $\% \mathrm{C}_{3} \%$ B3n\%2ode $\% 20$ la\%2oLiteratura\%2ode\%2oAm\%C3\%Agrica\%2oLatina\%2oy\%2oEl\%2oCaribe. pdf? sequence $=1 \&$ isAllowed $=\mathrm{y}$

Vera, F., \& Vera, O. (2013). Evaluación del nivel socioeconómico: presentación de una escala adaptada en una población de Lambayeque. Revista del Cuerpo Médico Hospital Almanzor Aguinaga Asenjo, 6(1). https://dialnet.unirioja.es/servlet/ articulo? codigo $=4262712$

Villamizar, G. (2011). Teorías implícitas de la inteligencia en el ámbito pedagógico. Revista Psicogente, 14(26), 321-335. http://oaji.net/articles/2017/1787-1485448348. pdf

Wang, Q., \& Fei-YinNg F. (2012). Chinese students' implicit theories of intelligence and school performance: Implications for their approach to schoolwork. Personality and Individual Differences, 52(8), 930-935. https://doi.org/10.1016/j.paid.2012.01.024

Woolfolk, A. (2010). Psicología educativa. Pearson Educación. 
Yeager, D.S., \& Dweck, C.S. (2012). Mindsets that promote resilience: When students believe that personal characteristics can be developed. Educational Psychologist, 47(4), 302-3014. https://doi.org/10.108o/00461520.2012.722805

Zapata, M. (2017). Teorías y modelos sobre los aprendizajes en entornos conectados y ubicuos. Bases para un nuevo modelo teórico a partir de una visión crítica del "conectivismo". Education in the knowledge Society, 16(1), 69-102. https://doi. org/10.14201/eks201516169102

Zegarra, C. D. (2013). Aspiraciones educativa y ocupacional de jóvenes: un estudio mixto sobre el rol del nivel socioeconómico y la percepción de barreras. [Tesis para optar por el título de Psicología con mención en Psicología Educacional]. Pontificia Universidad Católica del Perú, Lima, Perú. http://tesis.pucp.edu.pe/ repositorio/handle/20.500.12404/4840

Zimmerman, B. J., \& Schunk, D. H. (2001) Self-Regulated Learning and Academic Achievement: Theoretical Perspectives. Lawrence Erlbaum Associates.

Recibido: 25 de junio de 2020

Revisado: 8 de octubre de 2020

Aceptado: 12 de marzo de 2021 
Rev. Psicol. (Arequipa. Univ. Catól. San Pablo) / Año 2021 / Vol 11 / N 1 / pp. 101-126 ISSN 2306-0565 versión impresa / ISSN 2311-7397 versión on line

\title{
Presencia de berrinches en niños y niñas de 2 a 3 años
}

\author{
Presence of Tantrums in Boys and Girls from 2 to 3 Years of Age
}

\author{
Fabiola Stefany Tito Abado \\ Institución Educativa Víctor García Hoz, Arequipa Perú \\ (D) https://orcid.org/oooo-0oo1-7523-124X \\ Paola Arlette Cáceres Gallegos \\ Institución Educativa Víctor García Hoz, Arequipa Perú \\ (iD https://orcid.org/oooo-ooo1-7518-8878 \\ Charles Portilla Revollar \\ Universidad Católica de Santa María, Arequipa, Perú \\ (iD https://orcid.org/oooo-0oo3-2866-0695 \\ Correspondencia: charlesprı@hotmail.com
}

\section{Resumen}

Se investigó la incidencia y características de berrinches en niños y niñas de 2 y 3 años pertenecientes a los 8 distritos más populosos de Arequipa, Perú. Participaron 284 niños y 271 niñas $(N=555)$, 183 de 2 años ( 96 niños y 87 niñas); 372 de 3 años (188 niños y 184 niñas). El diseño fue descriptivo correlacional. Por medio de las instituciones educativas fueron enviadas 1,325 "encuestas" a las familias; el índice de retorno fue del $42 \%$ (555). Se aplicó una Ficha de Reporte de Conductas (que incluía datos demográficos) donde se identificaban y describían los berrinches preparada por los investigadores. Se encontraron 431 casos con berrinches y 124 casos sin berrinches, la incidencia es alta considerándose que es una muestra comunitaria. No se encontraron diferencias estadísticamente significativas de berrinches y género; sí se halló significativamente mayor intensidad de berrinches en los niños; los berrinches se caracterizaron por presencia de llanto, gritos, arrojar juguetes y tirarse al suelo. Las causas básicas fueron negación de petición de objetos y realización de acciones deseadas. La estrategia más común para detenerlos fueron tratar de calmarlos y cargarlos en brazos. Palabras clave: Berrinches, infancia, niños, niñas. 


\begin{abstract}
Was investigated the incidence and characteristics of tantrums in boys and girls between 2 and 3 years, belonging to 8 districts more populous of Arequipa, Peru. Participated 248 boys and 271 girls $(N=555,183$ were 2 years ( 96 boys and 87 girls) and 372 were 3 years old (188 boys and 184 girls). De design was descriptive correlational, 1325 surveys were sent to the families through schools, the returns percentage was $42 \%$ (555). Was applied a Report Card to describe demographic characteristics, identify and describe characteristics of tantrums prepared by the researchers. Were found 431 cases with tantrums and 124 cases without tantrums, the incidence is high because is a community sample. It was not found significant differences on incidence tantrums between boys and girls; however there is a statistically significant difference between intensity of tantrum, with children presenting the highest intensity of tantrums, unlike girls. The characteristics of tantrums were crying, screams, throw toys and fall to the ground. The basic causes were request of objects and activities denied. The used strategies were calm down and carry him in arms.
\end{abstract}

Keywords: Tantrums, childhood, boys, girls.

\section{Introducción}

El desarrollo socioemocional temprano es una habilidad que emerge formando cercanas y seguras relaciones con padres y compañeros, cuyas experiencias regulan paulatinamente la expresividad de las emociones de formas que son aceptadas social y culturalmente. Parte fundamental de la crianza es el control de las emociones, y su desarrollo está influenciado por factores biológicos y experiencias personales (Darling-Churchil \& Lippman, 2016; Papalia et al., 2001). Desde el nacimiento hasta los 5 años, los niños sientan las bases del desarrollo socioemocional que les permiten expresar sus emociones de manera apropiada hasta que llegan a ser independientes y confortables para explorar sus alrededores (Askeland, 2019. De acuerdo con Ashdown y Bernard (2011) y Thompson (2018), en los tres primeros años de vida los niños alcanzan logros fundamentales en el desarrollo socioemocional. Ellos logran un apego seguro con sus cuidadores, estableciendo las bases de la certeza y seguridad de ser protegidos, alimentados y apoyados emocionalmente, lo cual favorece el desarrollo de la competencia social con sus pares y otros adultos. Los niños empiezan a experimentar un amplio rango de emociones junto a la comprensión cada vez más amplia de los sentimientos e intenciones de los otros, los infantes también hace significativos progresos en la conciencia social y autorregulación de sus emociones e impulsos, aunque todavía les falta un largo camino.

El desarrollo emocional se inicia mediante expresiones básicas como agrado y desagrado, incluso en las primeras investigaciones se refería que los infantes nacían con sólo una emoción vivenciada llamada angustia (Tortosa \& Mayor, 1992). Sin embargo, ahora se conoce que al juzgar 
sus expresiones faciales se pueden identificar distintos tipos de emociones como la alegría, tristeza, interés, miedo e ira. Dentro de las emociones principales se acepta que esta última es una de ellas y se presenta generalmente cuando los infantes se sienten obstaculizados en la satisfacción de sus deseos, los problemas sociales y emocionales tales como frustración, ansiedad y depresión; generalmente relacionados con el rendimiento académico y la aceptación social (Bee, 1992; Rice, 1997; Romano et al., 2010).

Los niños y niñas desde que nacen presentan diferencias en sus reacciones, si bien la explicación parece estar en la forma en que las madres o adultos tratan a los infantes, hay respuestas emocionales que siguen con frecuencia patrones que persisten a través de los años, lo que indica que el temperamento básico es innato (California Childcare Health Program, 2006). En la investigación conocida como el estudio longitudinal de Nueva York (ELNY) Thomas et al., 1970) distinguieron tres patrones temperamentales básicos: niños fáciles, niños difíciles, y niños poco afectuosos.

\section{Los Berrinches}

La vida siempre está acompañada de momentos de ira, ésta es una motivación poderosa y ocasiona molestia, decepción y frustración que es expresada de distintas formas de acuerdo con su edad y temperamento, siendo una de estas expresiones el berrinche (Daniels et al., 2012; Eastman \& Rozen, 2001). En estas ocasiones se descarga el sistema de energía acumulada ante situaciones no aceptadas por el niño, generando que el cuerpo como el estado mental se agiten y tomen la forma de ansiedad y hostilidad, buscando la satisfacción de necesidades frustradas. Eastman y Rozen (2001), y más recientemente Solter (2020), refieren que los berrinches o rabietas son expresiones de ira y enojo propios de la inmadurez del desarrollo emocional, considerándose así, como una forma normal de expresar sentimientos negativos. Por tanto, los berrinches como expresión de ira o enojo pueden ser considerados como formas normales de manifestar sentimientos dolorosos o negativos; pero cuando estas manifestaciones son muy frecuentes e intensas podemos necesitar ayuda especializada para manejarlas. Green et al. (2011) encontraron que no sólo la emoción de la ira se asocia al berrinche, sino también la tristeza, y que los berrinches son una ventana para conocer cómo se expresan y regulan las emociones fuertes. Estos investigadores encontraron que las rabietas son difíciles de manejar una vez que se presentan por la intensa carga emocional que representan y que cuando son excesivos y persisten en el tiempo, pueden predecir futuros desajustes y aún desordenes psicológicos. Dado que son manifestaciones que nos permiten conocer algunas características de las expresiones emocionales, constituyen un fenómeno que debe ser estudiado por la ciencia. Para Davison (2003) y Osterman y Bjorkqvist (2010), los berrinches son definidos por sus manifestaciones conductuales físicas (tirarse al suelo, golpear) y manifestaciones conductuales vocálicas (llorar y 
gritar), donde las agresiones verbales no son usualmente sofisticadas.

El estudio de los berrinches de forma sistematizada fue realizado desde hace largo tiempo, pues ya Goodenough en 1931 (citado por Green et al., 2011) escribió una monografía sobre el enojo en la niñez donde describe las características de los berrinches entre los seis meses y ocho años. Kanner (1935) por su parte, reporta que los berrinches son uno de los malos hábitos más frecuentes y representan el $16 \%$ de los requerimientos en la consulta. De igual manera Geleerd (1944) presentó una investigación afirmando que no había buenas definiciones sobre los berrinches y recomienda que la mejor manera de manejarlos era dejar al niño solo hasta que se calme, pero si el niño tiene tendencia a destruir cosas es mejor que sea removido del lugar, aunque en general afirma que los berrinches no deben ser manejados con firmeza.

La American Academy of Pediatrics (1989) refiere que frecuentemente los niños y niñas tienen berrinches cuando se sienten frustrados consigo mismos. Las frustraciones pueden provenir de diferentes situaciones o eventos, y generalmente los padres y madres no entienden lo que desea. Las explosiones de ira se presentan en todas las edades, en niños y adultos, sólo quea medida que maduramos, vamos aprendiendo a canalizar esa ira con expresiones más acordes con las expectativas del entorno social. Alrededor de los dos años se descubre una manera de descargar el sistema de energía acumulada ante situaciones no aceptadas por el niño, y su cuerpo y su estado mental se agitan tomando la forma de ansiedad y hostilidad, buscando la satisfacción de necesidades frustradas. Si bien se acepta que los berrinches son bastante comunes en los primeros años, plantean un reto para los padres, madres, profesores y personas de su entorno.

Osterman y Bjorkqvist (2004) encontraron en Finlandia, que en el $87 \%$ de los hijos cuyos de padres y madres fueron entrevistados, habían tenido berrinches en algún momento y que el tiempo de duración más frecuente fue entre los $5 \mathrm{y}$ 10 minutos; pero que berrinches de más de media hora se presentaron en solo el $6 \%$ de los casos. Además, el lugar más frecuente donde se presentaban era en el hogar a la hora de vestirlos y/o alimentarlos, el segundo lugar más común fue en los vehículos cuando los transportaban a algún sitio. Parece ser que los berrinches en la niñez se presentan en diversas culturas, por ejemplo, en el pueblo amazónico peruano de los Matsigenkas se describe la presencia de berrinches en los niños (Johnson, 2003, citado por Osterman \& Bjorkqvist, 2004). Igualmente, en descripciones del folklore antiguo de Japón se relatan berrinches en la niñez (Tomm et al., 1990, citados por Osterman \& Bjorkqvist, 2004). Aún más, de Waal (200o, citado por Osterman y Bjorkqvist, 2004) refiere que conductas similares a los berrinches han sido observados en chimpancés.

\section{Características de los Berrinches}

La frustración, decepción o enojo se suelen expresar mediante el llanto, 
gritos, pataletas y hasta agresiones, sobre todo entre los 18 meses hasta los tres años (American Academy of Pediatrics, 1989), todo lo cual aparenta una conducta exagerada, fuera de proporción, aunque comunes en la niñez (Mireault \& Trathan (2007). En el pasado, Kanner (1935) refería que los berrinches se caracterizan principalmente por inicio rápido o gradual de llanto a gritos y zapateo, expresiones de insultos en voz alta, patear el suelo, agitar los brazos, empujar o golpear a las personas del entorno próximo, arrojar objetos, tirarse al suelo y golpearse a sí mismo la cabeza contra las paredes u otro objeto.

Los berrinches pueden considerarse un problema cuando son demasiado frecuentes (varias veces a la semana), son demasiado intensos (llanto exagerado, resistencia a calmarse), están cargados de alta agresividad, duran demasiado tiempo (más de 5 minutos); provoca agresiones, perjudican las relaciones familiares, escapan del control de los cuidadores y hacen daño a otras personas (Eastman \& Rozen, 2001).

Potegal y Davidson (2003) indican que los berrinches oscilan entre los más frecuentes, cuando solo hay llanto exagerado y los menos frecuentes, que llaman la atención, cuando el llanto es acompañado de retención de la respiración, golpearse la cabeza, enrojecimiento de mejillas, dilatación de los ojos y hasta vómitos. Estas reacciones desafortunadamente son frecuentes en la niñez y son una de las quejas más comunes de los padres y madres; por lo tanto, los berrinches intensos pueden ser clasificados dentro de los desórdenes de conducta externalizados. Según Potegal y Davidson (1998) las divergencias sobre si los berrinches son normales en la niñez o si son un aviso de posibles problemas posteriores, implican la identificación algunos factores psicosociales asociados a berrinches extremos tales como enfermedades menores, castigo corporal, depresión materna y clase social pobre.

Potegal etal. (2003) aseveran que la frecuencia de los berrinches es de uno por día y se presentan sobre todo cuando los niños y niñas están cansados, hambrientos, perturbados o indispuestos; aunque inclusive padres y madres experimentados no siempre pueden prevenir berrinches ocasionales. Además, la frecuencia e intensidad de los berrinches varían de acuerdo con el ambiente donde esté el niño, aunque la mayoría de los berrinches se presentan en el hogar. Ellos encontraron que en los leves la duración más común de los berrinches fue de 0.5 a 1 minuto, sobre todo cuando en los 30 segundos iniciales zapatea y se tira al suelo; pero en el $75 \%$ de los berrinches intensos la duración fue entre 1.5 a 5 minutos; considerando que el número yvariedad de conductas del berrinche aumenta si el berrinche tiene más duración. Si el berrinche persiste más allá de los 3 a 4 minutos, la mayoría de las conductas de berrinche son repeticiones o continuaciones de las conductas ya presentadas. Estos investigadores no encontraron relación entre la intensidad de los berrinches y la ansiedad o pánico de los padres.

Belden et al. (2008) afirman que el 70 $\%$ de los niños entre la edad de 18 y 60 meses presentan berrinches, y que 
las características de los berrinches varían de acuerdo con la relación con depresión, problemas de conducta o conducta saludable. Los investigadores refieren que en los niños preescolares que tengan un promedio de 10 a 20 berrinches en un periodo de 30 días, pueden ser indicadores de tener un problema clínico serio; igualmente si no es capaz de calmarse por sí mismo cuando los episodios son más allá de los 25 minutos. Además, si están asociados a manifestaciones depresivas y otros problemas de conducta.

Novotney (2012) encontró que los berrinches sólo se presentan en menos del 10 $\%$ de la población en edad preescolar, sin importar el género, nivel socioeconómico o etnia y que su presencia podría ser signo alarmante de significativos problemas de conducta que deberían ser afrontados antes que aumenten. De manera semejante, Wakschlag et al. (2012) han encontrado que el $87 \%$ de los preescolares presentan ocasionalmente berrinches, pero los berrinches diarios no son tan típicos y sólo los presentan el $10 \%$ de los preescolares evaluados.

Carlson et al. (2016), al estudiar la irritabilidad y los berrinches en muestras clínicas y de la comunidad, hallaron que en la muestra clínica el $45.9 \%$ tenían berrinches severos, pero sólo $23.8 \%$ de ellos fueron reportados como irritables. En la muestra de la comunidad el $11 \%$ presentaban berrinches, pero $78.4 \%$ fueron reportados como irritables; sin embargo, en la muestra clínica, aunque menos frecuente, la irritabilidad fue asociada a berrinches agresivos. En contraste en la muestra de la comunidad la irritabilidad sólo fue asociada a un pequeño número de niños y niñas con agresividad.

\section{Edad de inicio de los berrinches}

En pocas ocasiones se presenta los berrinches en las etapas iniciales del desarrollo infantil, y es aceptado que se inicien comúnmente a partir de los 18 meses, siendo posible que, en esta edad; al haber alcanzado un buen grado de desarrollo, ya caminen, se comuniquen y experimenten sus emociones con gran intensidad (Koch, 2003). Osterman y Bjorkqvist (2004) encontraron que los berrinches se inician alrededor de los 2 años y su frecuencia disminuye a partir de los 4 años.

\section{Motivos de los Berrinches}

Potegal y Davison (1998) hallaron que las conductas después de los berrinches están relacionadas con la edad, el llanto a gritos, el estrés fisiológico y el inicio de separación de los padres. Manning et al. (2019) los relacionan con un pobre lenguaje expresivo o con disciplina inconsistente, exagerado criticismo, exagerado proteccionismo o negligencia (Fetsch \& Jacobson, 2013).

De acuerdo con la experiencia y los reportes de investigaciones, Eatsman y Rozen (2001) encontraron que las motivaciones que desencadenan berrinches son: presión de la vida cotidiana, conflictos, etapas evolutivas y baja autoestima. 
Presión de la vida cotidiana. Las exigencias de la vida diaria hacen que los padres, madres o cuidadores constantemente estén presionándolos para que se apuren al vestirse, se apuren o terminen de comer, hagan bien las cosas, distingan cuando no es hora de jugar y/o que no pueden tocar ciertos objetos; y el enojo o frustración que provocan estas presiones los desbordan y puede reaccionar con rabietas.

Conflictos. Generalmente en la dinámica familiar hay diversos conflictos, como por ejemplo competencia entre hermanos para que se les preste atención, exigencias de los niños y niñas que los adultos no pueden satisfacer, o exigencias de estos que los niños y niñas no quieran complacer; y aunque los niños tienen distintos niveles de tolerancia, algunos terminan reaccionando con ira y explosiones de cólera.

Etapas evolutivas. Los infantes atraviesan diversas etapas de desarrollo. Las frustraciones son frecuentes cuando en cada fase hay que aprender cosas nuevas y las exigencias del entorno cambian o son mayores. Así, deben aprender a tener autodisciplina y adaptarse a los cambios que involucra el crecimiento.

Baja autoestima. Es importante que en el curso del desarrollo los niños y niñas vayan adquiriendo diversos grados de satisfacción sobre sí mismos y valorar positivamente el cariño o atención que les tengan las personas de su entorno. Es frecuente que a veces los niños se sientan poco atendidos, abandonados y poco queridos; por tanto, no es raro que expresen sus sensaciones de no ser lo suficientemente atendidos con manifestaciones de enojo en forma de berrinches.

Koch (2003) afirma que existen dos puntos de vista sobre los berrinches, uno de ellos plantea que son mecanismos mediante los cuales se descargan y regulan las emociones, es el caso de la explicación basada en el temperamento de los niños y niñas; otro punto de vista hace hincapié en la ansiedad, el manejo de la agresión que surge del inconsciente ya sea por necesidades o frustraciones que nacen por una inmadurez del ego, frecuente dificultad para tomar decisiones y seguir instrucciones, resolución de problemas mediante la agresión física, berrinches, dificultad de separarse de los adultos, no participar con otros niños, llorar y bajar su apetito (California Childcare Health Program, 2006). Se ha dado particular importancia al enojo que experimentan los niños cuando tienen rabietas, ya que surgen generalmente en el hogar con personas con las que suelen sentirse bien. En el enojo de los niños, los padres o cuidadores tiene un rol importante en su disminución, pero cuando los berrinches ocurren en corto periodo de tiempo con incremento de la intensidad, con cambios en el ritmo, cambios en la energía de las vocalizaciones, movimiento y adicionalmente signos fisiológicos como enrojecimiento, no hay dudas de que el niño está muy enojado (Potegal \& Qiu, 2010). 


\section{Curso de los berrinches con el devenir el tiempo}

Cuando los berrinches/rabietas se siguen presentando después de los cuatro años, a pesar de los esfuerzos de los padres y madres y de haber aplicado algunas técnicas de modificación de conducta, mediante el uso de reforzadores positivos y el castigo; es necesario que se derive a un profesional idóneo, cómo el psicólogo o neuropsicólogo, quienes determinarán si es necesario otras evaluaciones y los planes de intervención (Koch, 2003).

Es común aceptar que los niños y niñas demuestren su voluntad y autonomía con conductas que tengan que ver con sus padres o figuras con autoridad, pero su persistencia en intensidad pueden ser indicadores del inicio de un desorden de conducta oposicional desafiante, sobre todo cuando se presenta con excesiva conducta desafiante, falta de remordimiento o sentimientos de culpa por su conducta pasada la crisis, o no hay mayores resultados de la aplicación de técnicas de modificación de conducta cómo el castigo y otros (Baillargeon et al., 2012; Harvey, 2012).

Koch (2003) al investigar berrinches en niños y niñas, encontró que a los 21 meses el $45 \%$ de evaluados del grupo investigado y el $51 \%$ del grupo control manifestaron alguna forma de berrinches y que a medida que aumentaba su edad se disminuía la frecuencia y severidad de ellos. Además, de manera categórica, afirma que las tempranas manifestaciones de berrinches con llanto irritable y reacciones bruscas en los 3 primeros años no son necesariamente predictivas de serios problemas de conducta en el futuro, pero que si los berrinches se prolongan un tiempo, podrían ser predictores de futuros problemas. Según Osterman y Bjorkqvist (2010) los berrinches declinan a partir de los tres años, justo cuando mejoran su lenguaje, que inclusive ayuda a mejorar las conductas agresivas en general.

\section{Diferencias de género y berrinches}

Se cree que los niños suelen ser más activos, desordenados y reactivos que las niñas, pero ambos están en condiciones semejantes para aprender a reaccionar adecuadamente para aliviar la tensión. Lo que está claro es que los adultos les tratan de manera diferente de acuerdo con el sexo del infante. Por lo tanto, no se puede precisar si las diferencias se deben al hecho de ser de uno u otro sexo, o por la manera de que el sexo del infante influye en nuestra forma de tratarlos (Jacklin, 1989). Los estudios que han tomado en cuenta las diferencias de género han sido controversiales, pues los descubrimientos son pocas veces persistentes cuando se replican las investigaciones. Shafer (2000) refiere que las diferencias sólo se perciben en forma clara después de los dos años, pero de todas maneras, hay aceptación de que deben existir diferencias. No es considerado raro que un niño reaccione con un estallido agresivo e inclusive lo podemos pasar por alto, con lo que reforzamos esa conducta y cuando una niña reacciona con llanto fácilmente tratamos de consolarla, reacción que no sucede si es el niño el que llora (Eastman \& Rozen, 2001). 
Koch (2003) encontró que a los 21 meses de edad no se evidenciaron diferencias en los berrinches de niños y niñas, pero a medida que aumenta la edad, la frecuencia y severidad de los berrinches es mayor en niños. A los 9 años la presencia de explosiones de berrinches era por encima del $50 \%$ en los niños, mientras que en las niñas era sólo a un nivel de $30 \%$. Este autor plantea que las respuestas de ira frente a la frustración parecían darse en función de la aceptación cultural. En cuanto a la frecuencia de los berrinches Osterman y Bjorkqvist (2004) no hallaron diferencias entre los niños y niñas de 2 a 4 años.

Heras et al. (2016) hallaron que las niñas poseen mejor nivel emocional global, específicamente en tres de las cuatro dimensiones que la componen: conciencia emocional, regulación emocional y competencia social; solo en habilidades de la vida para el bienestar no obtuvieron superioridad. Por más que en los tiempos modernos vivimos en una sociedad interesada en la igualdad de género, los padres, madres y profesores en la niñez reaccionan de distinta manera; cuando es un niño el que tiene una explosión de enojo que cuando es una niña la que tiene la explosión de ira.

Dado que los hallazgos son contradictorios, el estudio que se presenta pretende saber si en nuestro medio hay diferencias de género en las características de los berrinches. Aquí se plantea que los niños presentan más berrinches que las niñas.

\section{Método}

\section{Diseño}

La investigación es de tipo descriptiva correlacional. Descriptiva porque se aplicó una encuesta para conocer rasgos o conductas de grupo de personas, en este caso, niños y niñas (Kerlinger y Lee, 2002); y correlacional porque se pretende encontrar la relación entre la variable berrinches y la variable género (Salkind, 2012).

\section{Participantes}

De acuerdo con los últimos datos censales disponibles del 2016, fueron matriculados 16,568 menores en edad preescolar en instituciones educativas de Arequipa (48.95\% varones y $51.05 \%$ mujeres): 2,570 de 2 años ubicados en cunas, cunas jardín y centros de estimulación temprana (Inicial Ciclo I) y 13,998 de 3 años ubicados en jardines, cunas-jardines y PRONOEI (Inicial Ciclo II). Casi el 80 por ciento de ellos asisten a los 8 distritos más populosos de la provincia: Cerro Colorado, Arequipa, Paucarpata, Cayma, José Luis Bustamante y Rivero, Alto Selva Alegre, Miraflores y Yanahuara. Para la presente investigación los participantes proceden de esos 8 distritos con mayor cantidad de población.

Respetando las proporciones señaladas se logró la participación de las madres de 555 estudiantes matriculados en nivel inicial, el 3.5\% de la población total; de los cuales: $284(51 \%)$ fueron hombres y 271 mujeres (49\%); 183 de dos años, 96 
hombres (52 \%) 87 mujeres $48 \%$ ); 372 de tres años, 188 hombres (51\%) y 184 mujeres (49\%).

\section{Instrumentos}

Se aplicó una Ficha de Reporte de Conductas preparada por los investigadores, donde en su parte inicial incluía datos demográficos. La ficha fue sometida a la revisión de dos psicólogos del medio con amplia experiencia en el tema estudiado. El listado de conductas sobre los berrinches de la Ficha de Reporte está dividido en tres apartados de acuerdo a tres grados de intensidad: leve, moderado y severo. Leve cuando lloray grita, se presentan berrinches una oalgunas veces al mes y dura menos de 5 minutos. Moderado cuando llora y grita, presenta alguna de las conductas de arrojar juguetes/objetos, tirarse al suelo, golpearse a sí mismo con manos y puño, se presenta varias veces a la semana y dura hasta 10 minutos. Severo cuando llora y grita, está presente alguna de las conductas de arrojar juguetes/objetos, tirarse al suelo, golpearse a sí mismo con manos o puños y alguna de las conductas de golpearse contra la pared, el suelo u objetos, agrede físicamente a las personas de su entorno, se presentan diario o varias veces al día y el berrinche dura más de 10 minutos.

\section{Procedimientos}

Se tuvo comunicación con más de una centena de centros de educación inicial que atendían a niños de dos y/o tres años. En las instituciones que hubo respuesta positiva se tuvo una reunión con el personal directivo y docente explicándoles las características de la investigación; resaltando la posibilidad de comunicarse con los padres (madres o cuidadoras principales) ya sea personalmente o por teléfono. Los jardinesy cunas-jardines fueron seleccionados de acuerdo con los siguientes criterios:

- Atendían a niños y niñas de 2 años a 3 años.

- Huboplena colaboración deladirección y personal docente.

- El personal docentetenía buenayperiódica comunicación con los padres y enviaban la agenda de los estudiantes diariamente a los hogares.

- Hubo comunicación por medio de la agenda anunciando que recibirían unas "encuestas" con la motivación y explicación de los objetivos de la investigación.

- Se resaltó la promesa de enviarles una "cartilla de orientación" con orientaciones de cómo manejar problemas de conducta de los infantesy en particular cómo actuar frente a los berrinches.

Fueron excluidas las encuestas en las cuales la edad de los estudiantes era menor a 2 años o mayor de 4 años, igualmente las que no fueron contestadas plenamente y cuando hubo algún reporte de algún tipo de incapacidad del niño o niña.

Inicialmente se aplicó el instrumento a manera de prueba piloto a 23 participantes que no fueron tomados en cuenta en la data final. Ésta sirvió para realizaralgunos reajustes en la aplicación como en la significación 
de algunas palabras de uso en el medio. Además, ayudóa tomar la decisión deubicar los datos de la ficha demográfica en la parte inicial de la encuesta enviada, a fin de que no parezcan como dos instrumentos.

Por medio de las instituciones educativas fueron enviadas un total de 1,325 encuestas a las familias de los niños y niñas. El índice de retorno fue del $42 \%$ es decir 555 fichas de niños y niñas.

Una vez recolectada la data se ha procedido a la calificación y valoración de los instrumentos para lo cual se ha procesado la información medianteel programa del SPSS 24.o, usando la prueba de Chi-cuadrado.

\section{Resultados}

Los resultados se presentan por medio de tablas con frecuencias, porcentajes y con la prueba estadística de Chi Cuadrado cuando fue posible. En primer lugar, considerando las respuestas a las 555 encuestas respondidas, es evidente que la gran mayoría ( $\mathrm{n}=431 ; 77.6 \%)$ de los varones y mujeres de 2 a 3 años presentan reacciones tipificadas como berrinches, solo el $24.4 \%(n=124)$ de los participantes no habían experimentado berrinches. En cuanto a las diferencias de con respecto a la presencia de berrinches entre niños y niñas, no se encontraron diferencias estadísticamente significativas $\left(\mathrm{X}^{2}=0.90\right.$; p> .05), pero 222 niños ( $40 \%$ ) presentaron berrinches al igual que 209 niñas (37.6\%). Por otro lado 62 niños (11.2 \%) no presentaron berrinches, de la misma manera 62 niñas (11.2 \%) tampoco presentaron esta conducta.

Con respecto a la relación entre edades de los participantes hombres y mujeres, y la presencia de berrinches, se observa que 144 (33.4\%) tienen 2 años, siendo 75 varones (17.4\%) y 69 mujeres (16.0\%); mientras que de los 287 (66.6 \%) que tienen 3 años, 147 son varones (34.1\%) y 140 mujeres (32.5\%). También se tiene que a los 3 años (66.6\%) hay mayor presencia de berrinches que a los 2 años (33.4\%).

Tabla 1.

Intensidad de los berrinche según el género

\begin{tabular}{|lcccccc|}
\hline & \multicolumn{2}{c}{ Varones } & \multicolumn{2}{c}{ Mujeres } & \multicolumn{2}{c|}{ Total } \\
Intensidad & $\mathbf{f}$ & $\%$ & $\mathrm{~F}$ & $\%$ & $\mathrm{f}$ & $\%$ \\
\hline Leve & 105 & 24.4 & 123 & 28.5 & 228 & 52.9 \\
Moderado & 105 & 24.4 & 80 & 18.6 & 185 & 43.0 \\
Severo & 12 & 2.7 & 6 & 1.4 & 18 & 4.1 \\
Total & 222 & 51,5 & 209 & 48.5 & 431 & 100.0 \\
\hline
\end{tabular}

$\mathrm{X}^{2}=0.40 ; \mathrm{p}<.05$

Se observa en la Tabla 1 que las niñas $\quad 80$ (18.6\%) en nivel moderados y sólo 6 presentan mayor intensidad de berrinches (1.4\%) en nivel severo. En cambio, los con 123 casos $(28.5 \%)$ en un nivel leve, niños presentan mayor intensidad con 12 
casos (2.7\%) en nivel severo y 105 (24.4 son estadísticamente significativas de $\%$ ) en nivel moderado con la misma acuerdo con la prueba Chi cuadrado cantidad en nivel leve. Estas diferencias $\quad\left(\mathrm{X}^{2}=0.40 ; \mathrm{p}<.05\right)$.

Tabla 2.

Características de los berrinches según el género

\begin{tabular}{|c|c|c|c|c|}
\hline \multirow{3}{*}{ Características de los berrinches } & \multicolumn{4}{|c|}{ Género } \\
\hline & \multicolumn{2}{|c|}{ Varones } & \multicolumn{2}{|c|}{ Mujeres } \\
\hline & f & $\%$ & f & $\%$ \\
\hline \multicolumn{5}{|l|}{ Llora } \\
\hline Sí & 203 & 91.4 & 197 & $94 \cdot 3$ \\
\hline No & 19 & 8.6 & 12 & $5 \cdot 7$ \\
\hline Total & 222 & 100.0 & 209 & 100.0 \\
\hline \multicolumn{5}{|l|}{ Grita } \\
\hline Sí & 175 & 78.8 & 165 & 78.9 \\
\hline No & 47 & 21.2 & 44 & 21.1 \\
\hline Total & 222 & 100.0 & 209 & 100.0 \\
\hline \multicolumn{5}{|l|}{ Arroja juguetes } \\
\hline Sí & 128 & $57 \cdot 7$ & 92 & 44.0 \\
\hline No & 94 & 42.3 & 117 & 56.0 \\
\hline Total & 222 & 100.0 & 209 & 100.0 \\
\hline \multicolumn{5}{|l|}{ Se tira al suelo } \\
\hline Sí & 92 & 41.4 & 74 & $35 \cdot 4$ \\
\hline No & 130 & 58.6 & 135 & 64.6 \\
\hline Total & 222 & 100.0 & 209 & 100.0 \\
\hline \multicolumn{5}{|l|}{ Se golpea a sí mismo } \\
\hline Sí & 15 & 6.8 & 5 & 2.4 \\
\hline No & 207 & 93.2 & 204 & 97.6 \\
\hline Total & 222 & 100.0 & 209 & 100.0 \\
\hline \multicolumn{5}{|l|}{ Se golpea contra la pared } \\
\hline Sí & 5 & 2.3 & $\mathbf{1}$ & 0.5 \\
\hline No & 217 & $97 \cdot 7$ & 208 & $99 \cdot 5$ \\
\hline Total & 222 & 100.0 & 209 & 100.0 \\
\hline \multicolumn{5}{|l|}{ Agrede físicamente } \\
\hline Sí & 73 & 32.9 & 51 & $24 \cdot 4$ \\
\hline No & 149 & 93.2 & 158 & 75.6 \\
\hline Total & 222 & 100.0 & 209 & 100.0 \\
\hline
\end{tabular}


La Tabla 2 muestra que de las 431 familias que respondieron en la ficha de reporte las características de berrinches en niños y niñas de 2 y 3 años, se distinguen siete características básicas: 203 niños (91.4\%) y 197 niñas (94.3\%) lloran, 175 niños (78.8 $\%)$ y 165 niñas (78.9 \%) gritan, 128 niños
(57.7\%) y 92 niñas ( $44.0 \%$ ) arrojan juguetes, 92 niños (41.4\%) y 74 niñas (35.4\%) se tiran al suelo, 15 niños $(6.8 \%)$ y 5 niñas (2.4\%) se golpean a sí mismos, 5 niños (2.3\%) y 1 niña (0.5\%) se golpean contra la pared, y finalmente, 73 niños $(32.9 \%)$ y 51 niñas (24.4\%) agreden físicamente.

Tabla 3.

Frecuencia de berrinches y género

\begin{tabular}{|lcccc|}
\hline & \multicolumn{3}{c}{ Género } \\
& \multicolumn{2}{c}{ Varones } & \multicolumn{2}{c|}{ Mujeres } \\
& f & \% & f & $\%$ \\
\hline Algunas veces al mes & 106 & 47.7 & 102 & 48.8 \\
Varias veces/semana & 90 & 40.5 & 80 & 38.3 \\
Diario/varias al día & 26 & 11.7 & 27 & 12.9 \\
Total & 222 & 100.0 & 209 & 100.0 \\
\hline
\end{tabular}

$\mathrm{X}^{2}=0.864 ; \mathrm{p}>.05$

La frecuencia de berrinches en niños y niñas son descritas en la Tabla 3, comprendida por la muestra que de 431 familias que respondieron la ficha de reporte, en la cual 106 niños (47.7\%) y 102 niñas ( 48.8 $\%)$ presentan berrinches algunas veces al mes; 90 niños (40.5 \%) y 80 niñas (38.3 $\%)$ presentan berrinches varias veces a la semana, 26 niños (11.7 \%) y 27 niñas (12.9\%) presentan berrinches diaria o varias veces al día. Sin embargo, no se encontraron asociaciones estadísticamente significativas entre la frecuencia y el género de los niños mediante la prueba Chi cuadrado $\left(\mathrm{X}^{2}=0.864 ; \mathrm{p}>.05\right)$.

Tabla 4.

Duración de berrinches y género

\begin{tabular}{|lcccc|}
\hline \multirow{2}{*}{ Duración } & \multicolumn{4}{c}{ Género } \\
& Farones & \% & f & \%ujeres \\
\hline Menos de 5 minutos & 165 & 74.7 & 159 & 76.1 \\
Hasta 1o minutos & 43 & 19.5 & 41 & 19.6 \\
Más de 1o minutos & 13 & 5.9 & 9 & 4.3 \\
Total & $\mathbf{2 2 2}$ & 100.0 & 209 & 100.0 \\
\hline
\end{tabular}

$\mathrm{X}^{2}=0.652 ; \mathrm{p}>.05$ 
La Tabla 4 muestra la duración de berrinches en niños y niñas de 2 y 3 años. Se describen tres categorías: 165 niños $(74.7$ \%) y 159 niñas (76.1\%) tienen una duración de berrinches menor de 5 minutos, 43 niños $(19.5 \%)$ y 41 niñas $(19.6 \%)$ tienen una duración de hasta 10 minutos, $\mathrm{p}>.05)$.

Tabla 5.

¿Cuándo se Presentan los Berrinches?

\begin{tabular}{|lcc|}
\hline & f & $\%$ \\
\hline No le dan el objeto & & \\
Sí & 315 & 73.9 \\
No & 111 & 26.1 \\
Total & 426 & 100.0 \\
\hline No se realiza la acción & & \\
Sí & 243 & 57.0 \\
No & 183 & 43.0 \\
Total & 426 & 100.0 \\
\hline No se le entiende & & \\
Sí & 139 & 32.6 \\
No & 287 & 67.4 \\
Total & 426 & 100.0 \\
\hline
\end{tabular}

La Tabla 5 describe cuándo se presentan años manifiestan berrinches cuando los berrinches en niños y niñas de 2 y 3 no le dan el objetivo que pide, el 57 años. Respondieron 426 familias este \% cuando no se realiza la acción que punto en la ficha de reportes. En ella quiere, mientras que el $32.6 \%$ tiene se identifican 3 situaciones básicas: berrinches cuando no se le entiende el $73.9 \%$ de los niños y niñas de 2 y 3 lo que desea o quiere. 
Tabla 6.

¿Cómo se le Pasan los Berrinches?

\begin{tabular}{|lcc|}
\hline & f & $\%$ \\
\hline Se le da el objeto que pide & & \\
Sí & 161 & 37.7 \\
No & 266 & 62.3 \\
Total & 427 & 100.0 \\
\hline Se realiza la acción que quiere & & \\
Sí & 97 & 22.7 \\
No & 330 & $77 \cdot 3$ \\
Total & 427 & 100.0 \\
\hline Lo consuelan y cargan en brazos & & \\
Sí & 356 & 83.4 \\
No & 71 & 16.6 \\
Total & 427 & 100.0 \\
\hline Se aleja y el niño(a) lo sigue & & \\
Sí & 190 & 44.5 \\
No & 237 & 55.5 \\
Total & 427 & 100.0 \\
\hline Se aleja y no permite que el niño(a) lo siga & & \\
Sí & 66 & 15.3 \\
No & 361 & 84.7 \\
Total & 427 & 100.0 \\
\hline Viene otra persona, lo atiende y se calma & & \\
Sí & 298 & 69.9 \\
No & 427 & 100.0 \\
Total & & \\
\hline
\end{tabular}

En la Tabla 6 se describe cómo se les pasan los berrinches a los niños y niñas de 2 y 3 años. Respondieron a esta pregunta 427 familias y en la ficha de reporte se han identificado 6 situaciones básicas: el $37.7 \%$ de personas a cargo de ellos le dan el objeto que pide, lo atiende y se calma. el $22.7 \%$ realiza la acción que quiere, el $83.4 \%$ le habla, lo calma y carga en brazos, el $44.5 \%$ se aleja y el niño o niña lo sigue, el $15.3 \%$ se aleja y no permite que el niño(a) lo siga, mientras que el $30.1 \%$ refiere que viene otra persona, 
Tabla 7 .

Lugar dónde se presentan los berrinches según el género

\begin{tabular}{|c|c|c|c|c|c|c|}
\hline \multirow{4}{*}{$\begin{array}{l}\text { Dónde se presentan } \\
\text { Casa }\end{array}$} & \multicolumn{4}{|c|}{ Género } & \multirow{2}{*}{\multicolumn{2}{|c|}{ Total }} \\
\hline & \multirow{2}{*}{\multicolumn{2}{|c|}{$\begin{array}{c}\text { Varones } \\
\text { f \% }\end{array}$}} & \multirow{2}{*}{\multicolumn{2}{|c|}{$\begin{array}{c}\text { Mujeres } \\
\text { f \% }\end{array}$}} & & \\
\hline & & & & & \multirow{2}{*}{$\frac{f}{214}$} & \multirow{2}{*}{$\frac{\%}{52.4}$} \\
\hline & 107 & 26.2 & 107 & 26.2 & & \\
\hline Lugares públicos & 14 & 3.4 & 18 & 4.4 & 32 & 7.8 \\
\hline Centro educativo & 7 & 1.7 & o & 0.0 & 7 & 1.7 \\
\hline Casa y lugares públicos & 64 & 15.6 & 58 & 14.2 & 122 & 29.8 \\
\hline Casa y centro educativo & 6 & 1.5 & 4 & 1.0 & 10 & 2.5 \\
\hline Todos los lugares & 18 & $4 \cdot 4$ & 6 & 1.4 & 24 & 5.8 \\
\hline Total & 216 & 52.8 & 193 & 47.2 & 409 & 100.0 \\
\hline
\end{tabular}

En la Tabla 7 se tienen en respuestas de las 409 familias que respondieron a la pregunta con respecto al lugar donde se presentan los berrinches según el género. Se tiene que 107 niños $(26.2 \%)$ y 107 niñas $(26.2 \%)$ presentan berrinches en casa, 14 niños (3.4\%) y 18 niñas (4.4\%) las tienen en lugares públicos,
7 niños ( $1.7 \%)$ y ninguna niña en las tienen en el centro educativo, 64 niños $(15.6 \%)$ y 58 niñas $(14.2 \%)$ en casa y en lugares públicos, 6 niños (1.5\%) y 4 niñas (1\%) en casa y el centro educativo, mientras que 18 niños (4.4\%) y 6 niñas (1.4\%) presentaron berrinches en todos los lugares.

Tabla 8.

\section{Intensidad de los berrinches y ser hijo único}

\begin{tabular}{|lcccccc|}
\hline $\begin{array}{l}\text { Intensidad } \\
\text { berrinche }\end{array}$ & \multicolumn{2}{c}{$\begin{array}{c}\text { Sí Hijo único } \\
\text { f \% }\end{array}$} & \multicolumn{2}{c}{$\begin{array}{l}\text { No } \\
\text { f \% }\end{array}$} & F & Total \\
\hline Leve & 103 & 24.6 & 119 & 28.5 & 222 & 53.1 \\
Moderada & 91 & 21.8 & 89 & 21.3 & 170 & 43.1 \\
Severa & 12 & 2.9 & 4 & 0.9 & 16 & 3.8 \\
Total & 206 & 49.3 & 212 & 50.7 & 418 & 100.0 \\
\hline
\end{tabular}

Cuatrocientos dieciocho familias respondieron en la ficha de reporte para procesar los datos con respecto a la intensidad de los berrinches y la condición de ser hijo único o no. En la Tabla 8 se observa que 103 niños y niñas hijos únicos (24.6\%) y 119 no hijos únicos (28.5\%) presentan berrinches leves, 91 hijos únicos $(21.8 \%)$ y 89 no hijos únicos (21.3\%) presentan berrinches moderados, y finalmente, 12 hijos únicos $(2.9 \%)$ y 4 no hijos únicos (o.9\%) presentan berrinches severos. 
Tabla 9.

Tipo de familia e incidencia de berrinches

\begin{tabular}{|lcccccc|}
\hline \multirow{1}{*}{ Tipo de familia } & \multicolumn{3}{c}{ Sí } & \multicolumn{9}{c}{ Berrinches } \\
& f & $\%$ & f & $\%$ & fo & $\%$ \\
\hline Nuclear & 213 & 51.1 & 60 & 57.1 & 273 & 52.3 \\
Monoparental & 44 & 10.6 & 8 & 7.6 & 52 & 10.0 \\
Extensa & 142 & 34.0 & 32 & 30.5 & 174 & 33.3 \\
Reconstituida & 18 & 4.3 & 5 & 4.8 & 23 & 4.4 \\
Total & 417 & 100.0 & 105 & 100.0 & 522 & 100.0 \\
\hline
\end{tabular}

$\mathrm{X}^{2}=0.643 ; \mathrm{p}>.05$

La Tabla 9 muestra las respuestas de las 522 familias que respondieron la ficha sociodemográfica con los cuatro tipos de familia y su cruce con la intensidad de los berrinches, donde se aprecia que 213 de niños y niñas $(51.1 \%)$ con presencia de berrinches y $60(57.1 \%)$ sin presencia de berrinches pertenecen a la familia nuclear, $44(10.6 \%)$ con presencia de berrinches y $8(7.6 \%)$ sin presencia de berrinches pertenecen a la familia monoparental, 142 (34\%) con presencia de berrinches y 32 (30.5\%) sin presencia de berrinches pertenecen a la familia extensa, y finalmente, $18(4.3 \%)$ con presencia de berrinches y $5(4.8 \%)$ sin presencia de berrinches pertenecen a la familia reconstituida. Sin embargo, la asociación entre el tipo de familia y la incidencia de berrinches no es estadísticamente significativa tras aplicar la prueba Chi cuadrado $\left(\mathrm{X}^{2}=0.643 ; \mathrm{p}>.05\right)$.

\section{Discusión}

La hipótesis planteada de que los varones de 2 años a 3 años presentarían mayor incidencia de berrinches en comparación con las mujeres de la misma edad, no ha sido confirmada. Si bien estos resultados no han sido los esperados, ya Shafer (200o), refería que los resultados muestran diferencias de temperamento entre niños y niñas, pero estas diferencias no son claras y no se asocian de manera evidente con las condiciones biológicas. Los resultados hallados en la presente investigación pueden deberse a que en los tiempos actuales, se promueve más la igualdad de género, y los estilos de crianza moderna han ido variando con el paso del tiempo. Por tanto, es posible que los padres, madres, docentes y otros adultos reaccionen de semejante manera cuando un niño o niña tienen explosiones de enojo y no como en el pasado en que se aceptaba más estas conductas en los niños y en las niñas no, ya que en las niñas no era femenino reaccionar de esa manera (Jacklin, 1989; Eastman \& Rozen, 2001). Es decir, que ahora, a la luz de nuestros resultados, tanto niños como niñas pueden reaccionar con berrinches para descargar su tensión. Es posible entonces, que la mayoría de padres modernos estén tratando de manera similar a sus hijos e hijas ya sean hombres o mujeres. 
Otra explicación, más de tipo cultural, es que biológicamente tanto los niños como las niñas tienen maneras similares de expresar sus emociones, pero recién en los años posteriores se hace evidente la influencia de la sociedad en las reacciones consideradas como masculinas o femeninas, y a partir de ello se hacen claras las influencias de la manera en cómo los adultos los tratan, con lo cual se hace referencia al rol de género. Si bien Shaffer (2000) afirmaba que el grado de conformidad con las expectativas sociales es mayor a medida que las personas aumentan de edad, las niñas tienden a conformarse mejor a diferencia de los niños, por lo tanto, son ellos quienes suelen presentar más berrinches o rabietas.

Los resultados de la investigación concuerdan con los hallazgos de Koch (2003) quien no encontró diferencias en los berrinches de varones y mujeres a los 21 meses de edad, aunque también encontró que al aumentar la edad (a los 9 años), aumentan la frecuencia y severidad de los berrinches en los varones. Igualmente Osterman y Bjorkqvist (2004), no hallaron diferencias en los berrinches entre niños y niñas de 2 a 4 años. En relación con área emocional Heras et al. (2016) señalaron que, si bien las niñas poseen mejor desarrollo emocional, los padres y profesores en la niñez reaccionan de distinta manera cuando se trata de un niño o una niña cuando tiene una explosión de enojo o de ira.

Es necesario señalar que, en las 555 fichas de registro de conductas, se halla que la gran mayoría $431(77.6 \%)$ presentan berrinches, resultados que confirman la aceptación de que los berrinches son manifestaciones consideradas frecuentes y normales en la infancia. $\mathrm{Al}$ respecto, Green et al. (2011) señalaron la posibilidad de que los berrinches sirvan para expresar emociones fuertes que vivencian los niños, como la ira o tristeza, y que paulatinamente aprendan a manejarlas. Igualmente, Eastman y Rozen (2001), afirman que los berrinches son formas de expresar las vivencias negativas que experimentan los niños y niñas. Asimismo, Wakschlaq et al. (2012) resaltan que el $83.7 \%$ de niños en etapa preescolar presentaron berrinches alguna vez, estos hallazgos guardan semejanza con los resultados encontrados en esta investigación. Es de notar que Novotney (2012), encontró que sólo el $10 \%$ de niños en la etapa preescolar presentan berrinches, esto en contraste con los resultados de esta investigación en la cual se observa que el $77.6 \%$ presentan berrinches.

En cuanto a edad, la American Academy of Pediatrics (1989) señala que las explosiones de ira y los berrinches se presentan en todas las edades de la infancia, pero son más frecuentes entre los 18 meses hasta los tres años. Belden et al. (2008) afirman que el $70 \%$ presentan berrinches entre los 18 y 60 meses. Koch (2003) refirió por otro lado, que a medida que aumentan de edad la severidad de los berrinches es mayor. En la presente investigación es muy claro, de las 431 familias que confirmaron la presencia de berrinches, que estos son significativamente más frecuentes a los 3 años que a los 2 años, indistintamente del género de los participantes. 
Si bien no se demostró el que los niños tengan mayor incidencia de berrinches, se halló que los niños de 2 a 3 años presentaban berrinches con mayor intensidad que en las niñas de 2 a 3 años. Estas diferencias de mayor intensidad de los berrinches en los varones son estadísticamente significativas. Parece ser que los niños son más fáciles de frustrarse y reaccionan más fácilmente con ira que las niñas. Al respecto, Koch (2003) refirió que a los 21 meses de edad no se encontraban manifiestas diferencias entre los berrinches de niños y niñas, pero que a medida que aumentan de edad la severidad de los berrinches es mayor en los varones. Wakschlag et al. (2012) han encontrado que los berrinches diarios no son tan típicos y Carlson et al. (2016), al estudiar muestras clínicas y de la comunidad, hallaron que los berrinches en muestras clínicas son más intensos que en las segundas. Asimismo, Eastman y Rozen (2001) afirman que los berrinches pueden considerarse como un problema serio cuando son muy intensos.

El llanto, gritos, arrojar juguetes y tirarse al suelo son las características más frecuentes en los berrinches estudiados. En el pasado, Kanner (1935) refería que los berrinches se caracterizan principalmente por inicio rápido o gradual de llanto a gritos y zapateo, expresiones de insultos en voz alta y en casos más serios, patear el suelo, agitar sus brazos, empujar o golpear a las personas cercanas, arrojar objetos, tirarse al suelo, golpearse a sí mismo la cabeza contra las paredes u otro objeto. De manera similar, de acuerdo con la American Academy of Pediatrics
(1989) se acepta que el llanto, gritos, pataletas y hasta agresiones son las características más frecuentes. Potegal y Davidson (2003) indicaron también que las conductas de agredirse a sí mismo o a los demás son más frecuentes en los niños que en las niñas.

Eastman y Rozen (2001) consideran que los berrinches pueden considerarse un problema cuando son demasiado frecuentes (varias veces a la semana). Potegal et al. (2003) aseveran que la frecuencia de los berrinches es de uno por día, pero, Wakschlag et al. (2012) reportaron que los berrinches diarios no son tan típicos y sólo los presentan el $10 \%$ de los preescolares. En la muestra estudiada, los berrinches se presentan en un $48.8 \%$ algunas veces al mes, $38.3 \%$ varias veces a la semana y 12.9 $\%$ diariamente; que de alguna forma son similares a las cantidades reportadas en estudios previos. En cuanto a la relación frecuencia y género no se han hallado diferencias significativas, los porcentajes son similares en la frecuencia mensual (varones $47.7 \%$ y mujeres $48.8 \%$ ), semanal (varones 40.5 $\%$ y mujeres $38.3 \%$ ); y diaria (varones $11.7 \%$ y mujeres $12.9 \%)$.

Con respecto a la duración de berrinches, en la gran mayoría de varones $(74.7 \%)$ como de las mujeres $(76.1 \%)$ se encontró un lapso de menos de 5 minutos. En menor frecuencia los berrinches son hasta de 10 minutos, y la duración de los berrinches es mayor de 10 minutos en bajos porcentajes (varones 5.9 \% y mujeres $4.3 \%$ ). Tampoco se halló 
relación entre el género y la duración de los berrinches. Nuestros resultados son cercanos a lo encontrado por Osterman y Bjorkqvist (2004), quienes en su informe refieren que el tiempo de duración en los infantes finlandeses fue entre los 5 y 10 minutos, pero que berrinches de más de media hora se presentaron en $6 \%$ de los casos. Para estos investigadores los berrinches que duran más de 10 minutos deben ser evaluados y seguidos ya que en el futuro pueden continuar y dejar de ser un berrinche para convertirse en un problema de conducta.

En el presente trabajo los berrinches se presentan cuando a los niños y niñas no se les da lo que piden ( $73.9 \%)$, no se realiza la acción que quieren ( $57 \%$ ) y no se le entiende en lo que desean o quieren (32.6\%). Todas esas situaciones les causan frustración, de forma similar a lo mencionado por la American Academy of Pediatrics (1989). Es posible que estas frustraciones estén mezcladas con tristeza o quejas que buscan llamar la atención sobre lo que se desea (Green et al., 2011). Al respecto, Kanner (1935) afirmaba que los berrinches deberían ser considerados como malos hábitos.

En el presente estudio se aprecia que en la frecuencia de berrinches de algunas veces al mes los porcentajes son similares en niños y niñas, con $47.7 \%$ y $48.8 \%$, respectivamente. La frecuencia acumulada de berrinches diarios o varias veces al día y varias veces a la semana es alta, por tanto a pesar de que se considere que los berrinches son expresiones normales en la niñez, su presencia afecta la vida del hogar. Asimismo, Osterman y Bjorkqvist (2004) no encontraron diferencias significativas en la frecuencia de berrinches, sin embargo reportan que el $37.3 \%$ presentan berrinches una vez a la semana, mientras que en la presente investigación se encontró que el promedio reportado en la frecuencia de berrinches es en el 48.3 $\%$, de una vez al mes.

Generalmente las estrategias que usan los adultos para que se les pasen los berrinches a los niños, son proporcionarles lo deseado en el $37.7 \%$ de los casos, hacer la acción que solicitan en el $22.7 \%$; aunque la gran mayoría, es decir, un $83.4 \%$, además de darle o ejecutar lo deseado, tratan de calmarlo hablándole con dulzura y cargándolo, pero algunos adultos recurren a alejarse del niño o niña. Es posible que los padres y madres ante estas situaciones sientan la necesidad de calmar los berrinches en el menor tiempo posible con estas acciones, acompañado con cierto grado de sensibilidad y empatía, la reacción de satisfacer lo deseado para que se cesen rápidamente los berrinches; pero también con ello es posible que se les refuerce tales conductas por lo tanto los berrinches pueden persistir a lo largo del tiempo. Si bien Geleerd (1944) recomendaba dejarlo solo hasta que se calme o ser cambiado de lugar si destruía cosas, en general sugería no tratarlos con firmeza ante los berrinches, quizá porque los berrinches eran considerados como expresiones normales en esa etapa del desarrollo. Al respecto, Osterman y Bjorkqvist (2010) afirman 
que los berrinches son más fáciles de controlar cuando mejoran su lenguaje.

En las 409 familias que respondieron a la pregunta de dónde se presentan los berrinches, se halló que mayormente los berrinches son manifestados en casa 52.4 $\%$, seguido de en casa y lugares públicos

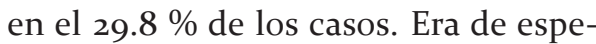
rarse que la mayoría de los berrinches se presentan en el hogar donde, ya que allí pueden manifestar con mayor libertad sus emociones, por ello cuando se trata de manejar los berrinches es necesario la participación de todos los miembros que habitan en el hogar. Es probable que la significación del berrinche sea mayor cuando se presentan en dos o más lugares, generalmente el hogar y en lugares públicos, sobre todo las tiendas ya que los niños suelen desear que les compren cosas que los adultos inicialmente se niegan a comprarles, pero producido el berrinche logran que les den lo que piden. Estos hallazgos son semejantes a las investigaciones de Osterman y Bjorkqvist (2004) quienes afirman que los berrinches en niños y niñas se presentan con mayor frecuencia en la casa y dentro de los vehículos.

En la muestra estudiada menos de la mitad son hijos únicos $49.3 \%$, es probable que esta alta proporción se deba a que las familias estudiadas son jóvenes. Es de notar que el berrinche de tipo leve es proporcionalmente similar en hijos únicos y no únicos, aunque si bien los porcentajes son bajos, $2.9 \%$ y $0.9 \%$ respectivamente, el porcentaje de berrinches severos en hijos únicos es el triple de los no únicos. Se acepta que como los hijos únicos tienen más probabilidad de que sean satisfechos todos sus deseos, se frustren fácilmente cuando se les niegue algo y hayan aprendido a tener berrinches más intensos con el fin de lograr lo que quieren o desean. Lamentablemente, en este punto, no se encontraron investigaciones que contrasten con los hallazgos obtenidos.

No se encontró una relación estadísticamente significativa entre el tipo de familia y la presencia de berrinches, sin embargo para Eastman y Rozen (2001), la presencia de berrinches se debe a la forma de reaccionar de los padres y madres, ya que ésta puede variar si se trata de un sólo progenitor o si están presentes ambos. En un caso es una sola persona la que debe tomar decisiones sobre sus reacciones, en el otro caso, se debe tomar en cuenta el estilo del otro progenitor, lo que puede resultar en apoyo o discrepancia en este tipo de situaciones. Por otro lado, se puede observar que los berrinches predominan en el tipo de familia nuclear, donde se obtuvieron los porcentajes más elevados, posiblemente, a que la discrepancia entre los padres contribuye a la expresión de este tipo de conductas.

En cuanto a las limitaciones del estudio, la más importante fue lograr la participación de los padres, que si bien el deseo fue hacerlo presencialmente, solo se pudo conseguir mediante el envío de los instrumentos a través de las profesoras. A pesar de ello, y de 
tratarse de una muestra comunitaria, puede concluirse que la incidencia de berrinches en los niños y niñas es alta. Aunque en frecuencia no hubo diferencias de género, si se halló que, significativamente, los varones presen$\tan$ mayor intensidad en los berrinches que las niñas.

\section{Financiamiento}

La investigación fue autofinanciada.

\section{Conflictos de interés}

Los autores declaran que no tienen conflictos de interés. 


\section{Referencias}

American Academy of Pediatrics (1989). Los berrinches y rabietas: Un elemento normal del crecimiento. Medem. http://www.mipediatra.com/pdf/berrinches-print.pdf

Ashdown, D., \& Bernard, M. (2011). Can explicit instruction in social and emotional learning skills benefit the social-emotional development, wellbeing, and academic achievement of young children? Early Childhood Educational Journal, 39(6), 397-405.

Askeland, D. (2019). Social emotional development in early childhood. (Tesis de grado) Northwestern College, USA.

Baillargeon, R. H., Keenan, K, \& Cao, G. (2012). Oppositional and defiant behaviors in toddlers: Maybe those aren't just temper tantrums. Journal of Developmental $\mathcal{E}$ Behavioral Pediatrics, 33, 6o8-617.

Bee, H. (1992). The developing child. Harper Collins.

Belden, A. C., Thomson, N. R., y Luby, J. L. (2008). Temper Tantrums behaviors as marker of clinical problems. Clinician's Research Digest. Briefings in Behavioral Science, 26(7). www.apa.org/journlas/crd

California Childcare Program (2006). Desarrollo social y emocional de los niños. Department of Education Child Development Division y de Federal Maternal and Child Health Bureau. https://cchp.ucsf.edu/sites/cchp.ucsf.edu/files/15_ CCHA_SP_SocialEmot_o6o6_v3.pdf

Carlson, G. A., Danzig, A. P., Dougherty, L. R., Bufferd, S. J., \& Klein, D. N. (2016). Loss of temper and irritability: The relationship to tantrums in a continuity and clinical sample. Journal of Child and Adolescent Psychopharmacology, 26, 114-122.

Daniels, E., Mandleco, B., \& Luthy, K. (2012). Assessment, management, and prevention of childhood temper tantrums. Journal of the American Academy of Nurse Practitioners, 24, 569-573.

Darling-Churchil, K. E., \& Lippman, L. (2016). Early childhood social and emotional development: advancing the field of measurement. Journal of Applied Developmental Psychology, 45, 1-7. 
Davison, D. H. (2003). Temper tantrums in young children. Children and Family. University of Hawaii at Manoa.

Eastman, M., \& Rozen, S. C. (2001). No más berrinches. Consejos para lograr armonía entre padres e hijos. Aguilar.

Fetsch, R. J., \& Jacobson, B. (2013). Children s anger and tantrums. Consumer Series Family. Extension. Fact Sheet. Colorado State University.

Geleerd . L. R. (1944). Observations on temper tantrums in children. Kansas Meeting.

Green, J. A., Whitney, P. G., \& Potegal, M. (2011). Screaming, yelling, whining, and crying: Categorical and intensity differences in vocal expressions of anger and Children's tantrums. American Psychological Association, 11, 1124-1133.

Harvey, K. (2012). Preventing abusive head trauma: Two promising new strategies to and toddler tantrums. Workshop, Session 128.

Heras, D., Copa, A., \& Lara, F. (2016). Desarrollo emocional en la infancia, un estudio sobre las competencias emocionales de niños y niñas. Revista de Psicología, 1(1), 67-74.

Jacklin, C. N. (1989). Female and male: Issues of gender. American Psychologist, $44,127-133$.

Kanner, L. (1935). Emotional disorders. En L. Kanner (Ed.), Child psychiatry (pp, 275-293). Charles C. Thomas.

Kerlinger, F., \& Lee, H. (2002). Investigación del comportamiento. McGraw-Hill.

Koch, E. (2003). Reflections on a study of temper tantrums in older children. Psychoanalytic Psychology, 20, 456-471.

Manning, B. L., Roberts, M. Y., Estabrook, R., Petitclerc, A., Burns, J., Briggs-Gowan, M., Wakschlag, L. S., \& Norton, E. (2019). Relations between toddler expressive language and temper tantrums in a community sample. Journal of Applied Developmental Psychology, 65, 1-10. https://doi.org/10.1016/j.appdev.2019.101070

Mireault, G., \& Trahan, J. (2007). Tantrums and anxiety in early childhood: a pilot study. Childhood Research Practice, 9(2), 1-10. https://ecrp.uiuc.edu/v9n2/ mireault.html 
Novotney, A. (2012). Daily temper tantrums aren't normal for preschoolers. Monitor on Psychology, 43, 10.

Osterman, K., \& Bjorkqvist, K. (2004). Temper tantrums among young children. Conference Society for Research on Aggression. XVI World Meeting. USA.

Osterman, K., \& Bjorkqvist, K. (2010). A cross-sectional study of onset, cessation, frequency, and duration of children's temper tantrums on a nonclinical sample. Psychological Reports, 106, 448-454.

Papalia, D. E., Olds, S. W., \& Feldman, R. D: (2001). Psicología del desarrollo. McGraw-Hill.

Potegal, M., \& Davidson, R. J. (1998). Young children s post tantum affiliation with their parents. Aggressive Behavior, 23(5).

Potegal, M., \& Davidson, R. J. (2003). Temper tantrums in young children: behavioral composition. Journal of Developmental \& Behavioral Pediatrics, 24, 140-147. http://journals.lww.com/jrnldbp/abstract//2003/o60oo/ Temper-Tantrums-in-Young-Children-1-Behavioral.2.aspx/

Potegal, M., \& Qiu, P. (2010). Anger in children's tantrums: A new, quantitative, behaviorally based model. En M. Potegal, G. Stemmler, \& C. Spielberger (Eds.), International Handbook of Anger: Constituent and concomitant biological, psychological, and social processes (pp. 193-217). Springer. https://doi. org/10.1007/978-0-387-89676-2-12

Potegal, M., Kosorok, M. R., \& Davidson, R. J. (2003). Temper tantrums in young children: tantrum duration and temporal organization. Journal of Developmental E Behavioral Pediatrics, 24, 148-154.

Rice, F. P. (1997). Desarrollo del ciclo vital. Estudio del ciclo vital. Prentice-Hall.

Romano, E., Babchishin, L., Pagani, L. S., \& Kohen, D. (2010). School readiness and later achievement: Replication and extension using a nationwide Canadian survey. Developmental Psychology, 46(5), 995-1007. https://doi.org/10.1037/aoo18880

Salkind, N. J. (2012). Exploring research. 8va ed. Pearson.

Shaffer, D. R. (200o). Psicología del desarrollo. Infancia y adolescencia. Thomson. 
Solter, A. (2020). Understanding tears and tantrums, Aware Parenting Institute. www.awareparenting.com

Thomas, A., Chess, S., \& Birch, H. G. (1970). The origin of personality. Scientific American, 223(2), 102-109. https://doi.org/10.1038/scientificamericano870-102

Thompson, R. A. (2018). Social-emotional development in the first three years. Establishing the foundation. The Pennsylvania State University.

Tortosa, F. \& Mayor, L. (1992). Watson y la psicología de las emociones: Evolución de una idea. Psicothema, 4, 297-315.

Wakschlag, L. S., Choi, S. W., Carter, A. S., Hullsiek, H., Burns, J., McCarthy, K. Leibenluft, E., \& Briggs-Gowan, M. J. (2013). When Temper Tantrums shift from normal to problematic. Clinician's Research Digest, 53, 1099-1108. https://doi. org/10.111/j.1469.7610.2012.02595.X

Recibido: 11 de octubre de 2020

Revisado: 6 de noviembre de 2020

Aceptado: 18 de junio de 2021 


\title{
Autoeficacia y felicidad en estudiantes que aspiran a ingresar a la universidad
}

\author{
Self-efficacy and Happiness in Students Wishing \\ to Apply to University
}

Melany Rosario Medina Chugnas

Universidad Peruana de Ciencias Aplicadas, Lima, Perú

(iD https://orcid.org/oooo-0oo2-5489-8966

Andrea Virginia Saxsa Alegre

Universidad Peruana de Ciencias Aplicadas, Lima, Perú

(iD) https://orcid.org/oooo-0oo3-1949-6176

Correspondencia: andrea.vsa13@gmail.com

Miguel Barboza-Palomino

Universidad Privada del Norte, Lima, Perú

(iD https://orcid.org/oooo-ooo1-8045-5491

\section{Resumen}

El estudio buscó determinar la relación entre la autoeficacia y la felicidad en estudiantes de academias preuniversitarias de Lima Metropolitana que aspiran a ingresar a la universidad. Participaron 303 estudiantes preuniversitarios, cuyas edades oscilaron entre los 16 a 23 años $(M=18.05$; $D E=1.252)$, quienes resolvieron la Escala de Autoeficacia General y la Escala de Felicidad. Los resultados evidencian una correlación positiva, alta y estadísticamente significativa entre la autoeficacia y las dimensiones sentido positivo de la vida, satisfacción con la vida y alegría de vivir. A su vez, se halló una relación positiva, moderada y estadísticamente significativa entre la autoeficacia y la dimensión realización personal. Por otra parte, no se encontraron diferencias en la autoeficacia y felicidad considerando el sexo, área de la carrera elegida, tipo y ubicación del colegio de procedencia. Con base en los resultados, se resalta la importancia de desarrollar competencias emocionales en los estudiantes preuniversitarios. Palabras clave: Autoeficacia, felicidad, academias preuniversitarias, estudiantes. 


\begin{abstract}
The study goal was to determine the relationship between self-efficacy and happiness in students from pre-university academies in metropolitan Lima. A sample of 303 pre-university students, whose ages ranged from 16 to 23 years ( $M$ = 18.05; SD =1,252), answered General Self-efficacy Scale and Happiness Scale. The results indicated a positive, high and statistically significant correlation between self-efficacy and the dimensions positive meaning of life, satisfaction with life and joy of living. In turn, a positive, moderate and statistically significant relationship was found between self-efficacy and the dimension of personal fulfillment. Also, no differences were found in self-efficacy and happiness considering sex, area of the chosen career, type and location of the high school. Based on the results, the importance of developing emotional competencies in pre-university acadamies students is highlighted.
\end{abstract}

Keywords: Self-efficacy, happiness, pre-university academies, students.

\section{Introducción}

El ingreso a la universidad es una meta importante para los estudiantes que finalizan la escuela, puesto que, continuar estudios superiores los aproxima al éxito profesional y personal (Peñafiel et al., 2019). En el Perú, el ingreso a las universidades públicas y las privadas de mayor prestigio está supeditado al logro de una vacantea través de un concurso de examen de admisión, por lo cual, muchos estudiantes que finalizan la escuela y aspiran a ingresar a una universidad, se preparan en las academias pre universitarias, en donde adquieren o refuerzan conocimientos (Atuncar Yrribari et al., 2015).

Según la Superintendencia Nacional de Educación Superior Universitaria (SUNEDU) (2019), en la ciudad de Lima existen 56 universidades, de las cuales, 45 son privadas y 11 públicas. Si bien, se observa un mayor número de instituciones privadas, muchos estudiantes siguen optando por ingresar a las universidades públicas. Al respecto, Ipsos (2018), en una encuesta que se realizó a jóvenes entre los 15 a 18 años, encontró que, un $77 \%$ planea continuar estudios superiores. De este grupo, el 39\% quiere ir a una universidad pública, el 32\% a una universidad privada y el $29 \%$ a un instituto superior. Aquí, se observa una mayor preferencia por la elección de las universidades públicas. Sin embargo, lograr el ingreso a una universidad pública es una tarea complicada, debido a la exigencia de los exámenes de admisión y al número de vacantes que se ofrecen. Así, por ejemplo, esta es una realidad que se observa en la Universidad Nacional Mayor de San Marcos (UNMSM), donde, en el año 2019, se puso a disposición 4768 vacantes para 24944 postulantes, lo cual dejó a 20176 postulantes sin acceso a esta universidad (Ludena, 2019).

Según el Ministerio de Educación del Perú (MINEDU) (2018), en el 2017, se encontró que, solo el 35.6\% de los estudiantes del nivel de educación secundaria 
tenían los conocimientos necesarios para postular a una universidad o seguir estudios técnicos. En consecuencia, más del 50\% requiere de una preparación adicional para enfrentar un examen de admisión. Frente a esto, las academias preuniversitarias se sitúan como una alternativa idónea para esta población estudiantil. De acuerdo con el diario El Comercio (2010), en una entrevista que se realizó a los jóvenes, la mayoría refirió que la educación recibida en el colegio fue buena, pero no suficiente, razón por la que recurren a instituciones que les aseguren una preparación académica para enfrentar el examen de ingreso. Asimismo, un representante de una academia preuniversitaria, mencionó que, una de las claves para ingresar a la universidad es elegir una buena academia de preparación, que permita al estudiante, incrementar sus posibilidades de ingreso en el menor tiempo posible (Gestión, 2017).

En los últimos años, las academias preuniversitarias se han ido posicionando en el Perú. Estos centros, buscan que los estudiantes consoliden lo aprendido a lo largo de su educación escolar y que amplíen sus conocimientos (Pontificia Universidad Católica del Perú [PUCP], 2019). Por lo tanto, su objetivo principal es que, luego de un determinado tiempo, los estudiantes se encuentren preparados académicamente para enfrentar un examen de admisión. Sin embargo, en la búsqueda de una rigurosa preparación académica, descuidan la atención de otras áreas, como es el aspecto emocional. Al respecto, Mello y Hernández (2019) mencionan que, para un buen rendimiento académico de un estudiante se deben considerar variables cognitivas, afectivas, conductuales e institucionales.

En el entorno pre universitario, el estudiante enfrenta una serie de exigencias y estresores que pueden llegar a afectar su desenvolvimiento académico. Por un lado, según Barraza (2006) existen factores externos como la competencia grupal, la sobrecarga de tareas, el ambiente físico desagradable, la falta de incentivos, los conflictos con los asesores o compañeros y las constantes evaluaciones. Por otra parte, Martínez (2014) considera que no se trabajan las experiencias de fracaso en el intento del ingreso a la universidad, las cuales pueden generar una concepción errónea de sí mismo y la devaluación de sus propias capacidades, afectando también su bienestar subjetivo.

Factores tanto internos como externos influyen en el desenvolvimiento académico y en la percepción que el estudiante tiene de sí mismo. Así, Paoloni y Bonetto (2013) consideran que las creencias que uno tenga de sí mismo, particularmente las que refieren a las percepciones de competencia, constituyen un aspecto relevante vinculado con los éxitos y fracasos de los estudiantes en los contextos de aprendizaje. Esto, puede explicar cómo es que dos personas con el mismo grado de habilidad muestran un desempeño diferente, lo que ocurre debido a que el éxito académico demanda procesos reguladores como la autoevaluación, el automonitoreo y el uso de estrategias metacognitivas de aprendizaje, procesos 
que son influidos por un alto grado de creencia en la propia capacidad o autoeficacia (Pajares \& Schunk, 2001).

Se puede definir a la autoeficacia como la percepción o creencia personal ante las propias capacidades para enfrentarse a una situación determinada. Esta creencia influirá en cómo la persona emplea sus recursos para llevar a cabo una acción y finalmente afronta nuevos retos, consiguiendo resultados deseados (Bandura, 1995). Por esto, se sostiene su gran valor predictivo de la conducta humana, debido a que actúa sobre los patrones de pensamientos, emociones, comportamientos y en la motivación que tenga la persona al momento de enfrentar una situación (Bandura, 1995; Blanco, 2010).

La teoría de la autoeficacia de Bandura explica en el ámbito académico cómo los estudiantes con altas expectativas de autoeficacia gozan de una mayor motivación académica, obtienen mejores resultados, autorregulan eficazmente su aprendizaje y muestran una mayor motivación intrínseca al aprender. En consecuencia, la mejora de las expectativas de autoeficacia incrementa la motivación y el rendimiento (González \& Tourón, 1992). Asimismo, González (2005) menciona como desde que el estudiante ingresa a clases comienza a percibir las creencias de autoeficacia, puesto que, evalúa sus expectativas de éxito ante los objetivos propuestos.

En los últimos años, las teorías de la emoción y el bienestar subjetivo susten$\tan$ que los estados afectivos son una función del estado de desarrollo y de la naturaleza de los objetivos personales (Sansinenea et al., 2008). Estos objetivos personales se relacionan con lo que el individuo quiere lograr en un momento determinado. Tomando en cuenta que las emociones influyen sobre el desarrollo de un objetivo, Alarcón (2006) define a la felicidad como un estado afectivo de satisfacción plena que experimenta subjetivamente el individuo en posesión de un bien anhelado, por lo tanto, una persona es feliz al poseer el objeto anhelado y estos bienes que generan felicidad pueden ser de origen variado (materiales, éticos, estético, psicológicos, entre otros).

En el caso de un estudiante preuniversitario, el ingreso a la universidad deseada implicaría el logro de ese objetivo. Para alcanzarlo, necesita de un rendimiento académico suficiente que le permita responder adecuadamente a las demandas de ingreso. Pero, este éxito académico, según Caballero-García y Sánchez Ruiz (2018), también está relacionado con la felicidad, debido a que esta variable funciona como un predictor. Por ende, en esta etapa de preparación se debe proveer al estudiante una serie de beneficios que le permitan sentirse satisfecho con sus capacidades y logros. Asimismo, Mercado (2014) indica que la felicidad se basa en el planteamiento y cumplimiento de metas; además que está relacionado con la satisfacción con la vida y existe una mejora en las expectativas personales. Es importante mencionar que algunos estudios revelan que un incremento de 
la autoeficacia disminuye las conductas antisociales y las alteraciones emocionales, y al mismo tiempo, influye en la mejora de las conductas de cuidado físico (Galleguillos \& Olmedo, 2017). Al respecto, Bandura (2006) recalca que las conductas de autoeficacia autorregulatoria son claves para entender la competencia emocional de las personas y el éxito en las relaciones interpersonales. Por su parte, Caprara y Steca (2005) reconocen que las creencias de la persona sobre su autoeficacia social, favorecen en la conexión social, la amistad, la cooperación y la conducta prosocial. En cuanto a las conductas de cuidado físico, existen autores que han señalado a la autoeficacia como una variable predictora, mencionándola como uno de los elementos para fomentar el estilo de vida saludable (Blanco et al., 2019). Asimismo, para la recuperación de enfermedades o para evitar sus riesgos potenciales; $y$ en el funcionamiento de distintos campos en busca de cambios positivos sobre los estilos de vida como el realizar ejercicio o deporte, bajar de peso, el manejo de enfermedades crónicas, la elección de carrera y el logro de metas académicas y del mundo laboral (Carrasco \& Del-Barrio, 2002).

Según Bandura (1997), las personas consiguen su bienestar como consecuencia del logro de sus objetivos personales, los cuales dependen en gran parte de sus creencias de autoeficacia. Por lo tanto, un funcionamiento mental positivo depende en gran parte de la competencia autopercibida. Así, los procesos cognitivos, afectivos-motivacionales y las habilidades sociales están muy influidos por las creencias de autoeficacia (Pajares, 2002). Por ende, la autoeficacia es una de las características personales que más promueve el bienestar subjetivo y la felicidad (Gómez et al., 2007). De este modo, se identifica la importancia de la autoeficacia en el desempeño de las diferentes actividades que pueda realizar el estudiante en el ámbito académico y también en su bienestar y felicidad.

En la revisión de la literatura, se han identificado investigaciones con ambas variables en población estudiantil. Al respecto, Morillo (2013) investigó la relación entre la autoeficacia y felicidad en estudiantes universitarios. Con base en sus resultados, señala que, existe una relación directa y significativa entre ambas variables $(\mathrm{p}<. \mathrm{ol})$. Asimismo, encontró un alto porcentaje (51.26\%) de estudiantes con un nivel de autoeficacia medio. Por su parte, Rosales (2017), reportó una correlación estadísticamente significativa entre la autoeficacia y felicidad $(\mathrm{p}<.05)$. De igual forma, indicó diferencias significativas según el género en la dimensión alegría de vivir de la variable felicidad ( $\mathrm{p}<.05$ ), a favor de los hombres.

Por otra parte, se ubican estudios que han considerado a las variables autoeficacia o felicidad de forma independiente. Así, por ejemplo, Ornelas et al. (2013) investigaron la autoeficacia percibida en la conducta académica de estudiantes universitarias de México que cursaban el primer ciclo académico. Los resultados evidencian que los perfiles de autoeficacia percibida son muy similares entre las estudiantes de las diferentes carreras profesionales. Además, 
se observó que los perfiles de autoeficacia actual, deseada y alcanzable están relacionados. Es decir, a mayor autoeficacia percibida existe un mayor deseoy mayores posibilidades de ser eficaz. En la misma línea, Covarrubias-Apablaza et al. (2019) analizaron la relación entre la autorregulación del aprendizaje y autoeficacia general en las dimensiones de las metas académicas de estudiantes universitarios chilenos. Los resultados muestran que las correlaciones fueron positivas y significativas. Asimismo, la sub dimensión metas de aprendizaje, es la que presenta mejores indicadores para explicar las metas académicas, considerando la autorregulación del aprendizaje como influyente, más que la autoeficacia.

Por su parte, Morales y Giménez (2019) evaluaron los niveles de autoeficacia percibida en universitarios españoles tomando en cuenta los cursos académicos (desde el primer ciclo hasta el máster). Entre sus resultados, reportan que existen diferencias de la autoeficacia según sexo, siendo los hombres quienes obtienen un mayor puntaje. En cuanto al curso, no se encontraron diferencias estadísticamente significativas, sin embargo, se identificó una variabilidad descendiente, con ligeros repuntes de niveles de autoeficacia, el cual se incrementa considerablementeal llegar al máster.

Por otro lado, Caycho y Castañeda (2015) analizaron la relación entre la felicidad y el optimismo en adolescentes y jóvenes peruanos y paraguayos. Los resultados de su investigación, arrojaron una relación positiva y significativa del optimismo con las variables de felicidad. No se observaron

diferencias estadísticamente significativas en la felicidad y optimismo deacuerdo con el sexoy la nacionalidad. Además, Alarcón y Caycho (2015) relacionaron la gratitud y felicidad en jóvenes de universidades públicas y privadas de Lima Metropolitana. Los resultados evidencian que los factores de la gratitud, reciprocidad y obligación moral correlacionan positiva y significativamente con la felicidad $(\mathrm{r}=.294, \mathrm{p}<.01$; $\mathrm{r}=.293, \mathrm{p}<.01$ ), así como, con los factores sentido positivo de la vida, satisfacción con la vida y realización personal de la variable felicidad. Por otro lado, no se evidenciaron diferencias estadísticamente significativas en la gratitud y la felicidad entre hombres y mujeres.

Como se ha expuesto, no se ha estudiado la relación entre las variables autoeficaciay felicidad en el contexto de los estudiantes preuniversitarios. En ese sentido, el objetivo del presente estudio es determinar la relación entre la autoeficacia y felicidad en estudiantes de academias preuniversitarias de Lima Metropolitana que aspiran a ingresar a la universidad. Asimismo, como objetivo específico se plantea comparar la autoeficacia y felicidad de acuerdo con el sexo, el área de la carrera elegida, el tipo y la ubicación del colegio de procedencia.

\section{Método}

Se realizó una investigación empírica empleando la estrategia asociativa retrospectiva (Ato et al., 2013).

\section{Participantes \\ Participantes}


Los participantes del estudio fueron 303 estudiantes deacademias preuniversitarias, 151 varones y 152 mujeres, cuyas edades estuvieron comprendidas entre los 16 a 23 años $(\mathrm{M}=18.05$; $\mathrm{DS}=1.252)$. La muestra se estimó a través del programa G-power (versión 3.1.9.2), con una potencia de .95 $\mathrm{y}$ un margen de error de .05 .
Se utilizó el tipo de muestreo no probabilístico por conveniencia, debido a que, la elección de la muestra se dio a partir de la participación voluntaria de los estudiantes preuniversitarios que cumplían con las características solicitadas (Kerlinger \& Lee, 2002). En la Tabla 1, se presentan los datos sociodemográficos de los participantes.

Tabla 1.

Datos sociodemográficos de los participantes

\begin{tabular}{|lcc|}
\hline \multicolumn{1}{|c|}{ Característica } & F & $\%$ \\
\hline Área de la carrera elegida & & \\
Letras & 116 & $38.3 \%$ \\
Ciencias & 187 & $61.7 \%$ \\
\hline Tipo de colegio de procedencia & & \\
Estatal & 182 & $60.1 \%$ \\
Particular & 121 & $39.9 \%$ \\
\hline Ubicación del colegio de procedencia & & \\
Lima & 277 & $91.4 \%$ \\
Provincia & 26 & $8.6 \%$ \\
\hline
\end{tabular}

\section{Medidas}

Escala de Autoeficacia general de Schwarzer y Jerusalem (1996)

La versión original fue propuesta por Schwarzer y Jerusalem (1996) y adaptada en el Perú por Grimaldo (2005). Está compuesta por 10 ítems, con un formato de respuesta tipo Likert de 4 alternativas ( $1=$ Incorrecto hasta $4=$ Cierto) que se agrupan en un factor. Para fines de este estudio, se realizó un Análisis Factorial Confirmatorio (AFC), a través del cual se verificó la estructura unidimensional de 10 ítems. Asimismo, la consistencia interna de la escala obtuvo un coeficiente de Alfa de Cronbach de $\alpha=.795$, considerándose un valor aceptable (Cicchetti, 1994).
Escala de Felicidad de Lima (EFL)

Fue elaborada por Alarcón en el 2006. Está compuesta por 27 ítems, con un formato de respuesta tipo Likert con cinco alternativas ( $1=$ Totalmente en desacuerdo hasta $5=$ Totalmente de acuerdo) que se agrupan en 4 factores: 1) Sentido positivo de la vida (SPV), 2) Satisfacción con la vida (SV), 3) Realización personal (RP), y, 4) Alegría de vivir (AV). En este estudio, se realizó un AFC que confirmó las 4 dimensiones originales, pero se decidió eliminar el ítem 11, ya que presentó una carga factorial menora .30. Asimismo, se evaluó la consistencia interna, encontrando valores altos entre .80 y .89 . y moderados entre.70 y 79 (Cicchetti, 1994). De esta forma, se obtuvo un valor alto en la dimensión sentido positivo $(\alpha=.874)$ y valores moderados 
en las dimensiones satisfacción con la vida $(\alpha=.786)$, realización personal $(\alpha=$ $.769)$ y alegría de vivir $(\alpha=.732)$.

\section{Procedimiento}

El proyecto fue aprobado por la Universidad Peruana de Ciencias Aplicadas. Para su ejecución, en primer lugar, se contactó y solicitó la autorización a los responsables de tres academias preuniversitarias. Después, se procedió a la planificación de un cronograma de recolección de datos.

La aplicación de las escalas fue realizada en las mismas academias preuniversitarias y estuvo a cargo de los responsables de la investigación, quienes explicaron los objetivos de la investigación, la forma de la devolución de los resultados, la participación voluntaria y entregaron previamente a los participantes un consentimiento informado.

Una vez recolectado los datos, se trasladó la información a una base de datos en Excel para delimitar las características de la población con base en los datos sociodemográficos. Después, se realizaron los análisis descriptivosy de correlación con el apoyo del Statistical Package for the Social Sciences (SPSS v. 25). En el proceso de análisis, se examinó la distribución normal a través de la prueba de KolmogorovSmirnov. Con base en el resultado de este análisis, se decidió utilizar el coeficiente de correlación de Spearman y se interpretó la magnitud de la correlación considerando la propuesta de Hemphill (2003): bajo $(<.20)$, moderado $(.20$ a .30$)$ y alto
(> .30). A su vez, se empleó la prueba no paramétrica de U de Mann Whitney, a fin de comparar la autoeficacia general y la felicidad en función de las variables sociodemográficas. Finalmente, se estimó el coeficiente de probabilidad de superioridad (PS) como una medida del tamaño del efecto (TE) y se interpretó los valores obtenidos considerando la propuesta de Grissom (1994): pequeño (>.56), mediano $(>.64)$ y grande $(>.71)$.

\section{Resultados}

\section{Análisis correlacional}

Se analizó la normalidad de la distribución de los puntajes mediante la prueba de Kolmogorov-Smirnov. De esta forma, se encontró que los p-valor de la variable autoeficacia y las dimensiones de la variable felicidad fueron menores a .05, lo cual señala la ausencia de normalidad. Con base en este resultado, se decidió hacer uso del coeficiente de correlación de Spearman. Este análisis demuestra una correlación positiva, estadísticamente significativa y con un tamaño de efecto alto entre la autoeficacia general y las dimensiones sentido positivo de la vida (SPV), satisfacción con la vida (SV) y alegría de vivir (AV) de la variable felicidad. A su vez, se evidencia una correlación positiva, estadísticamente significativa y con un tamaño de efecto moderado entre la autoeficacia general y la dimensión realización personal (RP) de la variable felicidad (Tabla 2). 
Tabla 2.

Correlaciones entre el cuestionario de Autoeficacia General (AG) y Felicidad de Lima (FL)

\begin{tabular}{|ccccc|}
\hline $\begin{array}{c}\text { Escala } \\
{[\text { IC95\%] }}\end{array}$ & SPV & SV & RP & AV \\
\hline $\begin{array}{c}\text { Autoeficacia } \\
{[31.71-32.69]}\end{array}$ & $.365^{* *}$ & $.303^{* *}$ & $.277^{* *}$ & $.393^{* *}$ \\
{$[38.36-40.03]$} & {$[21.01-21.94]$} & {$[18.47-19.48]$} & {$[15.61-16.24]$} \\
\hline
\end{tabular}

$\left.{ }^{* *}\right)$ La correlación es significativa en el nivel o,o1 (bilateral).

\section{Análisis comparativo}

Para el análisis comparativo de acuerdo con variables sociodemográficas, se aplicó la prueba U de Mann-Whitney. Según el sexo, no se encontraron diferencias estadísticamente significativas en autoeficacia. Por su parte, en la dimensión satisfacción con la vida (SV) de la escala de felicidad, se encontraron diferencias estadísticamente significativas $(\mathrm{p}<.05)$ a favor de los hombres. Sin embargo, el análisis del tamaño del efecto a través de la probabilidad de superioridad (PS) muestra que no existen diferencias (Tabla 3 ).

Tabla 3 .

Comparación por sexo

\begin{tabular}{|cccccc|}
\hline & $\begin{array}{c}\text { Hombres } \\
\text { Rango promedio }\end{array}$ & $\begin{array}{c}\text { Mujeres } \\
\text { Rango promedio }\end{array}$ & U & Sig. & PS \\
\hline Autoeficacia & 156.13 & 147.90 & 10853 & 0.413 & 0.47 \\
SPV & 149.74 & 154.24 & 11135 & 0.654 & 0.49 \\
SV & 165.31 & 138.78 & 9466 & $0.008^{*}$ & 0.41 \\
RP & 160.31 & 143.74 & 10221 & 0.099 & 0.45 \\
AV & 160.33 & 143.73 & 10218.5 & 0.097 & 0.45 \\
\hline
\end{tabular}

U= U de Mann Whitney; sig.= significancia estadística; $\mathrm{PS}$ = probabilidad de superioridad

Respecto a la comparación por área a la que postulan, tanto en la autoeficacia, como en las dimensiones de felicidad, no se encontraron diferencias estadísticamente significativas. El análisis de la probabilidad de superioridad también reveló la ausencia de diferencias (Tabla 4). 
Tabla 4.

Comparación por áreas

\begin{tabular}{|cccccc|}
\hline & $\begin{array}{c}\text { Letras } \\
\text { Rango promedio }\end{array}$ & $\begin{array}{c}\text { Ciencias } \\
\text { Rango promedio }\end{array}$ & U & Sig. & PS \\
\hline Autoeficacia & 152.30 & 151.81 & 10811 & 0.962 & 0.50 \\
SPV & 163.37 & 144.95 & 9527 & 0.075 & 0.44 \\
SV & 151.20 & 152.49 & 10753.5 & 0.900 & 0.50 \\
RP & 147.19 & 154.99 & 10287 & 0.450 & 0.47 \\
AV & 153.15 & 151.29 & 10712.5 & 0.856 & 0.49 \\
\hline
\end{tabular}

U= U de Mann Whitney; sig.= significancia estadística; $\mathrm{PS}$ = probabilidad de superioridad

Finalmente, considerando el tipo y autoeficaciay felicidad. La estimación de ubicación de colegio de procedencia, la probabilidad de superioridad también se encontró que no existen diferen- evidenció la ausencia de diferencias cias estadísticamente significativas en (Tabla 5).

Tabla 5 .

Comparación por tipo y ubicación del colegio de procedencia

\begin{tabular}{|cccccc|}
\hline & $\begin{array}{c}\text { Estatal } \\
\text { Rango promedio }\end{array}$ & $\begin{array}{c}\text { Particular } \\
\text { Rango promedio }\end{array}$ & U & Sig. & PS \\
\hline Autoeficacia & 152.49 & 151.26 & 10921 & 0.904 & 0.50 \\
SPV & 147.25 & 159.14 & 10146.5 & 0.247 & 0.46 \\
SV & 145.13 & 162.33 & 9761.5 & 0.093 & 0.44 \\
RP & 148.44 & 157.36 & 10362.5 & 0.384 & 0.47 \\
AV & 145.88 & 161.21 & 9896.5 & 0.133 & 0.45 \\
\hline Lima & Rango promedio & Rango promedio & U & Sig. & PS \\
\hline Autoeficacia & 152.28 & 149.02 & 3523.5 & 0.856 & 0.49 \\
SPV & 154.41 & 126.37 & 2934.5 & 0.118 & 0.41 \\
SV & 152.18 & 150.08 & 3551 & 0.907 & 0.49 \\
RP & 152.83 & 143.19 & 3372 & 0.591 & 0.47 \\
AV & 152.18 & 150.06 & 3550.5 & 0.905 & 0.49 \\
\hline
\end{tabular}

U= U de Mann Whitney; sig.= significancia estadística, $\mathrm{PS}=$ probabilidad de superioridad 


\section{Discusión}

El objetivo del estudio fue determinar la relación entre la autoeficacia y felicidad en estudiantes de academias preuniversitarias de Lima Metropolitana. Los resultados evidencian que la autoeficacia se relaciona significativamente y con un tamaño del efecto alto y moderado con las dimensiones de la variable felicidad. Por lo tanto, se puede afirmar que, cuanto más autoeficaces se perciben los estudiantes, también, perciben un mayor sentido positivo con la vida, satisfacción con la vida, alegría de vivir y realización personal.

En lo que corresponde a la interpretación de los resultados considerando los estudios previos, se encontró un hallazgo similar a lo reportado por Morillo (2013) y Rosales (2017), en cuanto existe una relación positiva y significativa entre la autoeficacia y felicidad. Esto, se podría explicar considerando el sustento que señala que la felicidad se basa en el planteamiento y cumplimiento de metas (Mercado, 2014). En el caso de los estudiantes preuniversitarios, este bien anhelado estaría determinado por el ingreso a la universidad deseada, para lo cual, el estudiante, deberá poner en marcha una serie de comportamientos influenciados por la motivación, patrones de pensamientos, emociones, los cuales devienen de la autoeficacia (Bandura, 1995; Blanco, 2010).

Por otra parte, se encontraron diferencias estadísticamente significativas según el sexo en la dimensión alegría de vivir, a favor de los hombres. Esto, coincide con lo reportado por Rosales (2017) y se infiere que los hombres podrían estar experimentando positivamente la vida, lo que implica sentirse bien en la vida en general (Alarcón, 2006). Para este punto, es importante tomar en consideración la participación de los factores asociados a las condiciones de vida de hombres y mujeres (Russo \& Green 1993). Puesto que, las desigualdades en el género pueden repercutir de alguna manera en los niveles de felicidad que tengan, brecha que debe ser menor en sociedades con igualdad de oportunidades, en comparación con aquellas en donde las oportunidades son menores para las mujeres (Tech-Romer et al., 2008).

De otro lado, los hallazgos de este estudio complementan lo reportado por Ornelas et al. (2013), cuyos resultados evidencian similitud en los perfiles de autoeficacia entre los estudiantes de las diferentes carreras profesionales. Esto, se podría deber a que desde la elección de la carrera el estudiante percibe la creencia de autoeficacia, a partir de la evaluación del éxito de sus objetivos (González, 2005). De este modo, se podría explicar que el área a la que postulan los estudiantes, no sería un determinante en los niveles de autoeficacia.

Por otra parte, considerando el sexo, se encontraron resultados similares a los expuestos por Morales y Giménez (2019), en cuanto existen diferencias de la autoeficacia a favor de los hombres en comparación con las mujeres. Las diferencias encontradas pueden ser explicadas mediante la Teoría Social Cognitiva 
(Bandura, 1999), la que sostiene que las expectativas de autoeficacia son uno de los principales condicionantes en la toma de decisiones de cada persona, lo que determina diferencias. Estas diferencias surgen como resultado del proceso de socialización que influye en la diferencia de percepción que construyen hombres y mujeres con relación a las tareas, actividades y ocupaciones que son apropiadas para cada género.

A diferencia de lo reportado en los trabajos de Alarcón y Caycho (2015) y de Castañeda y Caycho (2015), quienes no encontraron diferencias estadísticamente significativas en la felicidad según el sexo. En la presente investigación, se evidenció diferencias significativas en la dimensión satisfacción con la vida, a favor de los hombres. Lo que implicaría una mayor satisfacción por lo que se ha logrado o se está cerca de alcanzar, es decir, la obtención de un bien anhelado (Alarcón, 2006). Esta diferencia podría explicarse por la desigualdad de oportunidades, ya que, de cierto modo, las mujeres necesitan cumplir ciertos roles impuestos por la sociedad, lo que podría dificultar la consecución de objetivos personales.

La presente investigación no está exenta de limitaciones. En primer lugar, al emplear un muestreo de tipo no probabilístico, los resultados no pueden ser generalizados ni concluyentes para toda la población de estudiantes preuniversitarios de Lima Metropolitana. Por lo tanto, se sugiere que en futuras investigaciones se empleen muestreos de tipo probabilístico. En segundo lugar, en el estudio participaron estudiantes provenientes de academias preuniversitarias enfocadas en brindar una preparación exclusiva para el ingreso a algunas universidades. Por ello, se sugiere que en próximas investigaciones se incluyan a estudiantes de otras academias preuniversitarias.

Considerando la relación existente entre las variables en estudio, es relevante promover el desarrollo de aspectos emocionales en los estudiantes preuniversitarios. De este modo, el estudiante dispondrá de recursos para enfrentarse a las demandas y exigencias del contexto. Por lo tanto, sería propicio incorporar cursos, programas o actividades extracurriculares donde se fomente y refuerce las competencias emocionales de los estudiantes. A su vez, es necesario impulsar el desarrollo de otras investigaciones que indaguen diferentes variables en la población de los estudiantes preuniversitarios.

\section{Conclusiones}

En conclusión, en la presente investigación se encontró una relación significativa y con tamaño del efecto alto y moderado entre la autoeficacia y las dimensiones de la variable felicidad en estudiantes de academias preuniversitarias de Lima Metropolitana. Por otro lado, considerando las variables sociodemográficas, para la autoeficacia, no se encontraron diferencias en relación con el sexo, área a la que postulan, tipo y ubicación de procedencia del colegio. 
Por su parte, en lo que corresponde a la dimensión satisfacción con la vida de la variable felicidad, se evidenció diferencias estadísticamente significativas a favor de los hombres, pero, el análisis del tamaño del efecto revela que no existen diferencias.

Finalmente, se comprende que la autoeficacia y felicidad son variables relacionadas que influyen sobre el proceso de aprendizaje y el desempeño del estudiante en la obtención de un bien anhelado, en este caso, el ingreso a la universidad.

\section{Financiamiento}

El proyecto fue autofinanciado.

\section{Conflictos de interés}

Los autores declaran que no tienen conflictos de interés. 


\section{Referencias}

Alarcón, R. (2006). Desarrollo de una escala factorial para medir la Felicidad. Revista Interamericana de Psicología, 40(1), 99-106. http://pepsic.bvsalud.org/pdf/rip/ v4on1/v4onia1o.pdf

Alarcón, R., \& Caycho, T. (2015). Relaciones entre gratitud y felicidad en estudiantes universitarios de lima metropolitana. Psychología: Avances de la Disciplina. Avances de la disciplina, 9(1), 59-69. https://doi.org/10.21500/19002386.993

Ato, M., López, J., \& Benavente, A. (2013). Un sistema de clasificación de los diseños de investigación en psicología. Anales de Psicología, 29(3), 1038-1059. http:// www.redalyc.org/articulo.oa?id=16728244043

Atuncar Yrribari, J., Izaguirre Maguiña, R., Torres Calderón, A., León Nuñez, C., \& Guevara Minaya, B. (2015). Sistema blending de formación preuniversitaria. Electrónica, 18(2), 104-109. https://revistasinvestigacion.unmsm.edu.pe/index. php/electron/article/view/15291/13239

Bandura, A. (1995). Exercice of personal and collective efficacy. En A. Bandura (Ed.) Self-efficacy in Changing Societies (pp. 1-45). Cambridge University Press. https:// www.doi.org/10.1017/CBO9780511527692.003

Bandura, A. (1997). Self-Efficacy: The Exercise of Control. W. H. Freeman and Company.

Bandura, A. (2006). Adolescent development from an agentic perspective. En F. Pajares \& T. Urdan (Eds.). Self-efficacy beliefs of adolescents (pp. 1-43). IAP Information Age Publishing.

Barraza, M. (2006). Un modelo conceptual para el estudio del estrés académico. Revista Electrónica de Psicología Iztacala, 9(3), 110-129. http://www.psicologiacientifica.com/estres-academico-modelo-conceptual/

Blanco, A. (2010). Creencias de autoeficacia de estudiantes universitarios: un estudio empírico sobre la especificidad del constructo. RELIEVE, 16(1), 1-28. http://www. uv.es/RELIEVE/v16n1/RELIEVEv16n1_2.htm

Blanco, L., Díaz-Leal, A., Ornelas, M., Mondaca, F., \& Solano, N. (2019). La autoeficacia en el cuidado de la salud en la predicción de la satisfacción con la vida. Revista Iberoamericana de Diagnóstico y Evaluación Psicológica, 52(3), 53-65. https://doi.org/10.21865/RIDEP52.3.05 
Caballero-García, P.A., \& Sánchez-Ruíz, S. (2018). La felicidad en estudiantes universitarios. ¿Existen diferencias según género, edad o elección de estudios? Revista Electrónica Interuniversitaria de Formación del Profesorado, 21(3), 1-18. https:// doi.org/10.6o18/reifop.21.3.336721

Carrasco, O., \& Del-Barrio, V. (2002). Evaluación de la autoeficacia en niños y adolescentes. Psicothema, 14(2), 323-332. http://www.psicothema.com/pdf/727.pdf

Caprara, G., \& Steca, P. (2005). Affective and social self-regulatory efficacy beliefs as determinants of positive thinking and happiness. European Psychologist, 10(4), 275-286. https://doi.org/10.1027/1016-9040.10.4.275

Caycho, T., \& Castañeda, M. (2015). Felicidad y Optimismo en adolescentes y jóvenes peruanos y paraguayos: Un estudio predictivo. Salud E Sociedad, 6(3), 250-263. https://doi.org/10.22199/So7187475.2015.0003.00005

Cicchetti, D. (1994). Pautas, criterios y reglas generales para evaluar instrumentos de evaluación estandarizados y estandarizados en psicología. Evaluación Psicológica, 6(4), 284-290. http://doi.apa.org/getdoi.cfm?doi=10.1037/1040-3590.6.4.284

Covarrubias-Apablaza, C., Alcosta-Atognoni, H., \& Mendoza-Lira, M. (2019). Relación de Autorregulación del Aprendizaje y Autoeficacia General con las Metas Académicas de Estudiantes Universitarios. Formación Universitaria, 12(6), 103-113. https://dx.doi.org/10.4067/So718-50062019000600103

El Comercio (o7 de enero de 2010). Jóvenes empezaron clases en academias con un solo sueño: ser universitarios. https://archivo.elcomercio.pe/sociedad/lima/ jovenes-empiezan-clases-academias-sola-idea-universitarios-noticia-392681

Galleguillos, P., \& Olmedo, E. (2017). Autoeficacia académica y rendimiento escolar: un estudio metodológico y correlacional en escolares. ReiDoCrea, 6(14), 156-169. https://www.ugr.es/ reidocrea/6-14.pdf

Gestión (12 de julio de 2017). Claves para lograr ingresar a una universidad pública y no fracasar en el intento. https://gestion.pe/tendencias/management-empleo/ claves-lograr-ingresar-universidad-publica-fracasar-139231-noticia/?ref=gesr

Grimaldo, M. (2005). Validez y confiabilidad de la Escala de Autoeficacia General de Baessler y Schwarzer. Cultura, 19, 213-229. http://www.revistacultura.com. pe/revistas/RCU_19_1_propiedades-psicometricas-de-la-escala-de-autoeficacia-general-de-baessler-schwarzer.pdf 
Gómez, V., Villegas de Posada, C., Barrera, F., \& Cruz, J. E. (2007). Factores predictores de bienestar subjetivo en una muestra colombiana. Revista Latinoamericana de Psicología, 39(2), 311-325. https://www.redalyc.org/articulo.oa?id=80539208

González, A. (2005). Motivación académica. Teoría, aplicación y evaluación. Pirámide.

González, M., \& Tourón, J. (1992). Autoconcepto y rendimiento escolar: sus implicaciones en la motivación y en la autorregulación del aprendizaje. EUNSA

Grissom, R. J. (1994). Probability of the superior outcome of one treatment over another. Journal of Applied Psychology, 79(2), 314-316. https://doi. org/10.1037/o021-9010.79.2.314

Hemphill, J. F. (2003). Interpreting the magnitudes of correlation coefficients. American Psychologist, 58(1), 78-79. https://doi.org/10.1037/0003-066X.58.1.78

Ipsos. (19 de octubre de 2018). Imagen y percepción de institutos y universidades. https://www.ipsos.com/es-pe/imagen-y-percepcion-de-institutos-y-universidades

Kerlinger, F., \& Lee, H. (2002). Muestreo y aleatoriedad. En Investigación del comportamiento. McGraw-Hill.

Ludena, L. (o8 de marzo de 2019). Admisión San Marcos: Más de 20 mil postulantes rendirán examen este fin de semana. La República. https://larepublica.pe/ sociedad/1426743-admision-san-marcos-2019-20-mil-postulantes-rendiran-examen-semana-aatp/

Martínez, M. (24 de febrero de 2014). No ingresé a la universidad, ¿Todo está perdido? La República. https://larepublica.pe/archivo/775333-no-ingrese-a-la universidad-todo-esta-perdido

Mello, J. D., \& Hernández, A. (2019). Un estudio sobre el rendimiento académico en Matemáticas. Revista Electrónica de Investigación Educativa, 21, e29, 1-10. https://dx.doi.org/10.24320/redie.2019.21.e29.2090

Mercado, M. (2014). Concepto de felicidad en jóvenes. Ajayu Órgano de Difusión Científica del Departamento de Psicología UCBSP, 12(1), 64-78. http://www.scielo.org. bo/scielo.php?script=sci_arttext\&pid=S2077-21612014000100004\&lng=es\&tlng=es.

Ministerio de Educación (2018). Tasa de transición a educación superior (\% de egresados del nivel educativo anterior). http://escale.minedu.gob.pe/ueetendencias2016 
Morales, F., \& Giménez, J. (2019). Relación entre el curso académico y los niveles de autoeficacia general percibida en universitarios. Magister: Revista de Formación del Profesorado e Innovación Educativa, 31(1), 25-30. https://dialnet.unirioja.es/ servlet/articulo?codigo $=7081936$

Morillo, G. (2013). Autoeficacia y felicidad en ingresantes de una universidad peruana de Trujillo. Revista de psicología, 15(1), 22-36. http://revistas.ucv.edu.pe/index. php/R_PSI/article/view/209/118

Ornelas, M., Blanco, H., Gastelúm, G., \& Chávez, A. (2013). Autoeficacia percibida y conducta académica. (Tesis de licenciatura). Universidad Autónoma de Chihuahua, México.

Pajares, F. (2002). Overview of Social Cognitive Theory and Self-Efficacy. Emory University.

Pajares, F., \& Schunk, D. (2001). Self-beliefs and school success: self-efficacy, self-concept, and school achievement. En R. Riding \& S. Rayner (eds.) Self-perception (pp. 239- 266). Ablex Publishing.

Paoloni, P., \& Bonetto, V. (2013). Creencias de autoeficacia y rendimiento académico en estudiantes universitarios. Revista PsicologíaCientífica.com, 15(5). https://www. psicologiacientifica.com/creencias-de-autoeficacia-y-rendimiento-academico/

Peñafiel, I., Flores, J., \& Vaca, S. (2019). Percepción de estudiantes universitarios con respecto a la elección de su carrera profesional - una decisión de gran trascendencia. Revista Atlante: Cuadernos de Educación y Desarrollo. https://www.eumed. net/rev/atlante/2019/o2/estudiantes-carrera-profesional.html

Pontificia Universidad Católica del Perú (2019). Academias preuniversitarias. De la gran transformación a la hoja de ruta. San Miguel, Perú.: PUCP Vicerrectorado Académico. https://vicerrectorado.pucp.edu.pe/academico/noticias/ academias-preuniversitarias-la-gran-transformacion-la-hoja-ruta/

Rosales, A. (2017). Autoeficacia y Felicidad en estudiantes universitarios de la carrera de una universidad privada de Lima Sur. (Tesis licenciatura). Universidad Autónoma del Perú, Lima, Perú.

Russo, N. F., \& Green, B. L. (1993). Women and mental health. En F. L. Denmakr \& M. A. Paludi (Eds.), Psychology of women: A handbook of issues and theories (pp. 379-436). Greenwood. 
Sansinenea, E., Gil de Montes, L., Agirrezabal, A., Larrañaga, M., Ortiz, G., Valencia, J. F., \& Fuster, M. (2008). Autoconcordancia y autoeficacia en los objetivos personales: ¿Cuál es su aportación al bienestar? Anales de Psicología, 24(1), 121-128. https://www.redalyc.org/articulo.oa?id=167/16724115

Superintendencia Nacional de Educación Superior Universitaria (2019). Universidades. https://www.sunedu.gob.pe/lista-universidades/

Recibido: 11 de marzo de 2021

Revisado: 5 de junio de 2021

Aceptado: 10 de julio de 2021 
Rev. Psicol. (Arequipa. Univ. Catól. San Pablo) / Año 2021 / Vol 11 / № 1 / pp. 145-167

ISSN 2306-0565 versión impresa / ISSN 2311-7397 versión on line

\title{
Una aproximación a la clasificación de heridas afectivas
}

An Approach to the Clasification of Affective Wounds

Paola Rodríguez Pacas

Centro de Estudios Areté, Medellín, Colombia

iD https://orcid.org/oooo-0003-3215-2650

Humberto Del Castillo Drago

Centro de Estudios Areté, Medellín, Colombia

(iD https://orcid.org/oooo-0oo2-9135-8862

Correspondencia: psicologohumberto@centroarete.org

Mónica Caballero Andrade

Centro de Estudios Areté, Medellín, Colombia

(iD https://orcid.org/oooo-0oo2-2732-2566

\section{Resumen}

Las heridas afectivas son situaciones o acontecimientos fuertes que producen una alteración en la afectividad de la persona. Desde el modelo de la Psicoterapia de la Reconciliación (Del Castillo, 2016), se ha visto que dichas heridas pueden aparecer a lo largo de la historia personal, tanto en el ámbito familiar como en otras áreas vitales. Este artículo procura hacer una revisión de las manifestaciones psicológicas que las heridas afectivas tienen en la persona adulta, y además, presentar una clasificación y definición de las mismas. En general, los resultados indican que las heridas afectivas sí tienen consecuencias clínicamente significativas en el componente psicológico, y que estas pueden ser clasificadas para facilitar su identificación durante el proceso psicoterapéutico.

Palabras clave: Psicoterapia, trauma, herida afectiva, reconciliación personal.

\begin{abstract}
Affective wounds are powerful situations or events that produce an alteration in the affectivity of the person. From a Reconciliation Psychotherapy model (Del Castillo, 2016), it has been seen that these wounds can appear throughout one's personal history, both in the family environment and in other vital areas. This article attempts to outline the psychological manifestations that affective
\end{abstract}


injuries have in adults, and also present a classification and definition of these emotional wounds. Furthermore, it seeks to define and classify them according to the conditions in which they appear. In general, the results indicate that affective wounds do have clinically significant consequences on the psychological functioning, and that these consequences can be classified in order to facilitate their identification during the therapeutic process.

Keywords: Psychotherapy, trauma, affective wound, personal reconciliation.

\section{Introducción}

\section{Noción de trauma psicológico y heridas afectivas}

En la actualidad, se ha visto cada vez más un cambio en la actitud de la sociedad frente a la salud mental, particularmente frente a temas en los que su "felicidad" o bienestar psicológico se ve comprometido. En su libro, Norman Bradburn (1969) argumenta que, cuando se habla de bienestar psicológico, no se pretende indagar por la presencia o ausencia de diagnósticos psiquiátricos, sino describir los problemas cotidianos a los que se enfrentan las personas mientras luchan por cumplir sus metas de vida. Este autor distingue el afecto positivo del afecto negativo, e investiga cómo los macro o micro-cambios sociales e interpersonales influyen en el bienestar subjetivo de las personas. Más adelante, Carol Ryff (1989), basada en la teoría de Bradburn (1969), busca establecer los índices del funcionamiento personal positivo mediante la operacionalización de las seis dimensiones correspondientes al bienestar psicológico: aceptación personal, relaciones interpersonales positivas, autonomía, dominio ambiental, propósito de vida y crecimiento personal. A día de hoy, en la práctica clínica se ve cada vez más que las personas tienen serias dificultades para vivir adecuadamente muchas de las dimensiones del bienestar psicológico propuestas por Ryff (1989). Muchas veces, llegan a consulta sin saber a qué se atribuye su malestar.

Generalmente, en la Psicología se suele recurrir a la palabra "trauma" para describir esos acontecimientos que generan sufrimiento en la persona, y que en el CIE-11 (2018) se definen como: «cualquier exposición a una situación estresante de naturaleza excepcionalmente amenazante u horrorizante que probablemente producirá un malestar profundo en la mayoría de las personas» (p. 11). Sin embargo, el trauma y sus consecuencias dependen de tantos factores, que se ha tenido que ampliar el repertorio de situaciones potencialmente traumáticas, especialmente porque se ha visto que las manifestaciones traumáticas no se dan uniformemente en toda la población (Pereda et al., 2013). En otras palabras, el concepto de "trauma" o de "experiencia traumática” varía según el umbral de vulnerabilidad, los recursos de afrontamiento y el entorno socio-cultural de cada persona.

La noción de trauma sevuelve relevanteen la actualidad debido a que es una situación que puede generar un cambio significativo 
en la afectividad de la persona, siendo definido este último concepto por Sarráis (2016) como:

La facultad psíquica por la que las vivencias conscientes nos afectan. Permite convertir en experiencia interna (vivencia) cualquier contenido de conciencia y, así, experimentar íntimamente las realidades exteriores y las de uno mismo. Su función es dotar de significado personal la propia experiencia. (p. 141)

Samper (2016) afirma que el trauma psicológico afecta a todo el ser de la persona, por lo cual sus manifestaciones y consecuencias se podrán observar a nivel psíquico y corporal. Figueroa, Cortés, Accatino y Sorensen (2016) añaden que si los traumas más graves no se manejan, es posible que dejen diversas secuelas psicológicas, como Trastorno de Estrés Postraumático (TEPT), trastornos de ansiedad, trastornos del humor, entre otros. Adicionalmente, Figueroa et al. (2016) argumentan que las secuelas emocionales de los traumas generan una variedad de problemáticas psicosociales que pueden dificultar la realización y el bienestar de la persona, como serían los problemas maritales, la disfunción familiar, la baja laboral, el abuso de sustancias y el suicidio.

Sin embargo, es llamativo ver cómo en la actualidad, existen situaciones que, si bien no catalizan la aparición inminente de un trastorno psiquiátrico tras su vivencia, alteran la afectividad de la persona y llegan a considerarse "eventos potencialmente traumáticos”. Según Shapiro (2013), este tipo de eventos tienen la capacidad de generar pensamientos intrusivos, sentimientos de culpa, sueños perturbadores y aislamiento social. Además, argumenta que estas alteraciones pueden aparecer aunque no haya un diagnóstico de Trastorno de Estrés Postraumático, y que son una señal de que la persona tiene recuerdos no procesados que están generando el malestar. Los eventos potencialmente traumáticos pueden aparecer en distintas etapas del desarrollo, y debido al sufrimiento que traen consigo, pueden generar creencias y actitudes disfuncionales que producen un daño en la dimensión biológica, psicológica y espiritual de la persona, y sientan las bases para el desarrollo de patologías psiquiátricas graves. Shapiro (2013) resalta que, hasta los eventos "aparentemente menores" desde una perspectiva de adultos, pueden ser las causas del malestar que vive la persona en la actualidad, y Salgado (2014) apoya esta idea, argumentando que: «existe un gran vacío existencial y carencias afectivas que se traducen en una mayor prevalencia a nivel mundial de cuadros como la ansiedad, la depresión y estrés que lamentablemente forman parte de la vida, desde edades muy tempranas» (p. 123).

Desde el modelo del Centro Areté, estos eventos se denominan "heridas afectivas", y corresponden al principal elemento de intervención de la Psicoterapia de la Reconciliación (Del Castillo, 2016). Se entiende que una herida afectiva es una situación o acontecimiento fuerte que altera y afecta todo el componente afectivo de la persona, produciendo un daño en la dimensión física, psicológica y espiritual de la misma (Del Castillo, 
2016). Estas pueden darse por la no satisfacción de la necesidad afectiva, o por una satisfacción exagerada de la misma. En concreto, Del Castillo (2016) afirma que una inadecuada satisfacción de la necesidad afectiva produce heridas que, si no se cuenta con los recursos psicológicos o con una capacidad de resiliencia para afrontarlas, pueden generar graves afecciones y trastornos en la persona. No obstante, sin importar que se den por falta o por exceso, cuando las heridas afectivas aparecen desde la infancia, pueden catalizar la formación de esquemas cognitivos maladaptativos, creencias nucleares disfuncionales y, eventualmente, trastornos mentales. Shapiro (2013) expone que estos esquemas, creencias y trastornos mentales son únicamente el síntoma, no la causa, de la problemática del consultante. En definitiva, la causa serían los recuerdos o eventos que no han sido procesados adecuadamente, y se convierten en los agentes que generan reacciones desproporcionadas, y conductas destructivas con uno mismo y con los demás.

\section{La relevancia clínica de las heridas afectivas}

Se ha visto que cuando las heridas están ligadas a acontecimientos en la historia personal, estas producen un marcado dolor y sufrimiento (Del Castillo, 2016) que, dependiendo de la vulnerabilidad de cada uno, pueden generar pensamientos, emociones y conductas disfuncionales y perjudiciales en las personas. Sarráis (2016) añade a esta idea que, si bien la afectividad es fuente de conocimiento que nos ayuda a saber si la realidad nos afecta positiva o negativamente, tiene una doble función: sirve como un motor de la conducta, impulsa a tener comportamientos y acatar acciones orientadas a mantener o aumentar los afectos positivos, y a suprimir o reducir los negativos. En otras palabras, los afectos muchas veces entran en conflicto con la fuerza de la voluntad, y pueden llevar a la persona a desarrollar y mantener conductas que le perjudican en un intento de reducir su malestar.

De acuerdo a Bourbeau (2014), hay algunos síntomas que delatan la presencia de esta dinámica, como son los síntomas ansiosos, miedos, sentimientos de culpa, vergüenza e inseguridad, reacciones desproporcionadas ante los eventos, poca valoración personal, las compulsiones y, en general, un patrón negativo de conducta. Por tanto, se vuelve relevante intervenir en estos choques o heridas en la afectividad para que la persona no se vea envuelta en patrones vitales disfuncionales.

Si bien Bourbeau (2014) ha logrado describir adecuadamente algunas de las manifestaciones de las heridas afectivas, se encuentra que aún no hay investigaciones o revisiones teóricas que describen las consecuencias psicológicas que corresponden a la presencia de cada tipo de herida. Por otro lado, aunque Bourbeau (2014) ha clasificado las heridas en cinco tipos (el rechazo, el abandono, la humillación, la traición y la injusticia), en la revisión literaria no se ha concertado una 
clasificación definitiva, observándose cierta discrepancia entre los autores. Por lo que, es necesario realizar una clasificación que abarque todos los tipos de heridas, así como el impacto de cada una de ellas en las personas que las vivencian.

\section{Objetivos}

El objetivo principal de esteartículo de revisión es mostrar el estado actual de conocimiento acerca de las heridas afectivas propuestas por el modelo de la Psicoterapia de la Reconciliación, así como describir las consecuencias psicológicas que tienen en la persona adulta. Además, como objetivos específicos del artículo se enumeran los siguientes: 1) presentar la actual clasificación de heridas afectivas y sus definiciones, e 2) identificary sintetizar los principales impactos que tienen las heridas afectivas en el componente psicológico del adulto.

\section{Método}

\section{Protocolo y registro}

El presente trabajo tendrá como objetivo proponer una clasificación de las heridas afectivas, así como sus respectivas consecuencias en la dimensión psicológica de la persona. Con este objetivo en mente, se decidió elaborar un artículo de revisión basado en el formato IMRyD, propuesto por Instituto Americano de Estándares Nacionales en 1972 (Camps, 2007).

En concreto, el formato IMRyD es el acrónimo de los apartados que conforman la estructura general del artículo científico: introducción, métodos, resultadosy discusión (García y Castellanos-Verdugo, 2007). Según García y Castellanos-Verdugo (2007), esta estructura está diseñada para cualquier estudio que busca describir paso a paso el proceso de investigación llevado a cabo, $y$ «ayuda a guiar a directores, revisores y lectores en la consulta, comprensión y evaluación de un informe de una investigación científica» (García \& Castellanos-Verdugo, 2007, p. 3).

\section{Fuentes de información}

Esta revisión se basó en los artículos y estudios recopilados a partir de las siguientes fuentes:

UNIKA. Base de datos unificada desarrollada por la Universidad de Navarra. Esta herramienta hace una síntesis de los catálogos de la Biblioteca de la Universidad de Navarra, haciendo uso de los portales de DADUN y de SABIO (Universidad de Navarra, 2011). La búsqueda en esta fuente se comenzó el 11 de junio de 2020 y finalizó el 16 de septiembre de 2020.

Science Direct. Base de datos que da acceso por suscripción a publicaciones científicas y académicas en el ámbito de la medicina y la salud. La biblioteca electrónica contiene monografías académicas, guías técnicas y otros textos de referencia en texto completo. La búsqueda en esta fuente se comenzó el 11 de junio de 2020 y finalizó el 16 de septiembre de 2020 .

SciELO. Este sitio es la aplicación modelo de la metodología SciELO, con la cual se pretende divulgar por vía electrónica publicaciones periódicas y científicas 
que son compatibles con las iniciativas internacionales más importantes. Además, también pretende ser una base de datos bibliográfica para literatura científica y producir indicadores para subsidiar estudios de bibliometría, informetría y cienciometría (Packer et al., 2001).

EBSCOhost: es una base de datos que ofrece textos completos, referencias y resúmenes de publicaciones periódicas, científicas y académicas, de diferentes áreas de las ciencias y humanidades (Plasencia, 2008). La búsqueda en esta fuente se comenzó el 11 de junio de 2020 y finalizó el 16 de septiembre de 2020 .

\section{Búsqueda}

En la búsqueda del presente trabajo, se procuró incluir publicaciones tanto en español como en inglés, publicadas desde el 2010 hasta la actualidad, y cuyos contenidos estuvieran directamente relacionados al concepto de "herida afectiva" que intentábamos desarrollar. Las palabras clave que se utilizaron en los distintos buscadores son las siguientes: "Efectos psicológicos abandono físico", "Efectos psicológicos abandono psicológico", "Consecuencias psicológicas maltrato físico", "Consecuencias psicológicas maltrato psíquico", "Consecuencias del amor posesivo", "Conflictos conyugales efectos", "Consecuencias violencia intrafamiliar", "Consecuencias muerte de familiar", "Consecuencias psicológicas abuso sexual", "Efectos experiencias sexuales tempranas" , "Early sexual experiences",
"Consecuencias fracaso en amistades", "Efectos del duelo", "Consecuencias psicológicas ruptura amorosa”, "Consecuencias del acoso", "Bullying", "Bullying consequences", "Consecuencias psicológicas fracaso académico", "Consecuencias psicológicas fracaso laboral", "Fracaso académico y motivación", "Fracaso académico y autoestima", "Limitaciones intelectuales y motivación”, "Autoconcepto negativo", "Sentimientos de inutilidad psicología", "Consecuencias rechazo al cuerpo", “Consecuencias estigmatización”, "Consecuencias psicológicas aborto"

Cada término arrojó distintas cantidades de resultados, y se fueron eliminando automáticamente los artículos repetidos.

\section{Criterios de inclusión y exclusión}

Para este artículo, se seleccionaron artículos que cumplieran con los siguientes criterios de inclusión:

a) Artículos o investigaciones que fueron publicadas hace diez años o menos.

b) Publicaciones que estudian las consecuencias psicológicas de las heridas afectivas con personas mayores de 18 años.

c) Estudios que plantean una definición sobre los conceptos que se buscaban desarrollar en profundidad.

d) Investigaciones sobre las consecuencias que las heridas afectivas propuestas pueden generar en el bienestar psicológico de las personas. 
Con respecto a los criterios de exclusión, se tomaron en cuenta los siguientes:

a) Publicaciones de hace más de diez años.

b) Trabajos fin de grado (TFG), trabajos fin de máster (TFM) o tesis doctorales.

c) Estudios que no investigaban los efectos psicológicos de las heridas propuestas.

d) Investigaciones llevadas a cabo en poblaciones específicas (por países, por sexo, por nivel socioeconómico, etc.).

\section{Proceso de extracción de datos y lista de datos}

La extracción de datos de las publicaciones seleccionadas para este artículo se llevó a cabo por medio del análisis a texto completo de cada publicación, con el objetivo de decidir si los estudios cumplían con los criterios de inclusión mencionados en el apartado anterior, o no. Luego de esta revisión, se incorporó la nueva información a las definiciones de heridas afectivas propuestas en el libro, "Reconciliación de la historia personal" (Del Castillo, 2016).

\section{Resultados}

Al día de hoy, las heridas afectivas son clasificadas en dos grandes contextos: heridas familiares y heridas de otros ámbitos. Las heridas afectivas familiares son aquellas que se generan en el núcleo familiar de la persona, por lo que suelen estar relacionadas con figuras importantes de este sistema. La importancia de las heridas familiares radica en que impiden el desarrollo correcto del concepto de sí mismo y de la recta valoración personal. Esto se hace evidente desde la noción de que las heridas afectivas surgen por defecto o por exceso de la satisfacción de una necesidad afectiva (Del Castillo, 2016). En la misma línea, Shapiro (2013) menciona que, aunque no existan recuerdos tangibles de las heridas, puede pasar que hasta los padres que más buscan apoyar y hacer lo mejor para sus hijos, terminan enredándolos en una "red" de síntomas y dolor que los niños no procesan a nivel consciente. Kleponis (2018) añade que muchas son las personas que experimentan rechazo y abandono por parte de sus padres. Otros experimentan abuso, ya sea psicológico, emocional o sexual, que se constituyen en heridas de la familia de origen y que pueden incluir abusos, adicción, muerte, divorcio, abandono y rechazo. El mencionado autor destaca que todos los niños necesitan sentirse amados, seguros, valorados y protegidos por los adultos; al no recibir nada de esto, dichas experiencias pueden ser traumáticas para los niños (Kleponis, 2018).

Ya sea por un exceso o defecto en la satisfacción de las necesidades emocionales, el trato de los padres y la familia con el niño se vuelve un factor influyente en la calidad y el tipo de relaciones que este buscará y tendrá en la adultez. Polaino (2010) afirma que la ausencia del padre, su no 
comparecencia y desencuentro con el hijo, su deslocalización en el hogar, condiciona poderosamente el desarrollo afectivo tan anómalo en los hijos. Un desarrollo nefasto, que hace daño al hijo, genera distancia y rencores con el padre y, lo que es peor, lo incapacita a la larga para hacer feliz a la mujer de su vida. (p. 27)

Se considera importante entender cómo la insatisfacción de las necesidades primordiales de un niño puede generar problemas psicológicos, esquemas maladaptativos, déficits en la personalidad o trampas vitales (Young, 2013). Sin embargo, estas heridas, que se transforman en "patrones" de relación y que configuran la concepción que se tiene de uno mismo y del mundo, eventualmente terminan generandoalgún malestar importante en el sujeto, por lo que se hace relevante identificarlas para, posteriormente, poder aceptarlas, reconciliarlas y vivir una vida virtuosa y plena.

La actual clasificación de las heridas afectivas familiares se presenta a continuación:

Abandono físico: hace referencia a la falta de respuesta de los padres o cuidadores a las necesidades físicas de los hijos, como son el alimento, abrigo, higiene, atención de la salud y cuidado. De acuerdoa Young, Klosko y Janet (2012), el abandono físico también puede hacer referencia a situaciones diversas, como cuando el niño se ve separado de uno de sus cuidadores por un tiempo prolongado, cuando el niño fue criado por niñeras, instituciones o internados; incluyendo, cualquier situación en la que la relación con alguno (o ambos) padres se perdió, y generó, como consecuencia, respuestas de ansiedad, depresión o ira (Young et al., 2012). Suele manifestarse especialmente como una dificultad en las relaciones íntimas, en las que aparecen miedos relacionados a un posible abandono, que gatillan respuestas afectivas y conductuales disfuncionales.

Abandono psicológico: situación en la que los padres juegan con las necesidades emocionales básicas de los hijos, o llevan a cabo comportamientos que son insensibles al nivel de desarrollo de los niños (Zeanah \& Humphreys, 2018). Estos últimos se refieren a cualquier tipo de acto que comprometa la seguridad psíquica, la aceptación, la autoestima o la autonomía del niño; por ejemplo, falta de contacto o cuidado afectivo, causado por la presencia de sentimientos de indiferencia o rencor hacia los hijos. Según Godbout et al. (2019), cuando se presenta esta herida, el niño crece creyendo que es intrínsecamente inaceptable y no merecedor de ser amado, por lo que desarrolla un esquema de vulnerabilidad e impotencia, y termina desarrollando alguna de las siguientes tendencias: ansiedad por abandono o evitación de la intimidad. Por un lado, la ansiedad por abandono representa el miedo que tiene la persona de ser rechazado por los demás, lo cual lleva a que esta se encuentre híper-vigilante a cualquier señal de amenaza en sus relaciones. Por otro lado, la evitación de la intimidad, implica la supresión emocional y la incomodidad con la cercanía, que sirve para reducir la probabilidad de afectos negativos que pueden surgir por rechazo o abandono. Así mismo, esta herida se traduce como un "sentimiento de vacío", sensación que lleva al niño a pensar que 
está destinado a estar solo (Young et al., 2012); manifestándose una incorrecta valoración de sí mismo, e impidiendo la adecuada realización personal (Del Castillo, 2016).

Maltrato físico y psíquico: describe la agresión por parte de uno, o ambos cuidadores, hacia la integridad física o psíquica del resto de los miembros de la familia; en la que tanto los hijos que son maltratados, como sus agresores, sufren como consecuencia de la agresión. Esta tendencia es característica de los padres que tienen un estilo educativo autoritario, en el que la fuerza, las amenazas, los insultos y la intimidación suelen ser usados para educar. Estos aspectos pueden causar graves lesiones y daños psicológicos en los agredidos, a veces propiciando el desarrollo de un trastorno de la personalidad (Del Castillo, 2016). Esta herida afectiva puede repercutir en un inadecuado sentido de valoración personal como resultado de la privación de singularidad que vivió la persona, y manifiesta sus consecuencias tanto en la vida adulta de la víctima como en la sociedad en la que esta se desenvuelve ya que afecta las relaciones interpersonales (Forero et al., 2010).

\section{Super-corrección e hiperexigencia:} tendencia de padres o cuidadores que hacen vivir a sus hijos bajo el peso del perfeccionismo; que a diferencia de la búsqueda de la perfección, que es un "valor" humano, el perfeccionismo es un hábito riguroso, exteriorista, y se queda en la perfección por la perfección; es por eso que este tipo de herida se vuelve un impedimento para el desarrollo personal y para la recta valoración de sí mismo (Del Castillo, 2016). La persona con una herida afectiva basada en la super-corrección tiene dificultades para adaptarse, es inflexible y rígida, se le hace imposible vivir con espontaneidad y es incapaz de improvisar soluciones, vive constantemente bajo el peso de la culpa, ya que se esfuerza a diario para alcanzar la perfección, que en realidad, es imposible.

\section{Ausencia de confianza y comunica-} ción: hace referencia a la falta de comunicación entre padres e hijos, que impide el desarrollo de la confianza y la comunicación entre los miembros de la familia. Esta tendencia suele aparecer en los casos de padres autoritarios, y dificulta el desarrollo del compañerismo, el afecto, la confianza y unión en la familia. De esta forma, el niño crece en un ambiente en el que no han sido escuchados y en el que no se han sentido importantes, por lo que la comunicación familiar continúa siendo fluctuantey fría en la adolescencia y en la adultez.

\section{Ausencia de reconocimiento y afecto:} ambiente familiar en el que los logros, cualidades y características de sus miembros no son valorados y no reciben el reconocimiento que se merecen. Esta herida hace que los hijos crean que no serán reconocidos ni amados, hagan lo que hagan; en este sentido, el aprendizaje y los logros se ven subordinados al afecto de los padres, y eliminan la seguridad que los hijos deberían desarrollar a partir del cariño incondicional de sus padres. 
Crítica negativa: herida que surge cuando los comentarios o críticas de los padres hacia sus hijos suelen ir acompañadas de intensas respuestas emocionales negativas (Del Castillo, 2016), que casi siempre generan una inadecuada valoración personal, sentimientos de inferioridad y baja motivación en su vida diaria. La crítica negativa también enseña a los niños que los errores son imperdonables y rígidos, ya que no propone ninguna solución que fomente el bien del hijo y de la familia. Al ser criticado y comparado con los demás, esta herida dificulta al hijo a superar sus fracasos, ya que interpreta las críticas de sus padres como una falta de confianza en él y en sus habilidades.

Amor posesivo: esta herida surge cuando el niño rompe con la fase de simbiosis, al darse cuenta que no necesita del adulto para relacionarse con la realidad, ya que materializa la idea de que es un alguien (Papalia y Martorell, 2012), pero la madre no acepta conscientemente esta "ruptura", generando una relación de dependencia mutua y el amor hacia el hijo se podría convertir en un amor posesivo. Young et al. (2012) postula que son madres que refuerzan las conductas dependientes y desalientan las independientes, privando a los hijos de la libertad o el apoyo para ser autónomos. La manifestación de esta herida se da en situaciones en las que la persona debe tomar el control de su vida, pero se ve incapaz de hacerlo ya que no se encuentran las habilidades que se necesitan para afrontarlas por sí solo, y recurre a la aprobación o consejo de los demás, originando sentimientos de incapacidad en la persona.

Conflictos conyugales: Los conflictos conyugales se puede adoptar en distintas formas y afectar a los niños dependiendo de cómo los padres decidan resolver el conflicto; estos pueden ser constructivos o destructivos, siendo los primeros aquellos que lo resuelven con amor, comprensión y compromiso; y los últimos aquellos que lo resuelven con hostilidad y agresión, los cuales suelen generar emociones negativas en los hijos, ya que perciben que la seguridad de su familia está perjudicada (Koss et al., 2011). De esta manera, cuando la estructura afectiva que sostiene el mundo interno del niño se derrumba o se ve amenazada, este puede sufrir alteraciones en su sistema conductual, como intranquilidad, agresión e impulsividad, y en su sistema psicosomático, experimentando síntomas como cefaleas y problemas digestivos; adicionalmente, el sistema emocional se ve afectado de forma notable, predominando los síntomas depresivos y ansiosos (Nuñez et al., 2017). Además, los conflictos conyugales pueden tener un efecto en la idea y el modelo que los niños elaboran de la vida en pareja, poniendo en juego las futuras relaciones personales.

Violencia intrafamiliar: herida que surge cuando la persona creció en un ambiente en el cual hubo algún tipo de acto de poder recurrente dirigido a dominar, someter o agredir física o psicológicamente a uno o más miembros de la familia. Según la investigación de Baader (2014), existe un consenso mundial de que 
la exposición de los niños a cualquier tipo de violencia intrafamiliar trae consigo consecuencias psicológicas negativas. En concreto, parece ser que les genera dificultades para regular el afecto, para la identificación y expresión emocional, y para desarrollar conductas empáticas. Además, perjudica la autoestima de los niños y genera pérdida de autoconfianza, ocasionando a su vez, que los niños desarrollen un miedo crónico que les dificulta adaptarse a diferentes situaciones y ambientes (Baader, 2014). Esta herida también puede llegar a manifestarse mediante conductas agresivas, oposicionistas y antisociales, las cuales perjudican el correcto desarrollo de las relaciones interpersonales. Esta herida afectiva puede repercutir en un inadecuado sentido de valoración personal como resultado de la privación de singularidad que vivió la persona, y manifiesta sus consecuencias tanto en la vida adulta de la víctima como en la sociedad en la que esta se desenvuelve ya que afecta las relaciones interpersonales (Forero et al., 2010).

Del Castillo (2016) afirma que, además de las heridas familiares, se vuelve importante también estudiar y trabajar otros ámbitos de la vida del ser humano donde se pueden generar heridas afectivas. Las heridas de otros ámbitos, entre los que destacan el social, laboral, personal, cultural o económico; también pueden tener una resonancia considerable en el componente afectivo y psicológico de la persona, y son especialmente importantes porque llegan a impedir la realización personal del ser humano. En concreto, se ha visto que si estos sufrimientos no son aliviados, las personas tienen dificultades para vivir alegres y sanas a largo plazo, debido a que el malestar suele volver a aparecer, muchas veces de forma más intensa y extendida (Luciano \& Sonsoles, 2006, citado en Patrón-Espinosa, 2013).

La actual clasificación de heridas afectivas que surgen en otros ámbitos es la siguiente:

La muerte de un ser querido: debido a que la muerte de un ser querido significa la ruptura del vínculo con una persona amada, esta herida influye en las creencias y pensamientos que tiene la persona sobre la vivencia del dolor interior; por ejemplo: negando la ocurrencia del hecho, pensando en lo que pudo haber hecho diferente para evitar la pérdida, sintiéndose culpable (Pérez \& Atehortua, 2016). Las personas que no enfrentan ni reconcilian esta herida adecuadamente pueden presentar dificultades físicas, psicológicas y espirituales, como síntomas depresivos, ansiedad, insomnio, dolor agudo, estreñimiento, infartos, entre otros (Rodríguez-Âlvaro, 2019).

Abuso sexual o violación: es una herida que afecta el bienestar físico, psíquico, social y espiritual de la persona, produciendo daños profundos y duraderos, ya que es una experiencia difícil de integrary asimilar por la persona. En relación con el área psicológica, las personas que sufren este tipo de heridas pueden presentar diversas secuelas, que pueden surgir a corto o a largo plazo. De acuerdo a Girón (2015), a corto plazo, las niñas suelen manifestar síntomas ansioso-depresivos, 
y los niños fracaso escolar y dificultades de socialización. A largo plazo, un abuso de este tipo genera en los niños una sensación de impotencia y falta de control que los puede llevar a conductas dañinas en el futuro, como serían los trastornos alimenticios, la delincuencia y el abuso de sustancias (Hornor, 2010). Adicionalmente, esas personas crecen teniendo una incorrecta valoración de ellas mismas y conductas sexualizadas.

Experiencias sexuales tempranas: existen algunas experiencias sexuales tempranas no asimiladas que podrían ser fuente de heridas afectivas, especialmente cuando ocurren en una etapa en la que no existe madurez suficiente (Del Castillo, 2016). Algunas de dichas experiencias son: la pornografía, el autoerotismo, ver o escuchar a los padres teniendo relaciones íntimas, relaciones sexuales en temprana edad y el acoso sexual. Por ejemplo, Velasco y Gil (2017) describen que algunas de las consecuencias que puede generar la exposición a la pornografía son la adicción y dependencia a la misma, depresión, sentimientos de culpa, ira y vergüenza, aislamiento social, dificultades en las relaciones de pareja, percepciones distorsionadas con respecto a la sexualidad y al concepto de hombre y mujer. Así mismo, el consumo de pornografía está relacionado con la masturbación, la cual a su vez podrá originar síntomas ansiosos, depresivos, dificultades en la atención, dificultades en el sueño, problemas digestivos, entre otros (Velasco \& Gil, 2017).

Fracaso en amistades o relaciones interpersonales: herida que surge desde el dolory trauma que ha causado el fracaso en alguna amistad o relación interpersonal significativa (Del Castillo, 2016). La persona que presenta esta herida, cree que posee alguna característica especial que lo hace sentirse diferente, y por ello, las demás personas expresan desinterés hacia ella; generando sentimientos de soledad e inseguridad, y una sensación de no identificación con ningún grupo, especialmente cuando ha sufrido el rechazo por sus pares en la etapa infantil (Young et al., 2012). De ahí que, esta herida puede obstaculizar el desarrollo de habilidades sociales por miedo al rechazo, dificultades a la hora de afrontar conflictos, expresar sentimientos y pensamientos, y conductas de aislamiento, manifestando disconformidad en el trato con los demás; siendo un impedimento para el desarrollo adecuado de su identidad y del crecimiento personal (Calero et. al., 2018).

Ruptura amorosa: herida que surge como consecuencia del dolor y sufrimiento que genera el rompimiento definitivo con el enamorado o enamorada. De acuerdo con Izurieta Sánchez (2015), las consecuencias psíquicas y físicas de una ruptura amorosa pueden ser similares a aquellas que se viven cuando se atraviesa un duelo por muerte: llanto, labilidad emocional, alteraciones en la alimentación y alteraciones del sueño. Por lo tanto, la ruptura amorosa lleva a que la persona se enfrente a las fases del duelo descritas por Kübler-Ross (1969). Las personas que no logran asimilar la ruptura y elaborar el duelo correctamente pueden quedar con una pobre valoración de sí mismo, con baja autoestima y con 
miedo de tener formar otras relaciones (Del Castillo, 2016).

\section{Experiencias dolorosas en la relación} de pareja: esta herida se produce cuando la persona vive experiencias y problemas con su pareja que pueden generar dificultades notables en sus dimensiones física, psicológica y espiritual. Situaciones como la infidelidad, separación o divorcio, violencia, enfermedad grave, infertilidad, adicciones y viudez (Del Castillo, 2016) pueden generar consecuencias en las distintas dimensiones que acaban afectando la relación con uno mismo, con el otro, con el mundo y con Dios.

Bullying (acoso escolar): de acuerdo a Arroyave (2012), el bullying es un comportamiento agresivo que implica un desbalance de poder ejercido en forma intimidatoria, con intención de causar daño al más débil, el cual es repetido en el tiempo y va a aumentando en intensidad. Esta herida, por tanto, aparece cuando la persona ha sido víctima de este maltrato, ya sea por alguno de sus pares o por un grupo de ellos. La herida suele manifestarse a través de diversas conductas de ansiedad, labilidad emocional, humor inestable, ataques de ira, somatizaciones, nerviosismo, pesadillas y conductas de infantilización y dependencia; a largo plazo. Esta herida puede producir consecuencias sociales y emocionales en la edad adulta, aumentando las posibilidades de desarrollar ansiedad y depresión (Lugones \& Ramírez, 2017). También, Lugones y Ramírez (2017) describen que las víctimas de acoso pueden presentar muchas conductas antisociales y delictivas.
Fracaso en el ámbito académico o laboral: herida que surge como consecuencia de un fracaso o dificultad personal en el ámbito académico o laboral (Del Castillo, 2016). El fracaso académico, está asociado no sólo con factores cognitivos, sino con otros factores, en el ámbito personal como la motivación y la falta de esfuerzo; factores familiares como el nivel educativo de los padres y su nivel económico; factores relacionados con el sistema educativo como la preparación de los docentes (Antelm et al., 2018). Las personas que han experimentado situaciones relacionadas con el fracaso académico presentan sentimientos de tristeza, angustia, ira, se perciben con pocas capacidades cognitivas, un autoconcepto negativo en relación con su proceso de aprendizaje, debido a que dicho suceso se percibe como la confirmación de la percepción distorsionada que tiene de sí mismo, disminuyendo aún más su motivación; lo cual puede llevar a deserción escolar, convirtiéndose en un factor de riesgo de exclusión laboral en el futuro (Zamudio et al., 2019).

\section{Limitaciones o fracasos en lo inte-} lectual: hace referencia a la herida que se produce cuando hay una percepción personal de que se es tonto o ignorante, habiendo una incapacidad o dificultad intelectual real, o no (Del Castillo, 2016). Dweck (2015) afirma que la manera en que las personas perciben sus habilidades juega un papel importante en su motivación y en sus logros, y que es posible aumentar la frecuencia de los logros si se tiene una perspectiva de que la inteligencia puede ser desarrollada; en otras 
palabras, si se tiene una "mentalidad de crecimiento". Así mismo, se ha visto que el desarrollo de esta herida depende bastante del antiguo o tradicional concepto de inteligencia, es decir, aquellas personas que no saben que pueden sobresalir en otras áreas que no son estrictamente académicas, ya que hoy se sabe que existen distintos tipos de inteligencia, pueden desarrollar problemas psicológicos.

\section{Las distintas situaciones que han} llevado a la persona a percibirse o sentirse como un "inútil": hace referencia a heridas que surgen a partir de experiencias en las que la persona se ha etiquetado a sí misma como "inútil" o "incapaz". De acuerdo a Ellis (2010), esto ocurre cuando la persona hace una auto-evaluación condicional y dependiente. En este tipo de evaluaciones se pone una "nota" a lo que se hace, puede haber un otro con el que se compara o compite, o se cometen errores por la misma naturaleza falible del hombre. Este tema pasa por la recta valoración que uno mismo tiene ante cuestiones prácticas y de la vida cotidiana (Del Castillo, 2016), ya que genera una percepción de "incapacidad" y, como resultado, lleva a la persona a definir su valor de acuerdo a su capacidad para ser útil. Cuando se construye una valoración personal condicionada en las "capacidades" personales o en estándares mágicos e irreales, se caerá frecuentemente en problemas emocionales (Ellis, 2010).

Rechazo a su cuerpo: herida que surge cuando la persona se percibe menos valiosa que los demás porque le disgusta determinada parte de su cuerpo, o porque hay personas que la han juzgado o maltratado por dichas características. Cuando una persona no acepta esa parte de su cuerpo, percibe que en su aspecto físico hay algo que no está bien, generando sentimientos de inferioridad, llegando a creer que no merece ser aceptado por los demás, impidiendo el desarrollo de una recta valoración personal (Del Castillo, 2019). De esta manera, en el camino por cumplir con ciertos estereotipos sociales, se pueden generar perturbaciones en relación con la percepción del propio cuerpo, y puede llevar al desarrollo de trastornos relacionados con la imagen corporal, como el Trastorno Dismórfico Corporal o los Trastornos de la Conducta Alimentaria (Behar \& Arancibia, 2015). A su vez, esto puede generar síntomas ansioso-depresivos, especialmente en aquellas personas que se sienten gravemente perjudicadas por su corporalidad, y se culpabilizan por sentir rechazo hacia sí mismos.

\section{Rechazo a su raza o realidad socioe-} conómica: según Smith et al. (2010) hace referencia a las heridas que aparecen en la vida de las personas que alguna vez han sido excluidas o vulnerabilizadas por su raza, estrato social o realidad económica. Son personas que se han visto despreciadas por los demás debido a su realidad cultural y socioeconómica, en otras palabras, que han sido víctimas de la dimensión conductual del prejuicio. Como consecuencia, las experiencias de estigmatización generan en la persona sentimientos de enojo, humillación, insatisfacción personal, tristeza y una valoración negativa de sí mismo (Smith et al., 2010). 
Fracaso en la vida de fe o religión: herida que aparece cuando un creyente tiene fuertes dudas con respecto a la fe, hasta llegar a la angustia; las dudas pueden ser respecto a la existencia del ser supremo, de la vida eterna, etc. Este tipo de heridas puede generar un profundo malestar, especialmente en la dimensión espiritual de la persona, y podrán surgir a partir de decepciones profundas de personas religiosas, experiencias traumatizantes en ceremonias paganas o experiencias intensas negativas con su iglesia, religión o líderes de las mismas (Del Castillo, 2016).

\section{Decepción o infidelidad en la vida} consagrada o religiosa: según Del Castillo (2016) se refiere a las situaciones en las que el religioso/a no le va bien en la comunidad o con su superior, cuando el sacerdote diocesano no se entiende con el obispo o cuando tiene un fracaso en su ministerio apostólico como párroco o como animador vocacional o por acontecimientos relacionados al abuso de autoridad, maltrato físico o psicológico, abuso sexual, entre otros. También, estas heridas pueden surgir a raíz de una situación de infidelidad a los votos de consagrado como el de celibato y obediencia (Del Castillo, 2016). Es una herida que suele tener consecuencias especialmente serias en la dimensión psicológica y espiritual de la persona.

Aborto: heridas o secuelas psicológicas que surgen en la mujer tras haber tenido un aborto inducido, ya que se convierte en un evento estresante en su vida e incluso puede percibirse como una experiencia traumática, además de que puede incluir respuestas relacionadas al proceso de duelo por la pérdida de una vida humana; todo lo cual se denomina "síndrome postaborto" (Fernández, 2015). Algunas de las manifestaciones que se presentan son: sentimientos de culpa, vergüenza, tristeza, angustia, agresividad e irritabilidad, dificultades de adaptación ante el estrés, poca valoración personal, dificultades en la relación con los miembros de la familia, e incluso ideación suicida; los cuales suelen reaparecer un año después del suceso o ante eventos críticos; desencadenando en algunos casos trastornos del estado de ánimo y ansiedad, trastornos alimenticios, trastornos del sueño, entre otros (Prada et al., 2015). La intensidad y el tipo de consecuencias dependerán a su vez, de factores como las características de personalidad, estilos de afrontamiento, la naturaleza del aborto, el vínculo afectivo con la pareja, el estado psicológico previo al suceso, etc. (Fernández, 2015).

\section{Discusión}

Las heridas afectivas se presentan como una dificultad para la persona debido a que suelen generar ideas distorsionadas, esquemas disfuncionales y otro tipo de problemáticas (Del Castillo, 2016) que no permiten que ésta viva de acuerdo a su potencial. Estas ideas o esquemas disfuncionales van orientando a la persona a ver el mundo de una determinada manera, muchas veces retroalimentando un patrón sesgadoy poco objetivo de entender la realidady deafrontarla adecuadamente (Young, 2012). Al identificar el tipo de herida afectiva que pudo haberse generado a lo largo de la 
historia personal, terapeuta y consultante pueden tener una mejor comprensión de los pensamientos, emociones y comportamientos que predominan en la actualidad. Clasificar las heridas y ponerle nombre a la que trae el consultante a sesión, sirve para entender dequé forma sus patrones disfuncionales cumplen con la función de hacer frentea esa herida, ya que no secuentan con los recursos para manejarlay reconciliarla de forma sana por sí mismo.

El objetivo principal del presente artículo era demostrar a partir de la revisión de literatura científica el estado actual de conocimiento acerca de las heridas afectivas, y las consecuencias psicológicas significativas que generanen los distintosámbitosdelapersona adulta. A partir de lo que se ha presentado en este trabajo, se puedeargumentar que las heridas afectivas son situaciones que tienen el potencial de producir un impacto en la psique, ya que el dolor que estas producen puede llegara desencadenar pensamientos, emociones y conductas disfuncionales que desarrollan y mantienen el malestar de la persona (Shapiro, 2013). Además, a partirde los estudios revisados, se ha hecho posible clasificar las heridas en dos grandesámbitos según el área en la cual se producen, y según las similitudes encontradas en las consecuencias o manifestaciones de cada herida.

En cuanto a las heridas afectivas familiares, podemos concluir que, al día de hoy, es posible encontrar una diversidad de literatura acerca de los efectos que estas producen en las personas. Del Castillo (2016) argumenta que las heridas familiares afectan, especialmente, el desarrollo del autoconcepto y la autoestima de los niños, ya que se producen cuando hay una necesidad afectiva que no ha sido satisfecha adecuadamente. Deforma similar, Godbout et al. (2019), explican que estas situaciones generan en el niño una creenciadequeson imperfectos, inaceptables y no-merecedores del amor de los demás. A la larga, estas creencias van desarrollando tendencias deansiedad porabandonooevitación de la intimidad (Godbout et al., 2019) y síntomas depresivos y ansiosos (Nuñez et al., 2017). Finalmente, Baader (2014) añade también que, cuando las problemáticas en la familia son especialmentegraves, las heridas desencadenan distintas consecuencias psicológicas a largo plazo, como desregulación de los afectos, dificultades para identificar y expresar las emociones, y una incapacidad para desarrollar conductas de empatía.

Con respecto a las heridas afectivas de otros ámbitos, es posible concluir que también tienen la potencialidad degenerar dificultades en las personas, y que este tipo de malestarmuchasveces sevivede forma másintensa y duradera (Luciano \& Sonsoles, 2006, citados en Patrón-Espinosa, 2013). En el caso de la muerte de un ser querido, por ejemplo, se ve como un duelo que no ha sido resuelto puede desarrollar tristezay sentimientos de culpa ante la pérdida (Pérez \& Atehortua, 2016), síntomas similares a los de las heridas originadas poruna rupturaamorosa (Izurieta Sánchez, 2015). Por otro lado, las diversas experiencias sexuales que producen heridas afectivas suelen manifestarse por medio de síntomas ansiosos, depresivos, dificultades en la atención y en el sueño (Velasco \& Gil, 2017). Honor (2010) añadeque, a largo plazo, estas heridas son el origen de una sensación de impotencia y falta de control que los puede llevar a conductas perjudiciales, 
comolos trastornos deconductaalimentaria, las conductas delictivas y la dependencia a sustancias. Las heridas interpersonales, comoel fracaso de una amistad oel acoso en el área académica o laboral, son el origen de autoconceptos negativos en las personas, y además desarrollan sentimientos de soledad einseguridad, una sensación estigmatización (Young et al., 2012) y consecuencias sociales y emocionales en la edad adulta, las cuales aumentan la probabilidad de desarrollar ansiedad y depresión (Lugones \& Ramírez, 2017). Aquellas heridas referentes a la intelecto y a la "capacidad personal", que según Ellis (2010) y Dweck (2015) se desarrollan a partir de las evaluaciones personales y el concepto tradicional de inteligencia, suelen tener un impacto directo en el desarrollo adecuado del autoconcepto y la valoración personal (Del Castillo, 2016). Las heridas afectivas que surgen de distintos tipos de rechazo, comoal cuerpo, a la raza o a la realidad socioeconómica, suelen causar enojo, humillación, insatisfacción personal, tristeza y una pobre valoración personal (Smith et al., 2010), que si se prolongan, pueden llegar agenerarcuadros clínicosgraves. Las heridas quesurgen en lavida defe, tanto para religiosos como para laicos, suelen afectar tanto la dimensión psicológica comola espiritual (Del Castillo, 2016), teniendo más manifestaciones en la última mencionada. Finalmente, se puedeconcluir también quela herida afectiva que puede aparecer desde un aborto tiene consecuencias que se acercan a la vertiente del trastorno depresivo (Fernández, 2015) y que, por tanto, si no se manejan, pueden manifestarse también a muy largo plazo.

En definitiva, se puede argumentar que los méritos de este trabajo son significativos porque dan respuesta y facilitan el trabajo llevado a cabo en el primer paso del proceso de reconciliación personal, el mismo que hacereferenciaa la identificación dela herida afectiva (Del Castillo, 2016). Al proponer una clasificación más ordenaday concreta de los tipos de heridas afectivas, se hace más fácil que terapeuta y consultante puedan identificarlas correctamentey que, además, sepan las problemáticas de la vida del consultante que podrían tener queabordara raíz de dicha herida. De acuerdo a la Psicoterapia de la Reconciliación, cuando se han trabajado estas dificultades la persona tiene una base más fuerte para continuar con el proceso de reconciliación personal, en el quetendráque enfrentarse a la aceptación, el perdón y la reconciliación con el ofensor. Este proceso, sustentado en la correcta identificación de la herida afectiva, ayuda a que los cambios terapéuticos logrados con las técnicas de otras corrientes se vuelvan más duraderos y estables en el tiempo.

\section{Limitaciones y futuras líneas de investigación}

En cuanto a las limitaciones de esteartículo, sepuedeconsiderar, en primer lugar, queaún hay muy pocas publicaciones que estudian el impacto de las heridas afectivas, ya que es un término psicológico que se ha desarrollado hace menos de 10 años. En concreto, la primera clasificación de heridas afectivas quese publicó fueen el libro "Reconciliación de la historia personal” (Del Castillo, 2016).

Una segunda limitación sería que en la presente revisión solo se tomó en cuenta las consecuencias de las heridas afectivas en la población adulta. Se ha visto 
que el modelo de la Psicoterapia de la Reconciliación puedeser aplicado desdelos 7 años en adelante, ya que muchos niños y adolescentes también se pueden enfrentar a algunas de las heridas mencionadas y pueden tener dificultad para manejarlas adecuadamente. Sin embargo, la mayoría de casos que han sido abordados con este enfoque han sido de adultos, y por tanto se desconoce las consecuencias que estas heridas pueden tener en la población infantojuvenil y las herramientas que serían óptimas para abordarlas.

A partir de lo que se ha comentado en el apartadoanterior, y basado en las limitaciones que se han encontrado, se recomiendan las siguientes futuras líneas de investigación sobre este tema. En primer lugar y a partir de los resultados encontrados, se considera necesario no sólo establecer una clasificación completa de las heridas afectivas, sino también diseñar alguna herramienta de screening que permita a los profesionales identificar con rapidez el ámbito y el tipo de herida que presenta el consultante. Esto podría orientar la entrevista del consultante y facilitar el reconocimiento del recuerdo o evento no-procesado que le produce dolor en la actualidad.
En segundo lugar, sería interesante ahondar un poco más en los tipos de heridas afectivas, e investigar la recurrencia de cada herida en poblaciones específicas. Por poblaciones específicas podríamos entendergrupos de refugiados, grupos de consagrados, grupos que vivieron el conflicto armado en Colombia y en Venezuela, familias con miembros diagnosticados con un trastorno mental grave, familias con miembros diagnosticados con enfermedades crónicas, entre otros.

Por último, y según la demanda que puede surgir en el ámbito clínico, se recomienda estudiara profundidad las heridas quetienen una alta probabilidad de afectar a niños y adolescentes, para así poder elaborar una clasificación apropiadaa su edady desarrollar herramientas y técnicas que pueden ser de uso para abordarel proceso de reconciliación personal con ellos.

\section{Financiamiento}

El presente trabajo fue autofinanciado.

\section{Conflicto de intereses}

Los autores declaran no tener conflicto de interés. 


\section{Referencias}

Antelm, A., Gil, A. Cachaeiro, M., \& Pérez, E. (2018). Causas del fracaso escolar: un análisis desde la perspectiva del profesorado y el alumnado. Enseñanza $\mathcal{E}$ Teaching, 36(1), 129-149. https://revistas.usal.es/index.php/o212-5374/article/ view/et2018361129149/19128

Arroyave, P. (2012). Factores de vulnerabilidad y riesgo asociados al bullying. Revista CES Psicología, 5(1), 118-125.

Baader, B. (2014). Niños y niñas expuestos/as a violencia intrafamiliar. http://repositorio.uchile. cl/bitstream/handle/2250/134567/Christel\%2oBaader.pdf

Behar, R., \& Arancibia, M. (2015). Trastornos de la imagen corporal: anorexia nerviosa versus anorexia inversa (trastorno dismórfico muscular). Revista Mexicana de Trastornos Alimentarios, 6(2), 121-128. http://www.scielo.org.mx/scielo. php?pid=S2007-15232015000200121\&script=sci_arttext

Bourbeau, L. (2014). Las 5 heridas que impiden ser uno mismo. 2da ed. Ob Stare.

Bradburn, N. M. (1969). The structure of psychological well-being. Aldine.

Calero, A., Barreyro, J., Formoso, J., \& Injoque-Ricle, I. (2018). Inteligencia emocional y necesidad de pertenencia al grupo de pares durante la adolescencia. Revista Subjetividad y Procesos Cognitivos, 22(2). http://dspace.uces.edu.ar:818o/xmlui/ bitstream/handle/123456789/4683/Inteligencia_Calero_otros.pdf?sequence=1

Camps, D. (2007). El artículo científico: Desde los inicios de la escritura al IMRYD. Archivos de Medicina, 3(5). https://www.archivosdemedicina.com/medicina-de-familia/el-artculo-cientfico-desde-los-inicios-de-la-escritura-al-imryd.pdf

Del Castillo, H. (2016). Reconciliación de la historia personal. 2da Edición. Areté: Centro de Desarrollo Integral de la Persona.

Del Castillo, H. (2019). Creciendo en la valoración personal día a día. Areté: Centro de Desarrollo Integral de la Persona.

Dweck, C. (2015). Carol Dweck Revisits the "Growth Mindset". Education Week, 35(5), 20-24. 
Ellis, A. (2010). Overcoming destructive beliefs, feelings, and behaviors: New directions for rational emotive behavior therapy. Prometheus Books.

Fernández, E. (2015). El aborto terapéutico o cualquier tipo de aborto, ¿una cuestión de decisión personal en búsqueda de un bien? Secuelas psicológicas. UCV-HACER, 4(2), 148-156. http://revistas.ucv.edu.pe/index.php/UCV-HACER/ article/view/744/583

Figueroa, R. A., Cortés, P. F., Accatino, L., \& Sorensen, R. (2016). Trauma psicológico en la atención primaria: orientaciones de manejo. Revista Médica de Chile, 144(5), 643-655.

Forero, L. C. A., Araújo Reyes, A. P., Godoy Díaz, A. P., \& Vera Rueda, M. E. (2010). Maltrato infantil y sus consecuencias a largo plazo. MedUNAB, 13(2), 103-115. https://revistas.unab.edu.co/index.php/medunab/article/view/1155

García del Junco, J., \& Castellanos Verdugo, M. (2007). La difusión de las investigaciones y el formato IMRYD: Una pesquisa a propósito de la lectura crítica de los artículos científicos. Acimed, 15(1).

Girón, R. (2015). Abuso sexual en menores de edad, problema de salud pública. Avances en Psicología, 23(1), 61-71.

Godbout, N., Daspe, M. Ė., Runtz, M., Cyr, G., \& Briere, J. (2019). Childhood maltreatment, attachment, and borderline personality-related symptoms: Gender-specific structural equation models. Psychological Trauma: Theory, Research, Practice, and Policy, 11(1), 90.

Hornor, G. (2010). Child sexual abuse: Consequences and implications. Journal of Pediatric Health Care, 24(6), 358-364.

Izurieta Sánchez, C. (2015). Proceso de elaboración de duelo en rupturas amorosas de jóvenes de 18 a 25 años. (Tesis de bachillerato) Universidad de las Américas, Quito, Ecuador.

Koss, K. J., George, M. R., Bergman, K. N., Cummings, E. M., Davies, P. T., \& Cicchetti, D. (2011). Understanding children's emotional processes and behavioral strategies in the context of marital conflict. Journal of Experimental Child Psychology, 109(3), 336-352.

Kübler-Ross, E. (1969). On death and dying. The Macmillan Company. 
Kleponis, P. (2018). Pornografía. Comprender y afrontar el problema. Voz de Papel.

Lugones, M., \& Ramírez, M. (2017). Bullying: aspectos históricos, culturales y sus consecuencias para la salud. Revista Cubana de Medicina General Integral, 22(1), 154-162.

Ministerio de Sanidad, Servicios Sociales e Igualdad. (2018). Clasificación Internacional de Enfermedades. n1ava ed. Madrid.

Nuñez, C. S., Pérez, C., \& Castro, M. (2017). Consecuencias del divorcio-separación en niños de edad escolar y actitudes asumidas por los padres. Revista Cubana de Medicina General Integral, 33(3), 296-309.

Packer, A. L., Biojone, M. R., Antonio, I., Takenaka, R. M., Pedroso García, A., Silva, A. C. D., ... \& Delbucio, H. C. R. F. (2001). SciELO: una metodología para la publicación electrónica. Revista Española de Salud Pública, 75(4), 291-312.

Papalia, D. E., \& Martorell, G. (2012). Desarrollo Humano. McGraw-Hill.

Pubmed Central (s/f) US National Library of Medicine National Institutes of Health. NCBI. https://www.ncbi.nlm.nih.gov/pmc/?

Patrón-Espinosa, F. D. J. (2013). La evitación experiencial como dimensión funcional de los trastornos de depresión, ansiedad y psicóticos. Journal of Behavior, Health E Social Issues, 5(1), 85-95.

Pérez, D., \& Atehortua, M. (2016). La Comprensión del duelo desde la psicoterapia humanista. Psyconex, 8(12). https://revistas.udea.edu.co/index.php/Psyconex/ article/view/326982/20784208

Plasencia, C. (2008). EBSCO: un recurso de información de excelencia al servicio de los profesionales cubanos. MEDISAN, $12(4), 1-3$. https://www.redalyc.org/ articulo.oa?id=368445249001

Pereda, N., Forns, M., \& Abad, J. (2013). Prevalencia de acontecimientos potencialmente traumáticos en universitarios españoles. Anales de Psicología, 29(1), 178-186.

Polaino, A. (2010). ¿Hay algún hombre en casa? Editorial Desclée de Brouwer, S.A. 
Prada, D., Rojas, D., Vargas, P., \& Ramírez, J. (2015). El aborto en adolescentes, factores de riesgo y consecuencias: revisión de literatura. Salud Areandina, 4(1), 64-77. https://revia.areandina.edu.co/index.php/Nn/article/view/1319/120o

Rodríguez-Álvaro, M. (2019). Impacto del duelo complicado. Una lectura a través del lenguaje del cuidado. Santa Cruz de La Palma, 13(3). http://scielo.isciii.es/ scielo.php?script=sci_arttext\&pid=S1988-348X20190003000o8\&lng=es\&tlng=pt

Ryff, C. D. (1989). Happiness is everything, or is it? Explorations on the meaning of psychological well-being. Journal of Personality and Social Psychology, 57(6), 1069-1081. https://doi.org/10.1037/0022-3514-57.6.1069

Salgado, A. (2014). Revisión de estudios empíricos sobre el impacto de la religión, religiosidad y espiritualidad como factores protectores. Propósitos y Representaciones, 2(1), 121-159. http://dx.doi.org/10.20511/pyr2014.v2n1.55

Samper, E. (2016). Personalidad ante el trauma en el siglo XXI: fragilidad y antifragilidad ante el trauma. Sanidad Militar, 72(3), 209-215. http://scielo.isciii.es/ scielo.php?script=sci_arttext\&pid=S1887-85712016000300007\&lng=es\&tlng=pt

Sarráis, F. (2016) Psicopatología. EUNSA.

Shapiro, F. (2013). Supera tu pasado. Tomar el control de la vida con el EMDR. Kairós.

Smith, V., Moreno, M., Román, N., Kirschman, D., Acuña, M., \& Víquez, S. (2010). Discriminación social, consecuencias psicológicas y estrategias de afrontamiento en miembros de grupos sociales estigmatizados. Dominación, compromiso y transformación social. Universidad de Costa Rica.

Trautmann, A. (2008). Maltrato entre pares o "bullying": Una visión actual. Revista Chilena de Pediatría, 79(1), 13-20.

Universidad de Navarra (2011). Unika: Nuevo buscador unificado de la Biblioteca de la Universidad de Navarra. https://www.unav.edu/en/web/vida-universitaria/ detalle-noticia-pestana/2011/o9/28/unika:-nuevo-buscador-unificado-de-la-biblioteca-de-la-universidad-de-navarra?articleId=302098

Velasco, A., \& Gil, V. (2017). La adicción a la pornografía: causas y consecuencias. Drugs and Addictive Behavior, 2(1), 122-130. https://www.funlam.edu.co/revistas/ index.php/DAB/article/view/2265/1703 
Young, J., Klosko, J. S., \& Janet, J. (2012). Reinventa tu vida. Cómo superar las actitudes negativas y sentirse bien de nuevo. PaidósIbérica.

Young, J., Klosko, J. S., \& Janet, J. (2013). Terapia de Esquemas. Desclée de Brouwer, S.A.

Zamudio, P., López, F., \& Reyes-Sosa, H. (2019). La representación social del fracaso escolar. La hipótesis del núcleo central. Perfiles Educativos, 41(165). http://www. perfileseducativos.unam.mx/iisue_pe/index.php/perfiles/article/view/59051/52256

Zeanah, C. H., \& Humphreys, K. L. (2018). Child abuse and neglect. Journal of the American Academy of Child E Adolescent Psychiatry, 57(9), 637-644.

Recibido: 14 de noviembre de 2020

Revisado: 20 de marzo de 2021

Aceptado: 8 de abril de 2021 

Rev. Psicol. (Arequipa. Univ. Catól. San Pablo) / Año 2021 / Vol 11 / No 1 / pp. 169-187

ISSN 2306-0565 versión impresa / ISSN 2311-7397 versión on line

\title{
Afrontamiento de la Incertidumbre en jóvenes imposibilitados de regresar del extranjero por pandemia de COVID-19
}

\author{
Coping with Uncertainty in Young People Unable to Return \\ from Abroad Due to the COVID-19 Pandemic
}

Gina Chávez-Ventura

Universidad César Vallejo, Trujillo, Perú

(iD) https://orcid.org/oooo-0oo2-4638-3487

Correspondencia: gina.chavezv@hotmail.com

Henry Santa-Cruz-Espinoza

Universidad César Vallejo, Trujillo, Perú

(iD https://orcid.org/oooo-0oo2-6475-9724

César Vásquez-Olcese

Universidad Privada del Norte, Trujillo, Perú

(iD https://orcid.org/oooo-00o2-7232-3250

Janeth Molina-Alvarado

Universidad Privada del Norte, Trujillo, Perú

(iD) https://orcid.org/oooo-0oo2-6451-8613

\section{Resumen}

Para evitar la propagación de la COVID-19, muchos países —entre ellos Perúcerraron sus fronteras, imposibilitando el retorno de peruanos que tenían previsto volver al país y ya no contaban con recursos económicos para su manutención al haber concluido sus contratos laborales. Por ello, el propósito del estudio es caracterizar los modos de afrontamiento a la incertidumbre que experimentaron jóvenes peruanos cuando se encontraban imposibilitados de regresar a su país debido a la pandemia por COVID-19. Se diseñó un cuestionario con preguntas abiertas y cerradas, se obtuvo la validez de contenido $(V=1[.90,1])$ y se aplicó, mediante formularios Google, a 39 jóvenes entre 19 y 26 años $(M=20.9, D E=1.6)$, que cumplían su cuarentena, tras ser repatriados por el gobierno peruano. Los resultados reportan que los jóvenes se sintieron especialmente agobiados o angustiados (64.10\%) y tensos (56.41\%). Sus principales temores eran no poder regresar a Perú (43.8\%) y 
contagiarse de la COVID-19 (25\%). Afrontaban el malestar durmiendo (22.81\%), realizando actividades físicas para relajarse (21.03\%), recibiendo apoyo emocional de personas que recién conocían (79.49\%), y también proporcionaron apoyo a otras personas (80.95\%). Casi la totalidad de los participantes (92.31\%) realizaron acciones para intentar solucionar el problema, y el $100 \%$ buscaba estar informado de las noticias. La mayoría (74.36 \%) valoró como excitante la experiencia vivida de estar imposibilitados de poder retornar a su país. Se concluye que las principales acciones realizadas han sido para afrontar la incertidumbre emocional, cognitiva $y$ de deseo de cambio.

Palabras clave: Tolerancia a la ambigüedad, incertidumbre, afrontamiento, emociones.

\begin{abstract}
To prevent the spread of COVID-19, many countries, including Peru, closed their borders. As result, it was impossible for Peruvians to return to their country although they no longer had the financial resources to support themselves due to the ending of their employment contracts. The purpose of this study is to describe the ways of coping with uncertainty utilized by young Peruvians while they were unable to return to their country due to the COVID-19 pandemic. A questionnaire with open and closed questions was designed, content validity was obtained ( $V=$ $1[.90,1])$ and it was applied, using Google forms, to 39 young people between 19 and 26 years of age $(M=20.9, S D=1.6)$. The sample was surveyed during their quarantine period, following their repatriation by the Peruvian government. The results indicated that the young people felt especially overwhelmed or distressed (64.10 \%) and tense (56.41\%) prior to returning to Peru. Their main fears were not being able to return to Peru (43.8\%) and becoming infected with COVID$19(25 \%)$. They coped with discomfort by sleeping (22.81\%), by doing physical activities to relax (21.03\%), by receiving emotional support from people they just met (79.49\%), and, also by providing support to others (80.95\%). Almost all of the participants (92.31\%) carried out actions to try to solve the problem; $100 \%$ wanted to be informed of the COVID-19 news. The majority (74.36\%) valued the experience of being unable to return to their country as an exciting experience. This study concluded that the main actions taken were undertaken to deal with emotional, cognitive uncertainty and a result of a desire for change.
\end{abstract}

Keywords: Tolerance of ambiguity, uncertainty, coping, emotions.

\section{Introducción}

La pandemia ocasionada por la enfermedad COVID-19 ha generado, a nivel mundial, un impacto de gran magnitud a nivel económico, político, psicosocial y sanitario (Babore et al. 2020; Dawson \& Golijani-Moghaddam, 2020; Ramírez et al., 2020), razón por la cual diversos gobiernos han decretado una serie de 
disposiciones para contener la propagación rápida de la enfermedad infecciosa; entre ellas el aislamiento social y el cierre de fronteras. Tal es el caso del Estado Peruano que, en comparación a los demás países latinoamericanos, decretó tempranamente (17 de marzo de 2020) la prohibición de ingreso y salida del país, así como los viajes interprovinciales, entre otras medidas.

Ello dio lugar a que tanto los extranjeros, que estaban temporalmente en el Perú, como los peruanos en el extranjero viesen frustrados sus planes de retorno, sin tener claro cuál sería el plan de contingencia ni cuándo se resolvería su situación. Dentro del último grupo, más de 3000 corresponden a jóvenes del programa de intercambio cultural y laboral Work and Travel, que no pudieron retornar de EE.UU. (El Comercio, 19 de marzo de 2020).

Participan de dicho programa estudiantes universitarios que viajaron a Estados Unidos, por su período vacacional de diciembre a marzo, realizan trabajos remunerados (que les permiten su subsistencia), practican el inglés y se relacionan con estudiantes de otras nacionalidades. Sin embargo, el cierre de fronteras representaba para ellos: a) la pérdida de su pasaje aéreo de retorno al país sin saber si lo recuperarían, b) el vencimiento de su visa J-1 por trabajo temporal, c) la caducidad de su seguro de salud que cubría el período laboral, d) la caducidad de contrato laboral, e) tener, en varios casos, que desalojar el lugar de residencia temporal por el cese de trabajo, f) tener que cubrir sus gastos de hospedaje y manutención por un tiempo indeterminado sin tener ingresos económicos actuales, y g) estar lejos de su hogar. A esto se suma el riesgo de estar expuestos a un posible contagio de la COVID-19, la falta de una política de contención del gobierno estadounidense, las cuarentenas impuestas por los consulados, así como la incertidumbre de no saber la fecha de reapertura de los vuelos internacionales o desconocer si se será favorecido o no, con los vuelos de repatriación promovidos por el gobierno peruano en coordinación con los consulados. Todo ello representa una gran incertidumbre con respecto a su situación y su porvenir.

El fenómeno de la incertidumbre ha sido investigado especialmente desde el campo biomédico, en el cuidado de la salud (Brabow \& Kline, 200o) y más ampliamente vinculado a la enfermedad (Mishel, 1988; Wiener \& Dodd, 1993; Yang et al., 2015). Desde este último, la teoría explica que la valoración de la incertidumbre hacia la enfermedad puede ser positiva o negativa (Mishel, 1990). En el primer caso, la incertidumbre se considera como una oportunidad y en el segundo como un peligro, ya que las situaciones imprevistas irrumpen el sentido de control y planificación de la vida del ser humano, así como su homeostasis (Mishel, 1990), incluso a nivel hormonal (Voigt, Ziegler, Grunert-Fuchs, Bicke \& Fehm-Wolfsdorf, 1990) e inmune (Zakowski, 1985).

La valoración negativa de la incertidumbre se ve impulsada especialmente por la cultura con una visión mecanicista de la vida, donde se valora la precisión, 
la autoeficacia y el control interno. Por tanto, la incertidumbre se constituye en un potencial perturbador de las áreas del desenvolvimiento humano asociado a la angustia psicológica (Mishel, 1990), representa preocupación, inmoviliza para actuar, se valora como negativa e injusta (Buhr \& Dugas, 2002); y, su intolerancia actúa como mediadora entre el neuroticismo, la depresión y ansiedad (Clarke \& Kiropoulos, 2021).

En cambio, en el campo de la educación, la incertidumbre se percibe como una de las características de las sociedades del conocimiento (García-Cortés, 2019) y se considera equiparable a la gestión del riesgo que exige enfrentar el estrés y la ambigüedad (Walker et al., 2017). También se utiliza como una estrategia didáctica en los proyectos formativos, orientados al desarrollo del pensamiento complejo para la resolución de problemas del contexto con un producto real (Tobón et al., 2015).

En el presente estudio, el interés por comprender el afrontamiento a la incertidumbre se enfocó desde el ámbito psicosocial, específicamente en cómo los jóvenes peruanos hacen frente el no saber cómo resolver la situación de estar imposibilitados de regresar a su país, por el cierre de fronteras debido a la pandemia por COVID-19. Ante el carácter novedoso y coyuntural del fenómeno a investigar, no se encontraron instrumentos disponibles que puedan medir la variable de interés, debido a que los estudios instrumentales más próximos están enfocados en el afrontamiento al estrés (Lyne \& Roger, 2000; Tobin et al., 1989). Sin embargo, un reporte mostró la construcción de una medida de las vivencias emocionales de la incertidumbre (Greco \& Roger, 2001), en lugar de las estrategias empleadas para afrontar la experiencia emocional que genera la incertidumbre.

Para el estudio se asumen dos teorías, la que explica el afrontamiento al estrés y la que teoriza las respuestas a la incertidumbre. La primera se realiza desde el modelo transaccional del estrés de Lazarus y Folkman (1984), que afirma la interacción del individuo con el medio ambiente, sobre el cual puede ejercer influencia a través de estrategias conductuales, cognitivas o emocionales; sin embargo, cuando se presenta una discrepancia entre las demandas del ambiente y los recursos para hacerles frente, surge el estrés.

Ante ello, los esfuerzos cognitivos y conductuales para intentar manejar tales demandas, que exceden los recursos del individuo, y que procuran reducir el impacto emocional o alterar el problema, se denominan afrontamiento; el cual varía en su uso y duración y puede expresarse en tres estrategias: a) las orientadas al problema (e.g. conductas dirigidas a buscar información y prepararse activamente para estar en condiciones de afrontar el problema); b) las orientadas a la emoción (e.g. conductas orientadas a requerir el soporte de personas, con el fin de solucionar el problema o desahogar la emoción); y, c) las de evitación (e.g. conductas de postergación o evasión) (Lazarus \& Folkman, 1984). 
Vale señalar que la teoría transaccional relaciona las estrategias de afrontamiento con las emociones, luego de que se valora el suceso estresante, $y$ forma una unidad con el afrontamiento (Lazarus, 1999); por lo que es necesario reconocer la presencia de emociones positivas y negativas, su intensidad y duración (Berra et al., 2014). Las emociones positivas contribuyen al bienestar y las negativas al malestar (Padrós et al., 2012). También, es necesario conocer a quién se atribuye la responsabilidad del evento, si el suceso estresante afectó la consecución de las metas y cómo se valoraron las consecuencias, a nivel de la relación con los demás y el ambiente (Berra et al., 2014); aunque, se critica la falta de claridad y precisión respecto a las emociones negativas y estrés, en las formulaciones de Lazarus (Gómez, 2005).

En la segunda teoría, Greco y Roger (2001) señalan que la incertidumbre es un estilo de respuesta desadaptativo, que comprende tres tipos de respuesta. La incertidumbre emocional (incluye las respuestas fisiológicas y psicológicas a la anticipación de amenaza) se relaciona positivamente con el neuroticismo, está fuertemente relacionada con el estrés y rumiación y negativamente relacionada con la autoestima y el desapego. La incertidumbre cognitiva (desequilibra la necesidad de planificación y certeza) se relaciona inversamente con la tolerancia a la ambigüedad y marginalmente con la sensibilidad social del neuroticismo; mientras que el deseo de cambio (disfrute de incertidumbre, novedad y cambio) se relaciona con la impulsividad y sociabilidad e incluye la búsqueda de sensaciones.

Cabe señalar que, si una persona logra tolerar la incertidumbre, es capaz de tolerar la angustia del otro y contribuir a reducir de modo prosocial su malestar; por lo que el afrontamiento de la incertidumbre está mediado por habilidades de autorregulación y la habilidad cognitiva de asumir una perspectiva (Saarni et al., 2007).

Para el estudio, se asumen las definiciones siguientes: a) afrontamiento a la incertidumbre es el conjunto de esfuerzos cognitivos y conductuales para manejar la situación de desconcierto y ambigüedad por estar varados en un país extranjero; b) afrontamiento a la incertidumbre emocional, comprende conductas de búsqueda de apoyo o soporte social, para solucionar el problema o reducir el impacto afectivo mediante el desahogo de la emoción; c) afrontamiento a la incertidumbre cognitiva, abarca conductas de búsqueda de información y de preparación activa para estar en condiciones de afrontar el problema; y d) afrontamiento del deseo de cambio, que implica conductas que buscan mantener la excitación ante lo novedoso.

Por lo expuesto, el estudio responde a la necesidad de caracterizar los modos de afrontamiento a la incertidumbre que experimentaron jóvenes peruanos imposibilitados de regresar a su país por el cierre de fronteras debido a la 
pandemia de la COVID-19. Con ello, se posibilitará ampliar las investigaciones sobre el afrontamiento a la incertidumbre, desde un contexto no vinculado a la enfermedad, y comprender las vivencias emocionales de quienes han tenido que afrontar la incertidumbre de no saber cuándo retornarían al país en situaciones adversas para ellos.

\section{Método}

El diseño es de tipo selectivo, descriptivo, con muestreo no probabilístico transversal (Ato et al., 2013).

\section{Participantes}

Formaron parte del estudio jóvenes que viajaron al extranjero y estuvieron imposibilitados de regresar por el cierre de fronteras debido a la pandemia de la COVID-19. Los participantes se encontraban haciendo cuarentena en los hoteles limeños, designados por el gobierno peruano, tras ser repatriados o recientemente habían retornado a sus hogares luego del confinamiento obligatorio dispuesto por el Estado.
El estudio se llevó a cabo entre los meses de abrilajuniode 2020, en el momentoenqueel gobierno estadounidense no había dispuesto medidas de cuarentena, sino que algunos Estados los asumían voluntariamente y también los Consulados peruanosal asignar hoteles financiados por el gobierno peruano, para peruanos que estuvieran confinados.

Entre las características de los participantes, la mayoría son mujeres, y tienen edades entre 19 y 26 años $(\mathrm{M}=20.9, \mathrm{DE}=$ 1.6). El $100 \%$ son solteros, el $89.74 \%$ no presentan problemas de salud, el 94.87 $\%(\mathrm{n}=35)$ vive con su familia y proceden en su mayoría de la capital. Además, tras determinar el cierre de fronteras, los participantes se quedaron en casa de un familiar, o de amigos, o en el lugar de trabajo, o en el aeropuerto, y posteriormente en un hotel dispuesto por el Consulado peruano (Tabla 1).

La cantidad de días que estuvieron en el extranjero sin poder regresar era desde 2 a 65 días $(M=25.51, D E=15.78)$ y el tiempo transcurrido desde que retornaron a Perú es desde 1 día hasta 62 días $(M=39.18$, $\mathrm{DE}=18.43$ ) 
Tabla 1.

Características de los participantes

\begin{tabular}{|c|c|c|}
\hline Características & f & $\%$ \\
\hline \multicolumn{3}{|l|}{ Sexo } \\
\hline Mujer & 23 & 59 \\
\hline Hombre & 16 & 41 \\
\hline \multicolumn{3}{|l|}{ Procedencia } \\
\hline Lima & 23 & 58.97 \\
\hline Trujillo & 9 & 23.08 \\
\hline Arequipa & 3 & 7.69 \\
\hline Huancayo & 2 & 5.13 \\
\hline Chiclayo & 1 & 2.56 \\
\hline Ilo & 1 & 2.56 \\
\hline \multicolumn{3}{|l|}{ Carreras profesionales } \\
\hline Ingeniería & 15 & 38.46 \\
\hline Ciencias Administrativas & 7 & $17 \cdot 95$ \\
\hline Comunicaciones & 6 & $15 \cdot 38$ \\
\hline Salud & 4 & 10.26 \\
\hline Traducción & 2 & 5.13 \\
\hline Arte & 2 & 5.13 \\
\hline Humanidades & 3 & 7.69 \\
\hline \multicolumn{3}{|l|}{ Dónde se quedó tras declararse el cierre de fronteras: } \\
\hline Casa de familiar o amigo & 8 & 20.51 \\
\hline Lugar de trabajo & 13 & 33.33 \\
\hline Aeropuerto y luego hotel dispuesto por Consulado & 12 & 30.77 \\
\hline Lugar de trabajo y luego hotel dispuesto por & 3 & 7.69 \\
\hline Consulado & 3 & 7.69 \\
\hline Hotel pagado por mí & & \\
\hline \multicolumn{3}{|l|}{ Durante ese tiempo se encontró: } \\
\hline Solo & 5 & 12.82 \\
\hline Acompañado de amigos & 30 & 76.92 \\
\hline Acompañado de familiares & 4 & 10.26 \\
\hline
\end{tabular}

\section{Instrumento}

Debido a la imposibilidad de acceder a la población objetivo se aplicó, vía Internet, una ficha de datos sociodemográficos y un cuestionario (Tabla 2), diseñados para los fines de la investigación, con 10 preguntas abiertas y 11 cerradas. Para la obtención de la validez basada en el contenido, seis psicólogos evaluaron de manera positiva el instrumento, con una escala de 7 puntos, los criterios de claridad, relevancia y pertinencia $(\mathrm{V}=1$ $[.90,1])$. Además, se incluyó un rubro de observaciones para que puedan sugerir modificaciones al instrumento. 
Tabla 2.

Preguntas del Cuestionario sobre Afrontamiento a la Incertidumbre

\author{
Afrontamiento a 1. De las siguientes emociones indica, ¿cuáles describen mejor cómo te sentías \\ la incertidumbre durante el tiempo que tuviste que quedarte en el extranjero sin poder regresar a \\ emocional Perú? Puedes elegir más de una alternativa. \\ 2. ¿Qué temores tenías? Menciónalos \\ 3. ¿Qué acciones o qué tipo de conducta realizabas cuando las emociones o \\ sentimientos te generaban malestar? Menciónalas todas \\ 4. Durante el tiempo que estuviste en el extranjero sin poder regresar al Perú, \\ ¿preferías estar solo o acompañado? \\ 5. ¿Qué cambios experimentaste en tu organismo, durante ese tiempo? \\ 10. ¿Recibiste el apoyo emocional de personas importantes para ti? Marca \\ quiénes fueron. \\ 11. ¿Recibiste apoyo emocional de personas que recién conocías? \\ 12. Si tu respuesta fue "Sî" a la pregunta anterior, ¿de qué manera te apoyaron? \\ 13. ¿Brindaste apoyo a otras personas? \\ 14. Si tu respuesta fue "SÎ" a la pregunta anterior, ¿de qué manera brindaste \\ apoyo?
}

Afrontamiento a la incertidumbre cognitiva
6. ¿Intentaste algún modo de resolver la situación en la que te encontrabas para volver a Perú?

7. Si tu respuesta fue "SÎ" a la pregunta anterior, ¿qué fue lo que hiciste?

8. ¿Quiénes contribuyeron a encontrar la solución para tu pronto retorno al país?

9. De acuerdo tu respuesta a la pregunta anterior, explica qué fue lo que hicieron

15. Durante ese tiempo, ¿con qué frecuencia te informabas por las noticias, de la situación de los peruanos en el extranjero y las medidas para su retorno al Perú? (ejemplo: disposiciones del gobierno, comunicaciones del Consulado por la web)

18. ¿Procuraste planificar y cumplir una rutina diaria?

19. ¿Con qué frecuencia organizabas tu equipaje para retornar al Perú?

Afrontamiento a

16. Consideras que la experiencia de estar en el extranjero sin poder regresar al

la incertidumbre

del deseo de cambio
17. Si tu respuesta a la pregunta anterior fue "SI", explica por qué

20. Mientras estuviste en el extranjero sin poder retornar al país, ¿te refugiaste en alguna religión, credo o doctrina filosófica?, explica cómo

21. Cuando estuviste en el extranjero sin poder retornar al país, ¿encontraste algo positivo en esa experiencia vivida? explica 


\section{Procedimiento}

Diseñado el cuestionario, los jueces procedieron a evaluar los ítems de manera independiente, vía correo electrónico. Luego de tener la versión final de la prueba, se realizó laselección de los participantescon un muestreo no probabilístico por conveniencia.

Primero, se solicitó la autorización de una agencia de Work and Travel, la misma que envío los enlaces virtuales a los estudiantes para que, quienes deseen, participen del estudio. Además, algunos participantes contactaron a sus conocidos con la técnica de bola de nieve. En segundo lugar, para garantizar el bienestar y la autonomía de los participantes de estudio, se solicitó su consentimiento informado, vía formularios Googlea través de WhatsApp, previa presentación del equipode investigación, el objetivo del estudio, el carácter libre y voluntario de la participación, así como el anonimato de sus respuestas. De ese modo, se garantizaron los principios éticos en investigación científica para los participantes (American Psychological Association, 2016; Colegio de Psicólogos del Perú, 2017). Quienes estaban de acuerdo en participar, seleccionaron la opción "sí" y continuaron con el llenado del formulario, en cambio, quienes elegían la alternativa "no", daban por finalizada su participación.

\section{Análisis de datos}

Para la cuantificación de la valoración de los especialistas en la validez de contenido del instrumento aplicado se utilizó la V de Aiken y sus intervalos de confianza (Penfield \& Giacobbi, 2004), mientras que para el análisis descriptivo de la información recolectada se efectuó mediante las frecuencias relativas simples y porcentuales.

\section{Resultados}

\section{Afrontamiento a la incertidumbre emocional}

Antes de presentar los hallazgos acerca de cómo los participantes afrontaron la incertidumbre emocional cuando estuvieron en el extranjero imposibilitados de retornar al Perú, se explicará las emociones que hicieron frente. Experimentaron en mayor proporción emociones negativas, debido a que se sintieron agobiados o angustiados (64.10 $\%)$, tensos $(56.41 \%)$, nerviosos (41.03 $\%)$, intranquilos (41.03\%) y temerosos (41.03\%). Vivenciaron dichas emociones tanto quienes estuvieron pocos días en el extranjero antes de regresar a Perú, como quienes estuvieron mayor tiempo. Sin embargo, los que permanecieron de 45 a 65 días en el exterior sin poder retornar experimentaron más frecuentemente la coexistencia de emociones negativas y positivas. Vale decir, que la presencia de estas últimas emociones se presentó también en quienes tuvieron menos tiempo en el exterior, destacando como emociones positivas, sentirse esperanzado y activo (Tabla 3 ). 
Tabla 3.

Emociones experimentadas durante el tiempo en el extranjero sin poder regresar a Perú

\begin{tabular}{|c|c|c|c|c|c|}
\hline \multirow{2}{*}{$\begin{array}{l}\text { Días sin poder } \\
\quad \text { regresar }\end{array}$} & \multirow{2}{*}{\multicolumn{2}{|c|}{ Emociones }} & \multirow{2}{*}{$f$} & \multicolumn{2}{|c|}{ Total } \\
\hline & & & & $f$ & $\%$ \\
\hline \multirow[t]{7}{*}{$1-14$} & Negativas & Agobiado o angustiado, irritado & 3 & & \\
\hline & & Agobiado o angustiado, temeroso, tenso & 1 & 5 & 50 \\
\hline & & Temeroso, tenso, intranquilo & 1 & & \\
\hline & Ambas & Tenso, decidido, esperanzado & 1 & & \\
\hline & & Enojado, nervioso, esperanzado & 1 & & \\
\hline & & Agobiado, temeroso, esperanzado & 2 & 5 & 50 \\
\hline & & $\begin{array}{l}\text { Dispuesto, temeroso, nervioso, atento, } \\
\text { activo }\end{array}$ & 1 & & \\
\hline \multirow[t]{8}{*}{$15-29$} & Negativas & Agobiado, tenso, temeroso & 9 & & \\
\hline & & Agobiado o angustiado, enérgico & 1 & 10 & 62.5 \\
\hline & Positivas & Decidido, atento, activo, esperanzado & 1 & & \\
\hline & & Dispuesto, decidido, activo & 1 & 3 & 18.75 \\
\hline & & Animado, enérgico, atento & 1 & & \\
\hline & Ambas & Agobiado, tenso, esperanzado & 1 & & \\
\hline & & Tenso, entusiasmado, intranquilo, asustado & 1 & 3 & 18.75 \\
\hline & & Tenso, orgulloso, nervioso, inspirado & 1 & & \\
\hline \multirow[t]{6}{*}{$30-44$} & Negativas & Agobiado o angustiado, temeroso, tenso & 1 & & \\
\hline & & Temeroso, tenso, intranquilo & 1 & & \\
\hline & & Enojado, irritado, tenso & 1 & 4 & 57.14 \\
\hline & & Agobiado o angustiado & 1 & & \\
\hline & Positivas & Esperanzado & 1 & 1 & 14.29 \\
\hline & Ambos & $\begin{array}{l}\text { Agobiado o angustiado, enojado, } \\
\text { esperanzado }\end{array}$ & 2 & 2 & 28.57 \\
\hline \multirow[t]{6}{*}{$45-65$} & Negativas & Agobiado o angustiado, tenso & 1 & 1 & 16.67 \\
\hline & Ambos & Agobiado o angustiado, activo, esperanzado & 1 & & \\
\hline & & $\begin{array}{l}\text { Agobiado o angustiado, animado, tenso, } \\
\text { inspirado }\end{array}$ & 1 & & \\
\hline & & $\begin{array}{l}\text { Tenso, atento, intranquilo, activo, } \\
\text { esperanzado }\end{array}$ & 1 & 5 & 83.33 \\
\hline & & Agobiado o angustiado, tenso, orgulloso & 1 & & \\
\hline & & Agobiado o angustiado, temeroso, irritado & 1 & & \\
\hline Total & & & & 39 & 100 \\
\hline
\end{tabular}

Los participantes vivenciaron más de un temor a la vez y los más frecuentes fueron no poder regresar a Perú ( $43.8 \%)$, contagiarse de la COVID-19 (25\%), quedarse sin dinero $(12.5 \%)$ y preocupación por sus padres o temor a que se contagien (8.4\%). Además, entre los cambios en el organismo, los participantes refirieron experimentar especialmente alteraciones en el sueño (23.47\%), tensión muscular 
(22.45\%), cambios en el apetito (15.31\%), inquietud (14.29\%), problemas respiratorios o estomacales o dolor físico (16.32 $\%)$, alergias (4.08\%); y, fueron muy pocos quienes refirieron no vivenciar cambio alguno (4.08\%).

El $98 \%$ de los jóvenes accionaron modos de afronte ante las emociones displacenteras experimentadas por la incertidumbre, siendo las más frecuentes: dormir (22.81 $\%)$, intentar relajarse efectuando actividades físicas (21.03\%), realizar acciones de distracción como jugar o ver televisión o series (17.54\%), hablar con la familia o amigos (12.28\%), llorar (12.28\%), escuchar música (7.02 \%), salir con amigos (3.51\%), mientras que una persona no experimentó emociones displacenteras $(1.75 \%)$ y otra se autolesionaba.

En relación al apoyo emocional, éste lo ha proporcionado la familia (64.23\%), los amigos (22.76 \%) y la pareja (11.38\%). Vale señalar que el 79.49\% prefería estar acompañado que solo. Asimismo, una gran cantidad de los jóvenes participantes refirieron haber recibido apoyo emocional de personas que recién conocían (79.49 $\%)$; y, también la mayoría de los participantes $(80.95 \%)$ proporcionó apoyo a otras personas, de tipo emocional $(59.52$ $\%)$, material (14.29\%) o con información (7.14\%).

\section{Afrontamiento a la incertidumbre cognitiva}

Casi la totalidad de los participantes (92.31\%) realizaron acciones para intentar solucionar el problema, entre las cuales destacaron: contactarse con el Consulado (43.59\%), contactar con aerolíneas y vuelos chárter (25.64\%), organizarse en grupos para viaje (5.13\%), contactar con las agencias de Work and Travel (5.13 $\%)$, buscar ayuda de otros peruanos en igual situación (5.13\%) y contactarse con medios de comunicación (5.13\%).

Los que contribuyeron en la solución del problema, según la percepción de los participantes, fueron el Consulado peruano (40.35\%), los familiares (29.82 $\%)$, amigos (19.30 \%) y desconocidos (10.53 $\%)$. El tipo de apoyo recibido fue verse favorecido con el vuelo de retorno $(52.63$ $\%)$, haberse comunicado con los medios que posibiliten la solución del problema (39.47\%), recibir apoyo emocional (18.42 $\%)$, hospedaje y alimentación (5.26 \%) y apoyo económico (2.63\%).

El 100\% de los participantes buscaba estar informado de las noticias sobre la situación de los peruanos en el extranjero y las disposiciones de Estado para su retorno al Perú. La mayoría se actualizaba en las noticias diariamente (74.36\%), y otros lo hacían con menor frecuencia, como interdiaria $(15.38 \%)$, semanal (7.69 \%) y mensual (2.56\%). Además, el 53.85\% procuró cumplir una rutina diaria y organizaba su equipaje con cierta regularidad (28.21 \% semanal, $12.82 \%$ diaria y 12.82 $\%$ interdiaria).

\section{Afrontamiento del deseo de cambio}

Los participantes valoraron en su mayoría $(74.36 \%)$ como excitante o emocionante la experiencia vivida de 
estar imposibilitados de poder retornar a su país. Calificaron la situación como una experiencia nueva $(38.46 \%)$, de supervivencia o aventura (15.38\%), o que favoreció la autorregulación personal o la maduración $(10.26 \%)$ y les permitió conocer personas y solidarizarse $(2.56$ $\%)$. Solamente el $33.33 \%$ calificó la experiencia como "mala". Además, el 92\% de los participantes no se apoyó en alguna religión alguna, ni credo, ni doctrina filosófica mientras estuvo en el extranjero sin poder regresar al Perú.

Finalmente, ante la pregunta de si hubo algo positivo en la experiencia vivida, los participantes respondieron que aprendieron a controlar sus emociones 34.78 $\%)$, se hicieron más independientes o maduros $(26.09 \%)$, les ayudó a valorar a su familia (13.04\%), les permitió tener amigos (21.74\%) y sólo una persona respondió que el evento acentuó la depresión $(4.35 \%)$.

\section{Discusión}

El estudio se efectuó con el propósito de caracterizar los modos de afrontamiento a la incertidumbre de jóvenes peruanos que estuvieron imposibilitados de retornar a su país por el cierre de fronteras debido a las disposiciones del gobierno peruano por la pandemia de la COVID-19. Vale señalar que los jóvenes participantes son estudiantes universitarios, participantes del programa Work and Travel, quienes en su mayoría viven con su familia y tras declararse el cierre de fronteras tuvieron que permanecer en EE.UU., acompañados principalmente por amigos.
Los participantes, mientras no podrían regresar del extranjero, mayoritariamente vivenciaron la incertidumbre con emociones negativas (angustia, tensión, nerviosismo, intranquilidad y temor). Al respecto, se concuerda con un estudio que vincula los síntomas ansiosos respecto a la COVID-19 con la dificultad para tolerar la incertidumbre (Wheaton et al., 2021). Sin embargo, los que tenían mayor tiempo experimentaron en mayor porcentaje la coexistencia de emociones negativas y positivas, entre estas últimas se contaban la esperanza y sentirse activo, las mismas que son necesarias para orientar las estrategias para alcanzar las metas (Castillo et al., 2014).

Entre los temores, el más frecuente fue el riesgo de no poder regresar al Perú, seguido por el miedo a contagiarse de la COVID-19 y es que estar expuestos a las noticias - por necesidad- en el contexto de la pandemia resulta estresante (Vásquez et al., 2020); y más aún, ello se agudiza si se suma el no disponer de un seguro de salud debido a la finalización del contrato laboral y estar lejos de sus familias. Además, se adicionaron alteraciones en el sueño, así como dolencias físicas, que están asociadas al estrés (Del Río Portilla, 2006).

A pesar de ello, lo que contribuyó a que los jóvenes participantes manejen la situación de desconcierto y ambigüedad y a que reduzcan el impacto afectivo de lo vivido, fue haber estado acompañado, en su mayoría por amigos, haber recibido el apoyo emocional de la familia en la distancia, incluso el soporte de desconocidos, y 
haber practicadoactividades de ocio, lo que favorece la salud mental (Goodman et al., 2017). Posiblemente ello explique la puesta en marcha de acciones de apoyo en favor de quienes vivían igual experiencia, que les ayudó a tolerar su propia incertidumbre y a disminuir la que enfrentaba el otro, favoreciendo la autorregulación emocional (Saarni et al., 2007), la misma que fue señalada por los participantes como experiencia positiva, al haber madurado y aprendido a controlar las propias emociones.

Aún con la emocionalidad vivida, los participantes - durante su periodo vacacional-, obtuvieron la experiencia de haber dirigido su vida por sí mismos y haber trabajado, en un contexto cultural diferente y lejos a su entorno familiar, donde establecieron nuevos vínculos amicales. Ello posiblemente puede haber contribuido a que afronten la incertidumbre cognitiva activamente, buscando información y los recursos para intentar encontrar solución a su situación, lo que corresponde a la estrategia centrada en el problema, según Lazarus y Folkman (1984).

Aunque la solución final de la situación no dependió de ellos, el resultado no se hubiese alcanzado sin la puesta en marcha de las gestiones realizadas, que solamente benefició a algunos jóvenes bajo la misma situación. Por ello, la atribución acerca de quien contribuyó en la solución del problema fue dirigida especialmente al Consulado peruano, seguido por familiares y desconocidos. Además, el cumplimiento de una rutina diaria, seguida por la mayoría de los jóvenes, implicaba que se organicen y ejerzan el control sobre la distribución de su tiempo, lo que favorece el equilibrio y contribuye a la calidad de vida (Gómez, 2006), en un contexto de incertidumbre en el porvenir.

Respecto al afrontamiento de la incertidumbre del deseo de cambio, los participantes en su mayoría, experimentaron lo vivido como excitante o emocionante, lo que podría corresponder con el hallazgo de que la búsqueda de sensaciones y novedades se incrementa hacia la adolescencia y disminuye en la adultez, ya que la muestra evaluada fue en su mayoría de jóvenes con un promedio de 20 años (Alcázar et al., 2015). La solución a su situación con vuelos humanitarios o chárter, no dependía de los jóvenes, por lo que prolongar o no la situación de incertidumbre, no estaba bajo su control; sin embargo, las experiencias vividas contribuyeron a su autorregulación emocional, de acuerdo a lo referido por los participantes.

Cabe señalar que, como limitaciones del estudio, se considera haberlo realizado con una reducida cantidad de participantes, integrada únicamente por jóvenes peruanos del programa Work and Travel, lo que afecta la validez externa de la investigación. Además, no fue posible acceder a muestras con un tiempo mayor de permanencia en el extranjero ( $>65$ días) ni a quienes aún se encontraban en el extranjero sin poder retornar; por lo que las experiencias reveladas por los participantes fueron con una percepción en retrospectiva, cuando ya habían sido repatriados, acerca de cómo afrontaron la situación mientras aún permanecían 
en el exterior. Estudios futuros podrían superar estas limitaciones, para posibilitar una mayor comprensión de la variable de estudio, porque gran parte de los antecedentes se han focalizado al estudio de la incertidumbre vinculado a la enfermedad.

Otra de las limitaciones ha sido el diseño transversal del estudio, que imposibilitó recoger información sobre los cambios ocurridos a nivel fisiológico, emocional, cognitivo, comportamental y el afrontamiento de los participantes, desde el inicio hasta el término de su situación de incertidumbre. Asimismo, haber recogido información únicamente con una medida de autorreporte y no combinarlas con medidas físicas fue otra limitación del estudio.

Al no haber tenido disponible un instrumento estandarizado que evalúe el constructo de interés, como parte del estudio, se diseñó un cuestionario que incluye preguntas abiertas para recoger mayor profundidad en las respuestas. Para éste, sólo se obtuvo una evidencia de validez basada en el contenido, que constituye un aporte para comprender el constructo desde el ámbito psicosocial, poco explorado.

Aunque se recolectó información sobre el afrontamiento a la incertidumbre, en los hallazgos se reportan aspectos comunes con el afrontamiento al estrés, en la mayoría de los participantes, quienes se sintieron agobiados o tensos, como respuesta a la coyuntura política y sanitaria que impedía el regreso a su país, activándose en ellos respuestas fisiológicas, cognitivas y comportamentales, al percibir que se desbordan sus recursos personales ante una situación que está fuera de su control y que afecta su bienestar; y que se encaminó fundamentalmente al empleo de estrategias de centradas en el problema y en la emoción (Lazarus \& Folkman, 1984).

Sin embargo, como señaló Lazarus, el factor tiempo es un elemento que se debe considerar en el estudio del afrontamiento al estrés, y, en el caso del presente estudio, la cantidad promedio de días bajo incertidumbre vividas por los jóvenes fue de 25; por lo que no todos los participantes experimentaron estrés, pero sí todos vivenciaron la incertidumbre de su porvenir en un contexto de pandemia. Además, la perspectiva asumida para el estudio, permitió obtener, entre la información del afrontamiento a la incertidumbre emocional, el proveer de apoyo a otros, y no solo recibirlo. Asimismo, se exploró el afrontamiento a la incertidumbre de deseo de cambio, expresado en la excitabilidad y novedad de la experiencia vivida. Estudios futuros podrían utilizar medidas cuantitativas de intolerencia a la incertidumbre (Buhr \& Dugas, 2002), estilos de afrontamiento y considerar otras variables como la flexibilidad cognitiva, porque comprende la disposición o resistencia al cambio (Dennis \& Vander Wal, 2010).

Se concluye que los jóvenes peruanos del programa Work and Travel, que estuvieron imposibilitados de regresar a su país por el cierre de fronteras, debido a la pandemia por la COVID-19, utilizaron 
modos de afrontamiento a la incerti- afrontamiento de la incertidumbre desde dumbre emocional, expresado en temo- un panorama distinto al de la enfermedad res, emocionalidad negativa y malestar y en un contexto sin precedentes, como físico, con el soporte de amigos, familia- lo es la pandemia por la COVID-19. res y proveer apoyo a otros. El afrontamiento a la incertidumbre cognitiva, fue buscando alternativas de solución para su retorno a Perú, informándose de las noticias y cumpliendo rutinas diarias; mientras que, por el afrontamiento de deseo de cambio, la experiencia vivida se percibió como una experiencia excitante. Finalmente, esta información Los autores manifiestan no tener conflicto permitió caracterizar el fenómeno del de interés alguno. 


\section{Referencias}

Alcázar, M. A., Verdejo, A., Bouso, J. C., \& Ortega, J. (2015). Búsqueda de sensaciones y conducta antisocial. Anuario de Psicología Jurídica, 25, 75-8o. http://dx.doi. org/10.1016/j.apj.2015.01.003

American Psychological Association (2016). Ethical Principles of Psychologists and Code of Conduct. https://www.apa.org/ethics/code

Arias, M. M., \& Giraldo, C. V. (2011). El rigor en la investigación cualitativa. Investigación y Educación en Enfermería, 29(3), 500-514. https://www.redalyc. org/pdf/1052/105222406020.pdf

Ato, M., López, J. J., \& Benavente, A. (2013). Un sistema de clasificación de los diseños de investigación en Psicología. Anales de Psicología, 29(3), 1038-1059. http:// dx.doi.org/10.6o18/analesps.29.3.178511

Babore, A., Lombardi, L., Vicenconti, M. L., Pignataro, S., Marino, V., Crudele, M., ..., Trumello, C. (2020). Psychological effects of the COVID-2019 pandemic: Perceived stress and coping strategies among healthcare professionals. Psychiatry Research, 293. https://doi.org/10.1016/j.psychres.2020.113366

Berra, E., Muñoz, S., Vega, C., Silva, A. \& Gómez, G. (2014). Emociones, estrés y afrontamiento en adolescentes desde el modelo de Lazarus y Folkman. Revista Intercontinental de Psicología y Educación, 16(1), 37-57. https://www.redalyc. org/pdf/802/80230114003.pdf

Brabow, A., \& Kline, K. (200o). From "reducing" to "coping with" uncertainty: reconceptualizing the central challenge in breast self-exams. Social Science $\mathcal{E}$ Medicine, 51(12), 1805-1816. https://doi.org/10.1016/So277-9536(oo)oo112-X

Buhr, K., \& Dugas, M. J. (2002). The intolerance of uncertainty scale: psychometric properties of the English version. Behaviour Research and Therapy, 40(8), 931-945. https://doi.org/10.1016/Sooo5-7967(o1)ooog2-4

Castillo, H., Urrutia, C., Shimabukuro, M., \& Caycho, T. (2014). Análisis psicométrico del índice de esperanza de Herth en una muestra no clínica peruana. Psicología desde el Caribe, 31(2). http://dx.doi.org/10.14482/psdc.31.2.5974

Clarke, E., \& Kiropoulos, L. (2021). Mediating the relationship between neuroticism and depressive, anxiety and eating disorder symptoms: The role of intolerance 
of uncertainty and cognitive flexibility. Journal of Affective Disorders Reports, 4. https://doi.org/10.1016/j.jadr.2021.100101

Colegio de psicólogos del Perú (2017). Código de ética y deontología. CPP.

Dawson, D., \& Golijani-Moghaddam, N. (2020). COVID-19: Psychological flexibility, coping, mental health, and wellbeing in the UK during the pandemic. Journal of Contextual Behavioral Science, 17(20), 126-134. https://doi.org/10.1016/j. jcbs.2020.07.010

Del Río Portilla, I. (2006). Estrés y sueño. Revista Mexicana de Neurociencia, 7(1), 15-20. http://previous.revmexneurociencia.com/wp-content/uploads/2014/o6/ Nmo61-03.pdf

Dennis, J. P., \& Vander Wal, J. S. (2010). The Cognitive Flexibility Inventory: instrument development and estimates of reliability and validity. Cognitive Therapy and Research, 34, 241-253. https://doi.org/10.1007/s106o8-009-9276-4

El Comercio (19 de marzo de 2020). Work and Travel asegura que 3.0oo estudiantes peruanos de su programa están varados en EE.UU. https://elcomercio.pe/mundo/ eeuu/coronavirus-en-estados-unidos-work-and-travel-30oo-peruanos-estan-varados-en-diferentes-lugares-del-pais-covid-19-pandemia-nndc-noticia/?ref=ecr

García-Cortés, G. (2019). Modelo integral de calidad para las universidades politécnicas de México. Un enfoque desde la socioformación. Atenas, 3(47), 70-89. https:// atenas.reduniv.edu.cu/index.php/atenas/article/view/49o/761

Gómez, S. (2006). Equilibrio y organización de la rutina diaria. Revista Chilena de Terapia Ocupacional, 6. https://doi.org/10.5354/o719-5346.2010.111

Gómez, V. (2005). Richard Stanley Lazarus (1922-2002). Revista Latinoamericana de Psicología, 37(1), 207-209. https://www.redalyc.org/pdf/805/80537112.pdf

Goodman, W. K., Geiger, A. M., \& Wolf, J. M. (2017). leisure activities are linked to mental health benefits by providing time structure: comparing employed, unemployed and homemakers. Journal of Epidemiology and Community Health, 71(1), 4-11. http://dx.doi.org/10.1136/jech-2016-20726o

Greco, V. \& Roger, D. (2001). Coping with uncertainty: the construction and validation of a new measure. Personality and Individual Differences, 31, 519-534. 
Lazarus, R. S. (1999). Stress and emotion. A new synthesis. Springer.

Lazarus, R. S., \& Folkman, S. (1984). Stress appraisal and coping. Springer.

Lyne, K., \& Roger, D. (200o). A psychometric re-assessment of the COPE questionnaire. Journal of Personality and Individual Differences, 29(2), 321-335. https:// doi.org/10.1016/So191-8869(99)oo196-8

Mishel, M. H. (1988). Uncertainty in Illness. Image: The Journal of Nursing Scholarship, 20(4), 225-232. https://doi.org/10.1111/j.1547-5069.1988.tbooo82.x

Mishel, M. H. (1990). Reconceptualization of the Uncertainty in Illness Theory. Image: The Journal of Nursing Scholarship, 22(4), 256-262. https://doi. org/10.1111/j.1547-5069.1990.tboo225.x

Padrós, F., Soriano-Mas, C., \& Navarro, G. (2012). Afecto positivo y negativo: ¿Una dimensión bipolar o dos dimensiones unipolares independientes? Interdisciplinaria, 29(1), 151-164.

Penfield, R. D., \& Giacobbi, P. R. (2004). Applying a Score Confidence Interval to Aiken's Item Content-Relevance Index. Measurement in Physical Education and Exercise Science, 8(4), 213-225. https://doi.org/10.1207/s15327841mpeeo804_3

Ramírez, F. B., Misol, R. C., Alonso, M. del C. F., \& Tizón, J. L. (2020). Pandemia de la Covid-19 y Salud Mental: reflexiones iniciales desde la atención primaria de salud española. Atención Primaria. https://doi.org/10.1016/j.aprim.2020.06.0o6

Saarni, C., Campos, J. J., Camras, L. A., \& Witherington, D. (2007). Emotional Development: Action, Communication, and Understanding. Handbook of Child Psychology. https://doi.org/10.1002/9780470147658.chpsyo305

Tobin, D. L., Holroyd, K. A., Reynolds, R. V., \& Wigal, J. (1989). The hierarchical factor structure of the coping strategies inventory. Cognitive Therapy and Research, 13 , 343-361. https://doi.org/10.1007/BFo1173478

Tobón, S., Cardona, S., Vélez, J., \& López, J. (2015). Proyectos formativos y desarrollo del talento humano para la sociedad del conocimiento. Acción Pedagógica, 24, 20-31.

Yang, D., Ye, J., Zhou, F., Li, J., Huang, Q., \& Wan, L. (2015). Relationship between uncertainty in illness, mood state and coping style in patients with temporomandibular 
disorders. International Journal of Nursing Sciences, 2(4), 361-365. https://doi. org/10.1016/j.ijnss.2015.11.003

Vásquez, G., Urtecho-Osorto, O., Agüero-Flores, M., Díaz-Martínez, M., Paguada, R., Varela, M., Landa-Blanco, M., \& Echenique, Y. (2020). Salud mental, confinamiento y preocupación por el coronavirus: un estudio cualitativo. Revista Interamericana de Psicología, 54(2), e1333.

Voigt, K., Ziegler, M., Grunert-Fuchs, M., Bickel, U., \& Fehm-Wolfsdorf, G. (1990). Hormonal responses to exhausting physical exercise: the role of predictability and controllability of the situation. Psychoneuroendocrinology, 15, 173-184. https:// doi.org/10.1016/0306-4530(90)90028-8

Walker, D., Davis, P., \& Stevenson, A. (2017). Coping with uncertainty and ambiguity through team collaboration in infrastructure projects. International Journal of Project Management, 35(2), 180-19o. https://doi.org/10.1016/j.ijproman.2016.11.001

Wheaton, M., Messner, G., \& Marks, J. (2021). Intolerance of uncertainty as a factor linking obsessive-compulsive symptoms, health anxiety and concerns about the spread of the novel coronavirus (COVID-19) in the United States. Journal of Obsessive-Compulsive and Related Disorders, 28. https://doi.org/10.1016/j. jocrd.2020.100605

Wiener, C., \& Dodd, M. (1993). Coping amid uncertainty: an illness trajectory perspective. Scholarly inquiry for nursing practice: An International Journal, 7(1), 17-31. https://www.researchgate.net/profile/Carolyn_Wiener/publication/14711661_Coping_Amid_Uncertainty_An_Illness_Trajectory_Perspective/ links/555a647co8ae6943a877ce46/Coping-Amid-Uncertainty-An-IllnessTrajectory-Perspective.pdf

Zakowski, S. G. (1985). The effects of stressor predictability on lymphocyte proliferation in humans. Psychology and Health, 10, 409-425. https://doi. org/10.108o/o887044950840196o

Recibido: 22 de febrero de 2021

Revisado: 2 de abril de 2021

Aceptado: 7 de mayo de 2021 



\title{
Salud mental, bienestar psicológico y estrés en personal de salud en el contexto de la COVID-19
}

Mental Health, Psychological Wellbeing and Stress in the Healthcare Personnel in the Context of COVID-19

Giovanna Elizabeth Reyes Neyra Universidad Nacional de Huancavelica, Huancavelica, Perú

(iD) https://orcid.org/oooo-0oo1-8062-0156

Rossmery Shirley Arce Delgado Universidad Católica San Pablo, Arequipa, Perú

iD https://orcid.org/oooo-0002-5605-5102

Correspondencia: rsarce@ucsp.edu.pe

Alexander Cruz Sotomayor

Hospital III Goyeneche, Arequipa, Perú

(iD) https://orcid.org/oooo-0oo1-7262-1058

Nohely Andrea Portilla Pauccara Universidad Católica San Pablo, Arequipa, Perú

(iD https://orcid.org/oooo-0oo2-8616-4633

\begin{abstract}
Resumen
El presente artículo revisa, desde el análisis crítico de estudios, la salud mental y bienestar psicológico del personal de salud durante la pandemia de COVID-1, así como el estrés y estrés postraumático producto de la situación de incertidumbre, de estar lidiando directamente con el sufrimiento, agonía, muerte de personas de una forma masiva. Asimismo, se describe los sentimientos que experimentan debido al cambio radical de sus labores y nuevos estilos de vida con el fin de proteger la salud. Se realiza este estudio con el fin de hacer visible la importancia de atender la salud mental y proponer estrategias que contribuyan a disminuir los efectos adversos en el bienestar psicológico del personal de salud. Palabras clave: Personal de salud, COVID-19, salud mental, estrés.
\end{abstract}




\begin{abstract}
This article reviews, from the critical analysis of studies, the mental health and psychological well-being of healthcare personnel during COVID-19 pandemic as well as the stress and post-traumatic stress produced by uncertainty and by having to deal directly with the suffering, agony and death of others. In addition, it describes the feelings they experienced due to the radical changes to their work and their lifestyle required to protect their own health. This study was carried out in order to make visible the importance of attending to mental health, as well as, to propose strategies that contribute to reducing adverse effects on the psychological well-being of healthcare personnel.
\end{abstract}

Keywords: Health personnel, COVID-19, mental health, stress.

\section{Introducción}

A lo largo de la historia, las epidemias y/o pandemias han resultado ser desafíos únicos, golpeando periódicamente a la humanidad y cambiando el curso del mundo. Desde las antiguamente llamadas plagas que tuvieron escenario en Atenas, Roma en la época de Galeno, de Justiniano; la peste negra que inició en Florencia, así como las enfermedades que se trajeron a América durante la colonización o la gripe española. Todas estas catástrofes sanitarias cobraron millones de vidas, y sus consecuencias fueron seguidas por hambrunas y trastornos sociopolíticos.

En principio, se debe entender que entre más grande es el desafío, más juiciosa debe ser la respuesta, y la ésta no se centra tanto en las tecnologías médicas, sistemas sanitarios o nivel socioeconómico que pueda tener una sociedad, sino, en su capacidad de afrontar una situación límite. Pues una enfermedad llega cuando uno menos lo espera y encontramos en el pasado enseñanzas que nos pueden orientar para lidiar con una situación abrumadora y que nos supera en distintos aspectos.

La actual crisis de la enfermedad de la COVID-19 no está exenta de consecuencias socioeconómicas y políticas, así como otras aún insospechadas. En ese sentido, se quiere dar a conocer sobre el impacto negativo en la salud mental del personal sanitario. Por ello en este artículo se describe cuáles son las características de la salud mental y el bienestar psicológico, así como las consecuencias negativas que surgen a raíz de este problema, el estrés y el estrés postraumático.

A medida que la COVID-19 se ha esparcido a lo largo del país, el personal de salud enfrentó con incertidumbre esta problemática pues significó un cambio radical en el entorno laboral, por la aplicación de medidas de contención, la inestabilidad económica, la escasez de suministros de equipos de protección personal etc. A nivel mundial fue evidente que nadie estaba preparado para hacer frente a la pandemia y se fue actuando sobre la marcha con lo mejor que se tenía y se podía. 
Las circunstancias particulares de la pandemia han evidenciado la necesidad de mejorar y proteger la sensación de bienestar de la población. El apoyo al personal de salud en el plano preventivo se orienta al desarrollo de la promoción del bienestar psicológico, pues un adecuado nivel de bienestar psicológico se muestra como factor protector para la intervención específica de trastornos psicológicos.

Frente a las circunstancias en las que nos encontramos es fácil vernos afectados e implicados en una inestabilidad emocional, ya que el personal de salud es el más vulnerable por su contacto directo con pacientes cuya probabilidad de contagio es alta. Por ello es evidenciable un deterioro físico y emocional, y es muy importante poder brindar el soporte a todo el personal de salud involucrado, ya que un estrés acumulado junto con otros aspectos externos pueden causar deterioro en el bienestar general de estas personas, afectado directamente su desempeño laboral.

Cuando abordamos el tema de la salud mental en tiempos de crisis también podemos referirnos a una evolución personal, porque cualquier situación que nos orille al cambio tiende a tener efectos a nivel psicológico, lo que negamos nos somete y lo que aceptamos nos transforma, y se convierte en una especie de ley de supervivencia, pues si logramos adaptarnos al cambio podremos enfrentar mejor esta situación por demás compleja.

En la metodología para la presente revisión, se consideró estudios de PUBMED, Web of Science y Scielo desde marzo hasta agosto del 2020. Para la estrategia de búsqueda se utilizaron los siguientes términos MeSH: Health Personnel, COVID-19, Mental Health, Stress Disorders, Post-Traumatic Stress. Se consideraron estudios descriptivos, revisiones sistemáticas y metaanálisis. Para la lectura crítica de los estudios se utilizó el sistema CASPe (Critical Appraisal Skills Programme - Español) para evaluar la calidad de la evidencia científica.

\section{Salud Mental}

La salud mental es definida por la Organización Mundial de la Salud (OMS, 2018) como el estado de bienestar individual y fundamento de funcionamiento eficaz en la comunidad, sin embargo, es un concepto abstracto y complejo de definir. Cabanyes y Monge (2017) indican que consiste en un equilibrio dinámico que involucra la pasividad, accidentalidad y subjetividad individual y que incluye los aspectos afectivos como el ánimo, inclinaciones propias, sentimientos y emociones de donde se derivan los aspectos más complejos relacionados a la personalidad como la autoestima y la empatía. En ese sentido, se ha identificado que los indicadores de una salud mental "normal" tienen que ver con la capacidad de la persona de adaptarse al cambio, de lograr objetivos propuestos, una adecuada vinculación a la realidad, armonía, comunicación, creatividad y la apertura a otras experiencias que nos invitan a salir de nuestros propios límites. Por ello, la salud mental no es un estado si no una dinámica que no se posee, sino que se construye y está supeditada a la neurobiología, la personalidad y los 
factores ambientales, donde cada uno de ellos ejerce diversos grados de condicionamiento en distintos momentos de la vida y situaciones a las que se enfrenta la persona. Por lo tanto, comprender a la persona como un ser bio-psico-social y espiritual es fundamental, pues dejar de lado alguna de estas dimensiones sería caer en el reduccionismo o fraccionamiento de la persona (Cabanyes \& Monge, 2017).

Como se ha mencionado, los factores ambientales pueden condicionar de forma positiva o negativa el bienestar psicológico de la persona, y en este caso particular, el contexto actual que se vive con el desarrollo de la pandemia por el SARS$\mathrm{CoV}-2$, lleva a la persona a una situación inesperada y de incertidumbre. Distintos estudios evidencian que la presencia de una enfermedad puede afectar la salud mental de las personas, por ejemplo, en una revisión sistemática, Chew et al., (2020) encontraron que las respuestas psicológicas más comunes relacionadas con el ébola o la gripe $\mathrm{H}_{1} \mathrm{~N}_{1}$ incluyen ansiedad, miedo, depresión, ira, culpa, dolor y pérdida, estrés postraumático y estigmatización, pero también un mayor sentido de empoderamiento y compasión hacia los demás.

Con relación al personal de salud, en un estudio reciente, Salopek-žiha et al. (2020) encontraron que el $11 \%$ del personal de salud presentaba depresión moderada o severa, el $17 \%$ presentaba ansiedad moderada o extremadamente severa y el $67 \%$ refirió preocupación ante esta situación. De igual forma, la mayoría del personal de salud está asustado, exhausto, no duerme y pasa por una situación traumática al ver de cerca el sufrimiento humano (Feinstein \& Nemeroff, 2020). En algunos casos sienten frustración e impotencia de que sus esfuerzos no sean suficientes para poder salvar vidas ante este enemigo invisible. Por ello, es importante proteger la salud mental del personal de salud que diariamente está expuesto a factores estresantes, como estar en contacto cercano con el virus, estar expuestos a eventos traumáticos como la muerte y la agonía, mientras toman decisiones altamente desafiantes (Nochaiwong et al., 2020; Holmes et al., 2020).

A medida que se han incrementado los casos confirmados y sospechosos, la carga laboral en el personal de salud ha aumentado vertiginosamente (Wu \& Wei, 2020; Reger et al., 2020) y también se han evidenciado problemas interpersonales a consecuencia del uso de equipos de protección personal (EPP), debido a la imposibilidad de comunicarse adecuadamente por el uso de EPP y la falta de tiempo para dedicarlo al paciente (Walton et al., 2020).

Es probable que esta pandemia dará lugar a tasas altas de síntomas del trastorno de estrés postraumático, depresión y abuso de sustancias entre los supervivientes, familias de víctimas y otros trabajadores esenciales; por ello es de vital importancia identificar de forma temprana síntomas que puedan estar afectando la salud mental del personal de salud, así como establecer estrategias para mejorar su 
bienestar psicológico (Blake et al., 2020; Depierro et al. 2020).

\section{Bienestar Psicológico}

Las circunstancias particulares de la pandemia han evidenciado la necesidad de mejorar y proteger la sensación de bienestar de la población (Leiva et al., 2020). En las primeras concepciones del bienestar psicológico, se le vinculaba con conceptos como la autoactualización (Maslow, 1972) o el funcionamiento pleno de cada ser humano (Rogers, 1961). Sin embargo, principalmente debido a la dificultad para los procedimientos de medida sobre estas concepciones, Ryff (1989) operacionalizó seis dimensiones que constituyen el bienestar psicológico.

La primera dimensión es la autoaceptación, que permite el sentirse bien con uno mismo y tener conciencia de las limitaciones propias (Díaz \& RodríguezCarvajal, 2006). La siguiente dimensión definida como relaciones positivas con otras personas, conlleva la capacidad de entablar relaciones estables en el plano social, con la confianza y estimación que son fundamentales para bienestar y la salud mental (Ryff, 1989). La tercera dimensión responde a la autonomía o capacidad de las personas para conservar su independencia y autodeterminación frente a la presión social. Otra dimensión es el dominio del entorno, entendido como la habilidad de establecer u optar por entornos que permitan lograr cubrir necesidades y anhelos. Las dos últimas dimensiones son el propósito de vida por el cual la persona puede trazarse metas y objetivos para su existencia y el crecimiento personal o la constancia para el despliegue de las potencialidades (Keyes et al., 2002).

Los estudios de bienestar psicológico dirigidos a personal de salud suelen estar conectados a otras variables como el síndrome de burnout y el estrés laboral. En estudios con residentes de diversas especialidades médicas, se recaba un nivel entre medio y bajo de bienestar psicológico general (Delgado et al., 2020). Incluso, se sugiere la existencia de una relación inversa entre el bienestar psicológico y el burnout, pudiendo ser el primero un factor protector para la presencia del segundo (Paredes \& Sanabria- Ferrand, 2008).

En el contexto de la pandemia actual, el sentido de protección que permite la interacción con otros, manteniendo vínculos interpersonales, puede contribuir al bienestar de las personas, aunque no sea de forma presencial (Leiva et al., 2020). Además, es necesario el conocimiento del impacto psicológico enfocado en los datos de quiénes llegan a aminorar el efecto negativo en su bienestar (Dolan \& García, 2020). Considerando el incremento del deterioro del personal de salud en el contexto de la pandemia, la ONU ha hecho un llamado de respeto por parte de la población, para evitar exponer innecesariamente a los trabajadores de salud, pues se pone peligro de su bienestar (Bedoya, 2020).

Según la revisión de Cruz, Gutiérrez y Zaldivar (2020) la gestión en beneficio del 
bienestar psicológico de los profesionales de la salud en condiciones de emergencia debido a la pandemia es escasa. En la literatura revisada para el presente análisis se afirma la identificación y aprobación de la necesidad de la intervención psicológica orientada al personal de salud tanto en condiciones hospitalarias, así como en confinamiento. El apoyo al personal de salud en su etapa preventiva propone enfocarse en el desarrollo de la promoción del bienestar psicológico y la salud mental, por medio de actividades e intervenciones de autocuidado y grupos de apoyo. Además, de intervenciones específicas para el tratamiento de trastornos psicológicos tales como depresión, ansiedad, TEPT (Urzúa et al., 2020).

\section{Estrés}

La pandemia desatada por la COVID-19, evidencia que la mayoría de la humanidad atraviesa una de las pruebas más difíciles de vencer, ya que se trata de una situación que ha desatado en todo el mundo, miedos y frustraciones tanto a nivel físico como mental (Lozano, 2020).

La mayoría de las decisiones tomadas en el contexto de la pandemia se basan en evidencia de carácter científico, por lo que el desempeño de los profesionales de la salud cobra un rol de vital importancia, dadas sus capacidades y su formación académica en el ámbito de la salud (Alarcón, 2020). Es ese sentido, la seguridad y protección de los trabajadores de salud cobra relevancia en el resguardo del trabajo en el equipo clínico y de salud, de manera integral, lo cual incluye al personal técnico, de apoyo, profesionales y equipo médico (Huarcaya, 2020).

Alrededor del mundo la COVID-19 ha generado mucha inestabilidad emocional. Un estudio realizado por Wang et al. (2019) en 1210 personas de China durante la fase inicial de la pandemia, reveló que el $24.5 \%$ del total de personas presentaron un impacto psicológico mínimo, el 21.7 $\%$ un impacto moderado, y el $53.8 \%$ un impacto moderado o grave. Este impacto es más evidente en los profesionales de la salud, ya que ellos constantemente se enfrentan a una carga emocional con mucha presión debido a que existe un alto riesgo de infección y la falta de protección adecuada. El impacto actual que ha generado este virus ha llevado al incremento de la demanda de trabajo, la frustración, el cansancio por las largas jornadas laborales, falta de contacto con sus familiares y trato con pacientes que expresan emociones negativas; aspectos todos ellos que son propiciadores de estrés laboral (Kang, 2020).

La COVID-19 implica retos específicos para los trabajadores de la salud que están predispuestos a un manifestar mayores niveles de estrés (Muñoz et al., 2020), evidenciándose así, dificultades en la atención que brindan y toma de decisiones; y más aún, una disminución de su bienestar. Un estudio realizado por Lai et al. (2020) nos muestra que, en 1257 profesionales de la salud de 34 hospitales de China, entre el 29 de enero y el 3 de febrero de 2020, la presencia de síntomas depresivos (50.4\%), ansiosos (44.6\%), 
insomnio (34.0 \%) y reacción al estrés (71.5\%) es muy considerable.

El avance desmesurado que tiene este virus y los reportes de las muertes del personal de salud alrededor de todo el mundo, vienen generando un creciente temor en la atención a los pacientes diagnosticados con COVID-19 (Muñoz et al., 2020). A ello se suman estresores laborales preexistentes y otros aspectos organizacionales negativos, los cuales aumentan la vulnerabilidad y afectan el desempeño normal en la atención hospitalaria del personal de salud (Aragón-Nogales et al., 2020).

\section{Trastorno de estrés post traumático y COVID-19}

La pandemia por la COVID-19 puede exponer al personal de salud a sufrir eventos traumáticos de varias maneras. En medio del creciente número de casos y la percepción de no contar con el equipo de protección adecuado (Walton etal., 2020), el trabajador de primera línea puede sentir amenazada su vida o su integridad. Por otro lado, es posible que el trabajador sea testigo e incluso atienda a un colega o un familiar gravemente enfermo, lo cual le expone a traumas de tipo vicario. De manera que la pandemia genera un ambiente de inseguridad y miedo para el personal de salud que cumple con la definición de evento traumático (Restauri \& Sheridan, 2020).

El diagnóstico de trastorno por estrés post-traumático (TEPT) requiere de la exposición a un evento traumático y de la presentación de síntomas de reminiscencia de dicho evento, despersonalización o síntomas de hipervigilia durante al menos un mes después del evento (APA, 2013). En tal sentido, según lo anteriormente señalado, el personal de salud se encuentra en riesgo de padecer TEPT, pero además, se encuentra expuesto, de manera rutinaria, a sobrecarga laboral y estresores externos, lo cual agrava su situación.

Existen antecedentes de brotes que nos permiten comparar, predecir e intervenir sobre las condiciones de estrés a las que serán sometidos los trabajadores durante la pandemia por la COVID-19. Durante las anteriores pandemias del SARS en el 2003 y el MERS en el 2012, se estudió la prevalencia del TEPT y se encontró una frecuencia de $21 \%$ entre trabajadores de salud, señalándose también, que el $40 \%$ sufrían síntomas relacionados hasta tres años después del brote (Stuijfzand, 2020).

Un estudio en Taiwán durante la epidemia del SARS, en trabajadores del departamento de emergencia, identificó síntomas de estrés postraumático aplicando la escala de Davidson para el trauma (DTS-C). Los síntomas fueron más frecuentes en las áreas de mayor exposición a pacientes infectados con SARS, con una incidencia del $22 \%$. En áreas de mediana exposición los síntomas se encontraron con una frecuencia de $13 \%$ y en áreas sin exposición fue de solo el $7 \%$ (Lin et al., 2007). Durante el actual brote del SARS CoV-2, entre febrero y marzo de este año, Si et al. (2020) llevaron a cabo un estudio transversal en 863 trabajadores de salud en siete provincias de China utilizando el 
IES-6 (Escala de Impacto de Evento) y la DASS-21 (Escala de Depresión, Ansiedad y Estrés) para valorar problemas psicológicos, la percepción de amenaza y los estilos de afrontamiento. El $40.2 \%$ de trabajadores tuvo síntomas de estrés post traumático, que incluyeron, pensamientos intrusivos, hipervigilia y evitación. Estos síntomas se correlacionaron directamente con la percepción de amenaza y la percepción de soporte social se correlacionó inversamente con los síntomas de depresión y ansiedad.

Por otro lado, Carmassi et al. (2020) realizaron una revisión de los trabajos publicados sobre la presentación de síntomas de estrés post traumático durante las tres pandemias ocasionadas por coronavirus (SARS, MERS y COVID-19). Se incluyeron 24 estudios y se identificó algunos factores de riesgo relacionados con la presentación de síntomas como el mayor nivel de exposición (primera línea), una menor experiencia profesional, el sexo femenino, el aislamiento (cuarentena) y trastornos psiquiátricos previos (depresión mayor o ansiedad). La misma revisión encontró de manera consistente que los síntomas de estrés post traumático eran más frecuentes en enfermeras que en médicos. Específicamente durante la pandemia actual Lai et al. (2020) llevaron a cabo un estudio en 1257 trabajadores (493 médicos y 764 enfermeras) de 34 hospitales en China y encontraron que las enfermeras presentaban significativamente más síntomas de ansiedad, depresión y estrés. Ello sugiere que son las enfermeras quienes presentan mayor riesgo de ver afectada su salud mental que los médicos, debido a que tienen un contacto más próximo y permanente con los pacientes infectados

\section{Discusión}

La enfermedad producida por el virus SARS-CoV-2 surgió en diciembre del 2019 en Wuhan, China, y al extenderse vertiginosamente en dicho país y posteriormente alrededor del mundo, tuvo que ser declarada pandemia el $11 \mathrm{de}$ marzo del 2020 (Carmassi et al., 2020). En principio, el gobierno peruano aplicó distintas medidas para el control de la pandemia, siendo una de ellas la cuarentena, para dar oportunidad al personal de salud a organizarse y reunir esfuerzos para hacer frente a lo que se veía venir. A medida que los casos empezaron a incrementarse los trabajadores fueron expuestos progresivamente a situaciones laborales estresantes como el manejo de situaciones médicas críticas, sobrecarga laboral por más turnos de trabajo, entornos de atención colapsados y el déficit de equipos de protección personal (Carmassi et al., 2020; El-Hage et al., 2020).

Debido a esta situación de incertidumbre que luego empezó a cobrar vidas, las emociones y pensamientos negativos empezaron a amenazar la salud mental de las personas y sobre todo del personal de salud, que al estar directamente enfrentando la crisis sanitaria, llegó a reportarse sentimientos de miedo, soledad, tristeza e irritabilidad (Huarcaya-Victoria, 2020); por el peligro que representaba el 
cumplir con su rol profesional de servicio en el cuidado de la salud de la población general. Por ello, surgió la necesidad de identificary poner atención a los factores de riesgo que podrían resultar en la afectación de la salud mental del personal de salud y en manifestaciones psicopatológicas a largo plazo (Depierro et al., 2020).

En la actualidad, se han confirmado 1'561,723 casos confirmados en el Perú al 31 de marzo del 2021, según reporte del Ministerio de Salud (MINSA, 2021), donde más de 40000 casos corresponden a trabajadores de salud. Así mismo, el Colegio Médico del Perú reporta alrededor de 400 galenos fallecidos y 13,073 contagiados mientras que el Colegio de Enfermeras reporta 90 fallecidos y más de 7,700 enfermeros contagiados (Colegio Médico del Perú; Diario Gestión, 2021; Luceño-Moreno et al., 2020).

La pandemia se ha caracterizado por una publicación masiva de avances científicos con la finalidad de hacerle frente a través de un accionar profesional informado basado en evidencias, lo cual ha derivado en la formulación de protocolos de tratamiento e incluso la creación de vacunas. Sin embargo, pocos estudios han abordado el efecto directo que este problema sanitario podría generar en la salud mental de las personas que laboran en el ámbito sanitario (Vindegaard \& Benros, 2020). Se debe entender el contexto actual como una situación de emergencia y desastre a gran escala, que al permanecer por un periodo prolongado, puede ocasionar el incremento de casos de estrés postraumático, depresión y trastornos por abusos de sustancias (Restauri \& Sheridan, 2020). Es así entonces, que para poder prevenir las consecuencias psicológicas del COVID-19, distintas investigaciones internacionales se han focalizado en la salud mental del personal de salud (Arnetz et al., 2020; El-Hage et al., 2020; Hall, 2020; Luceño-Moreno et al., 2020; Preti et al., 2020; Restauri \& Sheridan, 2020; Simms et al., 2020; Vindegaard \& Benros; 2020). Inicialmente se han identificado factores de riesgo individual y laboral. Dentro de los factores de riesgo individuales que podrían afectar la salud mental de los trabajadores se menciona el miedo de infectar a un ser querido, el aislamiento o estigma social y el sexo; mientras que dentro de los factores laborales, se enlistan la disposición de equipos de protección personal, el nivel de exposición y el apoyo organizacional.

En este sentido, Luceño-Moreno et al. (2020) mencionan que las variables de riesgo para la ansiedad y la depresión serían el ser una persona de sexo femenino con turnos de 12 a 24 horas y la preocupación de contagiar a un familiar. Así también lo describe Hall (2020), donde además hace referencia a la escasez de equipo de protección personal y perder a colegas por la enfermedad, se da relevancia a la falta de comunicación y altos niveles de estrés en el trabajo (El-Hage et al., 2020).

El impacto que ha tenido la pandemia en la salud mental del personal de salud despierta gran preocupación en la comunidad científica, reportándose altas tasas de estrés postraumático, depresión clínica, 
así como consumo de sustancias como se mencionó anteriormente. Y peor aún, si se incluye un daño moral que va relacionado a la toma de decisiones difíciles, en este caso, asociada al racionamiento de la atención como puede suceder a la Unidad de Cuidados Intensivos (UCI) y/o el acceso a ventiladores mecánicos, lo que podría causar incluso, suicido mediado por los sentimientos de culpa (Depierro et al., 2020). En este sentido, el gobierno peruano está brindando apoyo al personal por líneas de atención telefónica para contribuir a identificary reducir los factores de riesgo anteriormente mencionados (Acosta \& Iglesias, 2020), pues como mencionan Werner et al. (2020), se ha identificado que las personas expuestas a estos factores también presentan somatizaciones y trastornos psicofisiológicos como hipertensión arterial, asma y dolor crónico; pues las situaciones difíciles que el personal de salud está viviendo pueden ser entendidas como una experiencia psicológica de trauma.

Dentro de las propuestas encontradas en la evidencia científica para mitigar el impacto en la salud mental de los trabajadores de la salud, se propone una mayor comprensión de la vulnerabilidad al sufrimiento psicológico para fortalecer estrategias de atención primaria y el manejo de situaciones de crisis sanitarias (El-Hage et al., 2020; Song et al., 2020). De igual forma, debe evaluarse las consecuencias neuropsiquiátricas directas y los efectos indirectos sobre la salud mental; aspectos fundamentales para mejorar el tratamiento, la planificación de la atención de la salud mental y las medidas preventivas durante posibles pandemias en el futuro (Vindegaard \& Benros, 2020).

Dentro de las herramientas propuestas para la identificación de riesgo se propone los autoreportes breves para analizar niveles de ansiedad, estrés, depresión, identificación de estrés postraumático, agotamiento, angustia psicológica, estrategias de afrontamiento del estrés y manejo de emociones con la finalidad de encontrar una solución que se adapte más a las necesidades del trabajador de salud (El-Hage et al., 2020). Así también, se propone enseñar estrategias rápidas para que las personas puedan controlar rápidamente el estrés, estrategias que se centren básicamente en el manejo de emociones frente al miedo y la promoción de actividades que contribuyan a la realización personal y el fortalecimiento psicológico a través de la resiliencia (Depierro et al., 2020; Restauri \& Sheridan; Song et al., 2020).

Finalmente, se propone el desarrollo de intervenciones psicosociales grupales interdisciplinarias, turnos rotativos más cortos y periodos de descansos regulares; sobre todo en personas que trabajan en áreas de alto riesgo. También es importante brindar capacitación e información clara del manejo de la enfermedad y protección personal, técnicas de relajación y manejo del estrés, fomentando visitas psicológicas para que puedan recibir el apoyo necesario y generar un ambiente de seguridad que permita mejorar el bienestar psicológico, y de esta forma, contribuir a que la persona se sienta motivada, mejore su rendimiento 
y la calidad de la atención (HuarcayaVictoria, 2020).

La promoción del bienestar psicológico se presenta como factor protector frente a situaciones estresantes como el actual contexto de pandemia, pudiendo reforzarse a través de grupos de apoyo e intervenciones de autocuidado dirigidos a los profesionales de la salud. El personal de salud al estar más expuesto a los diversos problemas psicológicos como el estrés, la ansiedad, depresión, entre otros; puede evidenciar una afectación en su rendimiento laboral y también en su vida personal. En ese sentido, es necesario poner énfasis en la protección del bienestar emocional de todo el personal de salud, ello mediante políticas públicas que ayuden a reforzar y brindar el soporte necesario para enfrentar las diversas circunstancias que se presenten en el desarrollo de sus funciones.

Entre los problemas psicológicos derivados de esta pandemia, esta revisión analizó el estrés y el estrés postraumático, como manifestaciones que afectan el bienestar psicológico y la salud mental del personal de salud, aspectos mencionados como problemas frecuentes durante la pandemia de la COVID-19 (Song et al., 2020). Sin embargo, diversos estudios (El-Hage et al., 2020; Preti et al., 2020; Vindegaard \& Benros, 2020) también hacen énfasis en la depresión, la ansiedad, el insomnio y el síndrome de burnout; como las principales afectaciones en el personal de salud. Asimismo, dado que se ha reportado que entre el 11 y el 73.4 $\%$ del personal de salud (principalmente médicos, enfermeras y personal auxiliar), presentaron síntomas de estrés postraumático durante los brotes epidémicos y pandémicos, con síntomas que duraron después de 1 a 3 años entre un 10 a $40 \%$ del personal sanitario (Preti et al., 2020); sería de vital importancia tomar medidas a largo plazo para mitigar los efectos de la COVID-19 en la salud mental de los trabajadores del sector salud.

\section{Financiamiento}

La realización del presente artículo no supuso financiamiento externo.

\section{Conflicto de intereses}

Las autoras declaran no tener conflictos de interés. 


\section{Referencias}

Acosta, J., \& Iglesias, S. (2020). Salud mental trabajadores expuestos a COVID-19. Revista de Neuro-Psiquiatría, 83(3), 212-213. https://doi.org/10.1002/jmv.25689

Ager, A., Pasha, E., Yu, G., Duke, T., Eriksson, C., \& Cardozo, B. L. (2012). Stress, mental health, and burnout in national humanitarian aid workers in Gulu, Northern Uganda. Journal of Trauma Stress, 25, 713-720. https://doi.org/10.1002/jts.21764

American Psychiatric Association (APA) (2013). Diagnostic and statistical manual of mental disorders. DSM-5. American Psychiatric Press.

Alarcón-Guzmán, R. D. (2020). Perspectivas éticas en el manejo de la pandemia COVID19 y de su impacto en la salud mental. Revista de Neuro-Psiquiatría, 83(2), 97-103. https://doi.org/10.20453/rnp.v83i2.3757

Aragón-Nogales, R., Vargas-Almanza, I., \& Miranda-Novales, M. (2019). COVID-19 por SARS-CoV-2: la nueva emergencia de salud. Revista Mexicana de Pediatría, 86(6), 213-218. http://www.scielo.org.mx/scielo. php?script=sci_arttext\&pid=So035-00522019000600213\&lng=es\&tlng=es

Arnetz, J. E., Goetz, C. M., Sudan, S., Arble, E., Janisse, J., \& Arnetz, B. B. (2020). Personal Protective Equipment and mental health symptoms among nurses during the COVID-19 Pandemic. Journal of Occupational and Environmental Medicine, 62(11), 892-897. https://doi.org/10.1097/JOM.oooooooooooo1999

Bedoya J. (2020). COVID-19: the pandemic of abuse against health personnel in times of pandemic. Interdisciplinary Journal of Epidemiology \& Public Health, 3(1), e-6276. https://doi.org/10.18041/2665-427X/ ijeph.1.6276

Blake, H., Bermingham, F., Johnson, G., \& Tabner, A. (2020). Mitigating the psychological impact of COVID-19 on healthcare workers : A digital learning package. International Journal of Enviromental Research and Public Health, 17, 1-15. https:// doi.org/10.3390/ijerphı7092997

Cabanyes, J., \& Monge, M. A. (Eds.) (2017). La salud mental y sus cuidados. 4ta ed. EUNSA.

Carmassi, C., Foghi, C., Dell'Oste, V., Cordone, A., Bertelloni, C. A., Bui, E., \& Dell'Osso, L. (2020). PTSD symptoms in healthcare workers facing the three coronavirus outbreaks: What can we expect after the COVID-19 pandemic. Psychiatry Research, 292, 113312. https://doi.org/10.1016/j.psychres.2020.113312 
Chew, Q. H., Wei, K. C., Vasoo, S., Chua, H. C., \& Sim, K. (2020). Narrative synthesis of psychological and coping responses towards emerging infectious disease outbreaks in the general population: practical considerations for the COVID-19 pandemic. Singapore Medicine Journal, 61(7), 350-356. https://doi.org/10.11622/smedj.2020046

Colegio Médico del Perú (2021). Más de 400 médicos perdieron la vida luchando contra el COVID-19. https://www.cmp.org.pe/ mas-de-40o-medicos-perdieron-la-vida-luchando-contra-el-covid-19/

Cruz, A., Gutiérrez, A., \& Zaldivar, E. (2020). Gestión de seguridad psicológica del personal sanitario en situaciones de emergencia por COVID-19 en el contexto hospitalario o de aislamiento. Revista Cubana de Enfermería, 36(2). http://www.revenfermeria. sld.cu/index.php/enf/article/view/3704

Delgado, C., Rodríguez, A., Córdoba, R., \& Vázquez, F. (2020). Psychological Well-Being of Medical Residents of a Public University in Mexico. Universitas Médica, 61(2). https://doi.org/10.11144/Javeriana.umed61-2.bpsi

Depierro, J., Lowe, S., \& Katz, C. (2020). Lessons learned from 9/11: Mental health perspectives on the COVID-19 pandemic. Psychiatry Research, 288, 113024. https://doi. org/10.1016/j.psychres.2020.113024

Díaz, D., Rodríguez-Carvajal, R., Blanco, A., Moreno-Jiménez, B., Gallardo, I., Valle, C., \& van Dierendonck, D. (2006). Adaptación española de las escalas de bienestar psicológico de Ryff [Spanish adaptation of the Psychological Well-Being Scales (PWBS)]. Psicothema, 18(3), 572-577.

Dolan, S., \& García, S. (2020). Covid-19, stress, self-esteem, values, and psychological well-being: How to assess risks of becoming depressed, anxious, or suicidal? The European Business Review. https://www.europeanbusinessreview.com/covid-19stress-self-esteem-values-and-psychological-well-being-how-to-assess-risks-ofbecoming-depressed-anxious-or-suicidal/

El-Hage, W., Hingray, C., Lemogne, C., Yrondi, A., Brunault, P., Bienvenu, T., Etain, B., Paquet, C., Gohier, B., Bennabi, D., Birmes, P., Sauvaget, A., Fakra, E., Prieto, N., Bulteau, S., Vidailhet, P., Camus, V., Leboyer, M., Krebs, M. O., \& Aouizerate, B. (2020). Health professionals facing the coronavirus disease 2019 (COVID-19) pandemic: What are the mental health risks? L'Encephale, $\left.46{ }_{3} \mathrm{~S}\right), \mathrm{S}_{73}-\mathrm{S} 8 \mathrm{o}$. https:// doi.org/10.1016/j.encep.2020.04.008 
Feinstein, R. E., \& Nemeroff, C. B. (2020). A health care workers mental health crisis line in the age of COVID-19. Depression and Anxiety, 37(8), 822-826. https://doi. org/10.1002/da.23073

Hall, H. (2020). The effect of the COVID-19 pandemic on healthcare workers' mental health. Journal of the American Academy of Physician Assistants, 33(7), 45-48. https:// doi.org/10.1097/o1.JAA.oooo669772.78848.8c

Huarcaya-Victoria, J. (2020). Consideraciones sobre la salud mental en la pandemia de COVID-19, Revista Peruana de Medicina Experimental y Salud Pública, 37(2), 327-334. https://doi.org/10.17843/rpmesp.2020.372.5419

Kang, L., Li, Y., Hu, S., Chen, M., Yang, C., Yang, B. X., Wang, Y., Hu, J., Lai, J., Ma, X., Chen, J., Guan, L., Wang, G., Ma, H., \& Liu, Z. (2020). The mental health of medical workers in Wuhan, China dealing with the 2019 novel coronavirus. The Lancet. Psychiatry, 7(3), e14. https://doi.org/10.1016/S2215-0366(20)30047-X

Keyes, C. L. M., Shmotkin, D., \& Ryff, C. D. (2002). Optimizing well-being: The empirical encounter of two traditions. Journal of Personality and Social Psychology, 82(6), 1007-1022. https://doi.org/10.1037/0022-3514.82.6.1007

Lai, J., Ma, S., Wang, Y., Cai, Z., Hu, J., Wei, N., Wu, J., Du, H., Chen, T., Li, R., Tan, H., Kang, L., Yao, L., Huang, M., Wang, H., Wang, G., Liu, Z., \& Hu, S. (2020). Factors associated with mental health outcomes among health care workers exposed to Coronavirus Disease 2019. JAMA Network Open, 3(3), e203976. https://doi.org/10.1001/ jamanetworkopen.2020.3976

Leiva, A., Nazar, G., Martínez-Sangüinetti, M., Petermann-Rocha, F., Ricchezza, J., \& Celis-Morales, C. (2020). Dimensión psicosocial de la pandemia: la otra cara del COVID-19. Ciencia y Enfermería, 26, 10. https://doi.org/10.29393/ce26-3dpal6ooo3

Liang, Y., Chen, M., Zheng, X., \& Liu, J. (2020). Screening for Chinese medical staff mental health by SDS and SAS during the outbreak of COVID-19. Journal of Psychosomatic Research, 133, 110102. https://doi.org/10.1016/j.jpsychores.2020.110102

Lin, C. Y., Peng, Y. C., Wu, Y. H., Chang, J., Chan, C. H., \& Yang, D. Y. (2007). The psychological effect of severe acute respiratory syndrome on emergency department staff. Emergency Medicine Journal, 24(1), 12-17. https://doi.org/10.1136/emj.2006.035089 
Lozano-Vargas, A. (2020). Impacto de la epidemia del Coronavirus (COVID-19) en la salud mental del personal de salud y en la población general de China. Revista de Neuro-Psiquiatría, 83(1), 51-56. https://doi.org/10.20453/rnp.v83i1.3687

Luceño-Moreno, L., Talavera-Velasco, B., García-Albuerne, Y., \& Martín-García, J. (2020). Symptoms of posttraumatic stress, anxiety, depression, levels of resilienceand burnout in spanish health personnel during the COVID-19 pandemic. International Journal of Environmental Research and Public Health, 17(15), 1-29. https://doi.org/10.3390/ ijerph17155514

Diario Gestión (19 de enero de 2021) Colegio de Enfermeros: "Más de 7,700 enfermeras fueron contagiadas con COVID-19 y 15 están en UCI". https://gestion.pe/peru/ mas-de-770o-enfermeras-fueron-contagiadas-con-covid-19-y-15-estan-en-uci-segun-decana-del-colegio-de-enfermeros-coronavirus-peru-segunda-ola-nndc-noti$\mathrm{cia} /$ ?ref=gesr

Maslow, A. (1973). El hombre autorrealizado. Kairós.

Ministerio de Salud (2021). Casos confirmados por coronavirus COVID-19 ascienden a 1561723 en el Perú. https://www.gob.pe/institucion/minsa/noticias/351082-minsa-casos-confirmados-por-coronavirus-covid-19-ascienden-a-1-561-723-en-el-peru-comunicado-n-474

Muñoz-Fernández, S. I., Molina, D., Ochoa-Palacios, R., Sánchez-Guerrero, O., \& EsquivelAcevedo, J. A. (2020). Estrés, respuestas emocionales, factores de riesgo, psicopatología y manejo del personal de salud durante la pandemia por COVID 19. Acta Pediátrica de México, 41(1), 127-136. https://doi.org/10.18233/APM41No4S1ppS127-S1362104

Nochaiwong, S., Ruengorn, C., Awiphan, R., Ruanta, Y., Boonchieng, W., Nanta, S., Kowatcharakul, W., Pumpaisalchai, W., Kanjanarat, P., Mongkhon, P., Thavorn, K., Hutton, B., Wongpakaran, N., \& Wongpakaran, T. (2020). Mental health circumstances among health care workers and general public under the pandemic situation of COVID-19. Medicine, 99(26), 1-7. 10.1097/MD.oooooooooooo20751

Organización Mundial de la Salud (OMS) (2018). Salud mental: fortalecer nuestra respuesta. https://www.who.int/es/news-room/fact-sheets/detail/ mental-health-strengthening-our-response

Paredes, O., \& Sanabria-Ferrand, P. (2008). Prevalencia del síndrome de burnout en residentes de especialidades médico-quirúrgicas, su relación con el bienestar 
psicológico y con variables sociodemográficas y laborales. Revista Médica de la Facultad de Medicina de Bogotá, 16(1), 25-32. http://www.scielo.org.co/pdf/med/ vi6ni/vi6niao5.pdf

Preti, E., Mattei, V. Di, Perego, G., Ferrari, F., Mazzetti, M., Taranto, P., Pierro, R. Di, Madeddu, F., \& Calati, R. (2020). The psychological impact of epidemic and pandemic outbreaks on healthcare workers: Rapid review of the evidence. Current Psychiatry Reports, 22(43). https://doi.org/10.1007/s11920-020-01166-z

Reger, M. A., Piccirillo, M. L., \& Buchman-Schmitt, J. M. (2020). COVID-19, Mental health, and suicide risk among health care workers: Looking beyond the crisis. The Journal of Clinical Psychiatry, 81(5). https://doi.org/10.4088/JCP.20comı3381

Restauri, N., \& Sheridan, A. D. (2020). Burnout and posttraumatic stress disorder in the Coronavirus Disease 2019 (COVID-19) Pandemic: Intersection, impact, and interventions. Journal of the American College of Radiology, 17(7), 921-926. https:// doi.org/10.1016/j.jacr.2020.05.021

Rogers, C. (1961). El proceso de convertirse en persona. Páidos.

Ryff, C. D. (1989). Happiness is everything, or is it? Explorations on the meaning of psychological well-being. Journal of Personality and Social Psychology, 57 (6), 10691081. https://doi.org/10.1037/0022-3514-57.6.1069

Salopek-Žiha, D., Hlavati, M., Gvozdanović, Z., Gašić, M., Placento, H., Jakić, H., Klapan, D., \& Šimić, H. (2020). Differences in distress and coping with the COVID-19 stressor in nurses and physicians. Psychiatria Danubina, 32(2), 287-293. https://doi. org/10.24869/psyd.2020.287

Si, M.-Y., Su, X.-Y., Jiang, Y., Wang, W.-J., Gu, X.-F., Ma, L., Li, J., Zhang, S.-K., Ren, Z.-F., Ren, R., Liu, Y.-L., \& Qiao, Y.-L. (2020). Psychological impact of COVID-19 on medical care workers in China. Infectious Diseases of Poverty, 9(1), 1-13. https://doi. org/10.1186/s40249-020-00724-o

Simms, A., Fear, N. T., \& Greenberg, N. (2020). The impact of having inadequate safety equipment on mental health. Occupational Medicine, $70(4), 278-281$. https://doi. org/10.1093/occmed/kqaa1o1

Song, X., Fu, W., Liu, X., Luo, Z., Wang, R., Zhou, N., Yan, S., \& Lv, C. (2020). Mental health status of medical staff in emergency departments during the Coronavirus 
disease 2019 epidemic in China. Brain, Behavior, and Immunity, 88, 60-65. https:// doi.org/10.1016/j.bbi.2020.06.002

Stuijfzand, S., Deforges, C., Sandoz, V., Sajin, C.-T., Jaques, C., Elmers, J., \& Horsch, A. (2020). Psychological impact of an epidemic/pandemic on the mental health of healthcare professionals: A rapid review. BMC Public Health, 20, 1-18. https://doi. org/10.1186/s12889-020-09322-Z

Urzúa, A., Vera-Villarroel, P., Caqueo-Urízar, A., \& Polanco-Carrasco, R. (2020). La Psicología en la prevención y manejo del COVID-19. Aportes desde la evidencia inicial. Terapia Psicológica, 38(1), 103-118. https://doi.org/10.4067/So718-48082020000100103

Vindegaard, N., \& Benros, M. E. (2020). COVID-19 pandemic and mental health consequences: Systematic review od current evidence. Brain, Behavior, and Immunity, 89, 531-542. https://doi.org/10.1016/j.bbi.2020.05.048

Walton, M., Murray, E., \& Christian, M. D. (2020). Mental health care for medical staffand affiliated healthcare workers during the COVID-19 pandemic. European Heart Journal: Acute Cardiovascular Care, 9(3), 241-247. https://doi.org/10.1177/2048872620922795

Wang, C., Pan, R., Wan, X., Tan, Y., Xu, L., Ho, C. S., \& Ho, R. C. (2020). Immediate Psychological Responses and Associated Factors during the Initial Stage of the 2019 Coronavirus Disease (COVID-19) Epidemic among the General Population in China. International Journal of Environmental Research and Public Health, 17. https://doi. org/10.339o/ijerph17051729

Wu, K., \& Wei, X. (2020). Analysis of psychological and sleep status and exercise rehabilitation of front-line clinical staff in the fight against COVID-19 in China. Medical Science Monitor Basic Research, 26, e924085. https://doi.org/10.12659/MSMBR.924085

Werner, E. A., Aloisio, C. E., Butler, A. D., D’Antonio, K. M., Kenny, J. M., Mitchell, A., Ona, S., \& Monk, C. (2020). Addressing mental health in patients and providers during the COVID-19 pandemic. Seminars in Perinatology, 44(7), 1-9. https://doi. org/10.1016/j.semperi.2020.151279

Recibido: 11 de noviembre de 2020

Revisado: 11 de marzo de 2021

Aceptado: 23 de abril de 2021 



\title{
Uso excesivo del celular, calidad de sueńo y soledad en jóvenes de la ciudad de Arequipa
}

\author{
Excessive Use of Cell Phone, Quality of Sleep and Loneliness \\ in Young People in The City of Arequipa \\ Atena Sota Velásquez \\ Universidad Católica San Pablo, Arequipa, Perú \\ (iD https://orcid.org/oooo-0oo2-0322-6967 \\ Melani Maldonado López \\ Universidad Católica San Pablo, Arequipa, Perú \\ (iD) https://orcid.org/oooo-oooz-2934-3395 \\ Correspondencia: melani.maldonado@ucsp.edu.pe \\ Manuel Ytuza Cusirramos \\ Universidad Católica San Pablo, Arequipa, Perú \\ (iD https://orcid.org/oooo-0oo2-3304-1453 \\ María del Carmen Cornejo Torres \\ Universidad Católica San Pablo, Arequipa, Perú \\ (iD) https://orcid.org/oooo-0oo3-1906-9959 \\ Yessenia Cusirramos Carpio \\ Universidad Católica San Pablo, Arequipa, Perú \\ iD https://orcid.org/oooo-0003-0817-338X
}

\section{Resumen}

Se dice que el uso excesivo de celulares entre adolescentes y jóvenes puede causar efectos negativos en su salud psicológica y física, así como en su calidad de sueño. En diversas investigaciones se menciona que las personas que informan un mayor nivel de soledad también refieren menos sueño. Sin embargo, todavía es necesario profundizar, la relación entre el uso excesivo al celular, la calidad del sueño y la soledad, ya que no existe suficiente evidencia para definirla. Se seleccionó una muestra de 397 estudiantes universitarios de la ciudad de Arequipa, utilizando como criterio de inclusión que cursen 
estudios en una universidad y que se encuentren entre el rango de edad de 17 a 25 años. Los estudiantes fueron invitados a completar un cuestionario anónimo que contenían datos demográficos, la Escala de Soledad de la Universidad de California los Ángeles ULS-8, el Índice de Calidad de Sueño de Pittsburgh ICSP y el cuestionario autoadministrable del Uso Problemático del Celular para adolescentes. Se encontró que las variables soledad, calidad del sueño y uso problemático del celular tienen una relación significativa entre sí. Los resultados obtenidos corroboran la hipótesis planteada, encontrando que, sí existe relación entre las variables soledad, calidad del sueño y uso problemático del celular en estudiantes universitarios.

Palabras clave: Uso del celular, calidad de sueño, soledad, jóvenes.

\section{Resumen}

It has been said that the excessive use of cell phones among adolescents and young people can have negative effects on their psychological and physical health, as well as their quality of sleep. In various investigations it is mentioned that people who report a higher level of loneliness also report less sleep. However, it is still necessary to deepen our understanding of the relationship between excessive cell phone use, sleep quality and loneliness, as there is limited evidence to support a full description of this association. A simple of 397 university students from the City of Arequipa was selected, using as inclusion criteria attendance at a university and being between the age range of 17 to 25 years. The students were invited to complete an anonymous questionnaire containing demographic questions, the University of California Los Angeles ULS-8 Loneliness Scale, the Pittsburgh ICSP Sleep Quality Index, and the self-administered Questionnaire on Problematic Use of Cell Phones by Teenagers. It was found that the variables loneliness, sleep quality and problematic cell phone use have a significant relationship with each other. The results obtained corroborate the proposed hypothesis, finding that there is a relationship between the variables of loneliness sleep quality and problematic use of the cell phones in university students. Keywords: Cell phones use, sleep quality, loneliness, young people. 


\section{Introducción}

Desde la aparición de los celulares inteligentes en 1997, capaces de enviar mensajes de texto, acceder a internet, redes sociales, música, videos, chats, correos electrónicos y todo tipo de aplicaciones que el usuario desee descargar; se dio un aumento descontrolado en el uso de esta tecnología, suscitando inquietudes entre los investigadores no solamente por su potencial de crear adicción sino por su capacidad de fortalecer o de debilitar los vínculos entre las personas, según el uso que se le dé al dispositivo (Peñuela et al., 2014).

En los últimos años el Instituto Nacional de Estadística e Informática (INEI) informó que durante el trimestre julio-agosto-setiembre de 2017, en el 9o.6 $\%$ de los hogares de Perú existe al menos un miembro que tiene celular y que del total de población que usa Internet, el $30.5 \%$ accedió a Internet únicamente por celular. Entre los que accedieron en mayor proporción a Internet se tiene a la población joven de 19 a 24 años de edad con $79.4 \%$ y el grupo de 12 a 18 años de edad con $72 \%$. A partir de estos datos se refleja que, en el Perú, en su mayoría, adolescentes y jóvenes tienen un celular y lo utilizan no sólo para llamar o mandar mensajes, sino que también se conectan a Internet (INEI, 2017).

Actualmente en varias investigaciones realizadas en Asia y Europa (Menglong \& Liya, 2017; Pamuk \& Atli, 2016; Peper \& Harvey, 2018) se evidencia que la nueva tecnología dio inicio a un marcado deterioro psicológico y social de los usuarios que en su mayoría son jóvenes, adolescentes y púberes. Hardell, Carlberg, Söderqvist, Hansson y Mild (2008) realizaron una encuesta sistemática, descubriendo que los adolescentes involucrados en el uso excesivo de teléfonos móviles reportan tener más problemas de salud, incluyendo fatiga, depresión, dolor de cabeza, ansiedad, trastorno de la atención y trastornos del sueño.

En investigaciones sobre exposiciones a campos electromagnéticos de radiofrecuencia, asociadas a síntomas de enfermedad, se ha reportado en algunos usuarios de celulares efectos en su salud durante y después de su uso, como mareos, dolores de cabeza, sensaciones de ardor, hormigueo en la piel de la cabeza y extremidades, perturbaciones del sueño, cansancio, pérdida de capacidad atencional, disminución del tiempo para reaccionar, pérdida de retención, problemas en el sistema digestivo, taquicardia y malestar general, entre otros. Estos síntomas coinciden con los del estrés y no deberían separarse de sus efectos nocivos (Roösli, 2008). Loughran et al. (2005) encontraron que la exposición a largo plazo a dispositivos electrónicos tales como los celulares reducen la frecuencia de los movimientos oculares durante el período de sueño de movimientos oculares rápidos, acorta la latencia del sueño y eleva la potencia del electroencefalograma (EEG) en el sueño temprano de $11,5-12,25 \mathrm{~Hz}$.

En el Perú, el neurólogo y director del Instituto Peruano de Neurociencias, el doctor David Lira mencionó que los 
trastornos de sueño consisten en una patología de la sociedad moderna, que en la actualidad tiene una estrecha relación con el uso prolongado de dispositivos electrónicos. En los países en los que se ha medido la relación entre el uso de dispositivos electrónicos y la falta de sueño se ha determinado que los que lo usan antes de dormir tienen más dificultades para conciliar el sueño. El doctor Lira comentó que este problema se está presentando cada vez más entre los jóvenes, debido a la permisividad de los padres con respecto al empleo de tabletas y celulares hasta altas horas de la noche. Así, el Dr. Lira menciona que:

Presentan un sueño fraccionado básicamente por ansiedad. Como están conectados toda la noche no duermen de forma profunda. Están a la expectativa de que les contesten los mensajes. Su sueño es superficial. Están pendientes de cualquier ruido para levantarse a contestar. Eso impacta en su desempeño académico (Lira, citado en Garay, 2016)

En la actualidad, el $84 \%$ de los adolescentes duerme con su celular en la cama (Gaglianone, 2015) y se ha visto repercusiones en su calidad de sueño. La calidad del sueño es un fenómeno complejo que resulta difícil de definir y medir de forma objetiva. Ésta incluye aspectos cuantitativos del sueño, tales como la duración del sueño, latencia del sueño, números de despertares y aspectos puramente subjetivos como "profundidad" o "descanso" del sueño (Buysse et al., 1989). La calidad de sueño se refiere al hecho de dormir bien durante la noche y tener un buen funcionamiento durante el día (Domínguez et al., 2007; Rosales et al., 2007) y no solamente es importante como factor determinante de la salud, sino como elemento propiciador de una buena calidad de vida (Rodríguez et al., 2002; Sierra, 2006).

El sueño es una necesidad fisiológica básica para la supervivencia de la persona. A esto se da, la importancia de conseguir la cantidad apropiada de las fases REM (Rapid Eye Movement) - NREM (No Rapid Eye Movement) y el tiempo total que pueda dormir un individuo. Además, el bienestar psicológico se puede comprobar en el funcionamiento mental (Guevara \& Torres, 2016). En una investigación realizada por Dexter, Bijwadia, Schilling y Applebaugh (2003), plantearon que la participación de los estudiantes en las actividades familiares, sociales y deportivas, así como los horarios de trabajo de los padres pueden producir conflictos a la hora de dormir. La angustia y el aumento de la confianza en las relaciones entre pares, así como la disponibilidad de medios de comunicación como es el celular, tienden a retardar las horas de sueño. La televisión, los videojuegos y las computadoras presentan el mismo efecto.

Diversos hallazgos sugieren que sujetos que consiguen dormir bien y tienen una buena calidad de sueño, poseen mayor capacidad de concentración, autocontrol y realización de tareas personales y profesionales, ya que dormir poco tiempo altera negativamente la capacidad de concentración, el aprendizaje y la memoria del individuo. Una mala calidad de sueño es 
un síntoma que con frecuencia aparece asociado a la fatiga, la disminución de las capacidades cognitivas y motoras durante el día y una mayor incidencia de accidentes de tránsito y laborales (Blasco et al., 2002). Aunque se ha demostrado en distintas investigaciones que el uso excesivo y la adicción al celular afectan la calidad del sueño de los adolescentes y jóvenes, existe poca evidencia que describa los mecanismos involucrados. Mrunal y Jaimala (2015) sugirieron que la adicción al celular entre los adolescentes correlaciona positivamente y de modo significativo con su soledad.

El sentimiento de soledad es un elemento inherente a la condición humana, es probable que todas las personas experimentan este sentimiento durante el curso de su vida, en forma transitoria o duradera (Carvajal-Carrascal \& Caro-Castillo, 2009; Rotenberg \& Hymel, 1999). Se presenta en todas las culturas, y ha sido identificado en diversas publicaciones recientes en diversos países como Australia, Canadá, Estados Unidos y Perú (Cuny, 2001). Existen definiciones que describen la soledad como un estado donde la persona se encuentra sola, sin compañía alguna simplemente, pero en realidad la soledad es un estado de ánimo que hace que las personas se sientan vacías e indeseadas. Sin embargo, para Cacioppo y Cacioppo (2016) es una elección personal, un lugar donde nace la creatividad, la concentración y el sentido de la vida. Weiss (2008) afirma que los sentimientos de soledad son considerados como una deficiencia en los sistemas de interacción interpersonal. Él diferenció entre soledad de tipo emocional y soledad de tipo social. La soledad emocional aparece en ausencia de apego emocional y ocurre como resultado de la pérdida de intimidad con personas cercanas como padres, pareja o hijos. Por el contrario, la soledad social aparece en ausencia de una red social de apoyo, por ejemplo, como consecuencia de la pérdida de amigos, vecinos y colegas. La soledad de tipo social puede propiciar hacia la aparición de soledad emocional.

Asher y Paquette (2003) afirman que, aunque la soledad está influenciada por características objetivas de las relaciones sociales (frecuencia del contacto social y número de amigos), está más influenciada por características subjetivas como la satisfacción con las relaciones sociales y la aceptación social percibida. Según Mrunal y Jaimala (2015), la soledad es una emoción experimentada por un individuo que desea un nivel de contacto diferente en la que se encuentra actualmente, es decir, la soledad es la angustia que resulta de las discrepancias entre las relaciones sociales ideales y las percibidas. Esta discrepancia cognitiva se ve reflejada en los pensamientos, sentimientos y comportamientos, los cuales repercuten en la salud y el bienestar de la persona.

En una investigación sobre la relación entre Internet y la soledad realizada por Kraut etal. (1998), se encontró que, aunque el uso de la red era fundamentalmente comunicativo, existía una disminución en la comunicación familiar, en los círculos sociales y un incremento de la depresión y la soledad. También descubrieron que, a mayor uso de Internet, mayores eran 
sus efectos. La soledad como experiencia desagradable se produce cuando la red social de una persona es deficiente de forma significativa en calidad o cantidad, y se asocia con sentimientos negativos (Borges et al., 2008).

Según Kersting (2016) parte de la cuestión de la soledad es que la mayoría de las personas que utilizan las redes sociales no sólo publican, sino que pasan mucho tiempo mirando los post de todos los demás, dónde están, a dónde van y qué están haciendo. La exposición constante a las experiencias de vida "perfectas" de todos los demás provoca sentimientos de soledad, depresión y ansiedad. Las personas que se han involucrado significativamente con sus celulares pueden estar expuestas a una disminución en el tiempo asignado a otras relaciones sociales, especialmente las relaciones cara a cara, de interacción, que puede provocar que se sientan solas. El investigador Arslan (2013), encontró que el uso problemático del celular asciende a medida que aumenta el tiempo de conversación, sin embargo, el aumento del tiempo que uno habla disminuye el nivel de soledad en los adolescentes.

Algunos investigadores (Doane \& Thurston, 2014; Hutchison \& Gerstein, 2016) consultaron a adolescentes con respecto a su estrés diario, emociones, soledad y calidad del sueño, y encontraron que una mayor presión conduce a un menor tiempo de sueño y que la soledad es una importante variable de control entre el estrés y la duración del sueño. En otras investigaciones se menciona que las personas que informan un mayor nivel de soledad también refieren menos sueño. A partir de los estudios mencionados se ha revelado la existencia de correlaciones negativas entre la adicción a los celulares de los jóvenes y su calidad de sueño, así como la correlación positiva entre la soledad y la adicción al celular (Oguz \& Cakir, 2014). Es por este motivo que consideramos importante investigar si existe relación entre la soledad, el uso excesivo de los celulares y la calidad de sueño en estudiantes universitarios, ya que existen pocas evidencias al respecto.

Por lo tanto, el objetivo de la investigación es analizar la relación entre el uso excesivo del celular, la soledad y la calidad de sueño en una muestra de jóvenes universitarios de la ciudad de Arequipa.

\section{Método}

\section{Diseño de la investigación}

La investigación corresponde a una estrategia asociativa con un diseño comparativo transversal, ya que en este estudio se analiza la relación entre las variables uso problemático del celular, calidad de sueño y soledad (Ato et al., 2013).

\section{Muestra}

Se trabajó con una muestra de 397 estudiantes universitarios, de tres universidades de la ciudad de Arequipa: Universidad Católica San Pablo, Universidad Nacional de San Agustín y Universidad Alas Peruanas. Las edades de los estudiantes fluctúan entre los 17 
y 25 años y la muestra está conformada por 149 varones (37.5\%) y 248 mujeres $(62.5 \%)$. Se cumplieron con los siguientes criterios de inclusión: que los participantes fueran tanto varones y mujeres en condición de estudiantes universitarios, cuyas edades estuvieran comprendidas entre los 17 y 25 años, y que hablaran español como lengua materna (Tabla 1).

Tabla 1.

Datos demográficos de los estudiantes universitarios

\begin{tabular}{|lccc|}
\hline \multicolumn{1}{|c}{ Variables } & Sujetos & Cantidad & Porcentaje \\
\hline Sexo & Varones & 149 & $37.5 \%$ \\
& Mujeres & 248 & $62.5 \%$ \\
\hline Hijo Único & Sí & 70 & $17.6 \%$ \\
& No & 327 & $82.4 \%$ \\
\hline Número & Ninguno & 70 & $17.6 \%$ \\
de hermanos & 1 & 155 & $39.0 \%$ \\
& 2 & 99 & $24.9 \%$ \\
& $3-5$ & 68 & $17.1 \%$ \\
& Más de 5 & 5 & $1.3 \%$ \\
\hline $\begin{array}{l}\text { Condición } \\
\text { económica }\end{array}$ & Pobre & 7 & $1.8 \%$ \\
familiar & Relativamente pobre & 13 & $3.3 \%$ \\
& Mediano & 347 & $87.4 \%$ \\
& Relativamente rico & 30 & $7.6 \%$ \\
\hline
\end{tabular}

\section{Instrumentos}

Para medir la variable soledad, se utilizó la Escala de Soledad para Adultos de la UCLA (Versión 3). La versión inicial de esta escala fue desarrollada por Russell, Peplau y Fergusson (1980), que en estudios con muestras de estudiantes reportaron buena consistencia interna $(\alpha=.96)$, y confiabilidad obtenida con el método test-retest fue de .73 , en un periodo de tiempo de dos meses. La validez concurrente indicó relación de los puntajes de las escalas con otros indicadores de soledad, relaciones sociales y estados afectivos (Russell, Peplau \& Fergusson, 1980). Adicionalmente, y con respecto a validez de criterio, se ha demostrado que la UCLA Loneliness Scale es un buen criterio para probar diferencias en la experiencia subjetiva de soledad emocional y social (Róquez \& Martínez, 2015). Posteriormente, Russell, Peplau y Fergusson (1980), reportaron los datos de validez, confiabilidad y dimensionalidad de la escala para la versión 3. Esta 
versión se ha desarrollado para tratar de corregir algunas limitaciones de la escala que pueden alterar su confiabilidad. A través de la literatura se reporta amplia utilización en muestras de adolescentes y adultos, y buenas cualidades psicométricas (Russell, Peplau \& Fergusson, 1980). Esta escala consta de 20 ítems, los cuales están redactados de la siguiente manera: 11 de forma positiva (no hay sentimiento de soledad) y 9 de manera negativa (hay sentimiento de soledad). Para responderla, a los participantes se les pide que indiquen el grado de soledad en una escala tipo Likert de 1 al 4. Para calificar las puntuaciones se suman juntas y las puntuaciones altas indican altos niveles de soledad.

Para medir la calidad de sueño se utilizó el Índice Pittsburg de Calidad de Sueño (PSQI) validado en una muestra peruana, la cual consta de nueve preguntas; las cuatro primeras son de respuesta subjetiva mientras que las otras 5 se responden en una escala de tipo Likert: (o) "Ninguna vez en el último mes", (1) "Menos de una vez a la semana", (2) "Una o dos veces a la semana y (3) "Tres o más veces a la semana”. Así mismo el ICSP está compuesta por siete componentes: calidad de sueño subjetiva, latencia del sueño, duración del dormir, eficacia del sueño habitual, alteraciones del sueño, uso de medicamentos para dormir y disfunción diurna; que al sumar el valor de cada componente da la calificación global del ICSP (Luna-Solís et al., 2015). Cabe resaltar que en cuanto a la calificación, a mayor puntaje indica una muy mala calidad de sueño y a menor puntaje indicará una mejor calidad de sueño.

También se utilizó la Escala de Uso Problemático del Celular, la cual fue traducida y adaptada por Manuel Ytuza, se eligió como juez a la Mg. Paula Delgado Cuzzi, docente de la Universidad Católica San Pablo, para que validara la traducción y la adaptación. La escala fue recuperada del artículo "Development of a problematic mobile phone use scale for University students: Validity and reliability study" (Pamuk \& Atli, 2016). Dicha escala cuenta con cinco subescalas que son: privación, resultados adversos, problema del control e interacción-evitación.

Por último, fue utilizado un cuestionario para reunir la información general de los sujetos tales como sexo, condición de hijo único, condición económica familiar, número de hermanos y tiempo que los padres pasan en casa por año. Los datos se muestran en la Tabla 1.

\section{Procedimiento}

La evaluación se realizó dentro de las instalaciones de las respectivas universidades, a las cuales se accedió por medio de permisos consentidos por los profesores. La recolección de datos se realizó en diversos horarios de estudio, durante los turnos mañana, tardey noche. Durante la encuesta, se proporcionó a los participantes información sobre la metodología y el propósito del estudio. Los cuestionarios se distribuyeron en estricta conformidad con el principio de consentimiento 
informado. Una vez hecho esto, procedieron a completar los instrumentos en presencia de los investigadores para que pudieran absolver cualquier interrogante que tuvieran.

\section{Criterios para el análisis de datos}

Se utilizó el programa estadístico SPSS versión 22.o para realizar el procesamiento de los datos. Para revisar la distribución de los datos se realizó un análisis de la asimetría y curtosis, teniendo como resultado, en su mayoría, los datos tienen una distribución no normal. Por lo que se eligió la prueba de correlación de Spearman, relacionando las variables de calidad de sueño, soledad y uso problemático del celular. En cuanto al establecimientodepercentiles en la escala del uso problemático del celular se hicieron cortes en los percentiles 25, 50 y 75 (Lloret-Segura et al., 2014); para diferenciar a los jóvenes universitarios que tenían una percepción de soledad de los que no, se analizó la media. Y para diferenciar la buena calidad de sueño de la mala calidad de sueño se realizó un análisis de la puntuación Z de cada ICSP, teniendo como referencia el intervalo [-2; 2] (Lloret-Segura et al., 2014).

\section{Resultados}

\section{Estadística descriptiva}

En la Escala de Soledad UCLA (versión 3), se hizo un análisis de la mediana, donde el $47.9 \%(n=190)$ de estudiantes universitarios no perciben soledad mientras que el $52.1 \%(\mathrm{n}=207)$ sí perciben soledad. En la Escala de Uso problemático del Celular, se encontró que 103 universitarios obtuvieron una puntuación baja (28.9\%), 103 un puntaje alto (28.9\%) y 191 tienen un uso moderado (48.2 \%). Estos resultados nos indican que las personas con bajo puntaje no tienen un uso problemático del celular, mientras que las personas con un puntaje alto sí tienen un uso problemático del celular y los restantes tienen un uso moderado. En los resultados del Índice de Calidad de Sueño de Pittsburgh, se encontró que 43 universitarios reportan tener una muy buena calidad de sueño (10.8 \%), 177 tienen una buena calidad de sueño (44.6\%), 154 tienen una mala calidad de sueño (38.8 \%) y 23 una muy mala calidad de sueño (5.8\%).

\section{Análisis de correlación}

La Tabla 2 muestra que las variables soledad y calidad del sueño correlacionan positivamente y de manera significativa, es decir que a más puntaje en el ICSP mayor será la percepción de soledad. Cabe recordar que a mayor puntaje en el ICSP se indica una mala o muy mala calidad de sueño. La soledad presenta una correlación significativa con el uso problemático del celular, es decir que a mayor uso problemático del celular mayor será la percepción de soledad, así como a mayor percepción de la soledad mayor será el uso problemático del celular. Así mismo, el uso problemático del celular y la calidad de sueño están significativamente correlacionadas, es decir que más uso del celular la calidad de sueño será de menor calidad. Lo cual valida la hipótesis de investigación; ya que hay respaldo estadístico acerca de las relaciones entre dichas variables. 
Tabla 2.

Correlación entre las variables

\begin{tabular}{|lccc|}
\hline & Soledad & $\begin{array}{c}\text { Calidad } \\
\text { de sueño }\end{array}$ & $\begin{array}{c}\text { Uso problemático } \\
\text { del celular }\end{array}$ \\
\hline Soledad & 1 & & \\
\hline Calidad de sueño & $.161^{* *}$ & 1 & \\
\hline Uso problemático del celular & $.143^{* *}$ & $.182^{* *}$ & 1 \\
\hline
\end{tabular}

${ }^{* *} \mathbf{p}<.01$

\section{Discusión}

En nuestra sociedad tan cambiante y globalizada, las tecnologías como el celular ocupan un espacio importante en la vida de las personas, impactando en sus estilos de vida, sus actitudes, conductas, hábitos, etc. (Castellana et al., 2007). El uso desmedido de este dispositivo ha generado distintas investigaciones y variadas consideraciones por estudiosos, debido a que su uso que inicialmente es placentero puede llegar a generar dependencia psicológica (Castellana et al., 2007) y repercutir en actividades que anteriormente eran gratificantes como el dormir o salir con amigos. Visto de esta forma, el uso problemático o excesivo del celular consiste en el fracaso de resistir el impulso de realizar llamadas, enviar mensajes o entrar a las redes sociales; que puede a lo largo, tener consecuencias negativas en la vida de la persona.

Llegar a comprender qué factores se asocian a este uso desmedido es adentrarnos a revisar diversos temas de índole bio-psico-social. Dentro de la literatura diversas investigaciones apuntan que estar constantemente pendientes de mensajes entrantes o de si el celular suena o vibra, es más un comportamiento asociado a sentimientos de soledad. Según un estudio realizado por Peper y Harvey (2018), se encontró que a pesar de que los teléfonos inteligentes y las posibilidades de conectarnos a Internet en cualquier lugar y momento, nos acercan a personas que tenemos lejos geográficamente o a quienes no podemos ver tan seguido; con el tiempo puede ser un comportamiento excesivo o adictivo que aumenta el riesgo de depresión, ansiedad y los sentimientos de soledad. En otro estudio publicado en el American Journal of Preventive Medicine, se encontró que el uso intensivo de plataformas como Facebook, Snapchat e Instagram se asocian con sentimientos de aislamiento social entre los adultos jóvenes (Primack et al., 2017).

En una investigación publicada en el Journal of Social and Clinical Psychology, Hunt, Marx, Lipson y Young (2018) reportaron que pasar mucho tiempo en redes sociales como Facebook, Instagram y Snapchat aumenta la sensación de soledad y genera depresión. En nuestro estudio, 
por ejemplo, evidenciamos resultados similares ya que la soledad presenta una correlación significativa con el uso problemático del celular lo que nos indica que a mayor uso de este dispositivo móvil mayor será el incremento del sentimiento de soledad. Asimismo, dentro de nuestros resultados se refleja que el uso excesivo del celular y la calidad de sueño están significativamente correlacionadas, es decir que, a más uso del celular, la calidad de sueño será menor.

Diversos estudios respaldan que el uso de estos dispositivos móviles, especialmente cerca de las horas de ir a dormir, está asociado con una peor calidad del sueño. Christensen et al. (2016) encontraron en su investigación que el uso de los celulares particularmente en las horas en las que los participantes dicen que van a la cama, estuvo asociado con un mayor tiempo para quedarse dormido y peor calidad de sueño durante la noche. Otro estudio realizado por Chang, Aeschbacha, Duffya y Czeislera (2014) muestra que la luz azul emitida por los teléfonos inteligentes (y otros aparatos digitales) pueden suprimir la función de melatonina del cuerpo, una hormona que induceal cansancioy contribuye a la sincronización de los ciclos de sueño y vigilia. Según investigadores del Hospital Brigham y de Mujeres de Boston, leer o escribir en celulares y tabletas en la cama momentos antes de dormir, retrasa la sensación de sueño y afecta la calidad del descanso durante toda la noche (citado en diario El Salvador, 2015).

Otra investigación hecha por un equipo de la escuela médica de Harvard comparó los efectos de leer en un dispositivo móvil o uno de papel, donde encontraron que las personas que utilizan libros electrónicos o apps de lectura con luz integrada o retroiluminados tardan más en dormir, lo cual deriva en una peor calidad del sueño durante la noche y en un mayor cansancio por la mañana (BBC citado en diario El Salvador, 2015). La OMS (2017) por su parte, señaló que existen efectos a corto plazo como consecuencia entre la interacción de la energía radioeléctrica y el cuerpo. Uno de ellos es el calentamiento de los tejidos, lo que afecta la función cognitiva, el sueño, el ritmo cardíaco e incluso genera ansiedad y estrés.

Por último, el impacto del móvil en la calidad del sueño es especialmente importante entre los más jóvenes de la casa. De hecho, un estudio realizado a unos 1000 estudiantes australianos entre 13 y 16 años afirma que los dispositivos móviles no solo influyen en la privación del sueño, sino que también puede afectar la salud mental de éstos, derivando en bajos estados de ánimo o periodos de depresión. Por otro lado, es importante no excluir la posibilidad de que algunas personas no pueden dormir por una razón completamente diferente, y como no pueden hacerlo, usan su celular sólo para pasar el tiempo.

Con respecto a la relación entre calidad de sueño y soledad, diversos autores afirman que existen factores ambientales que pueden desatar el insomnio, algunos de ellos son: el ruido, la falta de ventilación y los viajes. No obstante, el problema podría tener un origen físico o psicológico, como el estrés y la soledad. Un estudio 
realizado por Matthews et al. (2017) se encontró que la reducción en la calidad del sueño es una de las muchas formas en las que la soledad afecta a las personas. Los resultados asociaron los sentimientos de soledad con una peor calidad general del sueño. Sin embargo, esto debe analizarse con mayor profundidad en estudios posteriores, debido a los diferentes factores asociados en la baja calidad de sueño.

En un estudio realizado por Yan, Liu y Lei (2015) se investigó la adicción al celular, la calidad del sueño y la soledad en 346 estudiantes. Los resultados muestran que una alta prevalencia a la adicción al celular provoca mayor sensación de soledad y peor calidad del sueño. En nuestro estudio los resultados indican que las variables soledad, calidad de sueño y uso excesivo del celular correlacionan positivamente de manera significativa; es decir que los jóvenes universitarios que tienen un mayor uso del celular y menor calidad de sueño presentan tener mayor soledad. De esta manera respondemos a la pregunta inicial encontrando relación entre estas variables. Podemos concluir diciendo que el uso excesivo del celular es un problema psicológico, social y físico; que merece ser investigado en nuestro país con mayor contundencia.

Por otra parte, es necesario involucrar en posteriores investigaciones otras variables que también afectan el uso excesivo del celular y la calidad de sueño. Además, con estudios más detallados en un futuro cercano, se podría lograr mejores interpretaciones y explicaciones sobre la relación entre estas variables en jóvenes y adolescentes. Finalmente, consideramos de gran importancia y necesidad que se realicen estudios sobre la soledad en jóvenes y adolescentes que utilizan dispositivos móviles y celulares inteligentes en el Perú.

\section{Financiamiento}

El estudio fue autofinanciado.

\section{Conflicto de intereses}

Los autores declaran no tener ningún conflicto de interés. 


\section{Referencias}

Asher, S., \& Paquete, J. (2003). Loneliness and peer relations in childhood. Current Directions in Psychological Sciences, 12(1), 75-80. https://doi.org/10.111/1467-8721.01233

Arslan, A., \& Ünal, A.T. (2013). Examination of cell phone usage habits and purposes of education faculty students. International Journal of Human Sciences, 10(1), 182-201. https://www.j-humansciences.com/ojs/index.php/IJHS/article/view/2523

Ato, M., López, J. J., \& Benavente, A. (2013). Un sistema de clasificación de los diseños de investigación en psicología. Anales de psicología, 29(3), 1039-1055. https://doi. org/10.6018/analesps.29.3.178511

Blasco, J.E., Llor E.B., García, M., Saenz, M., \& Sánchez, M. (2002). Relación entre la calidad del sueño, el burnout y el bienestar psicológico en profesionales de la seguridad ciudadana. Mapfre Medicina, 13(1), 259-267. https://sid.usal.es/idocs/ f8/art8655/relacion.pdf

Borges, Á., Prieto, P., Ricchetti, G., Hernández-Jorge, C., \& Rodríguez, E. (2008). Validación cruzada de la factorización del Test UCLA de Soledad. Psicothema, 2o(4), 924-927. https://www.redalyc.org/pdf/727/72720462.pdf

Buysse, D. J., Reynolds, C. F., Monk, T. H., Berman, S. R., \& Kupfer, D. J. (1989). The Pittsburgh sleep quality index: A new instrument for psychiatric practice and research. Psychiatry Research, 28(19), 193-213. https://doi.org/10.1016/0165-1781(89)90047-4

Cacioppo, J., \& Cacioppo, S. (2016). La soledad, una nueva epidemia. Diario EL PAÍS. https://elpais.com/elpais/2016/o4/o6/ciencia/1459949778_182740.html

Castellana, M., Sánchez, X., Graner, C., \& Beranuy, M. (2007). El adolescente ante las Tecnologías de la Información y la Comunicación: Internet, móvil y videojuegos. Papeles del Psicólogo, 28(3), 196-204. https://www.redalyc.org/pdf/778/77828306.pdf

Carvajal-Carrascal, G., \& Caro-Castillo, C. (2009). Soledad en la adolescencia: Análisis del concepto. Aquichan, 9(3), 281-96. https://www.redalyc.org/pdf/741/741121470o8.pdf

Christensen, M. A., Bettencourt, L., Kaye., L., Sai, M., Nguyen, K., Olgin, L. E., Pletcher, M..., \& Marcus, G. M. (2016). Direct measurements of smartphone screen-time: Relationships with demographics and sleep. Plos ONE, 11(11). doi.org/10.1371/ journal.pone.0165331 
Cuny, J. A. (2001). Actitud y sentimiento de soledad en un grupo de adolescentes universitarios de Lima. Persona, 4(1), 111-128. https://revistas.ulima.edu.pe/index. $\mathrm{php} /$ Persona/article/view/816

Chang, A., Aeschbacha D., Duffya J., \& Czeislera C. (2014). Evening use of light-emitting eReaders negatively affects sleep, circadian timing, and next-morning alertness. Proceedings of the National Academy of Sciencies of the United Stades of America, 112(4), 1232-1237. www.pnas.org/cgi/doi/10.1073/pnas.1418490112

Dexter D., Bijwadia J., Schilling D., \& Applebaugh G. (2003) Sleep sleepiness and school start times: a preliminary study. World Medicine Journal, $102(1)$, 44-46. https://www.semanticscholar.org/paper/Sleep\%2Csleepiness-and-school-start-times\%3A-a-study.-Dexter-Bijwadia/ cae4a6981d992b107ad419b35e48a91c2653de6d?p2df

Doane, L. D., \& Thurston, E. C. (2014). Associations among sleep, daily experiences, and loneliness in adolescence: Evidence of moderating and bidirectional pathways. Journal of Adolescence, 37(2), 145-154. https://doi.org/10.1016/j.adolescence.2013.11.009

Domínguez, S., Oliva, M., \& Rivera, N. (2007). Prevalencia de deterioro del patrón del sueño en estudiantes de enfermería en Huelva. Revista Electrónica Semestral de Enfermería, 1(10), http://revistas.um.es/eglobal/article/viewFile/346/318

El Salvador (2016). ¿Por qué los celulares afectan la calidad del sueño? Diario El salvador. https://www.elsalvador.com/vida/144184/ por-que-los-celulares-afectan-la-calidad-del-sueno/

Garay, K. (2016). Smartphones: 41 \% de jóvenes peruanos lo considera imprescindible. Diario El Peruano. https://elperuano.pe/noticia-el-3o-de-poblacion-tiene-seriosproblemas-sueno-39164.aspx

Gaglianone, V. (2015). Adolescentes adictos al celular. Diario La Opinión. https:// laopinion.com/2015/o1/22/adolescentes-adictos-al-celular/

Guevara, K. G., \& Torres, E. T. (2016). Calidad de sueño y somnolencia diurna en conductores de taxi de una empresa privada en Lima Metropolitana-Santiago de Surco. (Tesis de Licenciatura). Universidad Peruana Cayetano Heredia, Lima, Perú. http://repositorio.upch.edu.pe/bitstream/handle/upch/647/Calidad\%2ode\%2o sue\%c3\%b1o\%2oy\%2osomnolencia\%2odiurna\%2oen\%2oconductores\%2ode\%2o taxi\%2ode\%2ouna\%2oempresa\%2oprivada\%2oen\%2oLima\%2oMetropolitana\%20-\%20Santiago\%2ode\%2oSurco\%2c\%202016.pdf?sequence=1\&isAllowed=y 
Hardell, L., Carlberg, M., Söderqvist, F., \& Hansson Mild, K. (2008). Meta-analysis of long-term mobile phone use and the association with brain tumours. International Journal of Oncology, 32(5), 1097-1103. http//:doi.org/10.3892/ijo.32.5.1097

Hunt, M. G., Marx, R., Lipson, C., \& Young, J. (2018). No more FOMO: Limiting social media decreases loneliness and depression. Journal of Social and Clinical Psychology, 37(10), 751-768. https://guilfordjournals.com/doi/pdfplus/10.1521/jscp.2018.37.10.751

Hutchison, A. N., \& Gerstein, L.H. (2016). The Impact of Gender and Intercultural Experiences on Emotion Recognition. Revista de Cercetare si Interventie Sociala, 54(1), 125-141. https://www.ceeol.com/search/article-detail?id=520443

Instituto Nacional de Estadística e Informática (INEI) (2017). El 30.5 \% accede a Internet desde su smartphones, según el INEI. Diario Gestión. https://gestion. pe/peru/30-5-accede-internet-smartphones-segun-inei-223558

Kersting, T. (2016). Disconnected. How to reconnect our digitally distracted kids. http:// tomkersting.com/

Kraut, R., Patterson, M., Lundmark, V., Kiesler, S., Mukophadhyay, T., \& Scherlis, W. (1998). Paradoja de Internet: ¿una tecnología social que reduce la participación social y el bienestar psicológico? Psicólogo estadounidense, 53(9), 1017-1031. https:// doi.org/10.1037/0003-066X.53.9.1017

Lloret-Segura, S., \& Ferreres-Traver, A., \& Hernández-Baeza, A., \& Tomás-Marco, I. (2014). El análisis factorial exploratorio de los ítems: una guía práctica, revisada y actualizada. Anales de Psicología, 30(3), 1151-1169. https://revistas.um.es/analesps/ article/view/analesps.30.3.199361

Loughran, S. P., Wood, A. W., Barton, J. M., Croft, R. J., Thompson, B., \& Stough, C. (2005). The effect of electromagnetic fields emitted by mobile phones on human sleep. Neuroreport, 16(17), 1973-1976. https://doi.org/10.1097/o1.wnr.0ooo186593.79705.3C

Luna.-Solís, Y., Robles-Arana, Y., \& Agüero-Palacios, Y. (2015). Validación del índice de calidad de sueño de Pittsburgh en una muestra peruana. Anles de la Salud Mental, 31(2), 23-30. https://www.academia.edu/34647099/VALIDACI\%C3\%93N_ DEL_\%C3\%8DNDICE_DE_CALIDAD_DE_SUE\%C3\%91O_DE_PITTSBURGH_EN_ UNA_MUESTRA_PERUANA_VALIDATION_OF_THE_PITTSBURGH_SLEEP_ QUALITY_INDEX_IN_A_PERUVIAN_SAMPLE 
Matthews, T., Danese, A., Gregory, A. M., Caspi, A., Moffitt, T. E., \& Arseneault, L. (2017). Sleeping with one eye open: loneliness and sleep quality in young adults. Psychological Medicine, 47(12), 2177-2186. https://doi.org/10.1017/Soo3329171700o629

Menglong, L. I., \& Liya, L. U. (2017). La influencia de la adicción al teléfono móvil en la calidad de sueño de estudiantes secundarios dejados atrás: el rol mediador de la soledad. Revista Argentina de Clínica Psicológica, 26(1), 71-81. https://www. redalyc.org/pdf/2819/281950399007.pdf

Mrunal B., \& Jaimala S. (2015). Mobile Phone Addiction and Loneliness among Teenagers. The International Journal of Indian Psychology, 2(1), 27-34. http://oaji. net/articles/2015/1170-1430026211.pdf

Organización Mundial de la Salud (OMS) (2017). Campos electromagnéticos y salud pública:teléfonos móviles. https://www.who.int/es/news-room/fact-sheets/detail/ electromagnetic-fields-and-public-health-mobile-phones

Oguz, E., \& Cakir, O. (2014). Relationship between the Levels of Loneliness and Internet Addiction. Anthropologist, 18(1), 183-189. https://doi.org/10.108o/o972 0073.2014.11891534

Pamuk, M., \& Atli, A. (2016). Development of a problematic mobile phone use scale for University Students: Valicity and Reliabity study. The Journal of Psychiatry and Neurological Sciences, 29(1), 49-59. https://dusunenadamdergisi.org/storage/ upload/pdfs/1585660689-en.pdf

Peper, E., \& Harvey, R. (2018). Digital Adicction: Increased loneliness, Anxiety and depression. Neuroregulation, 5(1), 3-8. https://doi.org/10.15540/nr.5.1.3

Peñuela, M., Patermina, J., Moreno, S., Camacho, L., Acosta, L., \& De León, L. (2014). El uso de los smartphones y las relaciones interpersonales de los jóvenes universitarios en la ciudad de Barranquilla (Colombia). Salud Uninorte, 30(3), 335-346. https://www.redalyc.org/articulo.oa?id=81737153008

Primack, B. A., Shensa, A., Sidani, J. E., Whaite, E. O., Lin, L., Rosen, D., ... \& Miller, E. (2017). Social media use and perceived social isolation among young adults in the US. American journal of preventive medicine, 53(1), 1-8. https://doi.org/10.1016/j. amepre.2017.01.010 
Rodríguez, R., Viegas, C., Abreu eSilva,A., \& Tavares, P. (2002). Daytimesleepinessandacademic performance in medical students. Arquivos de Neuropsiquiatria, 6o(1), 6-11. http:// www.scielo.br/scielo.php?script=sci_arttext\&pid=So004-282X2002000100002\&lng

Rosales, E., Egoavil, M., La Cruz, C., \& De Castro, J. (2007) Somnolencia y calidad del sueño en estudiantes de medicina de una universidad peruana. Anales de la Facultad de Medicina, 68 (2), 150-158. http://sisbib.unmsm.edu.pe/BVrevistas/ anales/v68n2/pdf/ao7v68n2.pdf

Röösli, M. (2008). Radiofrequency electromagnetic field exposure and non-specific symptoms of ill health: a systematic review. Environmental Research, 107(2), 277-287. https://doi.org/10.1016/j.envres.2008.02.003

Rotenberg, K. J., \& Hymel, S. (1999). Loneliness in childhood and adolescence. Cambridge University Press.

Róquez, E., \& Martínez, M. (2015). Propiedades psicométricas de la escala de soledad para adultos de la Universidad de California de los Ángeles. Versión 3. Universidad Rafael Urdaneta.

Russell, D., Peplau, L., \& Cutrona, C. (1980). The Revised UCLA Loneliness Scale. Concurrent and discriminant validity evidence. Journal of Personality and Social Psychology, 39(1), 472-48o. https://doi.org/10.1037/oo22-3514·39·3.472

Sierra, J. C. (2006). Calidad de sueño como factor relevante de la calidad de vida. En L. A. Oblitas (Ed.), Psicología de la Salud y Calidad de Vida (pp. 337-344). Thomson.

Weis, R. S. (2008). The experience of emotional and social isolation. MIT Press.

Yan, J., Liu, Q. S., \& Lei, C. H. (2015). Research on correlation among college students' mobile phone dependence, sleep quality and loneliness. Time Education, 19(1), 87-88.

Recibido: 3 de diciembre de 2020

Revisado: 23 de marzo de 2021

Aceptado: 30 de mayo de 2021 



\section{INSTRUCCIONES PARA LOS AUTORES}

La Revista de Psicología es editada por el Departamento de Psicología de la Universidad Católica San Pablo, con el objetivo de difundir la investigación científica que tiene lugar en su seno institucional, y de promover el intercambio de información científica con otras instituciones nacionales o extranjeras. Es una publicación abierta a la comunidad científica y académica nacional e internacional, la cual se edita dos veces al año, y que cubre diversas temáticas dentro del campo de la psicología.

Normas de presentación y envío de trabajos:

1. Los manuscritos deberán ser preparados y estructurados siguiendo las normas de publicación de la Asociación Psicológica Americana (APA, 2018), debe presentarse además, una carta en donde se consigne el nombre del autor principal y de los autores, con su respectiva filiación institucional, su código ORCID, y el correo electrónico del autor designado para la correspondencia; trasladando los derechos de autor a la Revista de Psicología de la Universidad Católica San Pablo. Ésta deberá incluir una declaración en donde se consigne que los hallazgos del manuscrito no han sido previamente publicados o no se encuentran en proceso de revisión por otra/s revistas de investigación.

2. Los manuscritos no deberán superar una extensión de 35 páginas a doble espacio, incluidas referencias, tablas y gráficos y deberá ser presentado en el tipo de letra Times New Roman número 12. Los gráficos no deben tener una resolución menor a 75 pixeles para ser incluidos en la revista.

3. Dirigir los artículos al Departamento de Psicología, Universidad Católica San Pablo, Quinta Vivanco s/n, San Lázaro; teléfono 051-54-6o802o (anexo 362); e-mail: warias@ucsp.edu.pe

Tipos de publicación aceptados:

- Artículos empíricos

- Artículos de revisión

- Artículos teóricos

- Artículos metodológicos

- Entrevistas

- $\quad$ Estudios de casos

Proceso de revisión (arbitraje) y criterios de evaluación 
1. El comité editorial tiene como objetivo velar el proceso de aceptación de un manuscrito para publicación, para ello contamos además con un comité científico de revisores nacional e internacional. Los manuscritos se valoraran en base a:

- $\quad$ La concordancia con la política editorial de la revista

- La relevancia del tema tratado

- Calidad en el desarrollo del tema tratado

- $\quad$ El seguimiento a las normas de publicación (formato APA, 2018)

2. Una vez recibido el manuscrito y cumplidas los criterios de evaluación editorial el manuscrito pasa por las siguientes etapas:

- Carta de recepción del manuscrito al autor/es.

- Evaluación por dos especialistas (Comité de Revisores Nacional e Internacional).

- Información del comité editorial a los autores sobre la aceptación, aceptación con modificaciones o rechazo.

- $\quad$ Revisión de la corrección por el Comité Editorial.

- $\quad$ Una vez que el manuscrito es aprobado por el Comité Editorial se envía a imprenta.

- $\quad$ Las pruebas de imprenta son revisadas por el Comité Editorial y por el autor principal del manuscrito.

- Aprobadas las correcciones de imprenta son enviadas para su publicación.

Estructura general de los artículos

- Título (español e inglés).

- $\quad$ Nombre autor(es), e-mail y filiación institucional.

- $\quad$ Resumen en castellano (Máximo 250 palabras)

- $\quad$ Resumen en inglés (Abstract, máximo 250 palabras).

- $\quad$ Palabras claves en castellano e inglés (entre 3 y 6 palabras)

- Introducción: Breve definición del problema, investigaciones relevantes y perspectiva teórica.

- Método: Incluye sujetos, instrumentos, técnicas y procedimientos. En el caso de estudios clínicos de caso(s) puede incluirse en este acápite la descripción de caso.

- Resultados y/o análisis del material: Presentación de los análisis cuantitativos y/o cualitativos (con gráficos y tablas, si se requiere).

- Discusión: Análisis teórico de los resultados.

- Referencias bibliográficas. 
Normas de citas bibliográficas (ejemplos)

Artículos

Sánchez, F., Bardales, M., \& Perales M. (1999). Percepción del clima organizacional en un grupo de trabajadores del Hospital Víctor Larco Herrera. Revista Peruana de Psicología, 4(8), 187-194.

Libros:

Delgado, H. (1962). Contribuciones a la psicología y la psicopatología. Editorial Peri-Psyches.

Capítulo de libro:

Spielberger, C. D., Reheiser, E. C., Owen, A. E. \& Sydeman, S. J. (2003). Measuring psychological vital signs of anxiety, anger, depression, and curiosity in treatment planning and outcome assessment. En M. Maruish (Ed.), The use of psychological testing for treatment, planning and outcomes assessment (3ra. Edición) (pp. 421-447). Lawrence Erlbaum.

Artículos electrónicos con DOI (Digital Object Identifier):

Soto-Añari, M. \& Cáceres-Luna, G. (2012). Funciones ejecutivas en adultos mayores alfabetizados y no alfabetizados. Revista Chilena de Neuropsicología, 7(3), 127-133. https://doi.org/10.5839.0703.06

Artículos electrónicos sin DOI:

Muratori, M., Delfino, G. \& Zubieta, E. (2013). Percepción de anomia, confianza y bienestar: la mirada desde la psicología social. Revista de Psicología, 31(1), 129-150. htpp://revistas.pucp.edu.pe/index.php/psicología/article/view/6373/6427 
